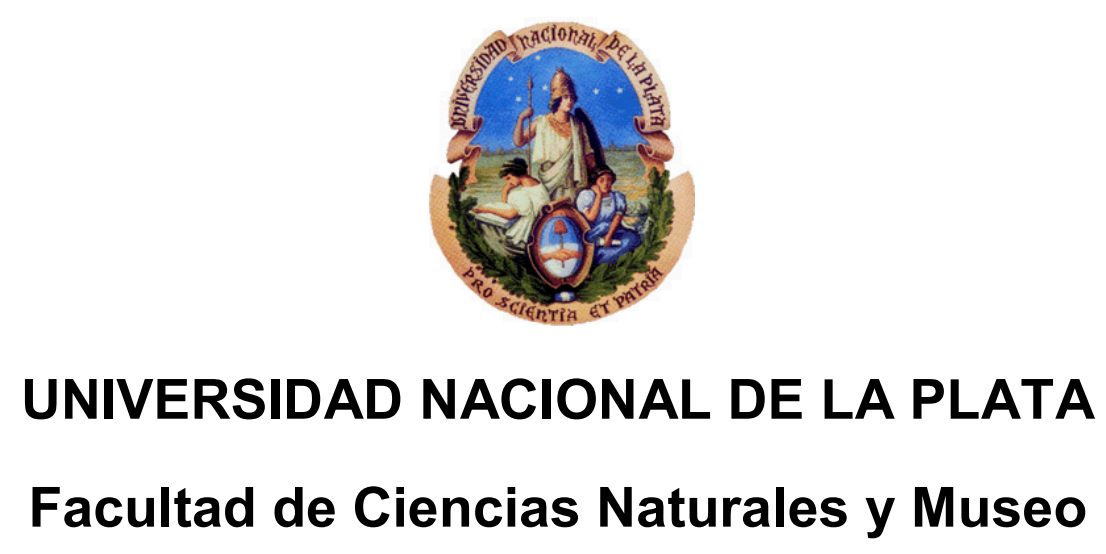

Tesis para optar por el título de Doctor en Ciencias Naturales

2015

"Desarrollo de un modelo experimental con larvas de Ceratophrys spp (Anura: Ceratophryidae) para su aplicación en estudios ecotoxicológicos de plaguicidas: efectos sobre variables convencionales y bioacústicas"

Lic. Carolina Salgado Costa

Directores: Dra. Alicia E. Ronco y Dr. Guillermo S. Natale Desarrollada con Beca Tipo I y II del CONICET 
A mi seres queridos,

$\mathrm{Y}$ a todos aquellos que hacen de su labor una pasión 


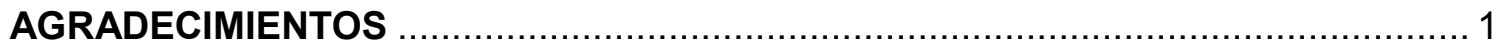

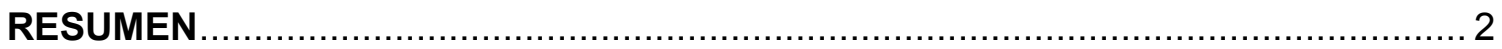

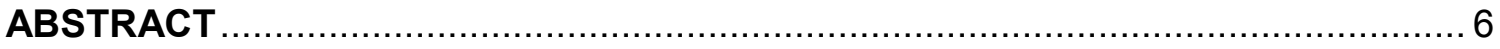

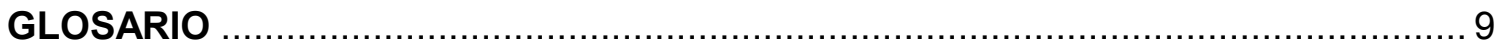

\section{INTRODUCCIÓN GENERAL}

La agricultura y sus efectos abordados por diferentes disciplinas.......................... 12

Investigaciones ecotoxicológicas a nivel mundial .............................................. 16

Los anfibios anuros en el contexto de la investigación ......................................... 17

\section{PRIMERA PARTE: DESARROLLO DE UN MODELO EXPERIMENTAL CON LARVAS DE LA FAMILIA CERATOPHRYIDAE}

\section{CAPÍTULO 1: Cría de individuos de la familia Ceratophryidae INTRODUCCIÓN}

El rol de la cría ex-situ en la conservación de especies ......................................... 24

La necesidad de criar animales para experimentación ............................................ 26

Métodos de inducción artificial de la reproducción: un factor clave para el

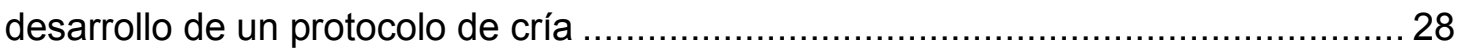

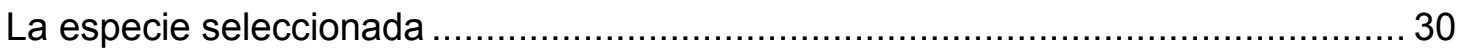

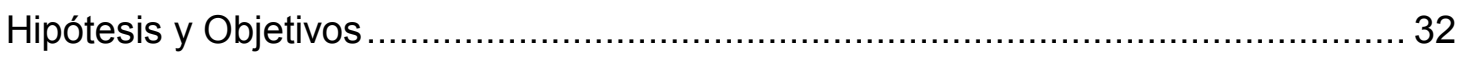

\section{MATERIALES Y MÉTODOS}

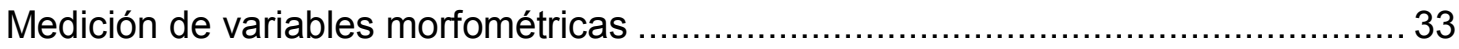

Prueba del protocolo de cría en cautiverio de individuos adultos de

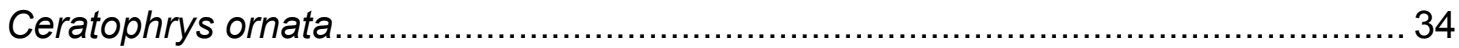

Inducción por el método AMPHIPLEX de individuos adultos de C. ornata................ 37

Prueba del protocolo de cría en cautiverio de $C$. ornata desde la eclosión

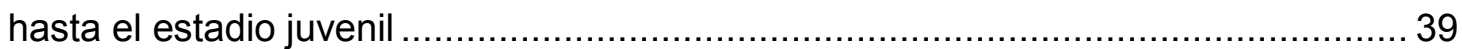

Cría de otras especies filogenéticamente relacionadas con C. ornata..................... 42

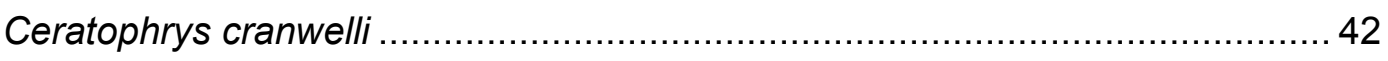

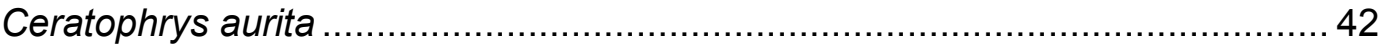

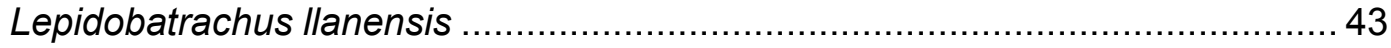

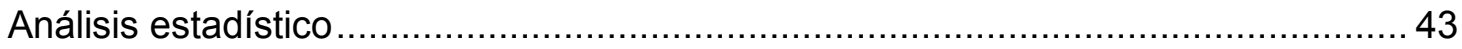




\section{RESULTADOS}

Validación del método de medición de variables morfométricas ............................. 44

Inducción por el método AMPHIPLEX de individuos adultos de C. ornata................ 47

Protocolo de cría en cautiverio de individuos de C. ornata

Otros resultados obtenidos producto de la cría en cautiverio y de muestreos de campo: biología y estado de conservación ....

Aplicación del protocolo de cría en otras especies filogenéticamente relacionadas

con C. ornata

DISCUSIÓN Y CONCLUSIONES

CAPÍTULO 2: Estudio de la variabilidad de sonidos producidos por individuos de la familia Ceratophryidae a lo largo de su desarrollo

\section{INTRODUCCIÓN}

Acústica y Bioacústica. 64

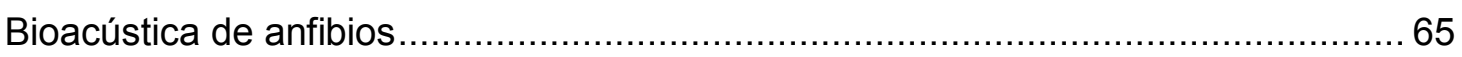

Producción de sonidos por parte de anfibios en estadios larvales ..........................66

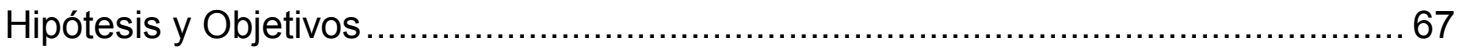

\section{MATERIALES Y MÉTODOS}

Calibración y evaluación del sistema de grabación 68

Método de mejoramiento de la relación señal-ruido

Registro y análisis de sonidos emitidos en un medio acuático y un medio aéreo por individuos de $C$. ornata.

Medición de sonidos en el medio aéreo emitidos por individuos de C. ornata ...........73

Registro y análisis de sonidos emitidos por otras larvas de anuros autóctonos ........ 75

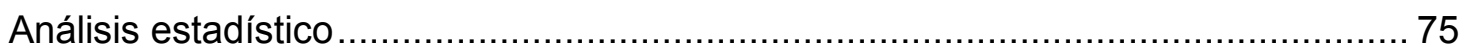

\section{RESULTADOS}

Compensación del sistema de grabación y mejoramiento de la relación

señal-ruido

Descripción del sonido emitido en un medio acuático y un medio aéreo por

individuos de $C$. ornata mediante variables bioacústicas.

Descripción del sonido emitido en el medio aéreo por individuos de C. ornata mediante variables acústicas

Descripción de sonidos emitidos por larvas de otras especies de anuros

autóctonos 
CAPÍTULO 3: Explorando el contexto y mecanismo de emisión de sonidos de larvas de la familia Ceratoprhyidae y las interacciones biológicas de la misma INTRODUCCIÓN

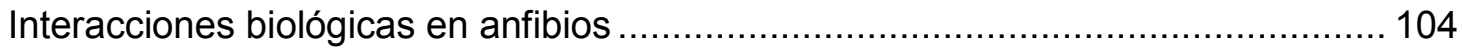

Interacciones predador-presa intraespecíficas en larvas de anfibios .................... 105

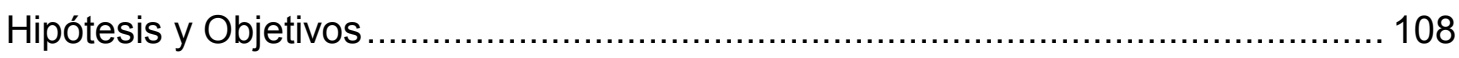

\section{MATERIALES Y MÉTODOS}

Evaluación del contexto y del mecanismo de emisión de sonidos por larvas

de C. ornata

Experimentos de comportamiento: evaluación del comportamiento de larvas

de $C$. ornata ante señales acústicas, visuales y químicas

Experimentos de interacción: evaluación de interacciones predador-presa

entre larvas de la familia Ceratophryidae y otras larvas de anuros.

Ceratophrys ornata

Ceratophrys cranwelli

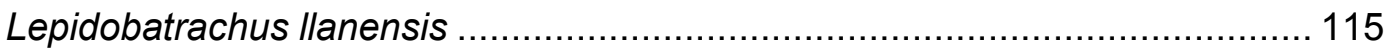

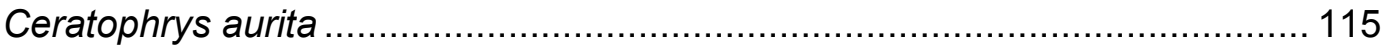

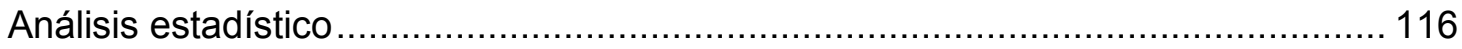

\section{RESULTADOS}

Contexto y mecanismo de emisión de sonidos por larvas de $C$. ornata

Comportamiento de larvas de $C$. ornata ante señales acústicas, visuales

y químicas

Interacciones predador-presa con larvas de C. ornata ..................................... 123

Interacciones predador-presa con larvas de C. cranwelli.................................. 127

Interacciones predador-presa con larvas de L. Ilanensis ................................... 129

Interacciones predador-presa con larvas de C. aurita .......................................... 130

Comparación de los ensayos de interacciones realizados................................... 131

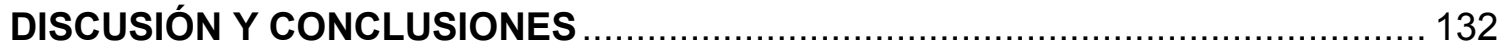


CAPÍTULO 4: Efectos agudos y crónicos del clorpirifós durante la etapa larval de Ceratophrys ornata

INTRODUCCIÓN

Impactos ambientales de la agricultura con énfasis en el modelo intensivo

y extensivo

Los anfibios como bioindicadores

Los plaguicidas y sus efectos sobre los anfibios

Uso del bioensayo de toxicidad como herramienta bioanalítica en la

evaluación de efectos sobre anfibios anuros

Evaluación del riesgo ecológico

Hipótesis y Objetivos

\section{MATERIALES Y MÉTODOS}

Condiciones controladas de laboratorio y preparación del material utilizado

Selección de plaguicidas organofosforados de uso frecuente en la región

Pampeana.

Diseño experimental - Efectos letales y subletales

Bioensayos con clorpirifós en STD 25

Bioensayos con clorpirifós en STD 31

Bioensayos con clorpirifós en STD 37

Aplicación de la herramienta de evaluación del riesgo ecológico

Análisis estadístico.

\section{RESULTADOS}

Bioensayos con clorpirifós - Efectos letales

Bioensayos con clorpirifós - Efectos subletales

DISCUSIÓN Y CONCLUSIONES

CAPÍTULO 5: Efectos del clorpirifós sobre el sonido emitido por larvas de Ceratophrys ornata

\section{INTRODUCCIÓN}

Biomarcadores utilizados en Ecotoxicología de anfibios.

Hipótesis y Objetivos

\section{MATERIALES Y MÉTODOS}

Grabación de sonidos de larvas de C. ornata expuestas a clorpirifós. 
Análisis estadístico

\section{RESULTADOS}

Efectos del clorpirifós sobre el sonido emitido por larvas de C. ornata 186

DISCUSIÓN Y CONCLUSIONES 200

CONCLUSIONES FINALES 204

REFERENCIAS

ANEXO I: Producción científica vinculada al desarrollo de la tesis

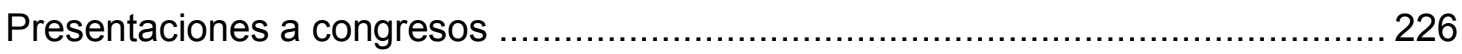

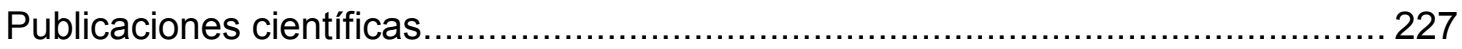

ANEXO II: Observaciones realizadas producto de la cría en cautiverio

Observaciones de comportamiento relacionadas con la inducción de la reproducción. 228

Observaciones biológicas relacionadas con la cría en cautiverio 231

ANEXO III: Efectos del UVB sobre el crecimiento y desarrollo óseo de Ceratophrys ornata. 
"...somos un mar de fueguitos. El mundo es eso -reveló- un montón de gente, un mar de fueguitos. Cada persona brilla con luz propia entre todas las demás. No hay dos fuegos iguales. Hay fuegos grandes y fuegos chicos y fuegos de todos los colores. Hay gente de fuego sereno, que ni se entera del viento, y gente de fuego loco, que llena el aire de chispas. Algunos fuegos, fuegos bobos, no alumbran ni queman; pero otros arden la vida con tantas ganas que no se puede mirarlos sin parpadear, y quien se acerca, se enciende." El mundo por E. Galeano.

Mi más profundo agradecimiento a todos aquellos "fueguitos" que de alguna u otra forma encendieron mi camino. Agradezco del primero al último, porque sin ellos esta tesis no hubiera sido posible:

Al CONICET, por su becas que permitieron que me dedique exclusivamente a esta tesis...

A mis directores, Alicia Ronco y Guillermo Natale, por brindarme la oportunidad de trabajar con ellos, contagiarme su pasión por la ciencia, guiarme, respetarme y por el apoyo constante. Especial agradecimiento a la familia Natale por abrirme las puertas de su casa para cada reunión, con todo lo que ello implica...

A Vance Trudeau, quien fue mi co-director de beca durante los primeros años de tesis, por su apoyo y presencia continua aún estando a miles de kilómetros de distancia...

A mis padres, por ser mi cable a tierra y por su incondicional apoyo desde el inicio, sufriendo y festejando a la par cada momento de esta tesis... A mis hermanos por su apoyo y motivación constante... A mis sobrinos por recordarme a diario que la inocencia es lo más puro que uno pierde cuando crece... Y a mis abuelos por demostrarme que aún siendo adulta siempre sería para ellos la niña inocente que vieren nacer (¡qué lindo sería tenerlos en este momento!)...

A Matías, por ser mi compañero de vida a quien vuelvo a elegir a diario, por su comprensión y apoyo constante en este camino que elegí transitar, por vivir a la par mis emociones encontradas en el camino y por llenar mis días grises de colores más alegres...

A mis amigas del alma, Belén, Marina y Nadia, con quienes compartí largos años de la carrera de grado y con quienes adoro compartir mi vida... Y a mis amigas de la vida, Ayelén, Grisel y Luciana, por compartir tantos años juntas y alegrar mis días...

A Nilda Vechiatti, Federico lasi y Carlos Posse del LAL-CIC por su compromiso, invaluable ayuda y por hacer de cada reunión laboral un ambiente más que ameno...

Al CIMA y toda su gente por hacer del lugar de trabajo un ambiente más cálido... y muy especialmente a los que conforman la Unidad 5 por su apoyo constante...

A los pasantes, que como su nombre lo indica han pasado por el CIMA y colaborado activamente con la ejecución de esta tesis...

$\mathrm{Y}$ a todas aquellas personas me he cruzado en el camino, aquellas que han participado del diseño y/o ejecución de ensayos y a las que he consultado durante el desarrollo de la tesis: A. Farina, D. Marino, F. Bondone, F. Licitra, G. Hermida, G. Basso, G. Bulus, G. Somoza, J. Williams, J. Lescano, L. Fabrega, L. Alcalde, M. Chuliver Pereyra, M. Fabrezi, M. Pueta, M. Boa, M. Delaloye, M. Ángel Franco, N. Basso, R. Villalba, R. Herrera y S. Olguin... 


\section{RESUMEN}

La emisión de sonidos por larvas de Ceratophrys ornata constituyó un novedoso hallazgo en el cual se presenta la primera evidencia para larvas de anfibios anuros. Tal hallazgo condujo al desarrollo de una nueva línea de investigación, siendo el fundamento de este trabajo de tesis doctoral, habiéndose dividido la investigación en dos partes consecutivas y concatenadas. La primera parte consistió en generar las bases para poder desarrollar un modelo experimental con larvas de esta especie. Para ello, se propuso un protocolo de cría ex-situ de individuos de C. ornata, el cual permitió obtener individuos sanos a lo largo de todo el ciclo vital (desde huevo hasta adulto). Esto último fue posible gracias a la utilización del método de inducción artificial de la reproducción denominado AMPHIPLEX. Dicho método, permitió obtener huevos en distintas épocas del año, no todas coincidentes con el periodo reproductivo de la especie (verano), y recolectar datos su biología, dos logros que de otro modo hubiera resultado dificultoso dado el hábito de vida de la especie. En tal sentido, el presente trabajo de tesis aporta datos de la biología de $C$. ornata relativos a su reproducción (actividad reproductiva, cantidad de huevos depositados por puesta, porcentaje de eclosión de los huevos), crecimiento (curvas de crecimiento desde la etapa larval hasta la adultez), desarrollo (tiempo promedio en alcanzar determinados estadios), enfermedades (diagnóstico y tratamiento), comportamiento (llamada agonística, llamada de anuncio y reciprocidad y movimiento pedal) y biología general. Al mismo tiempo, la aplicación del protocolo en especies filogenéticamente relacionadas a $C$. ornata y de hábitos similares (C. cranwelli, C. aurita y Lepidobatrachus llanensis), permitió su validación. La cría ex-situ es una estrategia que evita la continua extracción de animales de su hábitat natural y sienta las bases para el desarrollo de investigaciones en aquellos casos que los estudios insitu resultan imposibles o complejos de realizar.

Una vez desarrollado el protocolo de cría en cautiverio de individuos de C. ornata, y mediante la obtención de larvas de distintos estadios del desarrollo, se describió la variabilidad de los sonidos producidos tanto en un medio acuático como aéreo. Previamente, se realizó una consulta interdisciplinaria con especialistas en sonidos, a partir de la cual se descubrieron algunos aspectos a mejorar en el sistema de grabación. Se realizó un procedimiento de calibrado y compensado del sistema de grabación que permitió obtener grabaciones de alta confiabilidad. Además, se implementó un método de mejoramiento de la relación señal-ruido, el cual permitió obtener grabaciones con espectros más nítidos y fáciles de analizar. Se realizaron además mediciones del sonido emitido por individuos de $C$. ornata en el medio aéreo mediante un sistema de medición adecuado (sonómetro), el cual permitió caracterizar el sonido tanto cuali como cuantitativamente mediante variables acústicas. Se concluye que para caracterizar adecuadamente un sonido de las características aquí 
presentadas (bajo nivel de presión sonora), resulta necesario utilizar instrumentos de medición calibrados con sistemas de referencia acústica. La variables analizadas fueron a) bioacústicas: duración del sonido (Ds), expresada en segundos (s), número de pulsos (Np), número de interpulsos (Nip), frecuencia dominante $(\mathrm{Fd})$ expresada en Hertz $(\mathrm{Hz}) ; \mathrm{b})$ acústicas: nivel sonoro continuo equivalente $\left(L_{\mathrm{eq}}\right)$ expresado en decibeles $(\mathrm{dB})$, nivel sonoro máximo $\left(\mathrm{LAF}_{\max } \mathrm{dB}\right)$ y nivel sonoro que se ha igualado o superado durante el $90 \%$ del tiempo de medición (cercano al ruido de fondo; $\mathrm{LAF}_{90}, \mathrm{~dB}$ ). Se registró la emisión de sonidos desde el estadio 25 al 41, estadios luego de los cuales las larvas no emiten sonidos hasta completar el proceso metamórfico, momento en el cual los juveniles vuelven a producir sonidos manteniéndose esta situación durante todo el ciclo vital. Por último, la aplicación del protocolo de cría en otras especies de anuros filogenéticamente relacionados con C. ornata, permitió evaluar y describir la emisión de sonidos por otras larvas de anuros de la familia Ceratophryidae. Consecuentemente, se constató y registró el sonido emitido por larvas de C. cranwelli y $C$. aurita y la no emisión de sonidos por larvas de Lepidobatrachus llanensis dentro del rango de frecuencias evaluado. Por lo tanto, la hipótesis original que plantea que la emisión de sonidos está presente en todas las larvas de anuros macrófagas y carnívoras debe ser rechazada.

Luego de describir los sonidos, se evaluó el contexto de emisión por parte de larvas de $C$. ornata, pudiéndose concluir que las mismas emiten sonidos en diferentes contextos (interacción intraespecífica o con un objeto), habiéndose incluido a los sonidos en la categoría de llamada agonística (distress call). Hasta el momento, no existían estudios que analicen la variación de estos sonidos desde fases tempranas del desarrollo larval y a lo largo de todo el ciclo vital. Respecto a la evaluación del mecanismo de emisión de sonidos, a partir de una serie de pruebas morfo-funcionales realizadas, se hipotetizó que el aire empleado en la producción de sonidos durante estadios larvales proviene del estómago, pasa por la glotis (donde existiría una estructura resonante) y luego por la cavidad bucofaríngea ( $\sin$ salir de la misma). Además, se evaluaron interacciones predador-presa intra e interespecíficas, entre larvas de $C$. ornata y entre éstas y larvas que forman parte de su dieta habitual, en distintos estadios del desarrollo y bajo diferentes condiciones experimentales (densidad y proporciones predador-presa). Se concluye que $C$. ornata posee un mecanismo antipredatorio que disminuye la frecuencia de predación entre organismos conespecíficos ante la presencia de presas heteroespecíficas. Se evaluaron también interacciones intra e interespecíficas para larvas de C. cranwelli y L. Ilanensis con el objetivo de determinar similitudes y diferencias con el mecanismo antipredatorio de C. ornata. En tal sentido, se concluye que el mecanismo de Ceratophrys está compuesto por un rápido movimiento de la cola, más la emisión de sonidos y la consiguiente huida (escape) de la presa del predador. En cambio, si bien para L. llanensis también se describió un rápido movimiento de la cola seguido del escape de la presa del predador, no se registró la emisión 
de sonidos asociada. Más allá de las diferencias metodológicas, si se comparan los tres mecanismos se concluye que los mismos presentan el siguiente grado de eficiencia de mayor a menor: C. ornata, C. cranwelli, L. Ilanensis.

A partir de los estudios anteriormente detallados se planteó una segunda parte con el objetivo de evaluar los efectos del clorpirifós (CPF), un plaguicida organofosforado de uso frecuente en la región Pampeana, sobre larvas de $C$. ornata y aplicar el modelo desarrollado en la primera parte. El primer objetivo fue evaluar efectos letales y subletales sobre las larvas expuestas a este plaguicida. Teniendo en cuenta que los plaguicidas organofosforados poseen acción neurotóxica por inhibición de la acetilcolinesterasa, los mismos pueden alterar al aparato de emisión de sonidos y al sonido en sí mismo. En tal sentido, se evaluaron no solo los parámetros ecotoxicológicos convencionales sino también el efecto sobre los parámetros normales del sonido. Los puntos finales ecotoxicológicos analizados fueron: mortalidad, alteraciones en la natación, presencia de anormalidades e inhibición del crecimiento. Además, se evaluaron las mismas variables bioacústicas antes detalladas (Ds, Np, Nip, Fd). La sensibilidad de la especie al CPF se encuentra cercana al percentil 26 , teniendo en cuenta la curva de sensibilidades construida con datos de CL-50 a $96 \mathrm{~h}$ publicados para otras especies de anfibios anuros. En relación con los efectos subletales, la especie se encuentra cercana al percentil 5 (alteraciones en la natación) y 33 (presencia de anormalidades), teniendo en cuenta la curva de sensibilidades construida con datos de CE-50 a $96 \mathrm{~h}$ publicados para otras especies de anfibios anuros. El diseño experimental propuesto (larvas expuestas de forma individual), permitió demostrar que los efectos negativos del CPF, en el intervalo de concentraciones ensayadas, no revierten sino que se mantienen constantes. Se concluye que existe una progresión de efectos negativos del CPF, desde alteraciones en la natación seguidas por la presencia de anormalidades leves y luego severas hasta la muerte. Por último, se puso a prueba el modelo mediante la evaluación del sonido como punto final de efectos producidos por el CPF sobre larvas de esta especie. Se concluye que el sonido constituye un buen biomarcador de efectos subletales. A partir del resumen e integración de la información toxicológica existente sobre efectos del CPF en anfibios y exposición del CPF en el ambiente, mediante la herramienta de evaluación del riesgo ecológico, y la contextualización de los resultados obtenidos, se concluye que el CPF implica un riesgo muy bajo para las distintas especies de anuros evaluadas, al menos al considerar la exposición ante concentraciones esperadas en el ambiente (ecosistemas acuáticos pampeanos).

El presente constituye el primer bioensayo de exposición de larvas de C. ornata a un agroquímico de uso frecuente en la región Pampeana y la primera evidencia de efectos sobre el sonido emitido por larvas de esta especie. Consecuentemente, constituye el primer estudio sobre dicha temática (efectos del CPF sobre el sonido) realizado con larvas de vertebrados acuáticos. Por sus características biológicas y su manejo en laboratorio 
(facilidad para criarlas en condiciones controladas), la especie resulta de gran interés como modelo de estudio en Ecotoxicología. El estudio se encuentra en un marco general de investigación de impacto de plaguicidas en agroecosistemas de la región Pampeana, junto al desarrollo y aplicación de estrategias de monitoreo, para la evaluación de efectos biológicos de plaguicidas sobre anuros autóctonos. El modelo probado resultará una herramienta útil para el desarrollo futuro de más experimentos, generando así un modelo completo de evaluación de efectos. 
Underwater sound emission by Ceratophrys ornata larvae was a novel finding reporting the first evidence in anuran larvae. This result led to the development of a new research line, particularly being the main focus of the present doctoral thesis. The study has been divided into two consecutive parts. The first covered the development of an experimental model with larvae of this species. In this regard, a protocol for ex situ breeding of C. ornata was developed, towards obtaining individuals at all stages of development (from egg to adult). This was made possible by using an artificial induction method called AMPHIPLEX. The method allowed obtaining eggs at different times of year not always in coincidence with the breeding season of the species (summer), hence collecting data on the biology of the species, which otherwise would have been difficult or not possible given its habit. In this regard, this study provides data on the biology of $C$. ornata concerning reproduction (reproductive activity, number of eggs laid by clutch, percentage of hatching), growth (growth curves from larva to adult), development (average time to reach some stages), diseases (diagnosis and treatment), behavior (distress call, advertisement and reciprocal call, and pedal movements) and general biology. At the same time, the protocol was validated by the successful application on other phylogenetically related species with similar habits (C. cranwelli, C. aurita y Lepidobatrachus llanensis). Ex-situ breeding is a strategy that avoids continuous removal of animals from their natural habitat and allows the development of research in those cases where the in-situ studies are difficult to perform.

Once the protocol of captive breeding of individuals of $C$. ornata was developed, and larvae at all stages of development were obtained, the variability of the sounds produced was described, both underwater and out of the water. Previously, sound specialists were consulted to improve the recording system. A calibration method of the recording system allowed obtaining highly reliable recordings. Furthermore, a method for improving the signalto-noise ratio allowed obtaining recordings with clearer and easier spectra for further analyses. In addition, out of the water sounds emitted by individuals of $C$. ornata were measured with a sound level meter, allowing the characterization of the sound, both qualitatively and quantitatively by acoustic variables. In conclusion, registration devices commonly used in bioacoustics of amphibians do not provide adequate tools to measure the low pressure sounds as the one presented here. So, to effectively characterize these sounds, one must use calibrated instruments with acoustic reference systems. Analyzed variables were a) bioacoustic: sound duration ( $\mathrm{Sd}$ ) expressed in seconds (s), number of pulses (Np), number of interpulses (Nip), dominant frequency (Df) expressed in Hertz (Hz); b) acoustic: equivalent continuous sound level $\left(L A_{e q}\right)$ expressed in decibels $(d B)$, maximum sound level $\left(\mathrm{LAF}_{\max } \mathrm{dB}\right)$, and sound level that has been matched or exceeded during $90 \%$ of the measurement time (close to background) $\left(\mathrm{LAF}_{90}, \mathrm{~dB}\right)$. The emission of sounds was 
registered from stage 25 to 41 , after which the larvae do not emit sounds until completing the metamorphic process. At this point, juvenile individuals re-emit sounds remaining this situation throughout the entire life cycle. Finally, the application of the breeding protocol to other species of anurans phylogenetically related to $C$. ornata, allowed evaluating and describing the emission of their sounds at larval stages. Consequently, the emission of sounds was registered for $C$. cranwelli and $C$. aurita tadpoles. Lepidobatrachus Ilanensis tadpoles did not emit sounds in the evaluated range of frequencies. Therefore, the original hypothesis that states that sound emission is present in all carnivorous and macrophagic anuran larvae should be rejected.

After describing the sounds, the context of sound emission of $C$. ornata larvae was evaluated concluding that they emit under different contexts (intraspecific interactions or interactions with an object). Sounds were included in the distress call category. So far, no previous studies analyzing the variation of these sounds from early stages of larval development and throughout the life cycle were found. Regarding the assessment of the mechanism of sound production, a series of morpho-functional tests allowed building the hypothesis that the source of air used in the production of sounds during larval stages comes from the stomach, passes through the glottis (a resonant structure should be there) and then through the oro-pharyngeal cavity (without leaving it). Moreover, predator-prey interactions both intra- and interspecific, between larvae of $C$. ornata and between those larvae and larvae that are part of their diet, were evaluated, at different stages of development and under different experimental conditions (density and predator-prey proportions). We conclude that $C$. ornata larvae have an antipredator mechanism that decreases the frequency of predation between conspecifics in the presence of heterospecifics. Finally, intra and interspecific interactions were also evaluated for $C$. cranwelli and L. Ilanensis tadpoles in order to determine similarities and differences with $C$. ornata. In conclusion, the antipredator mechanism of Ceratophrys comprises a movement of the tail accompanied by the emission of sounds and the subsequent escape of the prey from the predator. However, while $L$. llanensis tadpoles also make a movement of the tail followed by the escape of the prey from the predator, no sound emission was registered. Beyond the methodological differences, the three mechanisms have the following level of efficiency from highest to lowest: $C$. ornata, $C$. cranwelli, L. Ilanensis.

As a consequence of these studies, a second part of the research was developed to evaluate the effects of clorpirifós (CPF), an organophosphate pesticide frequently used in the Pampas region, on $C$. ornata larvae, and apply the model developed in the first part. The first objective was to assess lethal and sublethal effects on larvae exposed to this pesticide. Considering that organophosphorus pesticides have neurotoxic action inhibiting acetylcholinesterase, sound production system and the sound by itself can be altered. In this sense, common ecotoxicological parameters were tested added of the effect on sound. The 
endpoints analyzed were: mortality, swimming alterations, presence of abnormalities and growth inhibition. In addition, the same bioacoustic variables detailed above (Sd, Np, Nip, Df) were evaluated. The sensitivity of the studied species to CPF was found to be close to the 26th percentile considering $96 \mathrm{~h} \mathrm{CL-50}$ data published for other species of anurans. Regarding sublethal effects, the species is close to the 5th (alterations in swimming) and 33rd percentiles (presence of abnormalities) taking into account published $96 \mathrm{~h} \mathrm{EC}-50$ values for other species of anurans. Furthermore, the proposed experimental design (larvae exposed individually), helped to show that the adverse effects of the CPF, within the range of concentrations tested, did not reverse but also remain constant. There is a negative progression of effects of CPF, from alterations in swimming followed by the presence of mild to severe abnormalities, followed by death. Finally, the proposed experimental model was tested by the evaluation of the effects of CPF on the sound as an assessment endpoint for larvae of this species. Sound effects are good biomarkers with potentiality for being tested in standardized protocols of sublethal effects. In addition, from the summarize and integration of existing toxicological data of effects of CPF on amphibians and environmental data of CPF, by means of ecological risk assessment tool, and the contextualization of the results obtained, we conclude that CPF implies a very low risk for the various species of anurans evaluated, at least when considering the exposure at measured environmental concentrations (Pampas aquatic ecosystems).

This is the first toxicity test for larvae of $C$. ornata to one agrochemical used in the Pampa region and the first evidence on the effects on the sound emitted by those larvae. Consequently, this is the first study on this subject (effects on sounds) carried out with larvae of aquatic vertebrates. The biological characteristics of the species and laboratory management (facility to raise them in controlled conditions), makes of great interest in using C. ornata as a good model in Ecotoxicology. This thesis was developed within the framework of studies on the impact of pesticides in agroecosystems of the Pampas region, together with the development and implementation of monitoring strategies for the assessment of biological effects of pesticides on native species. The model is a useful tool for the development of more experiments, generating a full impact assessment model. 


\section{GLOSARIO}

- \% de eclosión: cantidad de embriones que fragmentaron la membrana y cápsulas del huevo dando comienzo a la etapa larval

- AC: medio acuático en el cual se realizaron grabaciones de audio

- Adulto: individuo con caracteres sexuales secundarios

- AE: medio aéreo en el cual se realizaron grabaciones de audio

- Ca: Ceratophrys aurita

- Cc: Ceratophrys cranwelli

- CIMA: Centro de Investigaciones del Medio Ambiente

- Co: Ceratophrys ornata

- CPC: curva de probabilidad conjunta de la distribución acumulativa de la toxicidad de un determinado compuesto para un determinado grupo animal y de la distribución acumulativa de las concentraciones del tóxico en el ambiente

- CPF: clorpirifós

-DCE: distribución de concentraciones de exposición

-DE: desvío estándar

-Ds: duración de un sonido en segundos (s)

-DSE: distribución de sensibilidades de especies

- EC-50: concentración efectiva que provoca un efecto en el $50 \%$ de los individuos expuestos

- Embrión: estadios previos a la ruptura de la membrana y cápsulas del huevo (eclosión)

- F: estadístico de prueba del análisis de la varianza. Para esta prueba se indican entre paréntesis los grados de libertad de los cuadrados medios entre grupos y dentro de los grupos, seguido de la probabilidad ( $p$ ) asociada a la misma

- Fd: frecuencia dominante de un sonido en Hertz $(\mathrm{Hz})$

- g.I.: grados de libertad

- H: estadístico de prueba de Kruskal-Wallis utilizado cuando no se cumplieron los supuestos de su correspondiente prueba paramétrica. Para esta prueba se indican entre paréntesis los grados de libertad y el número de datos totales, seguido de la probabilidad (p) asociada a la misma

- HC: concentración de peligro (= hazardous concentration)

-HDRP: hipótesis de la disponibilidad relativa de presas

-HED: hipótesis del efecto de la densidad

- Hp: Hypsiboas pulchellus

- Huevo: óvulo rodeado de la membrana vitelina y capsulas (interna y externa) 
- Juvenil: individuo que completó el proceso metamórfico

- LAE (nivel de exposición sonora ponderado en $A$ ): es el nivel sonoro constante en dB (A) que, si se mantiene durante 1 segundo, produce la misma cantidad de energía acústica que el evento de ruido medido. Se suele utilizar para caracterizar eventos sonoros discretos

- $\mathrm{LAF}_{10}$ : valor estadístico que representa el nivel sonoro que se ha igualado o superado durante el $10 \%$ del tiempo de medición. Medido con ponderación A en frecuencias y respuesta temporal rápida (Fast)

- $\mathrm{LAF}_{90}$ : valor estadístico que representa el nivel sonoro que se ha igualado o superado durante el $90 \%$ del tiempo de medición. Medido con ponderación A en frecuencias y respuesta temporal rápida (Fast). En acústica se utiliza como representativo del ruido de fondo de un lugar

- $\mathrm{LAF}_{\text {máx }}$ (nivel sonoro máximo): medido con ponderación $\mathrm{A}$ y respuesta temporal rápida (Fast) de 125 ms. Es el máximo nivel sonoro registrado durante una medición

- LAL: Laboratorio de Acústica y Luminotecnia

- Larva: se consideran estadios larvales aquellos a partir de la eclosión y hasta la finalización del proceso metamórfico

- LC-50: concentración que mata al 50\% de los individuos expuestos

- LCE (nivel de exposición sonora ponderado en C): es el nivel sonoro constante en dB (C) que, si se mantiene durante 1 segundo, produce la misma cantidad de energía acústica que el evento de ruido medido

- $\mathrm{LC}_{\text {peak }}$ (nivel sonoro pico ponderado en $\mathrm{C}$ ): es el valor máximo alcanzado por la presión acústica (es el verdadero pico de la onda de presión sonora). El circuito detector de pico tiene una respuesta temporal de $50 \mu \mathrm{s}$

- $L_{e q}$ (nivel de presión sonora continuo equivalente): es el nivel sonoro constante, que en el mismo intervalo de tiempo, contiene la misma energía total que el ruido medido. Puede medirse con ponderación $A$ en frecuencias $\left(L A_{\text {eq }}\right), C\left(L C_{e q}\right)$, o linealmente $\left(L Z_{\text {eq }}\right)$ para hacer análisis espectral

- LFLC: leve flexión lateral de la cola. Implica una flexión lateral de la cola menor a $45^{\circ}$ respecto al eje longitudinal

- LHC/Peso: índice de condición corporal (Longitud Hocico-Cloaca/Peso)

- LHC: longitud hocico-cloaca en milímetros ( $\mathrm{mm})$

- LI: Lepidobatrachus llanensis

- LOEC: menor concentración que causa un efecto negativo

- Nip: número de interpulsos de un sonido

- NOEC: mayor concentración a la cual no se observa un efecto negativo

- Np: número de pulsos de un sonido 
- NPS: nivel de presión sonora en decibeles (dB)

- r: coeficiente de correlación de Pearson que cuantifica la relación lineal entre dos o más variables. Para este análisis se indica la probabilidad ( $p$ ) asociada a la prueba de significancia del coeficiente de correlación

- $r^{2}$ : coeficiente de regresión lineal que determina la existencia de relación lineal entre una variable dependiente y una variable independiente. Para este análisis se indica la probabilidad $(p)$ asociada a la prueba de significancia del coeficiente de regresión

- Ra: Rhinella arenarum

- Rf: Rhinella fernandezae

- RF: ruido de fondo

-RSR: relación señal-ruido

- SFLC: severa flexión lateral de la cola. Implica una flexión lateral de la cola de $90^{\circ}$ respecto al eje longitudinal

-STD: estadio del desarrollo

- $t$ : estadístico de prueba $t$ de Student. Para esta prueba se indican los grados de libertad y la probabilidad $(p)$ asociada a la misma

- TL-50: tiempo en el cual se observan efectos negativos en el $50 \%$ de los individuos expuestos

- U: estadístico de prueba $U$ de Mann-Whitney utilizado cuando no se cumplieron los supuestos de su correspondiente prueba paramétrica. Para esta prueba se indica la probabilidad $(p)$ asociada a la misma

- $X^{2}$ : estadístico de prueba Chi-cuadrado. Para esta prueba se indica la probabilidad $(p)$ asociada a la misma 


\section{INTRODUCCIÓN GENERAL}

\section{La agricultura y sus efectos abordados por diferentes disciplinas}

La agricultura, definida en un principio como el arte de cultivar la tierra, ha sido practicada en Argentina desde la época colonial. Desde entonces, el ser humano ha ido perfeccionando sus técnicas y expandiendo la superficie total cultivada (Brailovsky y Foguelman, 1995). La agricultura moderna, ampliamente extendida en la actualidad, se basa en un paquete tecnológico de alta productividad, siembra directa, utilización de organismos genéticamente modificados (OGM) y aplicación masiva de fertilizantes y plaguicidas que garantizan dicha productividad. El advenimiento de este modelo intensivo y extensivo hace aproximadamente cinco décadas, tiempo que representa tan solo un $0,001 \%$ comparado con la existencia del hombre en la Tierra, trajo asociado una serie de problemas ambientales y sociales que no solo ponen en duda la sustentabilidad del sistema, sino también afectan la biodiversidad y la salud humana mediante la destrucción y reemplazo de ambientes naturales, la pérdida de especies nativas y la contaminación de suelos y agua (ManuelNavarrete y col., 2005; Leguizamón, 2014). Particularmente, la utilización de OGM en Argentina tuvo sus comienzos en 1996 y hoy día coloca al país en el tercer puesto de mayor productor y exportador mundial de granos genéticamente modificados, siendo la soja la estrella del modelo (James, 2010; USDA, 2015). De la mano de los problemas ambientales surgen disciplinas y ciencias que los abordan, como combinaciones de disciplinas preexistentes, como especializaciones o producto de la incorporación de nuevas herramientas. La primera de las publicaciones al respecto que nos hace reflexionar acerca de los problemas ambientales que trae aparejado el uso de plaguicidas, es el famoso libro titulado "La primavera silenciosa" de Rachel Carson. Ya en la década del 70, hacen su aparición estudios toxicológicos orientados a la salud humana acerca del impacto de los agroquímicos, y con ellos la prohibición de utilización de algunos (Klaassen, 2008). Por otro lado, los estudios acerca del impacto de los agroquímicos (entre otros contaminantes ambientales) sobre animales no blanco, pasaron a ser objeto de estudio de la Ecotoxicología.

La Ecotoxicología ha sido definida de maneras muy diferentes y cambiantes a lo largo de su historia. Desde su primera mención se la definió como "la rama de la Toxicología que comprende el estudio de los efectos tóxicos causados por contaminantes naturales o sintéticos sobre los componentes de los ecosistemas (incluyendo al hombre) en un contexto integrado" (Truhaut, 1977). Con el paso del tiempo fue definida como "la extensión natural de la Toxicología, ciencia que estudia el efecto de los tóxicos sobre organismos individuales, al efecto ecológico de los contaminantes" (Moriarty, 1983). Finalmente, en el nuevo siglo 
surgen numerosas definiciones entre ellas, "la ciencia que estudia los efectos dañinos de los contaminantes sobre los ecosistemas" (Walker y col., 2006), y "la ciencia que estudia los contaminantes en la biosfera y los efectos sobre sus constituyentes, incluido el hombre" (Newman y Unger, 2003). Resulta interesante la definición de la Ecotoxicología como "una ciencia jerárquica con muchos niveles" (Newman y Clements, 2008), los cuales se corresponden con los niveles de organización ecológica (ej. biosfera, ecosistema, comunidad, población e individuo). Estos autores, introducen el contexto de Janus (deidad romana) propuesto por Koestler (1991), quien denominó holon a cada unidad de un sistema jerárquico, estando tal unidad compuesta de menores partes y siendo parte a su vez de una unidad mayor. En este sentido, Newman y Clements (2008) modifican dicho concepto proponiendo un esquema representado por la concatenación causa-efecto-significancia, siendo la unidad con la que uno debe moverse entre los holones de esa ciencia jerárquica. Para ello, se debe utilizar la consiliencia de principios explicativos y los paradigmas actuales de las diferentes disciplinas, los cuales entran en juego al momento de resolver las preguntas de investigación. Tal esquema, muestra una manera coherente de proceder en la investigación científica, estando involucrada la observación de efectos en un nivel, la búsqueda de explicaciones mediante experimentación en el nivel más bajo inmediato y la predicción de efectos en el nivel inmediatamente superior. Este mismo concepto es retomado por Newman (2013) en relación al estado del conocimiento de los efectos ecotoxicológicos a lo largo de los diferentes niveles de organización (Fig. 1). Tal como propuso Caswell (1996), si reconocemos estos principios teniendo claro que no son explicaciones fundamentales, esto hará posible movernos cuidadosamente subiendo y bajando entre los diferentes niveles de un sistema jerárquico, sin caer en las trampas del reduccionismo ingenuo ni del holismo pseudocientificista. Además, los problemas ambientales pueden ser abordados a diferentes escalas según la extensión geográfica de los mismos, pudiendo afectar a todo el planeta (escala global), extenderse por áreas menores (escala regional) o simplemente estar contenidos dentro del territorio de un país o ciudad (escala local) (Segura y Arriaga, 2003). Los estudios acerca de los efectos de la contaminación a distintas escalas y niveles ecológicos han sido incorporados en el paradigma que sustenta a la Ecotoxicología (Newman, 2013). 


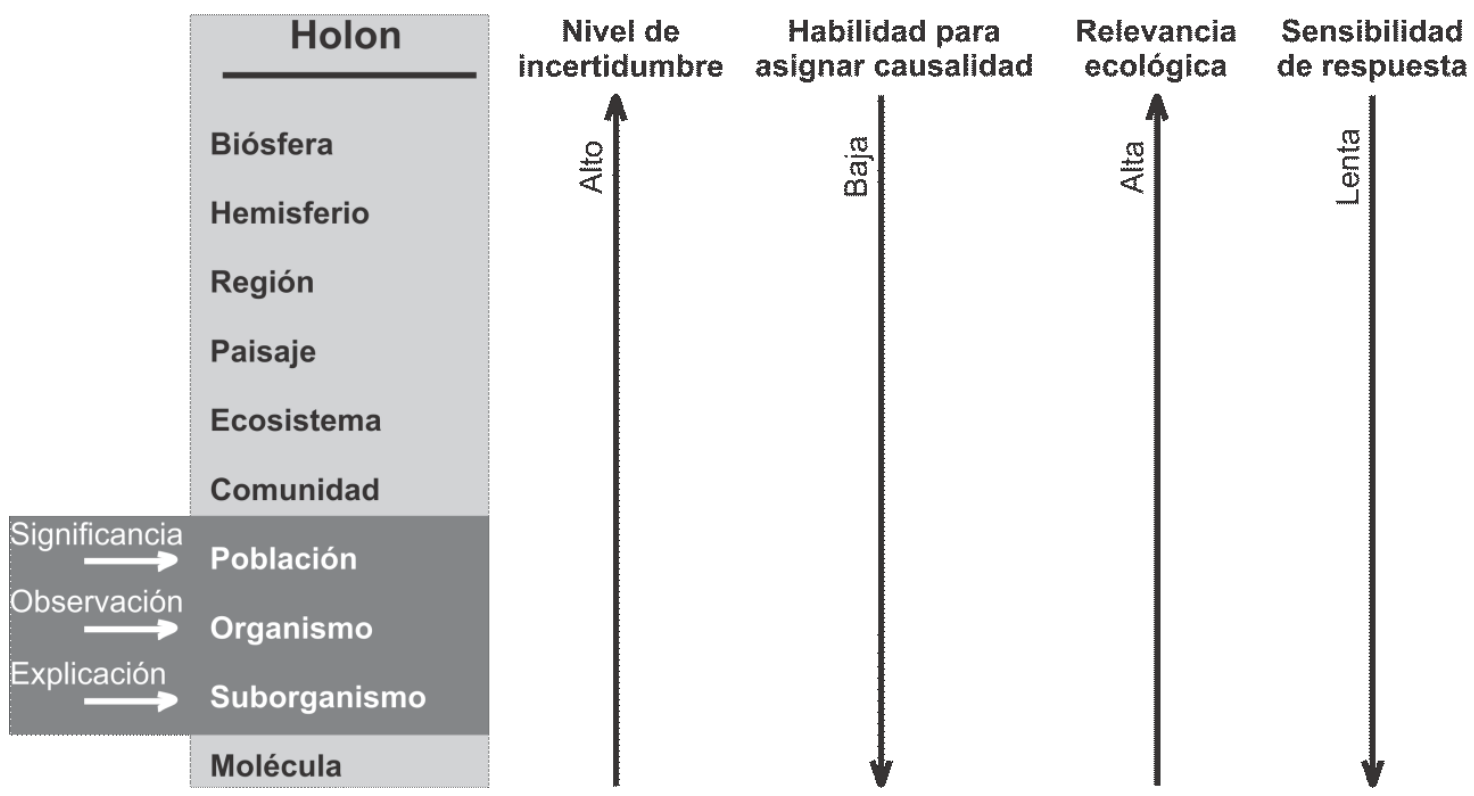

Figura 1. Esquema representativo de la concatenación causa-efecto-significancia, que propone la observación de efectos en un nivel, la búsqueda de explicaciones mediante experimentación en el nivel más bajo inmediato y la predicción de efectos en el nivel inmediatamente superior

Tal asociación, se visualiza al emplear el dispositivo conocido como caja negra, el cual es utilizado para corroborar hipótesis. Éste es un modelo predictivo que si bien no explica los procesos que suceden dentro de la caja, resulta de fácil aplicación y gran utilidad. Mediante este modelo experimental se adjudica al factor estudiado (variable independiente), la responsabilidad de generar la causa o el efecto, que a su vez mantienen una estrecha relación con la escala a la que se aborda el estudio. La medición se realiza habitualmente como diferencias significativas en la magnitud de la variable de respuesta del grupo tratado (variable dependiente) respecto al grupo control. De manera general, se estudian dentro de esta ciencia efectos entendidos como negativos o adversos para el sistema estudiado respecto de la normalidad. Particularmente en Ecotoxicología, la relación dosis-respuesta antes mencionada se denomina más comúnmente concentración-respuesta, ya que se evalúa el número de moléculas de un contaminante en un compartimento ambiental determinado (concentración), las cuales entran en contacto con el organismo estudiado (organismo de prueba), siendo la variable de respuesta el punto final de evaluación. La Ecotoxicología engloba también como parte de su paradigma actual al concepto de tolerancia individual (Newman y Unger, 2003), a partir del cual se acepta que la curva concentración-respuesta es de tipo sigmoidea (Finney, 1971) y que el modelo Probit (entre otros modelos) es válido para estimar los parámetros toxicológicos convencionales. Esto queda evidenciado en los protocolos publicados por USEPA (1989; 1991; 1998), ASTM (1991) y EC (1999). Todos estos elementos que constituyen el paradigma actual de la Ecotoxicología, deben interpretarse dentro del marco antes mencionado del concepto de 
consiliencia, entendido como la unión de los conocimientos y la información de distintas disciplinas para crear un marco unificado de entendimiento.

Como toda ciencia, la Ecotoxicología posee un objeto de estudio: los efectos adversos provocados por contaminantes físicos, químicos o biológicos sobre los diferentes componentes de un ecosistema. Sin embargo, se debe mencionar que no solo se hace hincapié en el efecto adverso de los contaminantes sino también en el destino y transporte de los mismos entre los compartimentos bióticos y abióticos (Newman y Clements, 2008). Considerando que tal objeto de estudio puede abordarse desde las más variadas disciplinas científicas, las diferentes escalas de estudio (desde el nivel de biosfera hasta el nivel molecular) condicionarán junto con la técnica aplicada, su pertenencia a una u otra disciplina. Esta diversificación de métodos de abordaje de la relación causa-efecto, la cual puede reconocerse como artificios del reduccionismo científico, termina contribuyendo a la consolidación de un paradigma claramente identificable con la Ecotoxicología y con su objeto de estudio. Es importante aclarar la definición de tóxico versus contaminante, siendo éste último un agente o sustancia introducido en el ambiente como resultado, al menos en forma parcial, de la actividad humana y el cual produce efectos adversos sobre los organismos y el ecosistema. En cambio, cuando se refiere a un tóxico se hace hincapié en el agente o sustancia que puede producir un efecto adverso sobre la estructura y/o función del sistema en estudio (USEPA, 1998; Newman y Unger, 2003; Newman y Clemens, 2008). Tal como citó Paracelsus (alquimista y médico suizo), "la dosis hace al veneno", pretendiendo explicar un principio básico de la Toxicología que considera que una sustancia puede producir el efecto perjudicial asociado, con sus propiedades tóxicas, sólo si llega a un sistema biológico susceptible en una concentración lo suficientemente alta (= dosis).

Ya abordados los anteriores conceptos y definiciones, cabe destacar que en el presente trabajo de tesis la caja negra es el bioensayo de toxicidad. Éste, tal como lo definió Finney (1971) es "un experimento realizado para estimar la naturaleza, constitución o potencia de un material (o de un proceso), por medio de una reacción que se aplica a la materia viviente". El concepto de bioensayo derivado de la Toxicología clásica ha sido modificado, adaptado y extendido al diagnóstico y manejo ambiental dentro del campo de la Ecotoxicología, y junto a los análisis fisicoquímicos convencionales son considerados una alternativa eficaz en la predicción de niveles seguros de concentración de compuestos tóxicos. En algunas circunstancias, los bioensayos de toxicidad son realizados con una única especie, en una etapa de su ciclo de vida, frente a un solo compuesto puro bajo condiciones controladas de laboratorio, presentando sus resultados una relevancia ecológica limitada (Burkhart y col., 2003). A pesar de las restricciones que impiden realizar extrapolaciones a escala ambiental a partir de la información proveniente de los bioensayos (Vignati y col., 2007), son los resultados de este tipo de estudios los que constituyen la 
fuente de información predominante para la evaluación ecológica de los efectos de los contaminantes (Ronco y col., 2004). Sin embargo, aun falta información tanto a nivel mundial como local, acerca de los contaminantes más utilizados y sus efectos en especies autóctonas representativas de los ecosistemas que integran. En tal sentido contribuye este trabajo, mediante el desarrollo de un modelo experimental para su aplicación ecotoxicológica en la evaluación de efectos de plaguicidas, ampliamente utilizados en la región pampeana, sobre larvas de anuros autóctonas. A continuación se resumen las investigaciones ecotoxicológicas a nivel mundial, con énfasis en aquellas realizadas dentro del ámbito de la Ecotoxicología Herpetológica. Finalmente, se describen los estudios ecotoxicológicos realizados en Argentina con especies de anfibios autóctonas, los que a su vez involucran efectos producidos por contaminantes de relevancia ambiental.

\section{Investigaciones ecotoxicológicas a nivel mundial}

El interés por el estudio de los vertebrados en Ecotoxicología reside en la relación filogenética más cercana de este grupo de animales con el hombre, respecto a otros grupos de organismos. Sparling y col. (2000) realizaron una investigación sobre los trabajos publicados entre 1972 y 1998 relacionados con ecotoxicología de vertebrados. Encontraron que en este periodo se publicaron un total de 12.727 trabajos, de los cuales el $28,6 \%$ fueron realizados con peces, el $29,9 \%$ con aves, el $13 \%$ con mamíferos, el 2,7\% con anfibios y el $1,4 \%$ con reptiles. Los mismos autores destacan la necesidad de realizar estudios en el área de la Herpetología, considerando que el grupo de los anfibios sumado al de los reptiles representa casi el $50 \%$ de las especies de vertebrados conocidos. Con el objetivo de actualizar esos datos una década más adelante, Sparling y col. (2010) realizaron una nueva búsqueda y concluyeron que se había logrado un gran desarrollo de la información ecotoxicológica de anfibios, mediante la evaluación de efectos de distintas familias de compuestos químicos. Concluyen que a partir del año 2000 el total de publicaciones con anfibios y reptiles superó la publicada hasta esa fecha, y que el aumento de interés y productividad en Ecotoxicología fue más evidente en anfibios. Remarcan que este incremento significativo en el número de trabajos publicados, se encuentra asociado a la aceptación del fenómeno denominado declinación mundial de las poblaciones de anfibios. Sin embargo, los autores reconocen la necesidad de realizar más trabajos para poder entender de manera global los efectos de los contaminantes tanto en anfibios como en reptiles. El último trabajo publicado que estima las extinciones globales de anfibios y reptiles desde 1940 hasta 2010, reporta para el grupo de los anfibios una pérdida del 3,05\% (Alroy, 2015). Este autor señala que un pulso de extinción sustancial para América Latina estaría mayormente relacionado con la epidemia por quitridiomicosis, aunque también reconoce otros factores como la deforestación y propagación de especies invasoras. En lo que 
respecta a Argentina, el país no se encuentra exento de la creciente crisis global de la biodiversidad, reconociéndose la necesidad por parte de herpetólogos locales de incrementar el conocimiento acerca de la diversidad de anfibios, y de generar información de base para su conservación. En tal sentido, en el año 2012 se realizó la última categorización del estado de conservación de anfibios de la República Argentina, con la finalidad de contribuir a establecer prioridades en ciertas regiones o especies que requieran de acciones de conservación inmediata (Vaira y col., 2012). A continuación se resumen algunos de los estudios ecotoxicológicos que han sido llevados a cabo hasta el momento en Argentina, involucrando especies de anuros autóctonas.

\section{Los anfibios anuros en el contexto de la investigación}

El Primer Congreso Mundial de Herpetología se realizó hacia finales de la década del ' 80 , momento a partir del cual empezó a manifestarse cierta preocupación por parte de los herpetólogos acerca de la disminución que comenzaban a sufrir gran número de poblaciones de anfibios. A partir de ese momento, se desarrollaron varios talleres y reuniones con el objetivo de evaluar el alcance de la declinación de anfibios. En estos talleres se resolvió constituir grupos de trabajo, entre ellos un grupo que impulsó el desarrollo de metodologías estandarizadas y protocolos para muestrear poblaciones naturales de anfibios (equipo de trabajo sobre la declinación de poblaciones de anfibios, DAPTF). Esto generó un aumento del número de trabajos publicados y proyectos que contribuyeron al conocimiento de la diversidad de anuros de las distintas regiones del mundo, su estado de conservación y diferentes aspectos de su ecología. Desde entonces, sucesivas y numerosas publicaciones han brindado información que sustenta la existencia de una creciente disminución global de anfibios. La mayoría se enfoca en estudios de relevo faunístico y la contribución de ciertos factores a la declinación. Otros proponen analizar las complejas interrelaciones que involucran a los múltiples factores, y la necesidad de realizar estudios de campo a largo plazo para comprender la dinámica de cada población y de su hábitat (Houlahan y col., 2000; Young y col., 2004; Natale, 2006; Sodhi y col., 2008; Collins y Crump, 2009; WWF, 2014).

El último y más reciente relevo de especies de anfibios amenazadas a nivel mundial se realizó en el año 2008, habiéndose incluido sus datos en la Lista Roja de los Anfibios de la Unión Internacional para la Conservación de la Naturaleza (IUCN). Según este informe, del cual participaron alrededor de 650 investigadores pertenecientes a 60 países, casi el $32 \%$ de las especies de anfibios a nivel mundial se encuentran amenazadas o extintas, el $43 \%$ no se encuentran amenazadas y del $25 \%$ restante no se cuenta con suficientes datos para determinar su estado. A partir de este relevo de datos se determinó que al menos el $42 \%$ de todas las poblaciones de anfibios se encuentran en disminución, mientras que menos del 
$1 \%$ se encuentra en un periodo de crecimiento poblacional (IUCN, 2008). Específicamente para Argentina, en el año 2012 la Asociación Herpetológica Argentina (compuesta en su mayoría por herpetólogos locales) publicó los resultados de un taller en el cual se re-evaluó el estado de conservación de los anfibios de Argentina (Vaira y col., 2012). Dicho taller reunió a 35 especialistas de todo el país, con el propósito de actualizar la información taxonómica, geográfica y bioecológica de anfibios acumulada desde el año 2000 (Lavilla y col., 2000). La nueva lista registra un total de 175 taxones de anfibios respecto a los 171 evaluados en la anterior categorización. De éste total, 51 taxones presentan algún grado de riesgo para su conservación (8 fueron categorizados como "en peligro", 11 "amenazados" y 32 "vulnerables") y los restantes se consideran "no amenazados" (103 taxones) o "insuficientemente conocidos" (21 taxones). Comparando estos resultados con los correspondientes a la anterior categorización, hubo un incremento en el número de taxones en la categoría "en peligro" (= $3 \%)$ y "amenazados" (= $5 \%)$, una disminución en el número de taxones poco conocidos (= 10\%) y un incremento de los taxones "no amenazados" (= $10 \%$ ). Se evidencia un alarmante aumento del número de taxones con algún grado de riesgo, aunque también resulta notorio el incremento de las investigaciones en regiones y especies poco conocidas. Estas investigaciones permiten conocer más acerca de la biología de algunas especies facilitando así la búsqueda y mitigación de aquellos factores que contribuyen con su disminución.

Las causas que contribuyen a la disminución global de anfibios han sido discutidas en detalle, contando hasta el presente con las siguientes hipótesis: (1) pérdida de hábitats por alteración irreversible y/o fragmentación, (2) alteración de hábitats por contaminación química y biológica, (3) introducción de especies exóticas, (4) enfermedades emergentes, (5) aumento de la radiación ultravioleta, (6) cambio climático global y (7) comercio de especies (Stebbins y Cohen, 1995). Específicamente para la disminución de las poblaciones de anfibios de Argentina, se han identificado los mismos siete factores, haciéndose hincapié en algunas particularidades locales para cada amenaza (Lavilla, 2001; Lavilla y Heatwole, 2010). Entre ellas, es bien conocido para nuestro país la creciente pérdida de hábitats por conversión de áreas naturales en campos de agricultura o pastoreo y la contaminación química de diferentes compartimentos ambientales por metales, productos farmacéuticos y agroquímicos (Brown y col., 2006; SAyD, 2007; Ronco y col., 2008; Cappello y Fortunato, 2013; Elorriaga y col., 2013); la introducción de peces no nativos (Úbeda y Grigera, 2007; Barrionuevo y Ponssa, 2008) y de anfibios exóticos para su comercio (Pereyra y col., 2006; Barrasso y col., 2009; Akmentins y Cardozo, 2010; Sanabria y col., 2011); y por último la presencia de enfermedades infecciosas emergentes, entre ellas ranavirus (Fox y col., 2006) y quitridiomicosis (Herrera y col., 2005; Arellano y col., 2009; Delgado y col., 2012; Ghirardi, 2012). Específicamente, el efecto de los plaguicidas utilizados en agricultura y su relación 
con la declinación mundial de anuros ha sido sugerida por diversos autores, presentando además de efectos letales y subletales, variados patrones de respuesta específicos en cada estadio de vida tanto a nivel individual como sub-individual (para mayor información ver página 143).

Teniendo en cuenta lo antedicho, y considerando la información existente acerca de la biología de anuros autóctonos, al realizar diseños experimentales que comprometen a sus larvas, particularmente en los aspectos relacionados con las condiciones óptimas de cría y manutención (alimentación, densidades, factores fisicoquímicos), la información disponible en la literatura científica resulta insuficiente. Tales son los fundamentos por los cuales desde hace más de diez años, los herpetólogos y ecotoxicólogos locales venimos remarcando, no solo la importancia de desarrollar estudios de monitoreo y observación de atributos biológicos y ecológicos de anuros en campo (tanto larvas como adultos), sino también de realizar estudios que contribuyan con conocimientos para lograr el mantenimiento de larvas y adultos en cautiverio. Esto último, permitirá generar conocimiento para poder comenzar a conservar especies autóctonas, desarrollar modelos experimentales con esas especies y abordar los problemas ambientales de las diferentes regiones de nuestro país. En este mismo sentido, el presente trabajo contribuye con datos de la biología de especies autóctonas de Argentina, de las cuales se desconocen aspectos básicos, cuyas poblaciones se encuentran en descenso numérico (resulta imperioso precisar que aún faltan estudios al respecto), y para las cuales se propone un protocolo de cría en cautiverio (ex-situ) como una estrategia adecuada para su conservación junto al desarrollo de un modelo experimental para la evaluación de efectos de plaguicidas.

En lo que respecta a protocolos estandarizados para evaluar efectos biológicos sobre especies autóctonas, investigadores locales han reconocido la importancia de contar con los mismos para su aplicación como herramienta bioanalítica en la evaluación de fuentes puntuales y difusas de contaminación (Ronco y col., 2000). Específicamente para anfibios, diferentes investigadores han utilizado el protocolo de bioensayo estandarizado para embriones de anfibios (ASTM, 1991; Bantle, 1995), para medir toxicidad y teratogenicidad de sustancias puras, mezclas, efluentes y cursos de agua contaminados. En Argentina, se ha propuesto un procedimiento para realizar bioensayos de toxicidad con embriones de anfibios de Rhinella arenarum denominado AMPHITOX (Herkovits y Pérez Coll, 1999a-b), que permite evaluar la toxicidad de sustancias químicas, mezclas y muestras ambientales. Particularmente en el CIMA, se ha trabajado en el desarrollo de protocolos estandarizados de bioensayos con larvas de anuros autóctonos (Natale, 2006; Natale y col., 2006; Agostini y col., 2010; Vera Candioti y col., 2010; Ruiz de Arcaute y col., 2012; Pérez Iglesias y col., 2014; 2015). A nivel local se han desarrollado estudios y propuestas para el monitoreo de efectos y su incorporación en estrategias de control (Ronco y col. 2005; 2008). 
El presente trabajo forma parte de una tesis doctoral y la información se presenta en dos partes consecutivas (Fig. 2). La primera parte tiene por objetivo el desarrollo de un modelo experimental utilizando larvas de anfibios anuros de la familia Ceratophryidae, particularmente de la especie Ceratophrys ornata. De la manutención y cría de individuos de todos los estadios del desarrollo de esta especie, surge un protocolo de cría ex-situ que garantiza el desarrollo de dicho modelo (ver capítulo 1). La posibilidad de criar larvas de determinados estadios del desarrollo también permitió describir la variabilidad del sonido producido por las mismas (ver capítulo 2) y su contexto de emisión (ver capítulo 3). La segunda parte tiene por objetivo la aplicación del modelo experimental en estudios ecotoxicológicos de plaguicidas de uso frecuente en la región Pampeana. Para ello, se describen bioensayos de toxicidad aguda y crónica mediante la exposición de larvas de $C$. ornata en diferentes estadios del desarrollo al clorpirifós, y se evalúan variables de respuesta ecotoxicológicas convencionales (mortalidad, alteraciones en la natación, presencia de anormalidades e inhibición del crecimiento; ver capítulo 4), y no convencionales (efectos en el sonido, ver capítulo 5). Cabe destacar, que el trabajo se encuentra en un marco general de estudios de impacto de plaguicidas en agroecosistemas de la región Pampeana, junto al desarrollo y aplicación de estrategias de monitoreo, para la evaluación de efectos biológicos de plaguicidas sobre anuros autóctonos. De esta manera, el presente trabajo de tesis aporta conocimientos innovadores en el ámbito de la Ecotoxicología y Herpetología, e información de base acerca de la sensibilidad de una especie de anuro autóctona no utilizada hasta el momento en estudios ecotoxicológicos. 
(1) Capítulo 1: cría de individuos de la familia Ceratophryidae

Muestreo, aclimatación y mantenimiento de adultos de Ceratophrys ornata en laboratorio 1 Inducción de la reproducción de $C$. ornata. Protocolo de cría de la especie desde huevo hasta la adultez.

Aplicación del protocolo

en otras especies de Ceratophrys y Lepidobatrachus
2

Capítulo 2: variabilidad de sonidos a lo largo del desarrollo

Calibración y compensación del sistema de grabación. Grabación y análisis de sonidos, producidos en agua y aire, en distintos estadios del desarrollo de C. ornata 1

Medición y análisis de sonidos producidos en aire distintos estadios del desarrollo de C. ornata 1

Exploración de la emisión de sonidos por larvas de otras especies.

Descripción de sonidos
(3) Capítulo 3: evaluación del comportamiento

Evaluación del contexto y mecanismo de emisión de sonidos por larvas de $C$. ornata $\downarrow$

Evaluación de interacciones predador-presa intra e interespecíficas entre larvas carnivoras y macrófagas de la familia Ceratophryidae y larvas herbivoras que forman parte de su dieta habitual. Descripción del contexto de emisión de sonidos $\downarrow$

Evaluación de la existencia de un mecanismo antipredatorio en larvas macrófagas y carnivoras de Ceratophrys y Lepidobatrachus

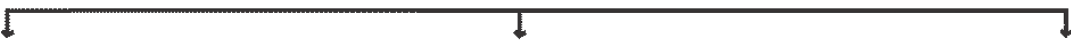 \\ Análisis de las variables de respuesta. Interpretación y discusión de resultados. Determinación de patrones normales para el desarrollo del modelo}

\section{Segunda Parte: Aplicación del modelo experimental}

(4) Capítulo 4: bioensayos de toxicidad con larvas de $C$. ornata

Ejecución de bioensayos de toxicidad aguda y crónica con larvas de C. ornata, en determinados estadios del desarrollo, bajo exposición a clorpirifós.

Evaluación de efectos a nivel individual tanto letales como subletales
(5) Capítulo 5: efectos sobre los sonidos emitidos por larvas de $C$. ornata

Ejecución de bioensayos de toxicidad aguda y crónica con larvas de $C$. ornata, en determinados estadios del desarrollo, bajo exposición a clorpirifós. Evaluación de efectos sobre la emisión de sonidos y sus parámetros normales

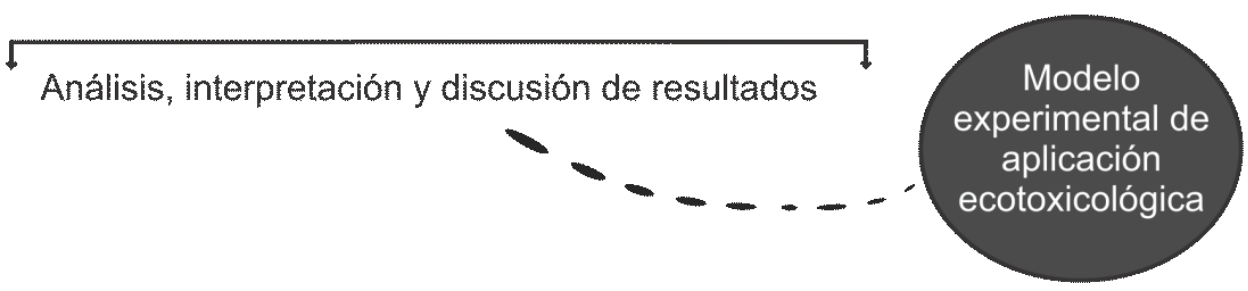

Figura 2. Esquema general del estudio realizado, explicitando los objetivos de cada capítulo y la relación entre ambas partes del estudio 
Primera parte: desarrollo de un modelo experimental con larvas de la familia Ceratophryidae 
Capítulo 1

Cría de individuos de la familia Ceratophryidae 
En el presente capítulo se detalla un protocolo de cría en cautiverio de la especie C. ornata desde huevo hasta adulto. El protocolo ha sido también aplicado a la cría de individuos adultos de especies filogenéticamente relacionadas con C. ornata, entre ellas C. cranwelli, C. aurita y Lepidobatrachus Ilanensis. Uno de los factores clave para el desarrollo y aplicación del protocolo ha sido la inducción artificial de la reproducción en cautiverio mediante el método AMPHIPLEX. Considerando ciertas particularidades biológicas de la especie, las cuales se detallan a lo largo del capítulo, y el estado de conservación de las poblaciones naturales ("vulnerable"), se concluye que este protocolo resulta ser una valiosa herramienta que permitirá, una vez mitigados los daños en el hábitat natural, reintroducir ejemplares sanos contribuyendo así con la conservación de la especie. Además, a partir del desarrollo de tal protocolo de cría ha sido posible desarrollar un modelo experimental con larvas de C. ornata (ver capítulo 2 y 3) para su utilización en estudios ecotoxicológicos de plaguicidas (ver capítulos 4 y 5).

\section{INTRODUCCIÓN}

\section{El rol de la cría ex-situ en la conservación de especies}

Teniendo en cuenta que las extinciones de anfibios ocurren a nivel mundial, en el año 2007 se formuló un plan con recomendaciones que pretenden dar soluciones a este mismo nivel, el "Plan de Acción para la Conservación de Anfibios" (ACAP, Gascon y col., 2007). En dicho plan, y tal como su nombre lo indica, se listan y profundizan algunos temas considerados relevantes para la conservación de anfibios. Entre ellos, (1) identificar, priorizar y proteger áreas consideradas clave por su contenido biodiverso; (2) proteger ambientes acuáticos y terrestres asociados, debiéndose realizar estudios para identificar las perturbaciones; (3) desarrollar investigaciones acerca del cambio climático y el contexto de la declinación para comprender las consecuencias de la pérdida de la biodiversidad; (4) detectar y controlar enfermedades infecciosas emergentes que constituyan una amenaza para las poblaciones de anfibios a nivel global (ej. quitridiomicosis); (5) identificar especies en peligro de extinción producto de la sobre-colecta humana y monitorear su comercio; y (6) evaluar el rol de la contaminación ambiental en la declinación de las poblaciones y mitigar su impacto. Por último, una de las principales actividades recomendadas en el ACAP es (7) la estrategia de reproducción en cautiverio y su cría ex-situ denominada "Arca de los Anfibios" (AArk). Ésta se presenta como el esfuerzo conjunto de la Asociación Mundial de Zoológicos y Acuarios (WAZA), el Grupo Especializado en Cría y Conservación (CBSG) de la IUCN y el Grupo Especialista en Anfibios (ASG). La propuesta de AArk es mantener en cautiverio, 
hasta su posible liberación de forma segura, a ciertas especies seleccionadas que de otra forma se extinguirían. Dicha estrategia se propone como una posible solución de conservación de aquellas especies cuyos daños no pueden mitigarse in-situ. En resumen, hay varias estrategias tendientes a conservar poblaciones de anfibios, las cuales no son consideradas excluyentes sino más bien complementarias, y tienen como factor común el desarrollo de programas de educación tanto a nivel escolar como a nivel comunitario. Tal factor común, es fundamental en todo programa de conservación.

Hasta la fecha, hay registrados 53 programas de conservación de anfibios a nivel mundial, los cuales tienen por objetivo implementar algunas de las estrategias de conservación antes mencionadas. Particularmente para América Latina y en relación a la cría ex-situ de anfibios, si tenemos en cuenta el total de especies actualmente descriptas (n = 4161; AmphibiaWeb, 2015) y el total de especies insertas en programas de manejo ex-situ $(n=85)$, éstos últimos abarcan solo el $0,02 \%$ de las especies conocidas (AArk, 2014). Particularmente en Argentina, la estrategia de cría ex-situ ha generado opiniones encontradas por parte de la comunidad de herpetólogos. Más allá de las voces a favor o en contra, debemos tener siempre presente que la cría ex-situ es una estrategia más de conservación de anfibios, y que integrada con investigaciones y actividades destinadas a la protección del hábitat y mitigación de las amenazas locales, se transforma en una valiosa y poderosa herramienta de conservación. En este sentido, teniendo en cuenta que las entidades que conforman AArk han venido fomentando y subsidiando formalmente programas de cría en cautiverio en todo el mundo, actualmente contamos en Argentina con dos proyectos de conservación ex-situ, uno que involucra a la Universidad Nacional de Jujuy a cargo del Dr. Akmentins, y otro que involucra a la Universidad Nacional de La Plata a cargo del Dr. Kacoliris y el Prof. Williams. Tales proyectos vislumbran un cambio de concepto acerca de la estrategia de cría en cautiverio por parte de la comunidad herpetológica local, quienes dan cuenta de sus beneficios y la utilizan en aquellos casos que lo requieren. El desarrollo factible de tales programas de cría en cautiverio reside en tener información acerca de la historia natural de la especie y de los parámetros ambientales de su hábitat natural (Michaels y col., 2014). En tal sentido, el presente capítulo contribuye con información de base y recomendaciones para la cría ex-situ de especies autóctonas de Argentina. Se considera dicha estrategia como la más adecuada para la conservación de aquellas especies que se encuentran amenazadas, y cuyas poblaciones se encuentran en tal descenso numérico o sus hábitats presentan tal grado de amenazas, que sumado a particularidades de su biología, dificultan su conservación in-situ. 


\section{La necesidad de criar animales para experimentación}

En el año 1978, la Liga Internacional de los Derechos del Animal proclamó la Declaración Universal de los Derechos del Animal con 14 artículos, posteriormente aprobada por la UNESCO y la ONU. Tal proclamación dio inicio en la sociedad moderna a la preocupación por el bienestar animal, debiéndose evitar el sufrimiento innecesario. En este sentido, se incorporó este concepto tanto en el ámbito académico universitario mediante la creación de cátedras específicas como en las instituciones que coleccionan animales vivos. Si bien la opinión acerca de tales instituciones y de otras en las cuales se crían animales con alguna finalidad específica resulta controvertida, se pretende remarcar y ponderar el hecho de que tal trascendental cambio de la relación humano-animal ha ocurrido y continúa en la actualidad.

Las investigaciones biológicas (observación y colecta) en el ámbito de la Herpetología tienen su origen en Argentina de la mano del naturalista del Museo de la Plata, Julio Koslowsky, quien es considerado el precursor de los estudios en anfibios y reptiles de nuestro país. Sus primeros trabajos publicados datan de fines del siglo XIX. Hacia mitad y fines del siglo $X X$, contamos con publicaciones de otros dos reconocidos herpetólogos, Ángel Gallardo y José María Cei. Muchos de tales trabajos, sumados a la mayoría de las investigaciones actuales que se realizan en laboratorio, involucran a especies locales que han sido extraídas (colectadas) del campo. Tales especies son muchas veces mantenidas en cautiverio hasta su aclimatación o por periodos más prolongados, habiéndose incluso logrado, para algunas de ellas, su reproducción en cautiverio. Sin embargo, tales prácticas no están formalmente documentadas aunque sí avaladas por las instituciones donde se realizan estas investigaciones. En tal sentido, y en relación con la cría de animales en cautiverio, es importante reconocer que se ha practicado informalmente desde el inicio de las investigaciones biológicas e incluso médicas. Sin embargo, la reciente oficialización de tal estrategia de cría por parte de entidades dedicadas a la conservación de la fauna, ha encontrado tantos partidarios como adversarios. Personalmente, considero que dicha estrategia es una valiosa herramienta de conservación que de ser utilizada con tales fines y siguiendo los métodos que la ciencia propone, permite realizar investigaciones con determinadas especies que de otra forma no podrían ser abordadas, siendo el objetivo final su conservación. Vale la pena citar, a modo de ejemplo, el descubrimiento de la emisión de sonidos por larvas de C. ornata (ver capítulo 2) a partir de su cría en laboratorio, descubrimiento que de otra forma no hubiera sido posible y el cual dio origen al trabajo de tesis.

En lo que respecta a investigaciones en el área de la Toxicología y Ecotoxicología herpetológica, el uso de organismos para la realización de bioensayos de toxicidad en laboratorio (para su definición ver capítulo 4, página 144) se restringe a un reducido número 
de especies. Para éstas, se han desarrollado protocolos de laboratorio estandarizados por organismos internacionales tales como la Agencia de Protección de los Estados Unidos (USEPA), la Sociedad Americana para Pruebas y Materiales (ASTM), la Organización Internacional para la Estandarización (ISO) y el Instituto Argentino de Normalización y Clasificación (IRAM). La aceptación de estos protocolos por parte de la comunidad científica y de los organismos de gobierno, permitió la realización de numerosas pruebas con una gran cantidad de sustancias químicas de distintos orígenes. El amplio número de publicaciones facilitó el establecimiento de niveles de sensibilidad de las especies ensayadas. Sin embargo, si bien muchas de las especies utilizadas poseen una amplia distribución, existen escasos protocolos estandarizados para especies neotropicales y menos aún para especies autóctonas de Argentina. Ello plantea un problema cuando se evalúa el impacto de una sustancia o mezcla sobre algún ecosistema acuático de esta región. La utilización de especies diferentes a las recomendadas por los organismos mencionados debe estar avalada por información de la nueva especie propuesta, demostrando que la misma cumple con una serie de características importantes. Entre ellas, conocer (a) los principales aspectos sobre la biología, ecología y fisiología de la especie elegida, (b) el grado de dificultad de obtención de adultos reproductores y/o puestas en campo, (c) la factibilidad y disponibilidad de métodos de reproducción y cría en laboratorio, (d) la tolerancia al manejo en condiciones de laboratorio y las respuestas a lo largo del ciclo de vida, (e) su susceptibilidad a enfermedades y parásitos, (f) la sensibilidad de la especie a sustancias tóxicas y compuestos de referencia ampliamente usados en estudios de toxicología clásica, (g) la relación filogenética y ecológica, además de otras similitudes con las especies recomendadas por la USEPA y demás organismos oficiales, (h) la relación del hombre con esa especie ya sea por medio de la cadena trófica o su relación filogenética, y por último (h) considerar la importancia ecológica y económica de la especie.

Por todo lo anteriormente dicho, queda evidenciada la necesidad de desarrollar protocolos de cría ex-situ con la finalidad de generar información sobre la biología de la especie y permitir el desarrollo de investigaciones en diferentes áreas (ej. bioquímica, fisiología), principalmente con especies para las cuales las investigaciones in-situ resultan imposibles o complejas de realizar. Tal estrategia es aún más necesaria cuando el objetivo es desarrollar un modelo de estudio biológico, debiéndose garantizar la reproducción de la especie en laboratorio. En este sentido, en el presente capítulo se seleccionó a una especie autóctona de Argentina para su utilización como modelo experimental aplicable en estudios ecotoxicológicos. Un factor clave para el desarrollo y aplicación de tal modelo ha sido la cría y reproducción de la especie en cautiverio. Esto permitió proponer un protocolo de cría para la especie seleccionada y su aplicación con especies filogenéticamente relacionadas y con similar hábito de vida. 


\section{Métodos de inducción artificial de la reproducción: un factor clave para el desarrollo de un protocolo de cría}

Existe bastante información sobre cómo mantener y criar anfibios en cautiverio, la cual ha sido recopilada, editada y difundida por las organizaciones involucradas en AArk. Generalmente, se asume que si se mantiene a los organismos en todas las condiciones óptimas, la reproducción es tan solo un hecho más a considerar. Sin embargo, las dificultades tienen su origen en conocer tales condiciones para cada una de las más de 6500 especies vivientes de anfibios anuros (AmphibiaWeb, 2015). De hecho, si bien los programas de cría en cautiverio han logrado el mantenimiento de numerosas especies de anfibios, solo algunos han conseguido su reproducción. Uno de ellos involucra a la especie Xenopus laevis, el cual permitió el desarrollo de un protocolo estandarizado de bioensayos ampliamente utilizado y conocido como "Ensayos de Teratogénesis con embriones del anuro Xenopus laevis" (FETAX; Bantle, 1995).

Teniendo en cuenta que la reproducción natural en cautiverio no es fácil de lograr para muchas especies de anuros, resulta necesario recurrir a técnicas de inducción artificial (Clulow y col., 2014). El método más difundido ha sido la administración de una hormona o la combinación de varias: la hormona liberadora de gonadotrofina $(\mathrm{GnRH}$, Licht y Porter, 1987), una forma sintética de la hormona liberadora de la hormona luteinizante (LH-RH, Licht, 1979), o gonadotrofina coriónica humana (HCG; Licht, 1979; Herkovits y Pérez Coll, 1991). En todos los casos, la efectividad de las hormonas depende de la época, el momento del día, modo de administración, edad, estado de salud y apetito de los organismos. Estas técnicas requieren de la fertilización artificial (in vitro) debiéndose conocer en su totalidad el ciclo reproductivo de la especie. Adicionalmente, ambos sexos deben estar bien alimentados y previamente aclimatados a una determinada temperatura, humedad y fotoperiodo. Por último, se debe sincronizar el ciclo reproductivo de ambos sexos mediante la administración de alguna de las hormonas antes mencionadas con el objetivo de conseguir la ovulación y espermiación simultánea. La madurez sexual de la hembra puede corroborarse por la presencia de huevos en la cloaca o el celoma, pudiéndose detectar por transparencia, tacto o mediante ultrasonido. Una vez que la hembra ovuló, se debe colectar el esperma del macho mediante un gotero conteniendo solución Ringer al 10\% (Rugh, 1962), debiéndose realizar un suave manejo del individuo para evitar el estrés. Si la administración hormonal no es factible, se puede recurrir a la extracción de una gónada o directamente al sacrificio del animal para obtención de los testículos con su esperma (Nace y col., 1974). Una vez colectado el esperma del macho se procede a la extracción de los óvulos de la hembra mediante masajes manuales que consisten en presionar su zona abdominal en dirección cráneo-caudal o mediante cirugía. Tales óvulos son colocados en una cápsula de petri junto a la suspensión espermática para su posterior incubación. Aquellos huevos que hayan sido 
fertilizados pueden reconocerse dado que rotan haciendo visible el polo animal de color negro.

Por todo lo antedicho, y ante la necesidad de desarrollar un método de inducción artificial de la reproducción en laboratorio más simple y que evite el sufrimiento innecesario, surgió la posibilidad de trabajar en colaboración con un grupo de investigadores de la Universidad de Ottawa a cargo del Dr. Trudeau. El método se probó por primera vez en Argentina en individuos adultos de $C$. ornata y luego se aplicó a otras especies de anfibios autóctonos ( $C$. cranwelli y Odontophrynus americanus), demostrando su aplicabilidad para la cría en cautividad en dos familias diferentes de anuros. Ello, permitió considerar a C. ornata como modelo de estudio y sentó las bases para la realización del presente trabajo de tesis, habiéndose propuesto su validación como parte del trabajo experimental. El nombre de dicho método deriva de la combinación de dos palabras en inglés que significan anfibios y amplexo, siendo conocido en la actualidad como AMPHIPLEX (Trudeau y col., 2010). Se basa en la inyección combinada de un agonista de la hormona liberadora de gonadotrofina $(\mathrm{GnRH})$ y un antagonista de la dopamina. Si bien es sabido para anfibios que tanto la $\mathrm{GnRH}$ como los agonistas de la GnRH pueden estimular la liberación de hormona luteinizante (LH) por parte de la glándula pituitaria (Licht y col., 1983), el desove puede no resultar eficaz si el tratamiento no es acompañado con otras hormonas o agentes neuroactivos (Browne y col., 2006; Kouba y col., 2012). Esto indica la existencia de un mecanismo neuroendocrino inhibidor que controla la liberación excesiva de LH, la cual es necesaria para la ovulación y el desove (Fig. 3). Esto último no había sido considerado hasta el momento. En el marco del presente trabajo de tesis, se propone este método para ser utilizado en distintas especies de la familia Ceratophryidae (particularmente en C. ornata), brindando bases más sólidas al modelo de estudio. A su vez, permite proponerlo junto con el protocolo de cría, como una herramienta factible de utilización e implementación en Argentina, para la realización de ensayos tanto biológicos como ecotoxicológicos, y como herramienta de conservación en programas de cría ex-situ, posterior re-introducción y monitoreo. 


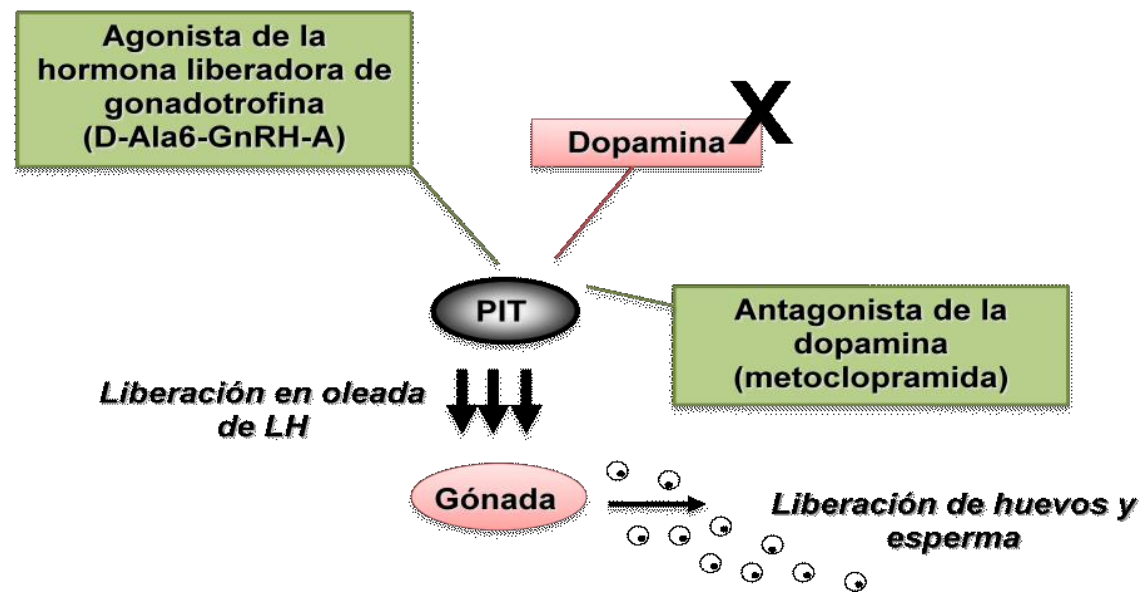

Figura 3. Mecanismo de acción del método de inducción artificial AMPHIPLEX por inhibición de la dopamina. PIT: glándula pituitaria; LH: hormona luteinizante

\section{La especie seleccionada}

Se seleccionó una especie perteneciente a la familia Ceratophryidae, la cual está compuesta por 12 especies distribuidas en tres géneros, Ceratophrys con ocho especies, Lepidobatrachus con tres y Chacophrys con una sola especie (Faivovich y col., 2014; Frost, 2014). La monofilia de este clado ha sido reconocida por varios autores (Maxson y Ruibal, 1988; Hanken, 1993; Haas, 2003; Fabrezi, 2006), siendo discutida hasta el momento la posición filogenética de cada taxón respecto a los otros (Fabrezi y Quinzio, 2008; Faivovich y col., 2014). Los adultos de estos tres géneros comparten ciertos caracteres, entre ellos macrocefalia, megalofagia y comportamiento agresivo (Hanken, 1993). Tal comportamiento ha sido reportado desde principios del siglo XIX (Raddi, 1823; Günther, 1882), aunque fue descripto en detalle recién a mediados del siglo XX (Barrio, 1963). Sin embargo, sus larvas poseen notorias diferencias intergenéricas, lo cual indica que las características que los reúnen en una misma familia aparecen luego de la metamorfosis. Entre las diferencias más notorias se puede mencionar el hábito alimenticio. Mientras las larvas de Chacophrys poseen una típica ecomorfología herbívora (Faivovich y Carrizo, 1992; Quinzio y col., 2006), las larvas de Ceratophrys y Lepidobatrachus poseen en términos generales hábitos carnívoros y macrófagos, las estructuras orales internas simplificadas (Wassersug y Heyer, 1988) y un tracto digestivo corto concordante con el hábito alimenticio (Ruibal y Thomas, 1988; Ulloa Kreisel, 2001). Ciertas características peculiares compartidas por los miembros de esta familia, han sido asociadas a los ambientes semiáridos en los que habitan. Entre ellas, la formación de un cocón para evitar la pérdida de agua (McClanahan y col., 1976; Faivovich y col., 2014), un corto periodo larval y una tasa de crecimiento acelerada (Fabrezi, 2011). 
La especie seleccionada es Ceratophrys ornata (Bell, 1843), vulgarmente conocida como escuerzo común. Se encuentra circunscripta a la región Pampeana de Argentina (Buenos, Córdoba, Entre Ríos, La Pampa, Mendoza y Santa Fe) y al sur de Brasil (Río Grande do Sul) (Gallardo, 1974; Cei, 1980). Los últimos registros de esta especie en Uruguay datan de 1982 en el Departamento de Rocha (Maneyro y Langone, 2001) (Fig. 4).

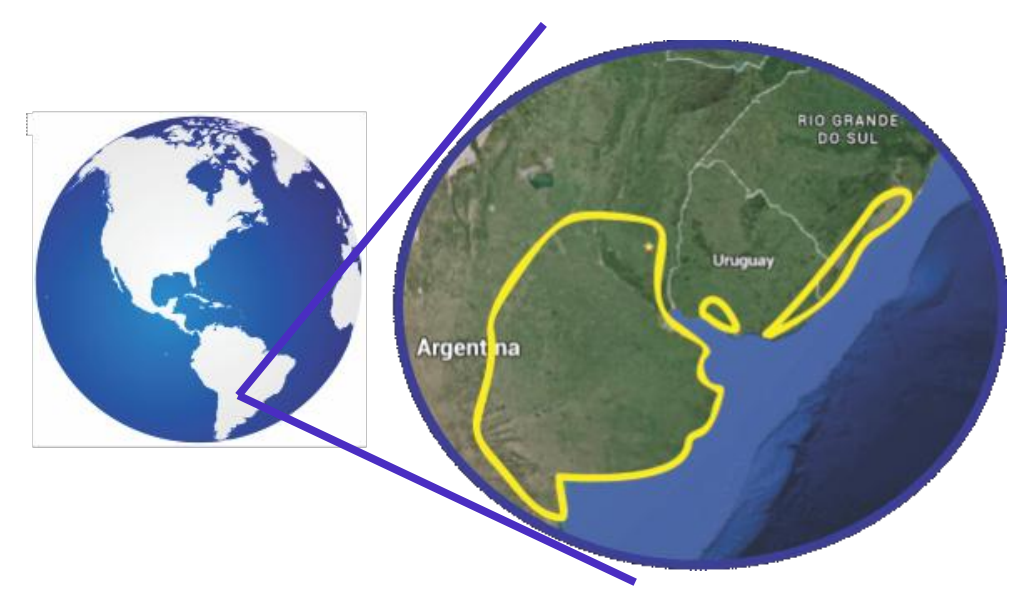

Figura 4. Distribución geográfica de la especie Ceratophrys ornata en Argentina, Brasil y Uruguay

Es una especie predadora que caza al acecho y excavadora (Duellman y Lizana, 1994) Posee un aspecto bufonoide, robusto y colorido, resultando llamativa tanto por sus caracteres externos como por su grito agresivo emitido al ser molestada (Gallardo, 1974; Cei, 1980). Esto conlleva que sea requerida como mascota, formando parte del mercado ilegal de especies al igual que la mayoría de los escuerzos de Sudamérica (Pistoni y Toledo, 2010). En individuos juveniles se ha descripto un movimiento pedal, el cual ha sido interpretado como una respuesta innata. Tal movimiento consiste en levantar ambos miembros traseros por encima de la cabeza acompañados de movimientos de los dedos (Radcliffe y col., 1986). Los datos acerca de la longevidad de la especie son procedentes de su cría en cautiverio al igual que para otras especies (entre 5 y 14 años; www.pondturtle.com), dada la dificultad para relevar tales datos en campo (Gallardo, 1974; Duellman y Trueb, 1994) y al hecho de no contar hasta el momento con datos provenientes de la esqueletocronología. Otra característica llamativa es su poliploidía extrema, siendo una especie octoploide a diferencia de $C$. cranwelli que si bien es su especie hermana de Argentina es diploide (Mercadal de Barrio y Barrio, 2002).

Considerando que la especie ha sido exportada como mascota fuera del rango de su hábitat natural, dado su gran valor para los coleccionistas de animales vivos, se han generado gran número de reportes relacionados con su mantenimiento en cautiverio. Sin embargo, se debe tener en cuenta que la dieta de una determinada especie debe corroborarse con datos del contenido estomacal de individuos de campo o con datos de observación directa en campo. Es decir, se debe diferenciar entre lo que un individuo es 
capaz de comer en cautiverio y lo que come la especie en campo (Schalk y col., 2014). Según datos del contenido estomacal de ejemplares en estado salvaje, la especie se alimenta de varios ítems según la etapa del desarrollo. Los adultos consumen $78 \%$ anuros, $11,7 \%$ paseriformes, $7,7 \%$ roedores, $0,3 \%$ serpientes y $1,8 \%$ otros ítems (Basso, 1990), habiéndose documentado en ocasiones casos de canibalismo (Gallardo, 1987). La dieta de individuos post-metamórficos (juveniles) incluye además gasterópodos, artrópodos y peces (Schalk y col., 2014). Las larvas también son carnívoras, se alimentan de pequeños crustáceos (Gallardo y Varela de Olmedo, 1992), larvas de la misma especie (Cei, 1980) y otras larvas con las que cohabitan y se desarrollan simultáneamente (Gallardo, 1987). Su reproducción en campo ha sido constatada en el mes de Enero (Fernández y Fernández, 1921) aunque también se han registrado ejemplares activos en épocas invernales (Hudson y col., 1958). La llamada de anuncio (= cortejo) de los machos es conocida (Barrio, 1963) pero no la edad a la que alcanzan la madurez sexual. Los individuos poseen un marcado dimorfismo sexual: si bien ambos sexos poseen manchas irregulares en la parte ventral de la boca, los machos poseen el saco vocal bien pigmentado en época reproductiva y la parte interna de los dedos de los miembros anteriores con callosidades nupciales de color negro. Además, son de menor tamaño que las hembras (De Vosjoli, 1990).

Según la categorización de anfibios de Argentina del año 2000 (Lavilla y col., 2000), la especie fue incluida en la categoría "no amenazada". Sin embargo, ha sido recomendada en el año 2010 para desarrollar programas de cría ex-situ por el Arca de los Anfibios (AArk, 2010). Teniendo en cuenta que los protocolos para mantener poblaciones de muchas de las especies que requieren de la conservación ex-situ son desconocidos, y las dificultades antes mencionadas para realizar estudios a campo con la especie seleccionada, se procedió a la cría ex-situ de $C$. ornata, siguiendo estándares de bioseguridad, manejo y cuidado general de anfibios. Dicho protocolo también ha sido utilizado para la cría ex-situ de otras especies de la familia Ceratophryidae con similar hábito de vida.

\section{Hipótesis}

- El protocolo de cría de individuos de C. ornata permite obtener organismos sanos a lo largo de todo el ciclo vital para su posterior inducción artificial de la reproducción y el desarrollo de un modelo experimental.

* El método de inducción de la reproducción AMPHIPLEX es factible de aplicar más de una vez en un mismo organismo permitiendo obtener individuos sanos a lo largo de todo su ciclo vital.

* El protocolo de cría en cautiverio de C. ornata es factible de ser aplicado en otras especies de la familia Ceratophryidae con similar hábito de vida. 


\section{Objetivos}

* Desarrollar un protocolo de aclimatación y cría controlada en laboratorio de C. ornata, implementando estándares de bioseguridad, higiene y bienestar animal, para su posterior inducción de la reproducción y el mantenimiento de individuos sanos a lo largo de todo el ciclo de vida.

* Desarrollar y ejecutar, a partir del protocolo de cría de C. ornata, un modelo experimental con dicha especie para su aplicación en estudios ecotoxicológicos de efectos de plaguicidas (ver cap. 4 y 5 ).

* Poner a prueba el método de inducción artificial AMPHIPLEX, mediante la inducción reiterada de individuos adultos de $C$. ornata.

Aplicar el protocolo de cría en especies filogenéticamente relacionadas a $C$. ornata, para su propuesta como alternativa de conservación de especies.

\section{MATERIALES Y MÉTODOS}

\section{Medición de variables morfométricas}

Los individuos adultos fueron pesados en balanza digital portátil de 0,01 $\mathrm{g}$ de precisión marca Scout Pro (Ohaus, EEUU de América). Los larvas y juveniles fueron pesados en balanza digital de 0,001 g de precisión marca Acculab (Grupo Sartorius, EEUU de América).

Todas las mediciones de longitud fueron realizadas con el programa Image ${ }^{\circledR}$ versión 1.46r (Rasband, Instituto Nacional de Salud, EEUU de América) mediante fotografía digital. Como referencia para calibrar el programa se utilizó una hoja milimetrada plastificada tamaño A3. Se colocó a cada individuo a medir en el centro de la hoja y se tomaron fotografías con una cámara digital marca Canon ${ }^{\circledR}$ modelo Eos T3i (Canon Argentina S.A, Argentina) con la máxima resolución (= $18 \mathrm{Mpx}$ ) para garantizar una correcta visualización de la imagen. La cámara fue montada a un trípode para homogenizar la altura a la cual se tomó cada foto $(45 \mathrm{~cm})$. Toda desviación en el método de captura fue luego corregida al calibrar cada foto individualmente. Con la finalidad de validar este método, se realizaron mediciones simultáneas con un calibre digital de 0,01 mm marca UPM modelo 111-811Y (China). Luego, se realizó un análisis de regresión y correlación lineal entre distintas medidas de LHC obtenidas con calibre digital y aquellas obtenidas en los mismos individuos por fotografía digital para tres STD diferentes (25, 31 y 37), habiéndose tomado 10 medidas por STD. La precisión de ambos métodos de medición se determinó mediante sucesivas mediciones de LHC $(n=10)$ de tres larvas de STD 37. 


\section{Prueba del protocolo de cría en cautiverio de individuos adultos de Ceratophrys ornata}

Teniendo en cuenta que los estándares de bioseguridad y manejo de anfibios pueden ser divididos en tres categorías complementarias (básica, intermedia y avanzada), basándose en la función que cumplen los animales criados en cautiverio, se consideraron aquellos de la categoría intermedia (Zippel y col., 2006). Los mismos hacen referencia a individuos mantenidos ex-situ con propósitos de investigación pero sin perspectiva de liberación a su medio natural, al menos durante el desarrollo del presente trabajo de tesis. En tal sentido, se tuvieron en cuenta los siguientes estándares básicos de bioseguridad: (1) alojamiento a prueba de escapes y de un tamaño adecuado para la especie; (2) alojamiento a prueba de plagas (roedores, cucarachas, hormigas, etc.) y fugas para prevenir la transferencia de patógenos y la fuga de insectos usados como alimento; (3) utilización de agua libre de patógenos y contaminantes químicos y (4) desinfección periódica de los recintos y cuartos donde se alojan anfibios. Adicionalmente, se tuvieron en cuenta los siguientes estándares intermedios de bioseguridad: (5) recintos con un diseño que minimice el contacto del cuidador con el animal; (6) maximización del uso de la automatización en el mantenimiento de la calidad del agua; (7) utilización de instrumentos individuales para cada recinto y/o especie y (8) mantenimiento de una rutina de manejo direccional de los individuos de menor riesgo a aquellos de mayor riesgo.

En relación al manejo en cautiverio se tuvieron en cuenta aquellos estándares básicos como: (1) cambio regular del agua; (2) temperatura/humedad apropiadas según la historia natural de la especie; (3) exposición a luz natural (o un equivalente artificial de calidad) si la exposición es habitual en la historia natural de la especie y (4) alimentación adecuada en función de la especie, con suplementos de vitaminas y minerales. Adicionalmente, se tuvieron en cuenta los siguientes estándares intermedios de manejo en cautiverio: (5) provisión de las condiciones climáticas (temperatura, humedad, iluminación, fotoperiodo, etc.) concordantes con el ciclo natural de la especie y automatización de las mismas. También se han tenido en cuenta aquellos aspectos básicos pero críticamente importantes para mantener anfibios en cautiverio según Nace y col. (1974) y Poole y Grow (2008). Se contó con asistencia de un veterinario dedicado a la clínica y manejo de especies no convencionales y silvestres ${ }^{1}$ (para detalles de diagnóstico y tratamiento ver Anexo II).

Dado que la calidad del agua es un factor importante para la supervivencia de los anfibios, ya que su piel funciona como órgano de absorción e intercambio gaseoso, se utilizó agua de red filtrada por un filtro físico Aqua-Pure ${ }^{\circledR}$ de 5 micrones (Modelo AP-110 H/C). Luego, se aireó por burbujeo continuo y enérgico durante $48 \mathrm{~h}$ para eliminar el cloro, debido

\footnotetext{
${ }^{1}$ Veterinario Federico Bondone M.N. 9098
} 
a la elevada toxicidad del mismo para este grupo de animales. Los parámetros de calidad de agua se mantuvieron dentro de ciertos rangos previamente testeados y dentro de los cuales resultó factible mantener anfibios en laboratorio, siempre teniendo en cuenta datos relevados en campo (Alcalinidad: $65-181 \mathrm{mg} \mathrm{CaCO} / \mathrm{L}$; Dureza: 21-150 mg CaCO$/ 3 / \mathrm{L} ; \mathrm{pH}$ : 6,40-8,05; Natale, 2006). Se realizaron caracterizaciones de su calidad empleando técnicas estandarizadas para el análisis fisicoquímico de las aguas de acuerdo a procedimientos de rutina puestos a punto en el laboratorio (APHA, 1998). A continuación se detallan los parámetros medidos, las técnicas empleadas y el instrumental utilizado:

Alcalinidad: se midió por titulación ácido base de acuerdo al método 2320 (APHA, 1998) expresando los resultados en $\mathrm{mg} \mathrm{CaCO}_{3} / \mathrm{L}$.

Dureza: se midió por titulación con EDTA de acuerdo al método 2340C (APHA, 1998), expresando los resultados en $\mathrm{mg} \mathrm{CaCO}_{3} / \mathrm{L}$.

Temperatura: se registró con un termómetro de mercurio con escala a la décima de grado.

pH: se midió mediante un sensor marca Metrohm ${ }^{\circledR}$ con escala en unidades de $\mathrm{pH}$.

Conductividad: se midió mediante un conductímetro digital de mesa marca Altronix ${ }^{\circledR}$ modelo CTX II ( $\mu \mathrm{S} / \mathrm{cm})$.

A continuación, se detalla el protocolo puesto a prueba para la cría de individuos adultos. Producto de la cría factible de este estadio surge su inducción artificial de la reproducción y posterior cría en cautiverio desde huevo hasta adulto.

Adultos:

- Teniendo en cuenta el concepto de bioseguridad, aquellos animales que ingresaron por primera vez al cautiverio fueron mantenidos en cuarentena por un mínimo de 30 días y monitoreados semanalmente (ganancia o pérdida de peso, postura, cambios en la textura o color de la piel, consumo de alimento, heces). El período de cuarentena debe proporcionar suficiente tiempo para visualizar algún síntoma que no se encuentre relacionado con el estrés del transporte. Se desinfectó todo equipo y material de campo con etanol $70 \%$ o hipoclorito de sodio $10 \%$ durante 10 minutos para prevenir la propagación de agentes infecciosos.

- La selección de los recintos para alojar a la especie tuvo en cuenta que sean de materiales no porosos para facilitar su limpieza, y que contengan tapas que ajusten perfectamente para evitar posibles escapes, permitiendo al mismo tiempo la ventilación adecuada. Se tuvieron en cuenta diferentes tamaños de recintos de plástico (bateas de $45,5 \times 32,5 \times 26,0 \mathrm{~cm}$ y $23,0 \times 15,5 \times 12,5 \mathrm{~cm}$, recipientes redondos de $26,0 \times 26,0 \times 28,5 \mathrm{~cm}$ ) y vidrio (pecera de $60,0 \times 30,0 \times 40,0 \mathrm{~cm}$ y de $40,0 \times 30,0 \times 20,0 \mathrm{~cm}$ ). Se consideraron recintos independientes (también llamados sistemas cerrados) con un adecuado drenaje de agua 
y recintos conectados (también llamados sistemas abiertos). Se evaluó la utilización de sustratos artificiales (toallas de papel) o naturales (tierra, arena) y la incorporación de algún objeto que sirva de refugio, proporcione mayor seguridad a los individuos y disminuya el estrés. Se evaluó también la frecuencia de recambio del sustrato de acuerdo a su aspecto y el estado de salud del animal. Para la construcción del ambiente se tuvo en cuenta la historia y hábitat natural de la especie.

- Se evaluó la incorporación de piletas plásticas de $23,0 \times 17,5 \times 5,0 \mathrm{~cm}$ con agua de calidad en cada recinto para proveer humedad y un sitio para que los individuos se refresquen. Para determinar la frecuencia de recambio del agua se tuvo en cuenta el volumen de la misma, la actividad de los organismos, la frecuencia de alimentación y la cantidad de desechos presentes.

- La temperatura ambiente apropiada se evaluó teniendo en cuenta el hábitat natural de la especie. Se proveyó un gradiente de humedad dentro de cada recinto y para ello se consideró la utilización de rociadores automáticos o manuales. Tal gradiente de humedad generó a su vez un gradiente de temperatura. Dicho parámetro fue controlado periódicamente mediante termómetros de máximas y mínimas, los cuales fueron ubicados en diferentes sectores y a diferentes alturas dentro del cuarto de cría. Las fuentes de iluminación consideradas fueron: (a) luz artificial mediante tubos de luz fluorescente de $36 \mathrm{~W}$ e incorporación de tubos de luz ultravioleta (ej. Reptisun ${ }^{\circledR}$ ) para favorecer el metabolismo del calcio; (b) luz natural. El fotoperiodo natural de la especie fue simulado mediante un temporizador.

- En lo que respecta a la dieta, se consideró proveer alimentos de la mayor variedad posible, teniendo en cuenta su dieta habitual en vida silvestre. El tamaño de cada ítem fue siempre acorde al tamaño del escuerzo y para su selección se tuvo en cuenta la proporción calcio:fósforo y el contenido de lípidos. La frecuencia de alimentación se determinó teniendo en cuenta la historia natural de la especie y su actividad, incluyendo aspectos básicos de comportamiento como la saciedad y el tamaño de la presa. Se evaluó la incorporación de suplementos vitamínicos y minerales comerciales (ej. Reptocal ${ }^{\circledR}$ ) para prevenir deficiencias en la dieta. Siempre que fue posible se ofrecieron presas vivas para fomentar comportamientos naturales que realcen el bienestar animal. También se criaron artrópodos para alimento de los escuerzos (Zophoba morio y Tenebrio molitor) por ser una forma más sencilla de controlar el estado nutricional del alimento brindado. Los mismos fueron criados siguiendo las recomendaciones de Poole y Grow (2008), en las mismas condiciones controladas de temperatura, humedad y fotoperiodo que $C$. ornata.

- Cada vez que se renovó el sustrato en su totalidad (en promedio, cada tres meses), se desinfectó por completo cada recinto individual y sus objetos con etanol $70 \%$ durante 10 
minutos con posterior enjuague con agua de calidad. Para ello, los individuos fueron colocados en recintos de iguales características con agua de calidad. Una vez evaporado el alcohol, se colocó a cada individuo en su recinto original. Se realizó una desinfección bimestral del cuarto de cría (piso, estantes y materiales utilizados en la cría como pinzas, cuchillos, tablas, etc.) con hipoclorito de sodio $10 \%$ durante 10 minutos. Para ello, los recintos contenedores de animales deben ser llevados a otro cuarto con similares características y re-ingresados a su cuarto original una vez evaporado el cloro.

- Por último, todos los adultos fueron pesados y medidos (longitud hocico-cloaca en milímetros, LHC) mensualmente con la finalidad de evaluar mediante índices de condición corporal el estado de salud individual y de obtener la curva de crecimiento. Semanalmente, se evaluó la presencia de enfermedades que pudieran afectar a cada individuo.

\section{Inducción por el método AMPHIPLEX de individuos adultos de C. ornata}

Los individuos adultos, tanto machos como hembras, fueron inyectados intraperitonealmente con $0,4 \mu \mathrm{g} / \mathrm{g}$ de peso corporal del agonista de la hormona liberadora de gonadotrofina (des-Gly10, D-Ala6, Pro-NHEt9-GnRH, marca Sigma-Aldrich ${ }^{\circledR}$ ) más $10 \mu \mathrm{g} / \mathrm{g}$ de peso corporal del antagonista de la dopamina (hidrocloruro de metoclopramida, marca Sigma-Aldrich ${ }^{\circledR}$ ) disuelto en $0,7 \% \mathrm{NaCl}$ (Fig. 5). Tanto la $\mathrm{GnRH}$ como la metoclopramida fueron previamente almacenadas en freezer a una temperatura promedio de $-15{ }^{\circ} \mathrm{C}$. Para las primeras inducciones correspondientes al año 2012 (ver más adelante), la solución fue preparada e inyectada en el mismo momento, habiéndose inyectado $2 \mu \mathrm{l} / \mathrm{g}$ de peso corporal de individuos maduros sexualmente. Las siguientes inyecciones correspondientes al período 2013-2014 (ver más adelante) fueron realizadas utilizando soluciones previamente preparadas, liofilizadas y almacenadas en eppendorf de $2 \mathrm{ml}$ en freezer a una temperatura promedio de $-15^{\circ} \mathrm{C}$. Tales soluciones fueron disueltas en $1 \mathrm{ml} \mathrm{NaCl} 0,7 \%$ al momento de ser utilizadas. Se utilizaron jeringas de insulina de 100 U.I. y se inyectó a cada individuo ventralmente en la región pélvica, aplicando a continuación suaves masajes circulares en la zona para evitar la salida de la solución.

Se realizaron tres eventos de inducción diferentes y en distintas épocas del año, habiéndose inyectado en total cinco parejas de escuerzos. Luego de cada inducción, se monitoreó a los individuos inyectados diariamente y por siete días consecutivos, en busca de enfermedades directamente relacionadas con el evento de inducción y/o ovoposición. Con la finalidad de cuantificar ciertas variables relacionadas a la reproducción de la especie, se realizaron observaciones directas y grabaciones de audio y video simultáneas del acto reproductivo (ver Anexo II). Además, se contabilizó manualmente y en su totalidad la 
cantidad de huevos puestos por pareja y la cantidad de huevos eclosionados por cada bandeja contenedora.

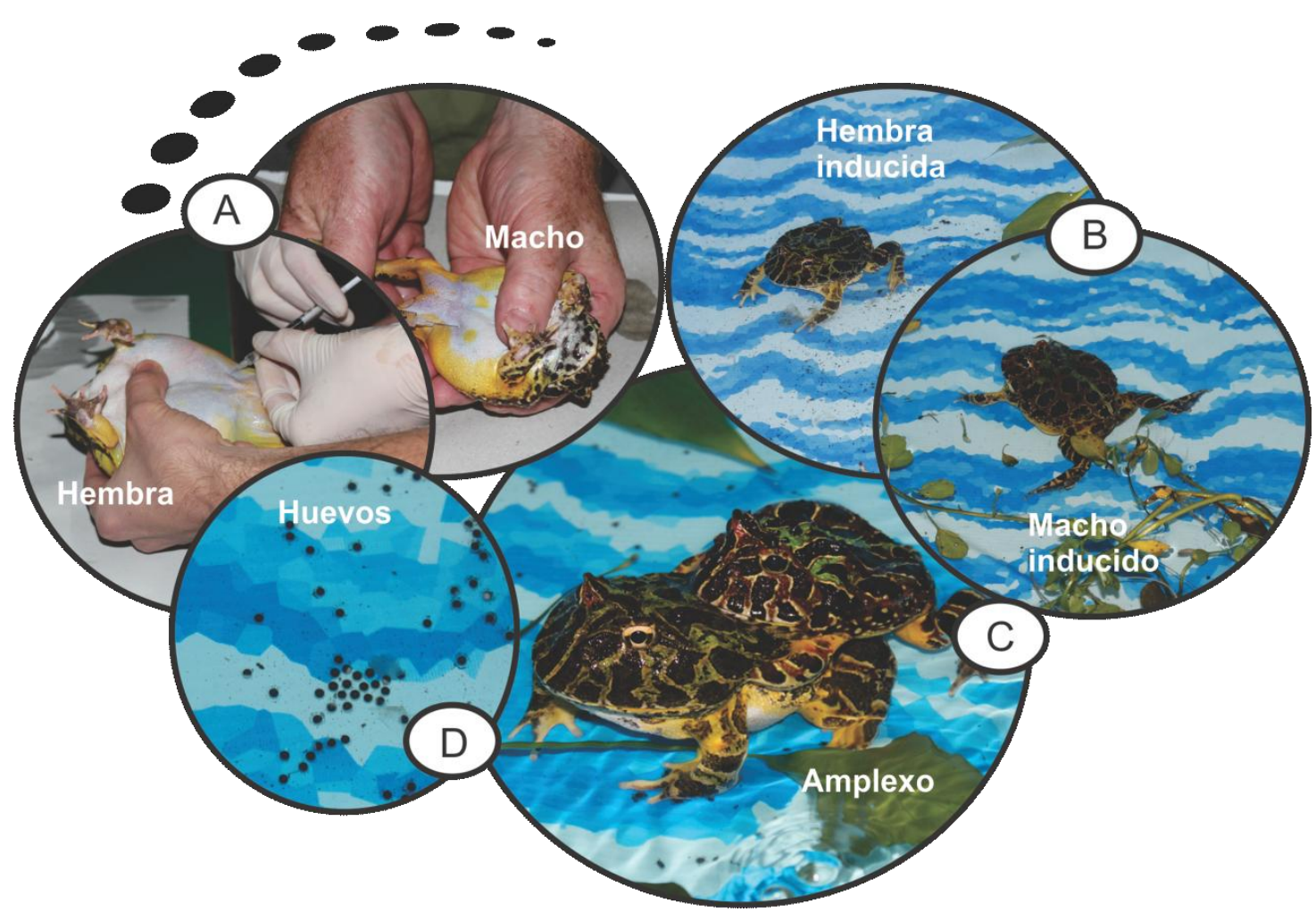

Figura 5. Método de inducción artificial de la reproducción utilizado. A: Inducción de un individuo de cada sexo (izquierda: hembra, derecha: macho); B: Disposición de ambos ejemplares en una pileta luego de la inducción; C: Amplexo axilar; D: Huevos fertilizados

A continuación se detalla cada evento y cada pareja:

Primera inducción:

El 26 de Marzo de 2012, se indujeron dos parejas de adultos de C. ornata, las cuales quedaron conformadas de la siguiente forma: $\phi_{1}+\hat{\partial}_{2} \mathrm{y} \stackrel{q}{2}_{2}+\hat{\partial}_{3}$.

Pareja 1: La $q_{1}$ es un ejemplar criado por un particular, siendo su procedencia desconocida. Su edad al momento de la inducción era desconocida aunque estimada en tres años. Luego de tres meses de haberla inyectado fue devuelta a su criador. El $\widehat{\partial}_{2}$ es una cría producto de la primera inducción de una pareja de adultos realizada en el año 2009 para probar la funcionalidad del método. Su edad al momento de la inducción era de tres años. Hasta la fecha este ejemplar se encuentra en buen estado de salud en el laboratorio.

Pareja 2: La $\bigcirc_{2}$ fue colectada el 02 de Febrero del 2012 en los alrededores de la ciudad de La Plata ( $\left.34^{\circ} 58^{\prime} 15,04^{\prime \prime S} 57^{\circ} 56{ }^{\prime} 38,50^{\prime \prime O}\right)$, transportada al laboratorio, aclimatada y criada en condiciones controladas. Previamente, se tramitó el correspondiente permiso ante Fauna Nación (Expediente 22500-14357/11, Disposición Número 209/11 y 14/12). Su edad al momento de la inducción era desconocida aunque estimada en dos años. Hasta la fecha 
este ejemplar se encuentra en buen estado de salud en el laboratorio. El $\hat{\delta}_{3}$ es al igual que el $\widehat{\partial}_{2}$ una cría producto de la primera inducción realizada para probar la funcionalidad del método, siendo su edad al momento de la inducción de tres años. Hasta la fecha este ejemplar se encuentra en buen estado de salud en el laboratorio.

\section{Segunda inducción:}

El 13 de Noviembre de 2013, se indujeron dos parejas de adultos. Una de las parejas se conformó por la $\phi_{3}+\widehat{O}_{2}(=$ pareja 3$)$, y la otra pareja se conformó por los mismos individuos inducidos en el año $2012\left(q_{2}+\hat{O}_{3}=\right.$ pareja 2/4).

Pareja 3: La $q_{3}$ fue colectada en Enero de 2011 en el partido de la costa, específicamente en la localidad de Las Toninas, y criada hasta entonces por un criador particular. Un mes antes de la inducción fue transportada al laboratorio para su aclimatación en condiciones controladas. Su edad al momento de la inducción era desconocida aunque estimada en tres años. Hasta la fecha este ejemplar se encuentra en buen estado de salud

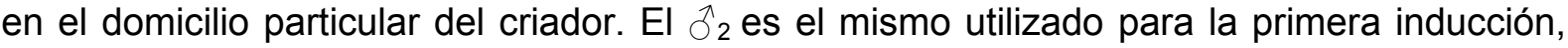
siendo su edad de cuatro años. Hasta la fecha este ejemplar se encuentra en buen estado de salud en el laboratorio.

\section{Tercera inducción:}

El 29 de Mayo de 2014, se indujo una pareja de adultos de $C$. ornata $\left(q_{4}+\hat{O}_{4}\right)$.

Pareja 5: La ${ }_{4}$ fue colectada el 03 de Enero de 2013 en los alrededores de la ciudad de La Plata $\left(34^{\circ} 56^{\prime} 38,50^{\prime \prime S} 57^{\circ} 52^{\prime} 14,07^{\prime \prime}\right.$ ) ), transportada al laboratorio, aclimatada y criada en condiciones controladas. Su edad al momento de la inducción era desconocida aunque estimada en un año. Hasta la fecha este ejemplar se encuentra en buen estado de salud en

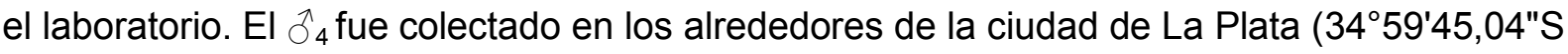
$57^{\circ} 51^{\prime} 44,33^{\prime \prime}$ ), transportado al laboratorio, aclimatado y criado en condiciones controladas. Su edad al momento de la inducción era desconocida aunque estimada en un año. Hasta la fecha este ejemplar se encuentra en buen estado de salud en el laboratorio. Para la colecta de ambos ejemplares se tramitó previamente el correspondiente permiso ante Fauna Nación (Expediente 22500-14357/11, Disposición Número 43/13).

\section{Prueba del protocolo de cría en cautiverio de C. ornata desde huevo hasta el estadio juvenil}

Se tuvieron en cuenta los mismos estándares de bioseguridad, manejo y cuidado general de anfibios indicados para adultos. A continuación, se detallan los aspectos tenidos en cuenta para la cría de huevos, embriones, larvas y juveniles de esta especie: 
Huevos, embriones y larvas: el agua utilizada y las condiciones de temperatura, humedad y fotoperiodo fueron las mismas que aquellas detalladas para adultos. La desinfección bimestral del cuarto de cría fue realizada en las condiciones ya detalladas. A continuación se detallan las diferencias respecto al recinto, sustrato, dieta y mediciones tomadas:

- Se consideraron recintos de distintos tamaños, desde piletas de lona de $130,0 \times 95,0 \times 40,0 \mathrm{~cm}$, bateas plásticas de $45,5 \times 32,5 \times 26,0 \mathrm{~cm}$ y bandejas plásticas de $33,0 \times 23,0 \times 8,5 \mathrm{~cm}$ para la cría de varios individuos juntos, hasta recipientes de polipropileno de $8,5 \times 8,5 \times 8,0 \mathrm{~cm}$ para la cría individual. También se evaluaron distintas densidades de larvas/L (20, 10, 5 individuos/L).

- Los recintos deben contener solo agua dada la dependencia de ésta del estadio considerado y se debe proveer aireación leve pero continua. Como sustrato se evaluó la utilización de piedras de distintos tamaños que también sirven como refugio y retención de desechos. Se realizó un recambio diario del agua y se evaluó su porcentaje de recambio $(10 \%, 50 \%, 100 \%)$.

- Para la dieta, se consideró proveer alimentos de la mayor variedad posible, teniendo en cuenta su dieta habitual en vida silvestre. En relación a esto último, se consideró la colecta de puestas de las especies disponibles (según la época de muestreo), el traslado al laboratorio y aclimatación en las mismas condiciones que los escuerzos. Se recomienda colectar solo el $10 \%$ de cada puesta. Luego, las diferentes puestas deben ser mezcladas por especie y alimentadas diariamente con lechuga procesada y alimento para peces marca Tetra ${ }^{\circledR}$. También se evaluaron otros ítems alimenticios como Tubifex y pedazos de hígado/corazón de vaca. En lo que respecta a Tubifex, se recomienda obtenerlos inicialmente de un criadero y luego criarlos en el laboratorio en una bandeja plástica de $33,0 \times 23,0 \times 8,5 \mathrm{~cm}$ con $5 \mathrm{~L}$ de agua y leve aireación continua. Deben ser alimentados cada $48 \mathrm{~h}$ con levadura en polvo marca Levex ${ }^{\circledR}$. El tamaño de cada ítem descripto fue siempre acorde al tamaño de las larvas. La frecuencia de alimentación se determinó teniendo en cuenta la historia natural de la especie, su actividad (incluyendo aspectos básicos de comportamiento como la saciedad) y el tamaño de la presa.

- Los huevos obtenidos de cada inducción fueron contabilizados manualmente con la finalidad de determinar el tamaño de la puesta. Asimismo, lotes de 25 larvas fueron medidos semanalmente hasta alcanzar la metamorfosis para obtener la curva de crecimiento por estadio. Siempre que resultó factible, se realizó la curva de crecimiento de determinados individuos haciendo su seguimiento desde larva hasta juvenil/adulto. Las medidas tomadas fueron peso $(\mathrm{g})$, LHC $(\mathrm{mm})$ y estadio del desarrollo (STD). Los estadios fueron determinados bajo lupa siguiendo la clasificación de Gosner (1960). Las larvas que alcanzaron la metamorfosis fueron individualizadas y se les asignó una identificación mediante dos letras (CO) y un número (ej. CO 25). 
- Por último, se realizaron observaciones de laboratorio preliminares de larvas criadas en distintas densidades (20, 10, 5 individuos/L) y distintas proporciones predador-presa (100, 10-10, 10-20), siendo las presas larvas de otras especies autóctonas que forman parte de su dieta habitual, con la finalidad de determinar un periodo de apetito normal y un periodo de alto apetito (ver capítulo 3).

Juveniles: el agua utilizada y las condiciones de temperatura, humedad y fotoperiodo fueron las mismas que aquellas detalladas para adultos, huevos, embriones y larvas. La desinfección bimestral del cuarto de cría fue realizada en las condiciones antes detalladas. Al igual que los adultos y larvas, fueron pesados ( $\mathrm{g}$ ) y medidos (LHC en $\mathrm{mm}$ ) mensualmente con la finalidad de evaluar mediante índices de condición corporal el estado de salud individual y de obtener la curva de crecimiento. A partir de la visualización de caracteres sexuales secundarios, fueron considerados adultos y criados como tales. A continuación se detallan las diferencias en el recinto, sustrato y dieta respecto al mantenimiento de adultos:

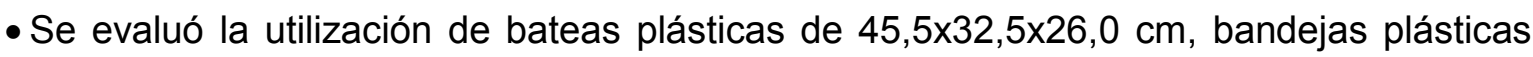
de $33,0 \times 23,0 \times 8,5 \mathrm{~cm}$ y peceras de vidrio de $60,0 \times 30,0 \times 40,0 \mathrm{~cm}$ para la cría de varios individuos juntos y recipientes de polipropileno de $8,5 \times 8,5 \times 8,5 \mathrm{~cm}$ para la cría individual.

- Para el sustrato se tuvo en cuenta la utilización de uno artificial (toallas de papel) o natural (tierra o agua). Para estos casos se evaluó la incorporación de piletas plásticas de $15,0 \times 15,0 \times 2,0 \mathrm{~cm}$ y $11,5 \times 11,5 \times 2,0 \mathrm{~cm}$ con agua en cada recinto para proveer humedad y un sitio para que los individuos se refresquen. Para determinar la frecuencia de recambio del agua se tuvo en cuenta el volumen de la misma, la actividad de los organismos, la frecuencia de alimentación y la cantidad de desechos presentes. También se consideró la posibilidad de utilizar solo agua en vez de sustrato más agua.

- En lo que respecta a la dieta, se consideraron los mismos ítems alimentarios que para los adultos pero de menor tamaño, siempre acorde al tamaño del escuerzo. La frecuencia de alimentación se determinó teniendo en cuenta la historia natural de la especie y la actividad de la misma, incluyendo aspectos básicos de comportamiento como la saciedad y el tamaño de la presa.

- La desinfección de cada recinto y sus objetos se realizó al igual que para adultos con etanol $70 \%$ durante 10 minutos con posterior enjuague con agua de calidad. Sin embargo, la frecuencia de desinfección fue mayor dada la mayor susceptibilidad a contraer enfermedades del estadio juvenil.

- Diariamente, se evaluó la presencia de enfermedades que pudieran afectar a cada individuo y se contabilizó la cantidad de larvas que alcanzaron el estadio juvenil en buen estado de salud. 


\section{Cría de otras especies filogenéticamente relacionadas con C. ornata}

En el mismo cuarto en el cual fueron criados todos los estadios del desarrollo de $C$. ornata, también se criaron ejemplares adultos de otras especies pertenecientes a la familia Ceratophryidae. Se tuvieron en cuenta los mismos estándares de bioseguridad, manejo y cuidado general de anfibios antes detallados. Todos los individuos fueron transportados al laboratorio, aclimatados y criados utilizando agua de la misma calidad y bajo las mismas condiciones controladas de temperatura, humedad y fotoperiodo detalladas para C. ornata. Fueron pesados ( $\mathrm{g}$, en balanza digital de $0,01 \mathrm{~g}$ de precisión) y medidos (LHC en $\mathrm{mm}$ ) mensualmente con la finalidad de evaluar mediante índices de condición corporal el estado de salud individual pero no se cuantificaron datos relativos a su reproducción. A continuación se detallan los aspectos tenidos en cuenta para cada especie:

\section{Ceratophrys cranwelli:}

El 6 de Diciembre de 2006, se colectaron 20 larvas de C. cranwelli en la provincia de Formosa $\left(24^{\circ} 20^{\prime} 44,5^{\prime \prime} \mathrm{S}, 61^{\circ} 06^{\prime} 54.5^{\prime \prime} \mathrm{O}\right)$, las cuales fueron transportadas y mantenidas en laboratorio por herpetólogos locales hasta alcanzar el estadio adulto. Luego, fueron transportados cuatro individuos adultos a la ciudad de La Plata para continuar con su cría. El material y tamaño del recinto, tipo de sustrato, material y tamaño de la pileta con agua y la dieta ofrecida fue la misma que la considerada para adultos de C. ornata.

Con el objetivo de probar el método AMPHIPLEX e indirectamente el protocolo de cría, el 9 de Junio de 2010 se indujo la reproducción de dos parejas $q_{1}+\hat{\gamma}_{2}$ (peso $=214,09 \mathrm{~g}$, $129,17 \mathrm{~g} ; \mathrm{LHC}=99,020 \mathrm{~mm}, 82,829 \mathrm{~mm}$, respectivamente) y $q_{2}+\hat{\sigma}_{1}$ (peso $=190,46 \mathrm{~g}$, $105,10 \mathrm{~g} ; \mathrm{LHC}=106,968 \mathrm{~mm}, 86,553 \mathrm{~mm}$, respectivamente) siguiendo el mismo procedimiento detallado para $C$. ornata, utilizando una solución que fue preparada e inyectada en el mismo momento. La edad de los ejemplares al momento de la inducción era de tres años. Hasta la fecha estos ejemplares se encuentran en buen estado de salud en el laboratorio. Por último, se realizaron observaciones preliminares de laboratorio de larvas criadas en distintas densidades $(20,10,5$ individuos/L) y distintas proporciones predadorpresa $(10-0,10-10,10-20)$, siendo las presas larvas de otras especies autóctonas, con la finalidad de determinar un periodo de apetito normal y un periodo de alto apetito (ver capítulo 3).

\section{Ceratophrys aurita:}

En Septiembre de 2008 se obtuvieron dos ejemplares adultos de $C$. aurita por parte de criadores particulares, los cuales fueron oportunamente colectados en Brasil, desconociéndose su procedencia. El material y tamaño del recinto, tipo de sustrato, material y tamaño de la pileta con agua utilizados y la dieta ofrecida fue la misma que la considerada para adultos de C. ornata. 
Con la finalidad de probar el método AMPHIPLEX e indirectamente el protocolo de cría, el

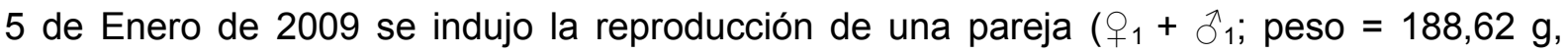
$83,10 \mathrm{~g} ; \mathrm{LHC}=102,743 \mathrm{~mm}, 79,202 \mathrm{~mm}$, respectivamente) siguiendo el mismo procedimiento detallado para $C$. ornata, utilizando una solución que fue preparada e inyectada en el mismo momento. La edad de los ejemplares al momento de la inducción era desconocida aunque estimada en dos años. Se desconoce el estado de salud actual de los ejemplares dado que fueron devueltos a su criador.

\section{Lepidobatrachus llanensis:}

En Febrero de 2011 se colectaron cuatro individuos adultos en la provincia de Córdoba

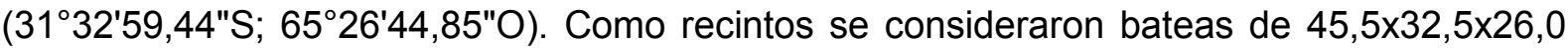
$\mathrm{cm}$. Dado el mayor hábito acuático de la especie, se consideró utilizar como sustrato tierra con abundante cantidad de agua para simular su ambiente natural. En lo que respecta a la dieta, se consideró proveer alimentos de la mayor variedad posible, teniendo en cuenta su dieta habitual en vida silvestre, entre ellos: artrópodos y anuros de otras especies autóctonas.

Con el objetivo de probar el método AMPHIPLEX e indirectamente el protocolo de cría, el

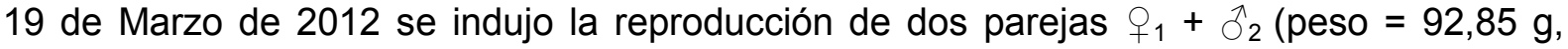
$59,74 \mathrm{~g} ; \mathrm{LHC}=88,553 \mathrm{~mm}, 72,341 \mathrm{~mm}$, respectivamente) y ${ }_{+_{2}}+\hat{\sigma}_{1}$ (peso $=77,00 \mathrm{~g}, 52,40$ $\mathrm{g} ; \mathrm{LHC}=80,976 \mathrm{~mm}, 75,021 \mathrm{~mm}$, respectivamente) siguiendo el mismo procedimiento detallado para $C$. ornata. Se utilizó una solución que fue preparada e inyectada en el mismo momento con una pequeña modificación. Antes de inyectarlos con la combinación GnRH + MET se les inyectó el día anterior un cebador (administración de una dosis de hormona previa a la administración de la dosis final) de $0,02 \mu \mathrm{g} / \mathrm{g}$ de peso corporal de $\mathrm{GnRH}$ para garantizar la funcionalidad del método. La edad de los ejemplares al momento de la inducción era desconocida aunque estimada en dos años. Por último, se realizaron observaciones preliminares de laboratorio de larvas criadas en distintas densidades $(20,10$, 5 individuos/L) y distintas proporciones predador-presa (10-0, 10-10, 10-20), siendo las presas larvas de otras especies autóctonas, con la finalidad de determinar un periodo de apetito normal y un periodo de alto apetito (ver capítulo 3 ).

\section{Análisis estadístico}

Los datos obtenidos producto de la inducción por el método AMPHIPLEX (cantidad de huevos puestos por pareja, cantidad de huevos eclosionados y cantidad de larvas que alcanzaron la metamorfosis y se convirtieron en juveniles sanos) fueron analizados mediante estadística descriptiva. En lo que respecta a la cría de individuos de $C$. ornata, con los datos obtenidos de LHC y peso se obtuvieron índices de condición corporal (LHC/Peso) y las 
respectivas curvas de crecimiento para larvas, a lo largo del desarrollo hasta la culminación del proceso metamórfico, y para juveniles hasta alcanzar el estadio adulto, siguiendo el modelo de crecimiento de von Bertalanffy (1934). Además, se evaluó la existencia de correlación entre el STD y las variables morfométricas medidas.

Para la realización de todas las pruebas estadísticas se utilizó el programa Statistica 7.0 $\left(\right.$ Statsoft ${ }^{\circledR}$ ) y se eligió un nivel de significancia de 0,05 . Además, todas las pruebas realizadas cumplen con sus respectivos supuestos (Zar, 2010).

\section{RESULTADOS}

\section{Validación del método de medición de variables morfométricas}

En la tabla $1 \mathrm{~A}$ se detallan las medidas de $\mathrm{LHC}(\mathrm{mm})$ tomadas simultáneamente mediante el método digital (fotografía digital y posterior medición por software) y calibre digital para larvas de $C$. ornata de distintos STD, siendo el promedio de la diferencia entre las mediciones de ambos métodos de tan solo 0,40 $\pm 0,43 \mathrm{~mm}$. En la fig. 6 se detallan los resultados del análisis de regresión y correlación lineal realizado entre la LHC medida por el método digital y calibre digital simultáneamente $\left(r^{2}=0,9963, r=0,9981\right.$, y $=0,5714+$ $\left.0,9883^{*} x, p<0,0005\right)$ para larvas de tres STD diferentes $(25,31$ y 37$)$. Por último, a partir de mediciones sucesivas de LHC $(n=10)$ de tres larvas de STD 37 utilizando ambos métodos (digital y calibre), se determinó que el método de medición por calibre brinda datos con cuatro cifras significativas (décima de milímetro) mientras que el método digital permite realizar mediciones a la centésima de milímetro. El método digital permite además obtener mediciones más precisas (veraces), lo cual conlleva a una disminución del error sistemático o error del medidor, siendo el coeficiente de variación (CV) de sucesivas mediciones de LHC $(n=10)$ de tres larvas medidas por el método digital: 0,009; 0,008 y 0,006, respectivamente; y el CV de sucesivas mediciones de LHC realizadas en las mismas tres larvas pero con calibre: 0,033; 0,018; 0,022, respectivamente (Tabla 1B). 


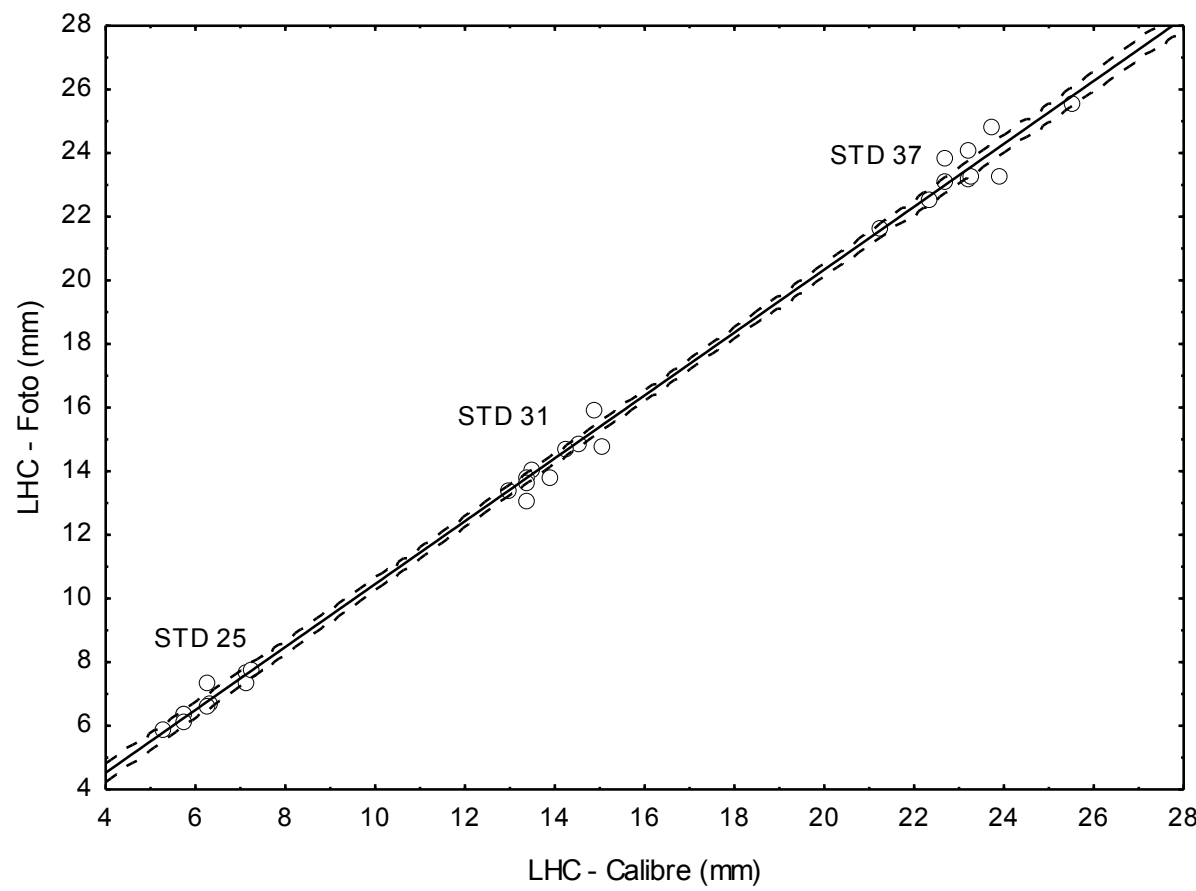

Figura 6. Regresión y correlación lineal entre mediciones de longitud hocico-cloaca (LHC) realizadas mediante el método digital (fotografía digital y posterior medición por software) y calibre digital en larvas de $C$. ornata de distintos estadios (STD). Línea punteada: bandas de regresión a un nivel de confianza de 0,95 
Tabla 1. A: Datos de la longitud hocico cloaca (LHC) en milímetros de 10 larvas de C. ornata en diferentes estadios (STD) medidos mediante dos métodos, digital (fotografía digital y posterior medición por software) y calibre digital; B: Datos de la LHC $(\mathrm{mm})$ de tres larvas de C. ornata de STD 37 medidas 10 veces cada una por los dos métodos (digital y calibre)

\begin{tabular}{|c|c|c|c|c|c|}
\hline STD & ${ }_{\text {Digital }}{ }^{\mathbf{A}}$ & Calibre & $\mathrm{N}^{\circ}$ medida & $\begin{array}{r}\text { B } \\
\text { Digital }\end{array}$ & Calibre \\
\hline 25 & 6,669 & 6,30 & 1 & 20,471 & 20,89 \\
\hline 25 & 6,410 & 5,72 & 2 & 20,507 & 18,96 \\
\hline 25 & 7,709 & 7,14 & 3 & 20,511 & 20,20 \\
\hline 25 & 6,661 & 6,26 & 4 & 20,724 & 20,06 \\
\hline 25 & 7,332 & 7,15 & 5 & 20,347 & 19,84 \\
\hline 25 & 6,375 & 5,71 & 6 & 20,544 & 18,95 \\
\hline 25 & 5,918 & 5,26 & 7 & 20,803 & 18,97 \\
\hline 25 & 7,371 & 6,28 & 8 & 20,903 & 19,88 \\
\hline 25 & 6,154 & 5,71 & 9 & 20,852 & 19,27 \\
\hline 25 & 7,742 & 7,26 & 10 & 20,769 & 19,37 \\
\hline 31 & 14,781 & 15,04 & 1 & 18,680 & 18,39 \\
\hline 31 & 14,849 & 14,52 & 2 & 18,362 & 18,88 \\
\hline 31 & 14,710 & 14,26 & 3 & 18,813 & 18,50 \\
\hline 31 & 13,062 & 13,39 & 4 & 18,830 & 18,81 \\
\hline 31 & 14,013 & 13,46 & 5 & 18,544 & 18,62 \\
\hline 31 & 13,820 & 13,39 & 6 & 18,854 & 19,37 \\
\hline 31 & 15,939 & 14,87 & 7 & 18,595 & 19,05 \\
\hline 31 & 13,813 & 13,89 & 8 & 18,702 & 18,45 \\
\hline 31 & 13,620 & 13,35 & 9 & 18,774 & 18,85 \\
\hline 31 & 13,361 & 12,94 & 10 & 18,740 & 18,33 \\
\hline 37 & 23,159 & 23,19 & 1 & 20,091 & 19,75 \\
\hline 37 & 22,551 & 22,34 & 2 & 20,549 & 19,23 \\
\hline 37 & 24,822 & 23,72 & 3 & 20,242 & 19,02 \\
\hline 37 & 23,310 & 23,23 & 4 & 20,415 & 18,44 \\
\hline 37 & 23,244 & 23,92 & 5 & 20,293 & 19,38 \\
\hline 37 & 23,104 & 22,65 & 6 & 20,233 & 19,25 \\
\hline 37 & 24,128 & 23,22 & 7 & 20,224 & 18,47 \\
\hline 37 & 21,639 & 21,25 & 8 & 20,219 & 19,45 \\
\hline 37 & 23,841 & 22,65 & 9 & 20,393 & 19,19 \\
\hline 37 & 25,519 & 25,49 & 10 & 20,291 & 19,39 \\
\hline
\end{tabular}




\section{Inducción por el método AMPHIPLEX de individuos adultos de C. ornata}

De las cinco parejas inducidas, el método resultó efectivo en el $100 \%$ de los casos, utilizando tanto la solución preparada en el momento como aquella liofilizada y congelada a $18{ }^{\circ} \mathrm{C}$, siendo la combinación más efectiva des-Gly10, D-Ala6, Pro-LHRH $(0,4 \mu \mathrm{g} / \mathrm{g}$ de peso corporal) y MET (10 $\mu \mathrm{g} / \mathrm{g}$ BWT. MET).

Se obtuvieron huevos en distintas épocas del año, algunas de ellas en coincidencia con la época reproductiva y otras fuera de la misma (marzo y mayo), demostrando la efectividad del método. En la tabla 2 se detallan los pesos y medidas de los individuos al momento de cada inducción, la cantidad de huevos puestos por pareja, el porcentaje promedio de huevos eclosionados y la cantidad de larvas que alcanzaron la metamorfosis y continuaron siendo criadas durante el estadio juvenil. Los datos recolectados de los distintos eventos reproductivos indican que $C$. ornata deposita en promedio $3370 \pm 1568$ huevos sueltos por evento con un elevado porcentaje de eclosión. Se constató una disminución en el número de huevos puestos por la pareja $2(=4)$ luego de un año de su primera inducción en laboratorio, no contándose con datos de sus posibles anteriores eventos reproductivos ya que la hembra de esta pareja $\left(\mathrm{q}_{2}\right)$ fue colectada en campo. Además, la puesta de la pareja 5 fue la más numerosa obtenida hasta el momento en laboratorio, siendo la primera puesta de la hembra dado que carecía de caracteres sexuales externos al momento de la colecta.

Los huevos son de gran tamaño $(0,22 \pm 0,01 \mathrm{~cm}, \mathrm{n}=20)$ y presentan las características membranas transparentes. Están cubiertos individualmente por una pequeña capa gelatinosa y transparente (a diferencia de las envolturas comunes frecuentemente observadas en anuros autóctonos). Si bien dicha envoltura tiene capacidad de adherencia a los objetos y plantas sumergidas, la mayoría cae al fondo y se cubre rápidamente con el material en suspensión del agua o con sedimento. A partir de la eclosión, la cual ocurre rápidamente a las $28 \pm 2$ h (entre el STD 18 y 19), las larvas permanecen adheridas a la vegetación o a las paredes del recipiente que las contiene hasta alcanzar el STD 25 a las 96 $\pm 3 \mathrm{~h}$. Desde este momento comienzan a alimentarse y nadar libremente, siendo predadoras y carnívoras. EI STD 31 lo alcanzan a partir de las $312 \mathrm{~h}$ (= 13 días), el STD 37 a partir de las $600 \mathrm{~h}$ (= 18 días) y finalmente la metamorfosis a partir de las 864 h (36 días). La longitud varía de acuerdo a la duración del período larval, pudiendo en algunos casos superar los 30 $\mathrm{mm}$ de LHC y los $4,8 \mathrm{~g}$ de peso corporal. Son larvas nadadoras de hábitos bentónicos, y si bien completan su fase larval rápidamente, pueden retrasarla en promedio hasta cinco meses en cautiverio, principalmente por falta de alimento. 
Tabla 2. Datos recolectados a partir de los individuos de Ceratoprhys ornata inducidos y de sus eventos reproductivos. ㅇ: hembra; $\mathcal{O}^{7}$ : macho; LHC: promedio Iongitud hocico-cloaca $(n=3)$; DE: desvío estándar; Huevos: cantidad de huevos por puesta sin tener en cuenta su viabilidad; \% Eclosión: promedio de la cantidad de huevos eclosionados por bandeja multiplicado por 100 (los valores fueron redondeados teniendo en cuenta un error del experimentador del $5 \%$ ), entre paréntesis se detalla la cantidad huevos a partir de los cuales se calculó el porcentaje de eclosión; Juveniles: cantidad de individuos que alcanzaron la metamorfosis; ${ }^{(a)}$ individuos inducidos más de una vez; ${ }^{(b)}$ datos no relevados

\begin{tabular}{|c|c|c|c|c|c|c|c|c|}
\hline Inducción & Fecha & Pareja & Individuo & Peso (g) & $\mathrm{LHC}(\mathrm{mm}) \pm \mathrm{DE}$ & Huevos & \% Eclosión & Juveniles \\
\hline \multirow{2}{*}{ Primera } & \multirow{2}{*}{$26 / 03 / 2012$} & \multirow{2}{*}{1} & $q_{1}$ & 281,41 & $108,181 \pm 0,270$ & \multirow{2}{*}{2450} & \multirow{2}{*}{- (b) $^{(b)}$} & \multirow{2}{*}{- (b) $^{(b)}$} \\
\hline & & & $\hat{\partial}_{2}{ }^{(a)}$ & 205,26 & $96,418 \pm 1,503$ & & & \\
\hline \multirow{2}{*}{ Primera } & \multirow{2}{*}{$26 / 03 / 2012$} & \multirow{2}{*}{2} & $q_{2}^{(a)}$ & 277,47 & $106,576 \pm 0,885$ & \multirow{2}{*}{2500} & $68 \%$ & \multirow{2}{*}{50} \\
\hline & & & $\hat{O}_{3}{ }^{(a)}$ & 133,68 & $88,831 \pm 2,619$ & & $(n=2500)$ & \\
\hline \multirow{2}{*}{ Segunda } & \multirow{2}{*}{$13 / 11 / 2013$} & \multirow{2}{*}{3} & $i_{3}$ & 325,30 & $121,466 \pm 0,955$ & \multirow{2}{*}{4800} & \multirow{2}{*}{- - (b) $^{-}$} & \multirow{2}{*}{- - (b) $^{-}$} \\
\hline & & & $\hat{\partial}_{2}$ & 161,38 & $89,718 \pm 0,976$ & & & \\
\hline \multirow{2}{*}{ Segunda } & \multirow{2}{*}{$13 / 11 / 2013$} & \multirow{2}{*}{4} & $\mathrm{P}_{2}$ & 309,77 & $111,813 \pm 1,110$ & \multirow{2}{*}{1800} & $78 \%$ & \multirow{2}{*}{47} \\
\hline & & & $\hat{O}_{3}$ & 145,74 & $88,802 \pm 0,567$ & & $(n=800)$ & \\
\hline \multirow{2}{*}{ Tercera } & \multirow{2}{*}{$29 / 05 / 2014$} & \multirow{2}{*}{5} & $q_{4}$ & 318,58 & $113,717 \pm 2,966$ & \multirow{2}{*}{5300} & $81 \%$ & \multirow{2}{*}{56} \\
\hline & & & $\hat{\partial}_{4}$ & 150,85 & $94,486 \pm 1,285$ & & $(n=2400)$ & \\
\hline
\end{tabular}




\section{Protocolo de cría en cautiverio de individuos de C. ornata}

Como producto final de la cría en cautiverio de individuos de C. ornata a lo largo de todo su ciclo de vida, se confeccionó un protocolo de cría que tiene en cuenta los estándares de bioseguridad, manejo y cuidado general de anfibios, garantizando la total ejecución del presente trabajo de tesis (para mayores detalles respecto al protocolo ver tabla 3).

Los individuos adultos deben ser alojados individualmente en bateas de polipropileno de un tamaño mínimo de $45,5 \times 32,5 \times 26,0 \mathrm{~cm}$ con tierra (como sustrato) hasta los $7-8 \mathrm{~cm}$ de altura. Se utilizaron tales recintos por ser más livianos y difíciles de resquebrajarse y romperse que aquellos de vidrio. Además, se utilizaron recintos individuales ya que los recintos conectados (sistemas abiertos) resultan menos efectivos para prevenir la transmisión de enfermedades. La tapa de los terrarios debe ser reemplazada en un $70 \%$ por tejido plástico para permitir la ventilación y evaporación del exceso de agua (Fig. 7A). Cuando la tierra se encuentra demasiado compacta no permitiéndole al escuerzo enterrarse, se debe realizar su recambio total. Se recomienda cambiar el sustrato cada dos o tres meses dependiendo del aspecto. Debe chequearse diariamente la presencia de heces $u$ otros desechos orgánicos (ej. comida), debiendo ser removidos. La pileta plástica de $23,0 \times 17,5 \times 5,0 \mathrm{~cm}$ con agua fue utilizada diariamente por los individuos que se encontraban activos, siendo recomendable su incorporación. Se les debe proveer humedad día por medio, pudiéndose realizar dicha tarea con rociador manual o automático. La desinfección trimestral de las bateas con etanol $70 \%$ permitió mantener individuos sanos y minimizar la aparición de microorganismos indeseados.

(A)

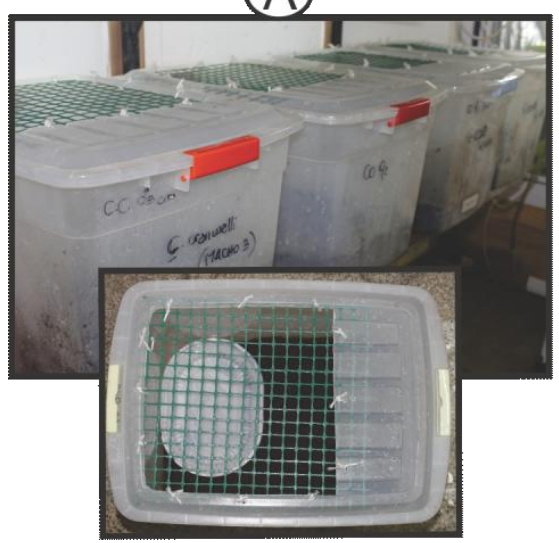

(B)

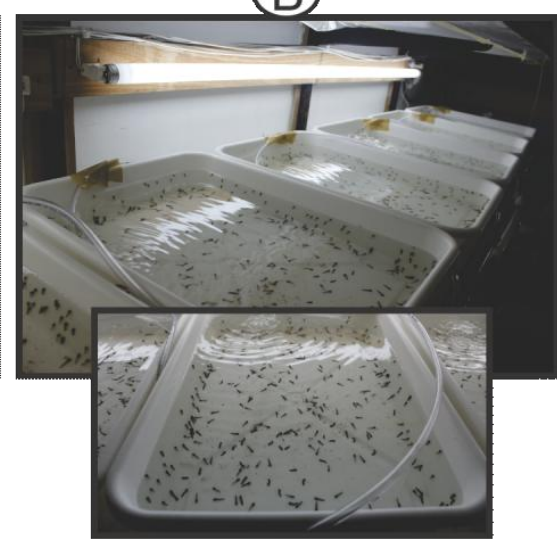

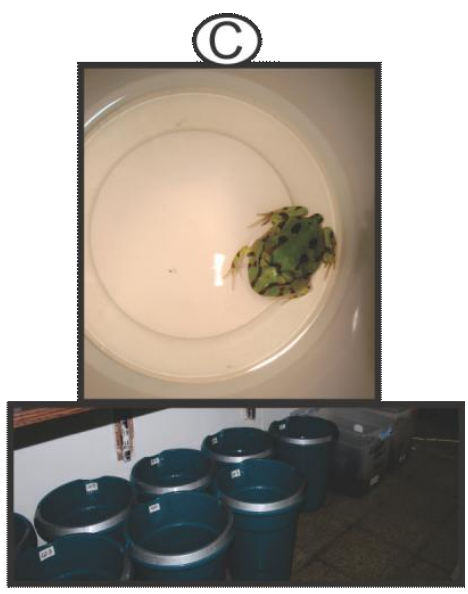

Figura 7. Recipientes utilizados para la cría de individuos de C. ornata a lo largo de su ciclo vital. A: Bateas donde fueron criados individuos adultos con tierra como sustrato y una pileta con agua; B: Bandejas con agua y aireación continua donde se criaron huevos, embriones y larvas; C: Recipientes individuales donde se criaron individuos juveniles con agua, aumentando el tamaño del recipiente acorde al tamaño del individuo 
En periodos de actividad, momento en el cual los organismos se encuentran desenterrados, deben ser alimentados cada dos semanas ofreciéndoles con una pinza un pedazo de hígado o pescado acorde al tamaño del escuerzo, no debiendo superar en un $5 \%$ el peso del individuo a alimentar. Pasado ese período de tiempo, se recomienda ofrecerles 5 individuos de Zoophoba morio embebidos en vitamina $D_{3}$ marca Tetra Reptocal ${ }^{\circledR}$ (Spectrum Brands Inc.) una vez por semana. También se recomienda proveerles ratones de bioterio pero solo cada 16 semanas dado su alto contenido en lípidos (durante la tesis se utilizaron roedores del bioterio de la Facultad de Ciencias Veterinarias de la UNLP). Todos los ítems alimentarios descriptos deben ser intercalados respetando los tiempos de digestión antes mencionados, a los fines de proveer una dieta balanceada. Es recomendable ofrecer a los organismos presas vivas para fomentar los comportamientos naturales de caza y la actividad (para evitar problemas de obesidad). Las presas vivas deben ser colocadas en el sector opuesto al sitio donde el escuerzo se encuentra, ya que si bien cazan al acecho, al visualizar la presa saltan directamente hacia ella atacándola. De encontrarse a los individuos completamente enterrados no deben ser molestados.

Los huevos, embriones y larvas deben ser mantenidos en condiciones controladas en bandejas plásticas de $33,0 \times 23,0 \times 8,5 \mathrm{~cm}$ en densidades máximas de 10 individuos/L, con agua filtrada y sin cloro. Se recomienda que cada bandeja tenga aireación propia para garantizar que el agua perdure por más tiempo (Fig. 7B). El recambio de agua más efectivo y menos laborioso es el del $10 \%$, filtrando los desechos del fondo de la batea mediante una manguera. Sin embargo, cabe aclarar que el recambio del $100 \%$ del agua no afectó a los individuos. Las larvas deben ser alimentadas dos veces por día siguiendo una dieta variada consistente en pedazos de hígado y pescado, larvas de otras especies de anfibios (Rhinella fernadezae, R. arenarum, Hypsiboas pulchellus) y anélidos del género Tubifex. En este sentido, la cría de las distintas especies de larvas de anfibios y anélidos resultó factible, permitiendo contar con alimento bioseguro. En la fig. 8 se detallan las curvas de crecimiento a lo largo del desarrollo larval hasta la culminación del proceso metamórfico. Se comprobó la existencia de correlación positiva entre las distintas variables estimadoras del tamaño corporal (Peso-LHC: $r=0,9059, p<0,0005$ ) y entre éstas y el STD (Peso-STD: $r=0,7146, p$ $<0,0005$; LHC-STD: $r=0,8577 ; p<0,0005)$.

Teniendo en cuenta observaciones preliminares de laboratorio, se determinó un periodo de apetito normal ( 0 a $3 \mathrm{~h}$ ) siendo éste el tiempo que las larvas utilizan para alimentarse cuando no están hambrientas, y un periodo de alto apetito ( $>3 \mathrm{~h}$ ) caracterizado por el consumo de todas las presas y la posible ocurrencia de eventos de canibalismo.

El procedimiento de cría más eficaz con individuos juveniles fue la utilización de recipientes individuales de polipropileno de $8,5 \times 8,5 \times 8,0 \mathrm{~cm}$ con $1-2 \mathrm{~cm}$ de agua filtrada y $\sin$ cloro, dependiendo del tamaño del individuo. El nivel del agua no debe superar la comisura 
de la boca y debe recambiarse en su totalidad diariamente. A partir de los seis meses de edad se recomienda criarlos en recipientes más grandes de 26,0×26,0×28,5 cm (Fig. 7C). Hasta los primeros dos meses de vida, deben ser alimentados tres veces por semana con individuos de Tenebrio molitor embebidos en vitamina $D_{3}$ marca Tetra Reptocal ${ }^{\circledR}$ (Spectrum Brands Inc.), pedazos de hígado y pescado ${ }^{2}$ de un tamaño acorde al juvenil. Luego debe disminuirse la frecuencia de alimentación a dos veces por semana. A partir de los seis meses de vida y hasta el año de edad, se les puede ofrecer cada dos meses un ratón de destete de bioterio y de un tamaño acorde al tamaño del escuerzo. Luego, se debe disminuir la frecuencia de alimentación con roedores a 16 semanas dado su alto contenido en lípidos, aumentando el tamaño de la presa acorde al tamaño del escuerzo. Todos los ítems alimenticios descriptos deben ser intercalados respetando los tiempos de digestión antes mencionados, con la finalidad de proveer una dieta balanceada y no deben superar en un $5 \%$ el peso del individuo a alimentar. Es recomendable ofrecer a los organismos presas vivas para fomentar los comportamientos naturales de caza y la actividad (para evitar problemas de obesidad). Los caracteres sexuales secundarios fueron visualizados a los seis meses en promedio, habiéndose obtenido este dato de individuos machos por ser los caracteres sexuales de éstos más fácilmente distinguibles que aquellos de las hembras. $A$ partir de este momento son considerados adultos, correspondiendo las condiciones de cría a las indicadas para ese estadio. Las curvas de crecimiento desde el estadio juvenil hasta la adultez se detallan en la fig. 9.

\footnotetext{
${ }^{2}$ El pescado debe ser ofrecido una sola vez por semana para evitar parálisis de los miembros por exceso de tiaminasa (ver Anexo II - página 232 para más detalle).
} 

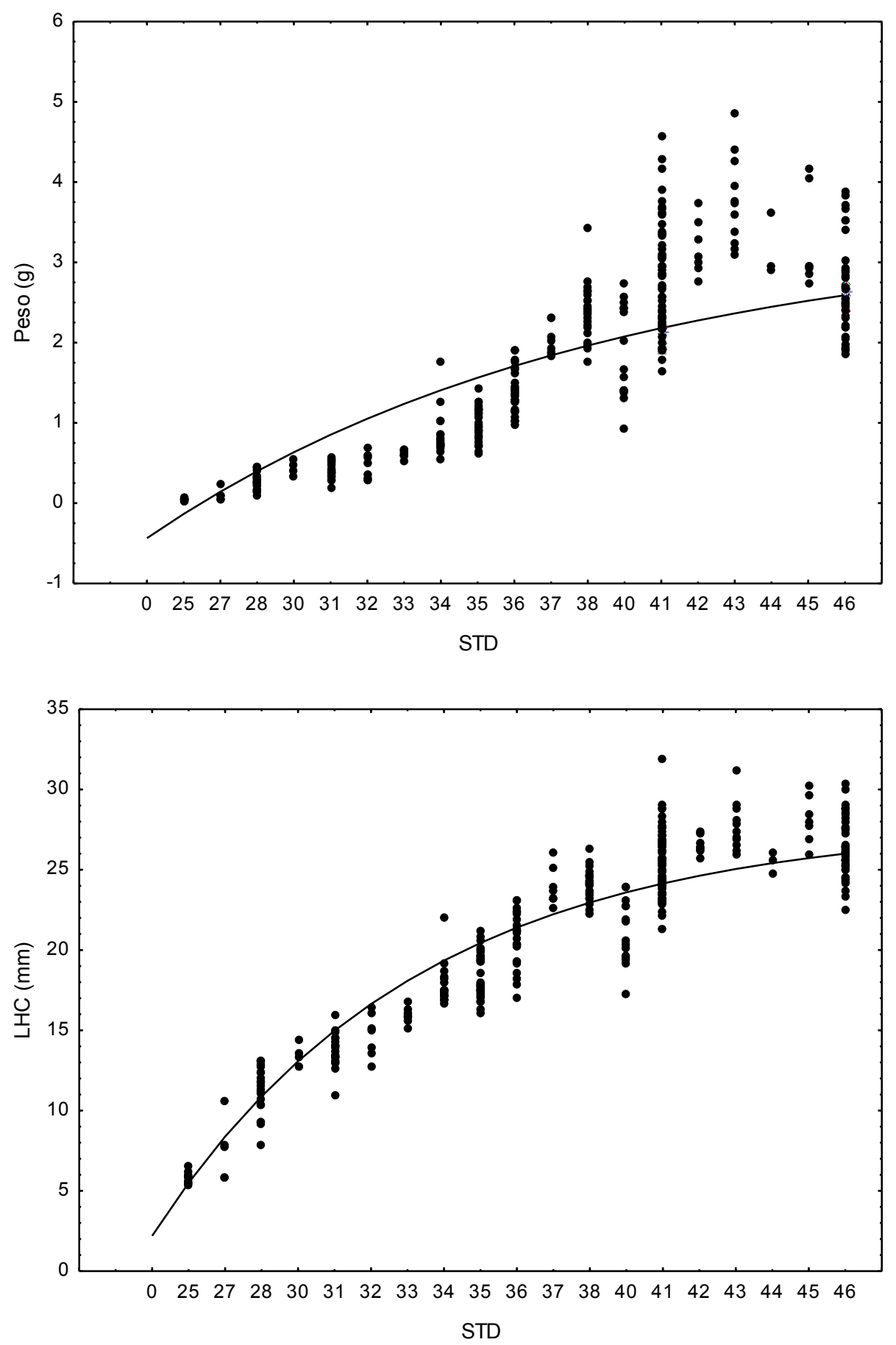

Figura 8. Curva de crecimiento de larvas de $C$. ornata desde el estadio (STD) 25 hasta completar la metamorfosis (46), construidas siguiendo el modelo de von Bertalanffy $(n=330)$. Peso en gramos $(g)$; LHC: longitud hocico-cloaca en milímetros (mm); STD: estadio del desarrollo 

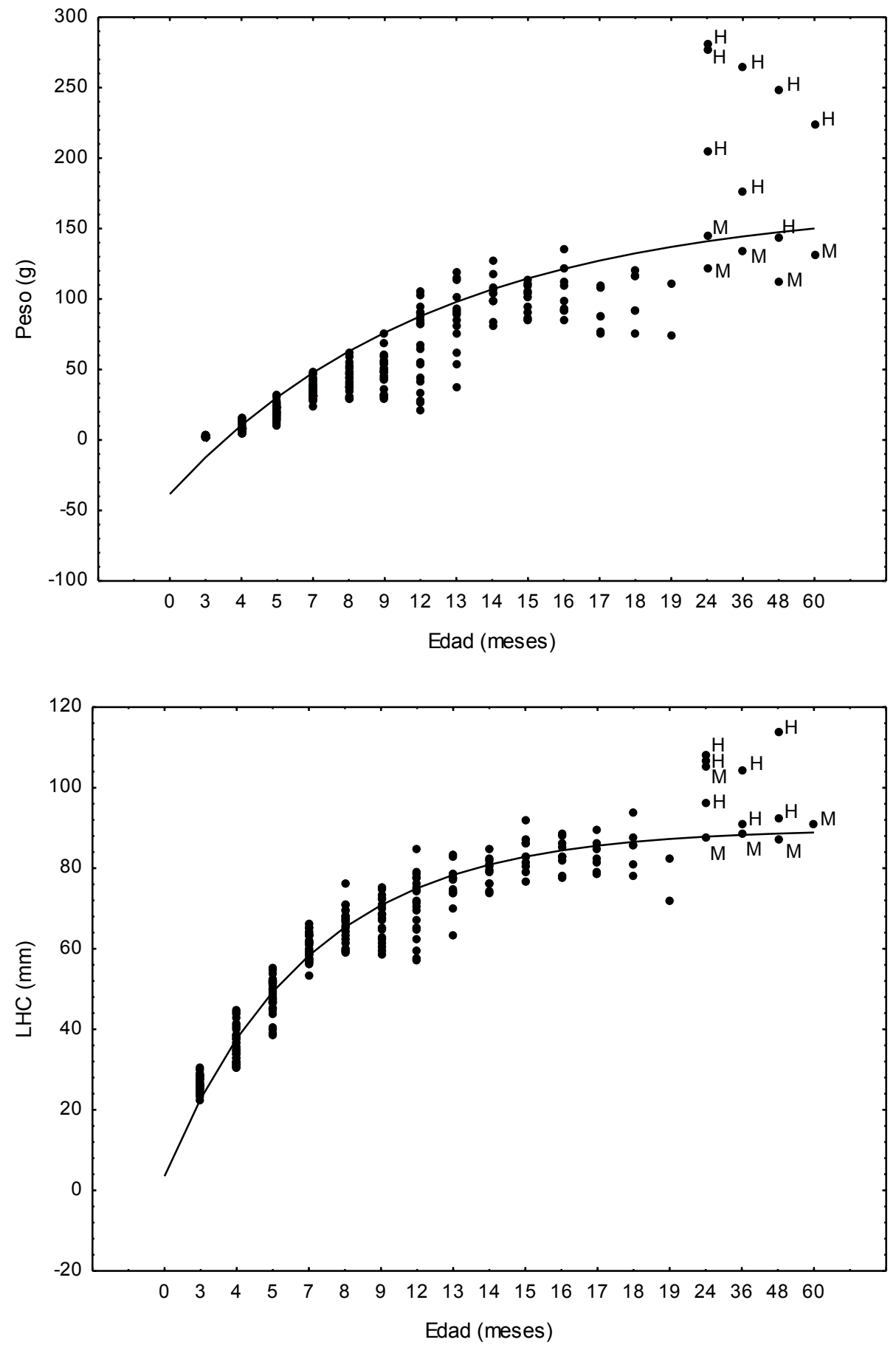

Figura 9. Curvas de crecimiento de individuos de C. ornata desde la culminación del proceso metamórfico (juveniles, tiempo promedio tres meses) hasta la adultez, construidas siguiendo el modelo de von Bertalanffy $(n=279)$. Peso en gramos $(g)$; LHC: longitud hocico-cloaca en milímetros $(\mathrm{mm})$; H: hembras; M: machos 
Tabla 3. Resumen de las condiciones recomendadas para la cría de Ceratophrys ornata

\begin{tabular}{|c|c|}
\hline Bioseguridad & $\begin{array}{l}\text { Desinfección bimestral del piso, estantes del cuarto de cría y todo } \\
\text { material utilizado para la cría de anfibios (incluidos los utensillos } \\
\text { para su manipulación y alimentación) con hipoclorito de sodio } 10 \% \\
\text { durante } 10 \text { minutos. } \\
\text { Desinfección completa de cada recinto individual y sus objetos con } \\
\text { etanol } 70 \% \text { durante } 10 \text { minutos con posterior enjuague con agua } \\
\text { de calidad. Durante la desinfección los individuos deben ser } \\
\text { colocados en otros recintos de iguales características con agua de } \\
\text { calidad. }\end{array}$ \\
\hline $\begin{array}{c}\text { Parámetros de calidad } \\
\text { del agua }\end{array}$ & $\begin{array}{l}\text { Agua de red filtrada por filtro físico Aqua-Pure }{ }^{\circledR} \text { Modelo AP-110 H/C } \\
\text { de } 5 \text { micrones, sin cloro por aireación enérgica durante } 48 \mathrm{~h} \text {. } \\
\text { Alcalinidad: } 128,00 \pm 26,72 \mathrm{mg} \mathrm{CaCO}_{3} / \mathrm{L} \\
\text { Dureza: } 122,71 \pm 21,26 \mathrm{mg} \mathrm{CaCO}_{3} / \mathrm{L} \\
\text { Temperatura: } 22 \pm 1{ }^{\circ} \mathrm{C} \\
\text { pH: } 7,92 \pm 0,15 \\
\text { Conductividad: } 708,5 \pm 50,9 \mu \mathrm{S} / \mathrm{cm}\end{array}$ \\
\hline $\begin{array}{c}\text { Tipo y tamaño de los } \\
\text { recintos }\end{array}$ & $\begin{array}{l}\text { Adultos: batea de polipropileno de } 45,5 \times 32,5 \times 26,0 \mathrm{~cm} \text {, tapa con } \\
70 \% \text { tejido plástico que permita la ventilación y evaporación del } \\
\text { exceso de agua. } \\
\text { Huevos, embriones y larvas: bandejas plásticas de } 33,0 \times 23,0 \times 8,5 \\
\text { cm en densidades máximas de } 10 \text { individuos/L, con aireación } \\
\text { propia. } \\
\text { Juveniles: recipientes individuales de polipropileno de } 8,5 \times 8,5 \times 8,0 \\
\mathrm{~cm} \text {. A partir del año de edad, utilizar recipientes de } 26,0 \times 26,0 \times 28,5 \\
\mathrm{~cm} \text {. }\end{array}$ \\
\hline Sustrato de los recintos & $\begin{array}{l}\frac{\text { Adultos: tierra orgánica (compost orgánico marca Terrafertil }{ }^{\circledR} \text { ) hasta }}{\text { los } 7-8 \mathrm{~cm} \text { de altura, recambio cada } 2-3 \text { meses. }} \\
\text { Huevos, embriones y larvas: } 30 \% \text { piedras de rio de diferentes } \\
\text { tamaños, que sirvan como refugio y retención de desechos. Agua } \\
\text { de calidad con recambio diario del } 10 \% \text {. } \\
\text { Juveniles: } 1-2 \mathrm{~cm} \text { de agua (dependiendo del tamaño del individuo) } \\
\text { filtrada y sin cloro. El nivel del agua no debe superar la comisura } \\
\text { de la boca y debe recambiarse en su totalidad diariamente. A partir } \\
\text { del año, tierra como sustrato y recambio cada } 2-3 \text { meses. }\end{array}$ \\
\hline $\begin{array}{c}\text { Cantidad de agua de los } \\
\text { recintos }\end{array}$ & $\begin{array}{l}\text { Adultos: pileta plástica de } 23,0 \times 17,5 \times 5,0 \mathrm{~cm} \text { con agua. Proveer } \\
\text { humedad diaria mediante rociador manual o automático. } \\
\text { Juveniles: A partir del año, proveer una pileta plástica de } \\
15,0 \times 15,0 \times 2,0 \mathrm{~cm} \text { y humedad diaria mediante rociador manual o }\end{array}$ \\
\hline
\end{tabular}




\begin{tabular}{|c|c|}
\hline & automático. \\
\hline Temperatura ambiente & $25 \pm 1^{\circ} \mathrm{C}$ \\
\hline Calidad de la luz & $\begin{array}{l}\text { Tubos de luz fluorescentes de } 36 \mathrm{~W} \text {. } \\
\text { Juveniles y adultos: baños de luz UV (tubos Reptisun }{ }^{\circledR} \text { ), mensuales } \\
\text { y durante un cuatrimestre al año para favorecer el metabolismo del } \\
\text { calcio, siguiendo siempre las recomendaciones de la marca (ver } \\
\text { Anexo III para más detalle). }\end{array}$ \\
\hline Fotoperíodo & $16 \mathrm{~h} \mathrm{luz} / 8 \mathrm{~h}$ oscuridad, automatizado mediante un temporizador. \\
\hline Dieta & $\begin{array}{l}\text { Adultos: cuando estén desenterrados, un pedazo de } \\
\text { hígado/pescado acorde al tamaño del escuerzo cada dos } \\
\text { semanas, o } 5 \text { zophobas con vitamina } D_{3}\left(\text { Reptocal }{ }^{\circledR}\right) \text { una vez por } \\
\text { semana; ratones cada } 16 \text { semanas. Todos los ítems alimentarios } \\
\text { deben ser intercalados respetando los tiempos de digestión antes } \\
\text { mencionados. En caso de falta de apetito, no deben ser forzados a } \\
\text { comer. } \\
\text { Larvas: alimentación diaria, pedazos de hígado/pescado, larvas de } \\
R . \text { fernadezae, } R \text {. arenarum, Hypsiboas pulchellus o Tubifex. } \\
\text { Proveer dos tipos de alimentos diferentes dos veces por día. } \\
\text { Juveniles: Hasta los dos meses de edad: } 1-2 \text { tenebrios embebidos } \\
\left.\text { en vitamina } D_{3} \text { (Reptocal }{ }^{\circledR}\right) \text {, o } 1-2 \text { pedazos de hígado/pescado }{ }^{3} \text { de } \\
\text { un tamaño acorde al juvenil, tres veces por semana. } \\
\text { A partir de los tres meses de edad: mismos ítems, disminuir } \\
\text { frecuencia de alimentación a dos veces por semana. } \\
\text { A partir de los seis meses y hasta el año de edad: mismos ítems, } \\
\text { adicionar un ratón de destete de un tamaño acorde al tamaño del } \\
\text { escuerzo cada dos meses y reemplazar tenebrios por zophobas. } \\
\text { A partir del año de edad: mismos ítems, disminuir la frecuencia de } \\
\text { alimentación con roedores a } 16 \text { semanas. } \\
\text { Todos los ítems alimentarios deben ser intercalados pero siempre } \\
\text { respetando los tiempos de digestión antes descriptos. En caso de } \\
\text { falta de apetito, no deben ser forzados a comer. }\end{array}$ \\
\hline $\begin{array}{c}\text { Índices de condición } \\
\text { corporal }\end{array}$ & $\begin{array}{l}\text { Adultos: promedio LHC/Peso: hembras }=0,44 ; \text { machos }=0,69 \\
\text { Larvas: promedio LHC/Peso: STD } 25=130,7 ; \text { STD } 28=40,4 ; \text { STD } \\
31=33,3 ; \text { STD } 37=11,8 ; \text { STD } 40=11,2 ; \text { STD } 46=9,9 \\
\text { Juveniles: promedio LHC/Peso }=2,0\end{array}$ \\
\hline
\end{tabular}

\footnotetext{
${ }^{3}$ El pescado debe ser ofrecido una sola vez por semana para evitar parálisis de los miembros por exceso de tiaminasa (ver Anexo II - página 232 para más detalle).
} 


\section{Otros resultados obtenidos producto de la cría en cautiverio y de muestreos de campo: biología y estado de conservación}

\section{Datos de la biología}

A partir de datos de muestreos propios y de otros herpetólogos, se puede confirmar que la especie se encuentra desde selvas ribereñas, barrancas del delta, pastizales pampeanos cercanos a arroyos, hasta ambientes psamófilos de la costa atlántica. Presenta intervalos de 2 a 4 años aproximadamente en los que no se reproduce ni se encuentra activa, permaneciendo enterrada y envuelta en capas de queratina (cocones) en estado de latencia (hibernación). Considerando datos producto de su cría en cautiverio, se estima que los individuos adultos pueden permanecer enterrados en promedio cuatro meses sin salir a alimentarse. Estas épocas coinciden con años o períodos secos. Solo vuelven a la actividad en períodos muy lluviosos, en los que se producen inundaciones (se constató su actividad durante o después de fuertes lluvias eléctricas $=70 \mathrm{~mm}$ de agua en promedio). En esas condiciones se desentierran y comienzan a comer y a migrar hacia los sitios reproductivos, siendo visibles en ese momento (cruzando rutas o en el campo) o bien en plena actividad reproductiva. Los sitios reproductivos suelen estar conformados por charcas temporarias, arroyos de primer orden o planicies de inundación de arroyos más grandes totalmente desbordados. Por lo tanto, se deduce que la especie se reproduce en lagunas efímeras de grandes extensiones, las cuales en pocos días se reducen a los cuerpos de agua originarios. La actividad reproductiva fue constatada en campo mayormente en los meses de Enero-Febrero, aunque también se registró el canto de individuos machos en el mes de Septiembre. Las observaciones realizadas indican una coincidencia espacial y temporal del período reproductivo de esta especie con la reproducción de $R$. arenarum y $R$. fernandezae, de las cuales se alimentan tanto los adultos (de adultos) como las larvas (de larvas). Es una especie longeva (> 5 años) teniendo en cuenta datos relevados en cautiverio.

Para la diferenciación de individuos adultos, se debe tener en cuenta que los machos poseen manchas marrones y/o negras en el saco vocal, pudiéndose distinguir un color grisáceo entre las manchas. Las hembras también poseen manchas marrones y/o negras en la parte ventral de la boca pero separadas por parches blancos. Sin embargo, en ocasiones el macho puede no poseer suficiente pigmentación del saco, siendo el tamaño corporal la segunda característica más fácilmente distinguible. El índice de condición corporal de las hembras (LHC/Peso) es 1,6 veces menor al de los machos y la proporción de sexos es 1:1. De todas formas, la pigmentación del saco vocal es la característica que confirma el sexo, pudiéndose en raras ocasiones estar en presencia de hembras adultas de pequeño tamaño.

En lo que respecta a comportamiento, se constató el movimiento pedal no solo en juveniles (Radcliffe y col., 1986; Saibene y col., 2009) sino también en adultos. Tal 
movimiento fue realizado al momento de abrir la tapa de los terrarios y ofrecerles comida. En ocasiones no hizo falta que visualicen una presa para comenzar con el movimiento sino que con solo visualizar a quien se acerca a alimentarlos, comenzaron a realizar el despliegue.

\section{Estado de conservación}

Se realizaron muestreos periódicos en los alrededores de la ciudad de La Plata, con el objetivo de colectar individuos adultos de $C$. ornata para su cría. Dichos muestreos permitieron obtener datos respecto a su estado actual de conservación. Teniendo en cuenta la última categorización de anfibios para Argentina (Natale y Salgado Costa, 2012), el estado fue elevado a la categoría de "vulnerable". Tal situación se debe a la falta de información respecto al estado de las poblaciones actuales, y por el solapamiento de su distribución con la zona sojera. Las poblaciones de las cuales contamos con información producto del monitoreo en campo son estables y presentan actividad pulsátil, ciclos de actividad cortos (días) y espaciados por hasta varios años. Esto último coincide con la información proveniente de datos de ingreso de material en museos, donde se registran lotes enteros en un año, contrastando con intervalos de ausencia de ingresos por muchos años. Es poco abundante en las comunidades donde habita (situación normal en predadores de gran tamaño) y la frecuencia de encuentro es baja.

\section{Aplicación del protocolo de cría en otras especies filogenéticamente relacionadas con C. ornata}

La cría de las tres especies de la familia Ceratophryidae (C. cranwelli, C. aurita y $L$. llanensis) resultó factible, permitiendo contar con individuos sanos para su posterior inducción artificial de la reproducción. El método AMPHIPLEX resultó efectivo en el $100 \%$ de los casos. Al igual que los huevos de C. ornata, los huevos de estas tres especies son de gran tamaño, poseen membranas transparentes y envoltura individual. Las larvas permanecen adheridas a la vegetación o a las paredes del recipiente que las contiene hasta

alcanzar el STD 25. Luego, comienzan a alimentarse y a nadar libremente, siendo predadoras, carnívoras y nadadoras de hábitos bentónicos.

Teniendo en cuenta observaciones preliminares de laboratorio, se determinó para $C$. cranwelli y L. Ilanensis un periodo de apetito normal y un periodo de alto apetito, ambos determinados con el mismo criterio utilizado para larvas de $C$. ornata. El periodo de apetito normal va de 0 a $12 \mathrm{~h}$ para $C$. cranwelli y de 0 a $4 \mathrm{~h}$ para $L$. llanensis, comenzando el periodo de alto apetito a partir de las $12 \mathrm{~h}$ para $C$. cranwelli y de las $4 \mathrm{~h}$ para L. Ilanensis. En lo que respecta a los índices de condición corporal (LHC en mm / peso en gramos) para individuos adultos de cada especie los mismos se detallan a continuación: 


\begin{tabular}{lrc} 
Especie & Hembra & Macho \\
\hline C. cranwelli & 0,52 & 0,81 \\
C. aurita & 0,53 & 0,87 \\
L. llanensis & 0,91 & 1,34 \\
\hline
\end{tabular}

\section{DISCUSIÓN Y CONCLUSIONES}

El método de inducción artificial de la reproducción utilizado (AMPHIPLEX), resultó efectivo no solo para inducir la reproducción de la especie seleccionada (C. ornata) sino también de especies filogenéticamente relacionadas con la misma. Además, resultó factible su aplicación reiterada en un mismo individuo, permitiendo obtener organismos sanos a lo largo de todo el desarrollo. Cabe destacar que se respetó un tiempo de 20 meses entre inducciones, pudiéndose probar en futuras investigaciones tiempos inferiores al reportado. Al momento de seleccionar una pareja de adultos a inducir se debe tener en cuenta que las primeras puestas son las más numerosas, reduciéndose las mismas con los sucesivos eventos reproductivos. Este dato resulta interesante al diseñar un experimento/ensayo específico con la intención de aprovechar al máximo el total de larvas obtenidas. El método permitió obtener huevos en distintas épocas del año, no todas coincidentes con el periodo reproductivo de cada especie y recolectar datos de la biología de las mismas que de otro modo hubiera resultado dificultoso y en ocasiones imposible dado su hábito de vida. En tal sentido, el presente trabajo aporta datos de la biología de $C$. ornata relativos a su reproducción (actividad reproductiva, cantidad de huevos depositados por puesta, porcentaje de eclosión de los huevos), crecimiento (curvas de crecimiento desde etapa larval hasta la adultez), desarrollo (tiempo promedio en alcanzar determinados estadios), enfermedades (diagnóstico y tratamiento, ver Anexo II), comportamiento (llamada de anuncio y reciprocidad - ver Anexo II, movimiento pedal) y biología general. Este capítulo hace un importante aporte de carácter científico sin precedentes, dado que se logró criar a sucesivas generaciones de una determinada especie y en todos los estadios del desarrollo, desde huevo hasta adulto.

A partir de la aplicación del método AMPHIPLEX, fue posible garantizar el desarrollo de un protocolo de cría ex-situ de individuos de $C$. ornata y su aplicación en especies filogenéticamente relacionadas y con hábitos de vida similares. En lo que respecta a la cría ex-situ, queda evidenciada la necesidad de criar organismos en cautiverio en aquellos casos en que las investigaciones in-situ resultan imposibles o complejas de realizar y los 
ambientes no se pueden conservar, siendo tal estrategia aún más necesaria cuando el objetivo del estudio es desarrollar un modelo debiéndose garantizar la reproducción de una determinada especie en laboratorio. En este sentido, la clave para el desarrollo y aplicación del modelo ha sido la cría y reproducción de la especie en cautiverio. Considerando todos los métodos de inducción artificial de la reproducción de anfibios que han sido utilizados hasta el momento, AMPHIPLEX presenta importantes ventajas. Entre ellas, no provoca la muerte de los organismos parentales, permite obtener huevos fecundados en cualquier época del año y evita el estrés por manejo manual, en comparación con otros métodos, dado que se inyecta a ambos sexos una sola vez y en forma simultánea. Además, posibilita la reproducción en laboratorio con los patrones propios de cada especie. Por lo tanto, teniendo en cuenta la elevada efectividad del método, se propone al mismo como herramienta de manejo reproductivo para la cría en cautiverio de anfibios autóctonos. De la mano de tan potente herramienta podrán surgir los protocolos de cría de las restantes 168 especies de anuros descriptas para Argentina, para ninguna de las cuales se cuenta hasta el momento con un protocolo completo de cría en cautiverio (desde huevo hasta adulto) que garantice la obtención de sucesivas generaciones de individuos. Es decir, si bien muchos herpetólogos han logrado mantener en cautiverio distintos estadios del desarrollo de diferentes especies de anuros (ej. ANFITOX e incluso el CIMA donde se han criado varias especies de anuros), no se ha reportado formalmente lo anteriormente expuesto. Por ello, resulta interesante remarcar que el protocolo de cría de individuos de C. ornata aquí desarrollado propone pautas para la cría de sucesivas generaciones de individuos de una determinada especie de Argentina. En relación al nivel intermedio de estándares de bioseguridad y manejo de anfibios seleccionado, se debe tener en cuenta que los estudios de reintroducción al hábitat natural de la especie escapan a los objetivos del presente trabajo pero son considerados de vital importancia para futuras investigaciones. Por lo tanto, aquellos programas de conservación cuyo objetivo final sea la reintroducción al hábitat natural de los individuos criados, deberán tener en cuenta los estándares de bioseguridad y manejo correspondientes a la categoría avanzada, debiéndose mantener a los individuos lo más separados posible y en un estado de cuarentena permanente, entre otras consideraciones (Zippel y col., 2006). Se concluye que el mantenimiento en cautiverio de la especie C. ornata, no presenta complicaciones si se mantienen adultos y juveniles de manera individual y larvas en bajas densidades, para disminuir la frecuencia de eventos de canibalismo ante condiciones de alto apetito. Tales conclusiones se extienden a la cría en cautiverio de C. cranwelli, C. aurita y L. llanensis. En relación a la calidad del agua, se recomienda mantener los parámetros de alcalinidad, dureza, temperatura, $\mathrm{pH}$ y conductividad dentro del rango previamente informado (el cual fue determinado teniendo en 
cuenta los parámetros correspondientes al hábitat natural de la especie), siendo importante realizar mediciones periódicas de los mismos para asegurar las condiciones apropiadas.

Los datos referentes a la actividad reproductiva de $C$. ornata se detallan en el Anexo II. A modo de cierre del capítulo, se esbozan aquí algunas conclusiones aunque para más detalle deberá consultarse el mencionado anexo. La actividad reproductiva de $C$. ornata posee una duración muy corta (48 a 72 h) en comparación con otras especies de anuros. Los datos registrados durante los distintos eventos reproductivos indican que $C$. ornata no deposita gran cantidad de huevos como otras especies autóctonas de la región Pampeana, las cuales triplican la cantidad reportada para la especie (Gallardo, 1974; Cei, 1980;). Tal hecho, podría estar asociado al modo de ovoposición de cada especie, ya que los huevos sueltos (y de gran tamaño) de C. ornata versus los huevos depositados en cordones gelatinosos de otras especies, requieren de un alto gasto energético. Más allá de la cantidad de huevos depositados, la especie posee un elevado porcentaje de eclosión.

El crecimiento se evaluó mediante índices de condición corporal como un método de control del estado de salud individual. El método de medición digital (foto) resultó ser el más adecuado para evaluar la LHC, no solo porque no presenta diferencias en los resultados arrojados respecto al método tradicional (medición por calibre), sino porque los datos son más precisos y disminuye el estrés de los organismos evitando su manipulación durante todo el proceso de medición. Por otra parte, se debe tener en cuenta que el crecimiento es un fenómeno complejo que no se debe exclusivamente a factores genéticos sino también ambientales, entre ellos la disponibilidad de alimento y el estado de salud. En este sentido, existen en la literatura varios modelos para describir el crecimiento de un organismo, entre ellos el modelo logístico, modelo de Gompertz y de von Bertalanffy (Hota, 1994). A lo largo del presente trabajo de tesis, se utilizó el modelo de crecimiento exponencial de von Bertalanffy por considerarse el más adecuado para el grupo estudiado, ya que asume que el crecimiento no es constante a lo largo del tiempo de vida de cada individuo. Si bien el peso es considerado la variable que mejor estima el crecimiento de un organismo (Hota, 1994), a partir de las curvas de crecimiento de juveniles hasta adultos pareciera que tal modelo se encuentra mejor representado por la LHC (Fig. 9). Esto se debe a que la especie estudiada presenta un dimorfismo sexual muy marcado en relación al tamaño corporal, siendo las hembras en promedio 1,8 veces más pesadas que los machos. Tal como se puede observar en la fig. 9, la diferencia en el tamaño resulta más evidente a partir de los 24 meses de edad. Esto puede también verificarse al analizar la curva de crecimiento a lo largo del desarrollo larval, ya que la misma se encuentra igual representada por ambas variables (peso y LHC) dado que aún no ha ocurrido la diferenciación sexual. Si se compara la curva de crecimiento que involucra a larvas a lo largo del desarrollo hasta la culminación del proceso metamórfico (Fig. 8) con la curva que involucra a juveniles y adultos 
(Fig. 9), puede observarse en la segunda una etapa de crecimiento asintótico, donde el crecimiento es cada vez más lento a partir de los 18 meses de edad, hecho que se corresponde matemáticamente con una asíntota horizontal. Es decir, si bien el peso y la LHC de individuos adultos de esta especie nunca se hace constante sí tiende a estabilizarse a medida que aumentan los años de vida. Sin embargo, durante el desarrollo larval tal asíntota no resulta evidente. Esto permite concluir, que la especie seleccionada (al igual que la mayoría de los anfibios) posee un crecimiento discontinuo, estabilizándose el peso y la longitud hacia la adultez y pudiendo presentar pequeños altibajos en el peso que dependen de la frecuencia de alimentación y del agua retenida, entre otros factores.

La edad a la que alcanzan la madurez sexual (seis meses de edad) fue relevada por primera vez mediante observación de caracteres sexuales externos masculinos. Los machos son de menor tamaño que las hembras (De Vosjoli, 1990), siendo el tamaño corporal la segunda característica distinguible para diferenciar sexos, y la diferente pigmentación del saco vocal la característica más importante que permite constatar el sexo. Si se comparan los índices de condición corporal para C. ornata, C. cranwelli, C. aurita y L. Ilanensis se puede concluir que las tres especies pertenecientes al género Ceratophrys presentan diferente tamaño corporal según el sexo, siendo las hembras más grandes y pesadas que los machos. Sin embargo, para el caso de L. llanesis el tamaño corporal no es una característica de diferenciación sexual.

En relación al desarrollo, se pudo determinar el tiempo que tardan las larvas de $C$. ornata en alcanzar el STD 25, 28, 31, 37 y 46, coincidiendo este último (tiempo a la metamorfosis) con los tiempos descriptos por (Honegger y col., 1985; Kollros y Bovbjerg, 1997). Se concluye que la especie posee una tasa de crecimiento acelerada tal como postula Fabrezi (2011) sumado a un desarrollo de muy corta duración en comparación con otras especies (Natale, 2006).

En cuanto a datos de su biología que pudieron ser relevados en campo y por material de museos, la especie posee largos intervalos de inactividad en los que permanece enterrada y envuelta en capas de queratina (cocones), en coincidencia con las descripciones de McClanahan y col. (1976) y Faivovich y col. (2014). Se constató la actividad reproductiva durante el mes de Enero tal como describen Fernández y Fernández (1921). Además, se amplió la descripción realizada por esos autores ya que la actividad comienza en Septiembre y finaliza en el mes de Febrero, coincidiendo los días de actividad con fuertes lluvias eléctricas (durante o después de las mismas). En contraste con las descripciones de Hudson y col. (1958), no se constató actividad reproductiva durante la estación invernal. En relación a datos de su biología que pudieron ser relevados en 
cautiverio, es una especie longeva (> 5 años) coincidiendo los datos relevados con aquellos publicados por curadores de zoológicos de EEUU de América (www.pondturtle.com).

Teniendo en cuenta que los individuos adultos de $C$. ornata son difíciles de encontrar en campo, su puesta consiste en huevos dispersos por el fondo cubiertos con sedimento y/o vegetación (dificultando su localización) y que se ha elevado el estado de conservación de las poblaciones naturales de la categoría "no amenazada" a "vulnerable" (Natale y Salgado Costa, 2012), se concluye que el protocolo de cría en cautiverio aquí presentado constituye una valiosa herramienta que permitirá, una vez mitigados los daños en el hábitat natural, reintroducir ejemplares sanos contribuyendo así con la conservación de la especie. Además, la implementación del protocolo con especies filogenéticamente relacionadas y de hábitos similares, permite su validación. De todas formas, resulta necesario destacar que la reintroducción de la especie puede no resultar viable de no contarse con sitios libres de contaminación. A partir del desarrollo de este protocolo de cría, se propone a la especie como modelo experimental (ver capítulos 2 y 3 ) para su utilización en estudios ecotoxicológicos de efectos de plaguicidas (ver capítulos 4 y 5). 
Capítulo 2

Estudio de la variabilidad de sonidos producidos por individuos de la familia Ceratophryidae a lo largo de su desarrollo 
El protocolo de cría en cautiverio de individuos de C. ornata desarrollado en el capítulo anterior, permitió obtener larvas de todos los estadios del desarrollo. Ello a su vez permitió, en el presente capítulo, describir la variabilidad de los sonidos producidos por larvas de esta especie a lo largo del desarrollo larval, tanto en un medio acuático como aéreo y compararlos con los sonidos producidos en estadio juvenil y adulto bajo el mismo contexto de emisión. Previamente, se realizó una consulta interdisciplinaria con especialistas en sonidos. Los aportes de tales consultas han sido esbozados a lo largo del capítulo. Por último, la aplicación del protocolo de cría a otras especies de anuros filogenéticamente cercanas a C. ornata, permitió obtener larvas de otras especies para evaluar y describir la producción de sus sonidos.

\section{INTRODUCCIÓN}

\section{Acústica y Bioacústica}

Los sonidos son vibraciones mecánicas generadas por una determinada fuente (ej. un instrumento musical, una máquina, el órgano de fonación de un animal) que se propagan por un medio (gaseoso, líquido o sólido) desde un punto a otro en forma de ondas de energía elástica, las cuales son percibidas o detectadas por un determinado receptor (ej. una persona, un animal) (Roederer, 1997). Los sonidos son estudiados por una rama de la física denominada acústica. Las investigaciones en esta rama datan de la época de Pitágoras, avanzaron rápidamente durante los siglos XVI al XVIII vislumbrándose un aceleramiento aún mayor a partir del siglo XX gracias a las aplicaciones tecnológicas. En el ámbito de la acústica se realizan tanto mediciones como grabaciones. Las mediciones se realizan mediante la utilización de un instrumento (ej. sonómetro) que permite obtener una expresión de forma numérica de aquello que se quiere medir (ej. ruido), y el cual debe ser previamente calibrado para garantizar la confiabilidad de los resultados. Tanto en las mediciones como en las grabaciones de un sonido que se propaga por el aire se utiliza un micrófono (transductor), el cual consiste en un sensor que detecta cambios de la presión atmosférica en el tiempo. Respecto a las grabaciones, las mismas pueden ser analógicas, mediante el registro directo de la señal del micrófono en un medio de almacenamiento continuo (ej. cinta de cassette, disco de vinilo), o digitales, en las cuales se añade la digitalización de datos y presenta como ventaja la disponibilidad de la información para su procesamiento posterior. En términos generales, al realizar grabaciones con algún tipo de sistema, se deben evaluar las características del sonido a grabar, las posibles variaciones del sistema elegido y del lugar de grabación, la fidelidad de la grabación requerida y la 
necesidad de calibrar el sistema. Respecto al lugar de medición y/o grabación, se pueden utilizar ambientes interiores con condiciones controladas (o condiciones de laboratorio) o ambientes exteriores (naturales). En acústica, trabajar en condiciones controladas de laboratorio significa que se pueda garantizar un ruido de fondo (RF, señal no deseada) muy bajo y sin interferencia de ruidos ajenos a la medición/grabación. Ello requiere que las cámaras de ensayo o las mediciones/grabaciones posean un elevado aislamiento acústico respecto de su entorno, suficiente como para disminuir al máximo las otras señales ambientales que no resultan de interés (en adelante ruido). De este modo, aumenta la precisión de la medición o grabación. Sin embargo, a pesar de contar con estas instalaciones, cuando la señal que se desea medir (= sonido) es de niveles sonoros muy bajos, las mediciones y grabaciones no poseen una buena relación señal/ruido. Por lo tanto, resulta conveniente recurrir al empleo de procedimientos que permitan "limpiar" la señal mediante la disminución del ruido. La relación señal/ruido (RSR), se define como el cociente entre la potencia media de la señal $\left(P_{S}\right)$ y la potencia media del ruido de fondo $\left(P_{R F}\right), R S R=P_{S} / P_{R F}$, debiéndose medir estos niveles de potencia en el mismo ancho de banda de frecuencias. Tal relación, también puede expresarse en decibeles, $R S R(d B)=10$ $\log _{10}\left(P_{S} / P_{R F}\right)$. Tener una buena RSR significa que el sonido pueda ser claramente discriminado del RF del lugar en el que se está realizando la medición y/o grabación. La misma situación ocurre cuando se trabaja en condiciones exteriores donde, además, las condiciones ambientales cambian más rápidamente (en comparación con los tiempos de registro), dificultando la obtención de mediciones y/o grabaciones de similares características a distintos tiempos.

Dentro de la acústica existen varias ramas especializadas en un determinado objeto de estudio, entre ellas la psicoacústica, que estudia la relación entre la sensación percibida por un sonido determinado y los parámetros de éste; la arqueoacústica, que estudia los sonidos en sitios arqueológicos, y la bioacústica, que estudia la audición y los sonidos producidos por animales no humanos. En el presente capítulo, se detallan los estudios bioacústicos realizados hasta el momento dentro del grupo de los anfibios y se describen los estudios bioacústicos realizados en el marco de la tesis, enfatizando su particularidad.

\section{Bioacústica de anfibios}

La mayoría de los anfibios adultos son capaces de emitir sonidos dentro del intervalo de frecuencias audibles $(20 \mathrm{~Hz}$ a $20.000 \mathrm{~Hz}$ ) (Duellman y Trueb, 1994), y algunos otros dentro del ultrasonido (> $20.000 \mathrm{~Hz}$ ) (Feng y col., 2006). Particularmente, los anuros adultos

producen diversos tipos de señales acústicas, siendo las más descriptas en el ámbito científico las llamadas de anuncio (= advertencia) producidas por machos sexualmente activos, cuya función principal es atraer a las hembras (Duellman y Trueb, 1994). 
Considerando las especies de anfibios anuros de Argentina, las llamadas de anuncio por parte de machos adultos que se propagan por un medio gaseoso (atmósfera), han sido descriptas por distintos grupos de herpetólogos locales. Entre ellos, distintos grupos de investigación de Córdoba (Bionda y col., 2008; Lescano y col., 2011; Grenat y col., 2013; Valetti y col., 2013), Corrientes (Cajade y col., 2010; Cajade, 2012; Duré y col., 2014), Jujuy y Tucumán (Ferrari y Vaira, 2001; 2008; Vaira y col., 2011; Akmentins y col., 2015). Sin embargo, no todos los anuros adultos emiten sonidos en un medio gaseoso, sino que algunos utilizan el medio acuático, aunque tal condición no ha sido descripta para ninguna de las especies de Argentina (Yager, 1992; Kelley y Tobias, 1999; Ladich y Bass, 2003). Respecto a la emisión de sonidos por parte de hembras de anuros, si bien su registro no ha sido tan numeroso, se ha publicado para algunas especies la emisión de una llamada de reciprocidad (Duelman y Trueb, 1994), aunque ninguna de ellas se distribuye en Argentina (Roy y col., 1995; Tobias y col., 1998; Emerson y Boyd, 1999). Recién en el año 2014, desde el grupo de investigación del CIMA describimos sonidos emitidos por hembras de $C$. ornata siempre en respuesta a las llamadas de anuncio del macho y/o antes/durante el amplexo (Salgado Costa y col., 2014a; ver Anexo II). En relación con ambos sexos se han descripto llamadas agonísticas (= distress calls) en cualquier estadio postmetamórfico ante alguna perturbación (Duellman y Trueb, 1994; Toledo y Haddad, 2009).

Tales grabaciones de sonidos, producidos y transmitidos en un medio gaseoso, han sido realizadas mediante instrumental económicamente accesible y específicamente diseñado para las grabaciones en ese medio (ej. grabadora de cinta o grabadora digital más micrófono direccional). Además, teniendo en cuenta que la mayoría de los registros son realizados en ambientes exteriores (hábitat natural de la especie), se reportan junto con los parámetros del sonido aquellos correspondientes a las condiciones ambientales. Sin embargo, para realizar grabaciones en un medio acuático, se debe utilizar instrumental específicamente diseñado para tal fin (con un hidrófono como transductor), siendo su costo muy elevado. Quizás sea ésta la razón principal por la cual en el ámbito científico no hay cuantiosos registros acerca de la emisión de sonidos por parte de anfibios en un medio acuático, siempre en comparación con la cantidad de publicaciones existentes acerca de la emisión de sonidos en un medio gaseoso.

\section{Producción de sonidos por parte de anfibios en estadios larvales}

A diferencia del grado de avance alcanzado en la bioacústica de anuros adultos, las investigaciones acerca de la producción de sonidos por parte de sus larvas son escasas. Teniendo en cuenta que las larvas de los anfibios tienen un hábito de vida acuático, nuevamente quizás sea ésta la razón principal por la cual se describió la emisión de sonidos subacuáticos por larvas de anuros recién en el año 2011. En tal publicación, se documentó 
por primera vez la producción de sonidos subacuáticos audibles por larvas de Ceratophrys ornata, cuya emisión establecería un modo de comunicación y reconocimiento intraespecífico para larvas de esta especie (Natale y col., 2011). Tal hallazgo tuvo gran repercusión en el ámbito científico y fue considerado significativo para diversas disciplinas biológicas como la ecología, etología y bioacústica (BBC, 2010). Para el comienzo del presente trabajo de tesis, solo se había descripto la emisión de sonidos larvales de dos especies de anuros, la ya citada especie perteneciente a la familia Ceratophryidae (Natale $y$ col., 2011) y otra perteneciente a la familia Mantellidae, Gephyromantis azzurrae (Reeve y col., 2011). En ambos casos, los sonidos fueron asociados con el hábito macrofágico y carnívoro de cada especie. Particularmente, el trabajo de Natale y col. (2011), al ser un trabajo novedoso, solo se centró en comunicar el hallazgo de la emisión de sonidos y especular sobre el posible contexto de emisión. Consecuentemente, no se profundizó en el estudio de la variabilidad del sonido a lo largo del desarrollo larval. En dicho trabajo, las grabaciones fueron realizadas con un micrófono direccional marca Audio-Technica ${ }^{\circledR}$ modelo ATR55 cubierto con una membrana de látex para poder sumergirlo, el cual fue conectado a una placa de audio Behringer ${ }^{\circledR}$ Eurorack MX1602 y ésta a una computadora portátil. Con tal sistema de grabación, si bien se logró registrar el sonido no se pudieron obtener grabaciones de alta fidelidad y con una buena RSR a lo largo de todo el desarrollo larval. En tal sentido, durante el desarrollo del presente trabajo de tesis se investigó acerca de las diferentes técnicas e instrumentos disponibles para realizar grabaciones en un medio acuático. Sin embargo, dado el alto costo de los hidrófonos se debieron desarrollar técnicas que permitieran obtener grabaciones de alta fidelidad pero con instrumental no diseñado para tal fin. En el presente capítulo se describen varios cambios realizados en el sistema de grabación originalmente utilizado por Natale y col. (2011). Asimismo, se midieron parámetros acústicos de los sonidos en una cámara anecoica mediante un instrumento calibrado con una fuente acústica de referencia. Más allá de las hipótesis concernientes al contexto de emisión de tales sonidos, las cuales son abordadas en el capítulo 3, se describe en este capítulo la técnica de calibración del sistema de grabación empleado y los métodos de medición y grabación de sonidos tanto de larvas de $C$. ornata como de otras especies filogenéticamente cercanas (C. cranwelli, C. aurita y Lepidobatrachus llanensis). Específicamente, para la especie $C$. ornata se describen y analizan sonidos larvales a lo largo de todo el desarrollo y se comparan con los sonidos producidos en etapa juvenil y adulta bajo el mismo contexto de emisión.

\section{Hipótesis}

* Las larvas de C. ornata emiten sonidos durante toda la etapa de desarrollo larval, desde el STD 25 hasta completar la metamorfosis (STD 46). 
* Las variables bioacústicas de los sonidos emitidos por larvas de C. ornata en los distintos estadios larvales se correlacionan entre sí y con variables estimadoras del crecimiento (Peso, LHC) y desarrollo (STD).

* Los sonidos emitidos por larvas de C. ornata a lo largo del desarrollo larval son los mismos sonidos que aquellos emitidos por individuos juveniles y adultos al ser molestados (tocados con una pipeta).

* Las larvas de otras especies filogenéticamente cercanas a C. ornata y con similar hábito de vida también emiten sonidos en estadios larvales.

\section{Objetivos}

* Evaluar la variabilidad y precisión del sistema de grabación del CIMA, el cual fue adquirido teniendo en cuenta los métodos de grabación más utilizados en bioacústica de anfibios. Optimizar la fidelidad de las grabaciones realizadas con este sistema, a través de la mejora de la RSR.

* Estudiar, describir y analizar los sonidos emitidos por larvas de C. ornata en dos medios diferentes (acuático y aéreo) a lo largo del desarrollo larval y hasta el final de la metamorfosis, mediante equipos de grabación (variables bioacústicas) y medición (variables acústicas) calibrados con fuente acústica de referencia.

* Conocer la similitud y correlación de los parámetros bioacústicos/acústicos de sonidos grabados en el medio acuático y aéreo entre sí y con variables estimadoras del crecimiento (Peso, LHC) y desarrollo (STD).

* Comparar el sonido emitido por larvas de C. ornata con aquellos emitidos por juveniles y adultos de la misma especie y bajo el mismo contexto de emisión.

* Explorar la emisión de sonidos en estadios larvales en otras especies de anfibios anuros filogenéticamente cercanas a $C$. ornata.

\section{MATERIALES Y MÉTODOS}

\section{Calibración y evaluación del sistema de grabación}

Teniendo en cuenta los métodos de grabación disponibles en el área de la bioacústica de anfibios, se investigó la forma adecuada de registro de sonidos tanto en un medio acuático (AC) como aéreo (AE) y de análisis de los mismos, mediante la consulta a ingenieros electrónicos del Laboratorio de Acústica y Luminotecnia (LAL) de la Comisión de Investigaciones Científicas (CIC) de la provincia de Buenos Aires. Con la ayuda de este 
grupo, se evaluó la respuesta en frecuencias y en niveles del sistema de grabación del CIMA, compuesto por un micrófono marca $C A D^{\circledR}$ modelo e70 con cápsula cardioide con atenuación de $-10 \mathrm{~dB}$, una placa de adquisición de audio marca Native Instruments ${ }^{\circledR}$ modelo Guitar Rig Session I/O, y una computadora portátil con software de medición SpectraPLUS ${ }^{\circledR}$ 5.0. Este sistema de grabación fue colocado en la cámara anecoica del LAL-CIC (diseñada para absorber en su totalidad y en cualquiera de sus superficies las reflexiones producidas por ondas acústicas), junto a un sistema de medición perteneciente al propio laboratorio, compuesto por un Sonómetro marca Bruel \& $\mathrm{Kjaer}^{\circledR}$ modelo 2250, una placa de adquisición de audio marca M-Audio ${ }^{\circledR}$ modelo Audiophile USB, una PC genérica con software de medición SpectraPLUS ${ }^{\circledR} 5.0$ y un parlante de dos vías con sus transductores dispuestos axialmente (fuente emisora de sonido). Ambos sistemas (CIMA y LAL-CIC) fueron calibrados dentro de la cámara anecoica. La calibración consistió en generar un tono sinusoidal puro de $1000 \mathrm{~Hz}$ mediante el software SpectraPLUS ${ }^{\circledR}$ y observar el nivel de presión sonora (NPS) medido por el sonómetro, el cual fue considerado como instrumento patrón (por su precisión y trazabilidad a patrones nacionales e internacionales). El tono emitido fue registrado por el sistema de medición del LAL-CIC durante 1 segundo aproximadamente y el valor numérico de NPS obtenido se introdujo como parámetro de calibración en el software Spectra PLUS ${ }^{\circledR}$. De esta manera, el software registra una señal (con su NPS correspondiente) que emplea como referencia para efectuar las mediciones posteriores.

Una vez calibrados ambos sistemas se procedió a evaluar la respuesta del sistema de grabación CIMA. Para ello, los micrófonos de ambos sistemas (CIMA y LAL-CIC) fueron ubicados a una distancia de $1 \mathrm{~cm}$ entre sí y direccionados hacia la fuente emisora, la cual fue ubicada a distintas distancias $(15 \mathrm{~cm}, 30$ y $60 \mathrm{~cm}$ ) (Fig. 10). Desde esa fuente se emitieron varias señales (tonos puros) generadas con el software SpectraPLUS ${ }^{\circledR}$ con determinada frecuencia y NPS conocidas, las cuales fueron captadas al mismo tiempo por ambos sistemas. Luego, se evaluaron las diferencias en la respuesta en frecuencias del sistema CIMA con respecto al patrón (sonómetro del LAL-CIC), lo cual permitió construir las curvas de compensación para corregir los errores de linealidad del sistema. Tales curvas fueron cargadas en el software SpectraPLUS ${ }^{\circledR}$ del sistema CIMA y se realizó luego una nueva medición para re-evaluar la respuesta de tal sistema de grabación. 

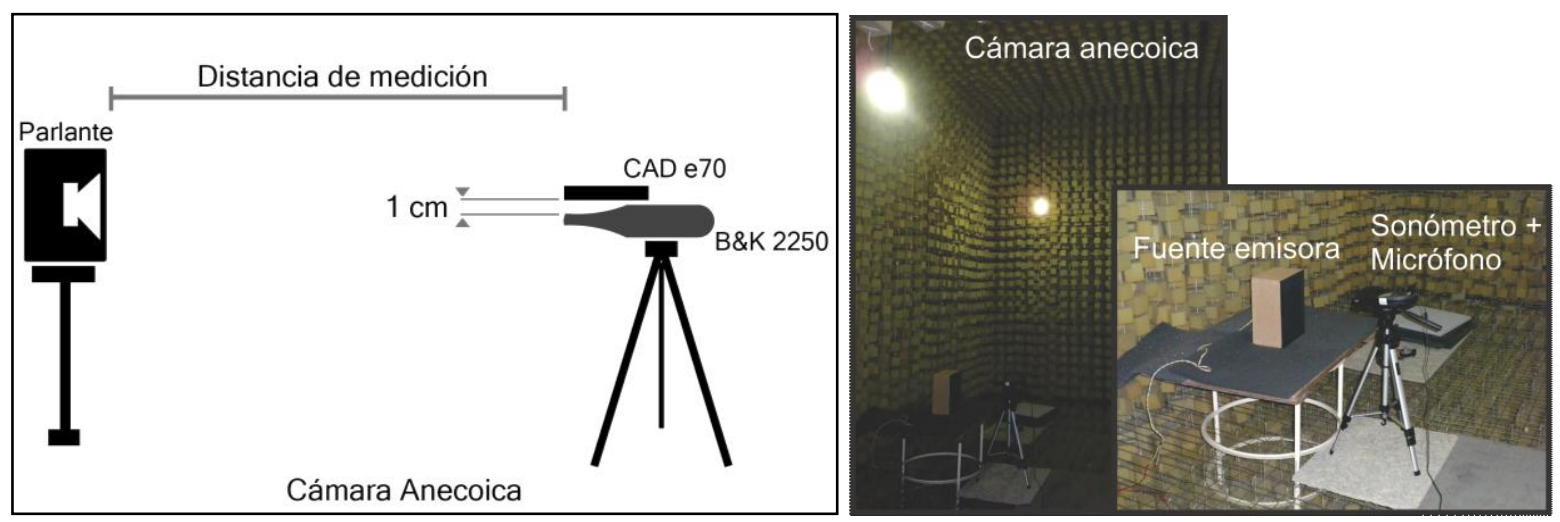

Figura 10. Metodología utilizada para evaluar la respuesta del sistema de grabación (micrófono), mediante la emisión de tonos puros desde una fuente (parlante) y su captación simultánea por un micrófono (CAD e70) y un sonómetro (B\&K 2250) ubicados a una distancia de $1 \mathrm{~cm}$ entre sí dentro de una cámara anecoica. Se muestra un esquema representativo y una fotografía de la situación descripta

Con el objetivo de determinar y cuantificar la diferencia en la respuesta en frecuencia del micrófono CAD e70 cuando es cubierto con una membrana de látex (para poder grabar sonidos en un medio $A C$ ), se emitieron tonos centrados en filtros de 1/3 de octava cubriendo el ancho de banda de interés $(80 \mathrm{~Hz}$ a $10.000 \mathrm{~Hz}$ ) mediante un parlante de dos vías con sus transductores dispuestos axialmente (fuente emisora de sonido). En la emisión sucesiva de los tonos se registró el NPS instantáneo del software SpectraPLUS ${ }^{\circledR} 5.0$ para determinar la respuesta en frecuencia de toda la cadena de medición (micrófono + placa de audio + computadora portátil). Este procedimiento se efectuó tanto para el micrófono descubierto como cubierto con membrana de látex. El procedimiento detallado se realizó para tres muestras de membrana de látex de distinta marca.

\section{Método de mejoramiento de la relación señal-ruido}

Todas las mediciones y grabaciones fueron realizadas en condiciones controladas de laboratorio, es decir en cámaras de ensayo con un elevado aislamiento acústico respecto de su entorno y con bajos tiempos de reverberación (reflexiones de sonido minimizadas). Sin embargo, dado que los sonidos a medir y registrar poseen niveles sonoros muy bajos, se recurrió al empleo de procedimientos de post-procesado para disminuir el RF. Con la ayuda de los ingenieros del LAL-CIC, se utilizó un método para mejorar la RSR de todas las mediciones y grabaciones de sonidos realizadas. El mismo consistió en comparar el espectro de niveles sonoros equivalentes $\left(L Z_{\text {eq }}\right)$ y de niveles sonoros máximos $\left(L Z_{\max }\right)$ del sonido emitido por una larva con el $L Z_{\text {eq }} y L Z_{\text {max }}$ del $R F$ de la cámara anecoica. $A$ partir de estas comparaciones, se pudieron visualizar claramente las componentes del ruido que se 
elevan cuando una larva o juvenil emite un sonido. Es decir, se procedió a eliminar las frecuencias en las que se observaron componentes con niveles sonoros predominantes que no dependían del sonido del individuo sino que formaban parte del RF.

Por último, con el propósito de cuantificar la mejora se evaluó la potencia acústica involucrada en la señal (cantidad de energía por unidad de tiempo) comparándola con la potencia acústica del RF. Esta comparación se realizó antes y después de eliminar las componentes de baja frecuencia (= filtrar) propias del RF, es decir antes y después del proceso de filtrado de los sonidos. Considerando que las frecuencias en las cuales se elevan los niveles sonoros durante la emisión de un sonido larval son superiores a $2.500 \mathrm{~Hz}$, se procedió a eliminar las componentes del espectro por debajo de $1.000 \mathrm{~Hz}$ (para garantizar que no se pierda información). Para ello se calculó la potencia acústica involucrada de la señal sin filtrar, la señal filtrada y del RF de niveles sonoros equivalentes $\left(P_{\text {eq }}\right)$ mediante la siguiente fórmula: $\left.P_{e q}=\sum_{1}^{33} 10^{(L / 10}\right)$, siendo $L$ el nivel sonoro equivalente medido para cada una de las 33 bandas de tercios de octava con frecuencias centrales comprendidas entre $12,5 \mathrm{~Hz}$ y $20.000 \mathrm{~Hz}$. Luego, se calculó la RSR mediante la siguiente fórmula: $R S R=10 \log P_{\text {eqseñal }} / P_{\text {eqRF }}$. El mismo procedimiento fue aplicado para los espectros sin filtrar y filtrados de niveles sonoros máximos.

\section{Registro y análisis de sonidos emitidos en un medio acuático y un medio aéreo por individuos de C. ornata}

Con el asesoramiento de los ingenieros del LAL-CIC, mediante la colocación de placas fonoabsorbentes marca FONAC ${ }^{\circledR}$ sobre las superficies interiores, se acondicionó un aula del CIMA para ser utilizada como sala de grabación. Tales placas redujeron las reflexiones de sonidos y junto con la ubicación de la sala, contribuyeron a la obtención de un RF de niveles muy bajos (Fig. 11). El mismo procedimiento de calibrado y compensado del sistema de grabación realizado en la cámara anecoica del LAL-CIC fue también realizado en el cuarto de grabación del CIMA, el cual intenta asemejar las condiciones de la cámara anecoica del LAL-CIC. Las grabaciones de sonidos fueron realizadas tanto en el medio AC como AE, con la finalidad de determinar las características y variaciones del sonido en los distintos medios. Para las grabaciones realizadas en un medio $A C$ el micrófono fue cubierto con una membrana de látex. Se seleccionaron cuatro estadios del desarrollo (STD) representativos de la fase de vida acuática $(25,31,37$ y 41), morfológicamente diferentes, fácilmente diferenciables y con sonidos claros y audibles. EI STD 25 (LHC: 6,586 \pm 0,776 mm; peso: $0,069 \pm 0,011 \mathrm{~g}$ ) fue seleccionado por ser el primero de vida libre con branquias internas y con la morfología larval completa, y por ser el primer estadio en el cual se registra la producción de sonidos coincidente con la apertura y formación completa de la boca. EI STD 
31 fue seleccionado por ser intermedio y estar caracterizado por larvas de mayor tamaño (LHC: $13,748 \pm 1,063 \mathrm{~mm}$; peso: 0,413 $\pm 0,104 \mathrm{~g}$ ), con las extremidades posteriores en crecimiento y en forma de pala. EI STD 37 fue seleccionado por estar caracterizado por larvas de gran tamaño (LHC: 21,430 $\pm 2,054 \mathrm{~mm}$; peso: 1,538 $\pm 0,375 \mathrm{~g}$ ) con los cinco dedos de las extremidades posteriores separados, y por tener todas las características larvales ya desarrolladas antes del comienzo de la metamorfosis. El STD 41 (LHC: 24,591 \pm $2,564 \mathrm{~mm}$; peso: $2,570 \pm 0,723 \mathrm{~g}$ ) fue seleccionado por ser uno de los últimos estadios en los cuales se constató la emisión de sonidos antes de la culminación del proceso metamórfico (Duellman y Trueb, 1994). Si bien se registraron sonidos sistemáticamente en los cuatro STD antes mencionados, la producción de sonidos fue corroborada y registrada desde el STD 25 hasta el 46 (fin del proceso metamórfico). Todas las grabaciones se realizaron en el cuarto acondicionado acústicamente del CIMA.

Las larvas fueron obtenidas producto de las inducciones realizadas en el año 2012 y 2013 (ver Cap. 1). Los sonidos fueron registrados con el sistema antes descripto, calibrado y compensado a $15 \mathrm{~cm}$ de la fuente de emisión, a una velocidad de muestreo de $44.100 \mathrm{~Hz}$ y una resolución de 16 bits. Se realizaron búsquedas de bibliografía actualizada y consultas con expertos en el tema acerca de las variables más relevantes a analizar y la forma de análisis de las mismas. Se realizó un análisis del oscilograma (duración del sonido en segundos / amplitud en pascales) y sonograma (duración del sonido / frecuencia en Hertz) de cada sonido obtenido mediante el programa Adobe Audition ${ }^{\circledR} 1.5$ (Adobe Systems Inc.), midiendo de forma manual diferentes variables bioacústicas (Fig. 12), entre ellas duración del sonido (Ds), expresada en segundos (s), número de pulsos (Np), número de interpulsos (Nip) y frecuencia dominante $(\mathrm{Fd})$ expresada en Hertz $(\mathrm{Hz})$. Las variables discretas Np y Nip fueron transformadas a variables continuas mediante el logaritmo natural de cada valor más uno (Ln $X+1)$. Cabe aclarar que el análisis del oscilograma se utilizó como complemento del análisis del sonograma para la medición manual de variables, dado que no corresponde la utilización de éste por no haberse medido el NPS (dB) mediante un sonómetro. Éste instrumento solo se utilizó para calibrar el sistema de grabación y realizar algunas mediciones de NPS $(\mathrm{dB})$ de sonidos producidos por larvas y juveniles de $C$. ornata en un medio AE (ver más adelante). La terminología utilizada se corresponde con aquella de Duellman y Trueb (1994). Las grabaciones en un medio AC fueron realizadas en diferentes

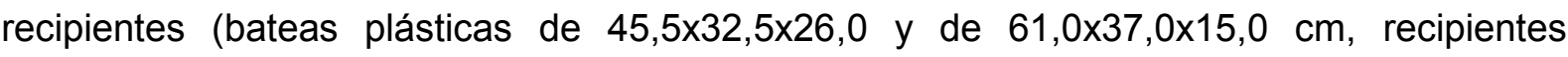
redondos de polipropileno de 9,5×9,5×15,0 y en diferentes densidades (2, 3, 5 y 10 larvas/L), aunque siempre respetando la densidad máxima de 10 larvas/L, la distancia vertical del micrófono a la fuente emisora $(15 \mathrm{~cm})$ y una temperatura del agua promedio de $20^{\circ} \mathrm{C}$. Las grabaciones en el medio AC fueron realizadas colocando a cada larva sobre una red a 15 $\mathrm{cm}$ de distancia vertical del micrófono y con una temperatura ambiente promedio de $20^{\circ} \mathrm{C}$. 
Cada sonido individual fue recortado de su archivo original y guardado. El objetivo final fue obtener 100 sonidos por STD y contexto (medio AC y AE). Los sonidos utilizados para caracterizar cada STD corresponden a diferentes larvas. Cada larva fue medida mediante imagen digital utilizando el programa Image $J^{\circledR}$ (longitud hocico-cloaca, en $\mathrm{mm}$ ) y pesada en balanza digital de $0,001 \mathrm{~g}$ de precisión. Tanto las medidas morfométricas (=variables) como los datos del desarrollo (STD) se emplearon para evaluar la correlación con las variables acústicas y bioacústicas.

Por último, se realizaron grabaciones del sonido emitido por individuos juveniles y adultos de $C$. ornata al ser molestados (tocados con una pipeta plástica), con el objetivo de comparar los sonidos emitidos por esta especie desde larva hasta adulto bajo el mismo contexto de emisión. El método de grabación se corresponde con el detallado para grabaciones de larvas en el medio AE.

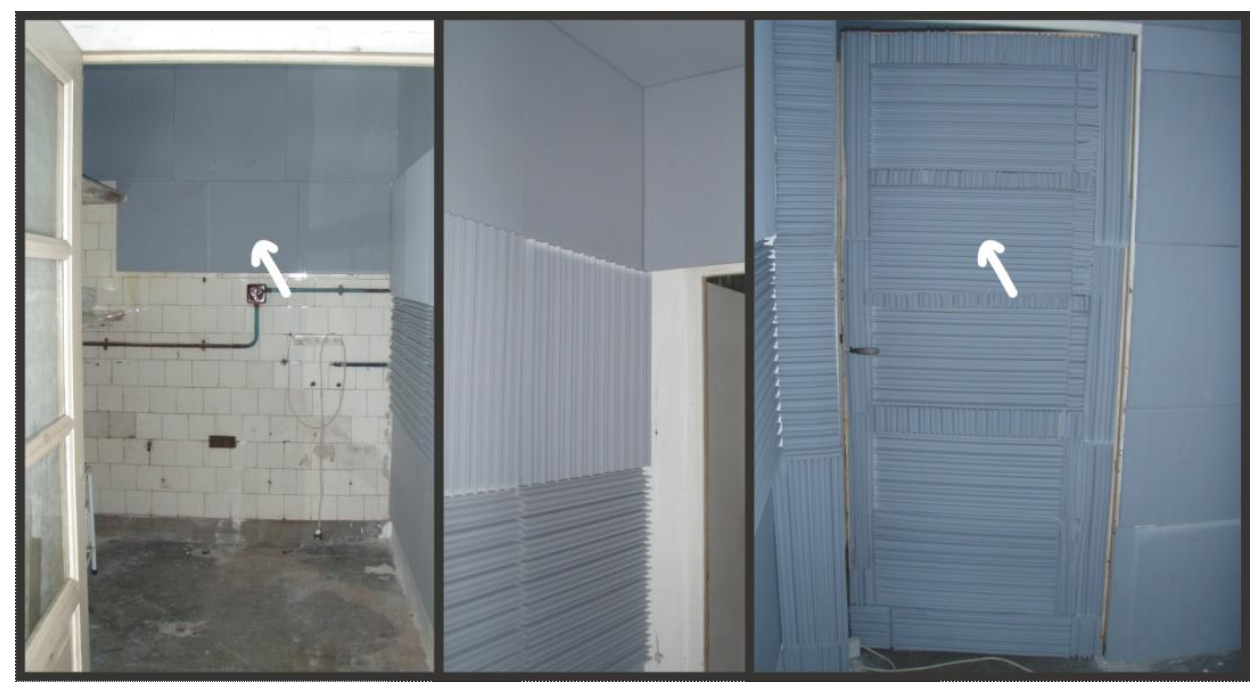

Figura 11. Adecuación de un cuarto mediante paneles fonoabsorbentes (se indican algunos paneles con flechas) para la grabación de sonidos con bajos niveles de ruido de fondo, asemejando las condiciones a las de una cámara anecoica

\section{Medición de sonidos en el medio aéreo emitidos por individuos de C. ornata}

Además de las grabaciones realizadas en un medio $A C$ y $A E$ en la cámara acústica del CIMA, se realizaron mediciones del sonido emitido en el medio AE por larvas de STD 31 al 37 y juveniles (STD 46) de C. ornata en la cámara anecoica del LAL-CIC. Para ello, se midió el sonido emitido por diferentes organismos de manera individual, los cuales fueron colocados sobre una red. Las mediciones fueron realizadas con el sonómetro B\&K colocado a $15 \mathrm{~cm}$ de la fuente de emisión y a una temperatura ambiente promedio de $20^{\circ} \mathrm{C}$. Tal instrumento permitió obtener diferentes variables acústicas para cada individuo medido. Simultaneamente, se realizaron grabaciones con el sistema del CIMA antes detallado (Fig. 13). 


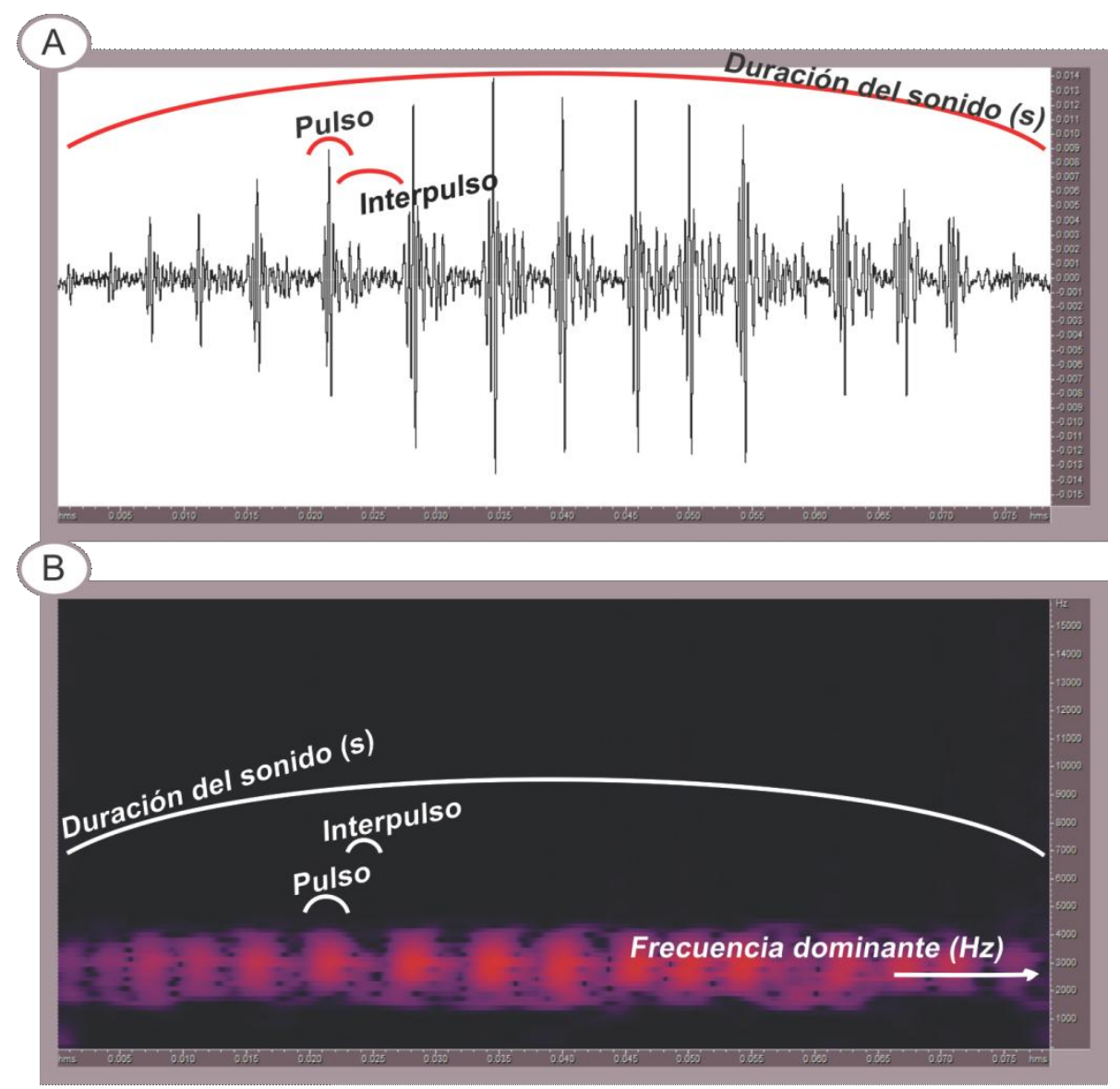

Figura 12. Método de medición de forma manual de cada variable bioacústica a partir del (A) oscilograma (duración del sonido en segundos, s / amplitud en pascales) y (B) sonograma (duración del sonido, s / frecuencia en Hertz, $\mathrm{Hz}$ ) de cada sonido. Nótese la correspondencia exacta entre las variables medidas en el oscilograma y el sonograma

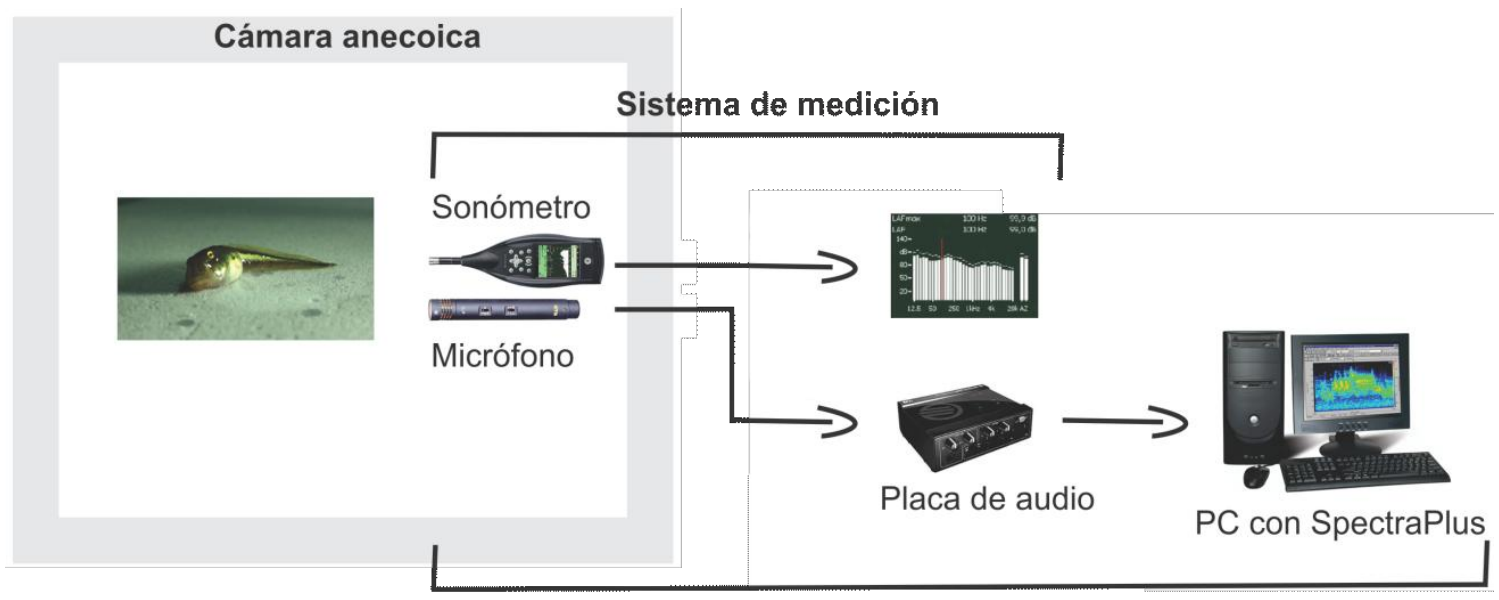

Sistema de grabación

Figura 13. Método de grabación y medición de sonidos producidos por larvas y juveniles de $C$. ornata en el medio aéreo en una cámara anecoica del Laboratorio de Acústica y Luminotecnia. SpectraPlus: software de grabación de sonidos con curva de calibración cargada 


\section{Registro y análisis de sonidos emitidos por otras larvas de anuros autóctonos}

Con el objetivo de comprobar la emisión de sonidos por parte de larvas de otras especies de anuros de la Región Pampeana, especialmente de aquellas filogenéticamente cercanas a C. ornata, se realizaron grabaciones en un medio AC en las mismas condiciones antes detalladas para $C$. ornata. Las especies grabadas fueron las siguientes: C. cranwelli, $C$. aurita, Lepidobatrachus llanensis, Odontophrynus americanus, Hypsiboas pulchellus, Pseudis minuta, Leptodactylus latrans, Rhinella fernandezae y Rhinella arenarum.

\section{Análisis estadístico}

Para demostrar que el recorte realizado para mejorar la RSR no influye en el posterior análisis de los sonidos, es decir que no se pierde información, se realizó una prueba de $t$ pareada entre distintas variables bioacústicas (Ds, Np, Nip y Fd) de sonidos producidos por larvas en STD 31, tanto en el medio AC como AE, recortados por debajo de los $1.000 \mathrm{~Hz}$ y sin recortar. Se realizó el mismo análisis pero entre las variables de sonidos recortados por debajo de $3.000 \mathrm{~Hz}$ y sin recortar. Con el objetivo de determinar y cuantificar la diferencia en la respuesta en frecuencia del micrófono utilizado cuando es cubierto por una membrana de látex, se realizó una ANOVA de una vía entre el NPS $(\mathrm{dB})$ de sonidos medidos con el micrófono cubierto con diferentes membranas de látex y sin cubrir.

Luego de obtener 100 sonidos de C. ornata de cada STD y contexto de emisión (medio $A C$ y $A E)$, se seleccionaron los valores atípicos teniendo en cuenta el primer y tercer cuartil, eliminando aquellos valores menores al valor de $Q_{25 \%}$ - 1,5 y mayores al valor de $Q_{75 \%}+1,5$ (Alperin, 2013). Esto mismo fue corroborado mediante un análisis de componentes principales realizado para cada STD con todas las variables bioacústicas seleccionadas (Ds, $\mathrm{Np}$, Nip, Fd). Se eliminaron las variables que cayeron por fuera del $\pm 2,5$ del factor 2 . El factor 1 fue considerado en toda su extensión por ser el factor con mayor contribución a la variabilidad de los datos. Todos los parámetros bioacústicos de los sonidos producidos por C. ornata fueron descriptos mediante medidas de resumen de posición \pm el nivel de confianza al 95\%. Para evaluar el tipo de correlación entre las distintas variables bioacústicas medidas y el peso/STD se realizó un análisis de correlación lineal. Se compararon las mismas variables bioacústicas de sonidos producidos en un medio AC con aquellos producidos en el medio AE por las mismas larvas, en diferentes STD. Para la realización de este análisis todas las variables bioacústicas fueron estandarizadas por el peso de cada larva. Además, los sonidos producidos por larvas, juveniles y adultos de $C$. ornata fueron analizados mediante estadística descriptiva y mediante un análisis de correlación lineal. Por último, se realizó una prueba de $t$ de diferencia entre medias entre las distintas variables bioacústicas de los sonidos producidos por individuos adultos machos y hembras al ser molestados tocándolos con una pipeta plástica.. 
Las variables correspondientes a los sonidos producidos por larvas de otras especies de la familia Ceratophryidae fueron también descriptas mediante medidas de resumen de posición \pm el nivel de confianza al 95\%. Para demostrar que las larvas de L. llanensis no producen sonidos dentro del rango de frecuencias evaluado, se realizó un ANOVA entre el NPS promedio de 10 sonidos grabados durante interacciones intraespecíficas entre larvas de L. Ilanensis en tres STD $(25,28$ y 37$)$ y aquellos producidos antes de la interacción, usando 20 bandas de frecuencia de $1,000 \mathrm{~Hz}$ cada una.

Para la realización de todas las pruebas estadísticas se utilizó el programa Statistica 7.0 $\left(\right.$ Statsoft ${ }^{\circledR}$ ) y se eligió un nivel de significancia de 0,05 . Además, todas las pruebas realizadas cumplen con sus respectivos supuestos (Zar, 2010).

\section{RESULTADOS}

\section{Compensación del sistema de grabación y mejoramiento de la relación señal-ruido}

Las curvas de compensación construidas permitieron que el sistema CIMA se comporte linealmente mientras no se altere la distancia de calibrado y compensado (15 cm) (Fig. 14). Además, se verificó que el sistema posee portabilidad con respecto a sus mediciones, pudiendo en el LAL-CIC post-procesarse y analizarse los datos adquiridos por el sistema CIMA de manera independiente.

Los espectros de los $L Z_{\text {eq }}$ y $L Z_{\max }$ de una determinada larva y del $R F$ de la cámara, los cuales fueron medidos linealmente (con ponderación $Z$ en frecuencias), se muestran en la fig. 15. Si bien se evaluó la respuesta en frecuencia del micrófono desde los $12,5 \mathrm{~Hz}$ hasta las $20 \mathrm{kHz}$, en la figura se muestra el rango $80-10.000 \mathrm{~Hz}$ ya que la respuesta en frecuencia del micrófono es más lineal (plana) en ese rango. Para el caso mostrado, las componentes que se elevan en ambos espectros son las superiores a $2.500 \mathrm{~Hz}$ en todas las mediciones realizadas. Es decir, para ambas variables ( $L Z_{\text {eq }} y\left(L Z_{\text {max }}\right)$ hay componentes en las bajas frecuencias que poseen niveles sonoros predominantes no dependientes del sonido de la larva sino que forman parte del RF. Por comparación del ruido medido durante la emisión de sonidos con el RF medido en la misma cámara, las componentes que están por debajo de 1.000 Hz fueron eliminadas sin pérdida de información, mejorando la calidad de la grabación. La cuantificación de dicha mejora se resume en la tabla 4, mediante el cálculo de la potencia sonora involucrada en la señal y el RF tanto del espectro de $L Z_{\text {eq }}$ como del espectro de $L Z_{\max }$, ambos sin filtrar y filtrados. La prueba de $t$ pareada entre distintas variables bioacústicas de sonidos producidos por larvas de $C$. ornata tanto en un medio $A C$ como AE en STD 31, para sonidos recortados y no recortados por debajo de $1.000 \mathrm{~Hz}$, demuestra que no se pierde información con el recorte (se obtienen los mismos valores de 
Ds, Np, Nip y Fd para los sonidos grabados tanto en un medio AC como AE, recortados y sin recortar por debajo de $1.000 \mathrm{~Hz}$, por lo tanto $\mathrm{p}=1$ ). Por el contrario, el mismo análisis pero recortando los sonidos por debajo de $3.000 \mathrm{~Hz}$ demuestra que se pierde información de la Fd (Fd-AC: $t=-4,736$, g.I $=9, p=0,001$; Fd-AE: $t=-2,861$, g.I. $=9, p=0,019)$. En la fig. 16, se muestran los espectros de los $L Z_{\text {eq }} y L Z_{\max }$ para el STD juvenil. Al igual que para la figura anterior, si bien se evaluó la respuesta en frecuencia del micrófono desde los $12,5 \mathrm{~Hz}$ hasta las $20 \mathrm{kHz}$, en esta figura se muestra el rango $80-10.000 \mathrm{~Hz}$ ya que la respuesta en frecuencia del micrófono es más lineal (plana) en ese rango. Para este STD, las componentes que se elevan en ambos espectros son las superiores a $500 \mathrm{~Hz}$ en todas las mediciones realizadas. Por último, el ANOVA realizado entre el NPS (dB) de sonidos medidos con el micrófono cubierto con diferentes membranas de látex y sin cubrir no arrojó diferencias significativas entre las distintas mediciones $(F(3,116)=0,300, p=0,825)$ (Fig. 17). Cabe aclarar, que para las grabaciones de sonidos realizadas en un medio AC se utilizó siempre una membrana de la misma marca $\left(\mathrm{M} 2=\right.$ Prime $\left.^{\circledR}\right)$.

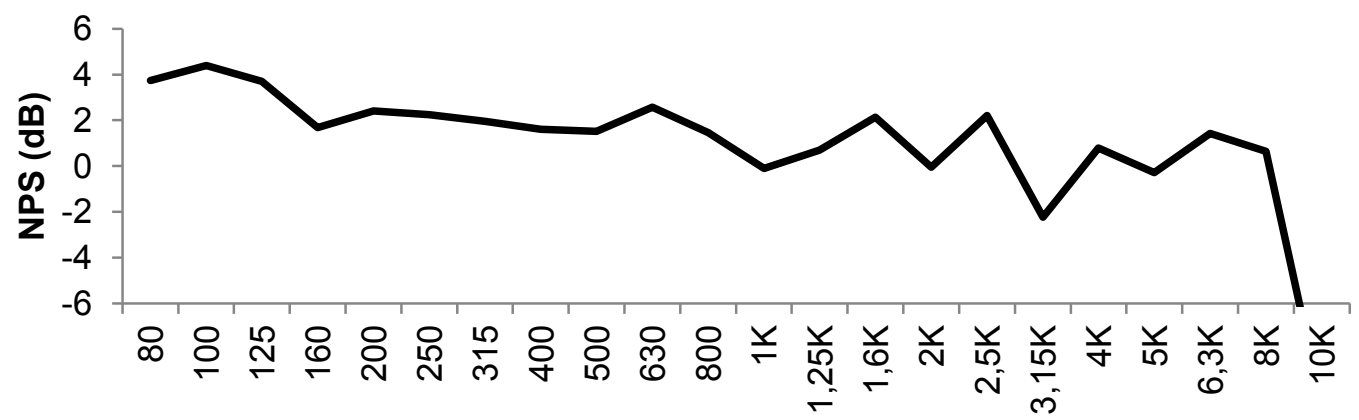

Frecuencias $(\mathrm{Hz})$

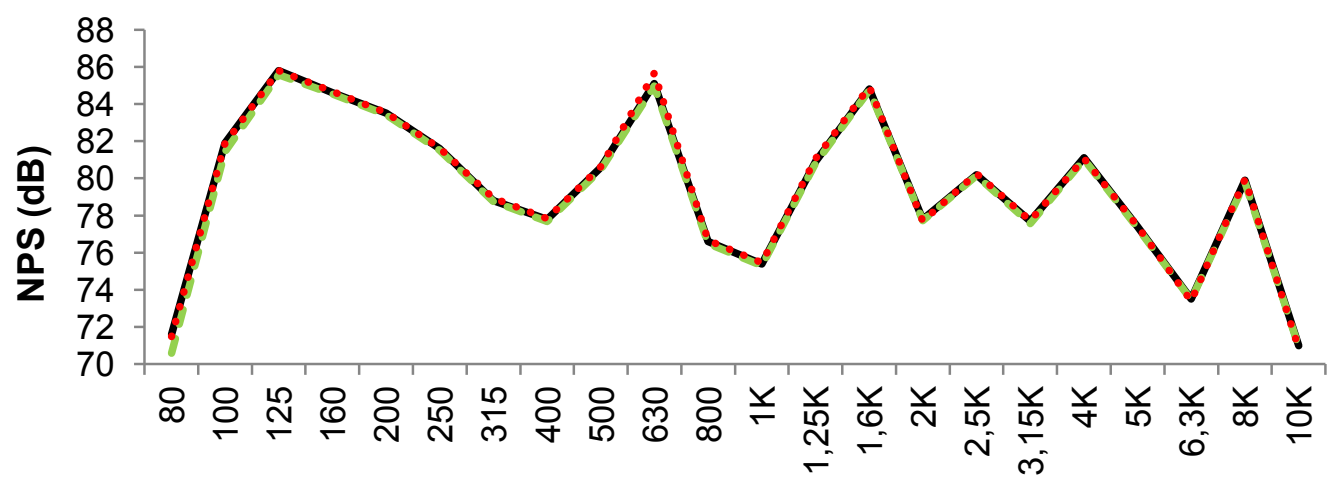

Frecuencias $(\mathrm{Hz})$

Figura 14. Parte superior: Curva de compensación construida a partir de la diferente respuesta en frecuencias del sistema CIMA respecto al sonómetro (línea negra). Parte inferior: Registro realizado con la curva de compensación cargada en el software comparando la respuesta del sistema CIMA (línea roja), con aquella del sistema LAL (línea verde) y el sistema patrón (línea negra). K: kilo; Hz: Hertz; NPS: nivel de presión sonora en dB (decibeles) 


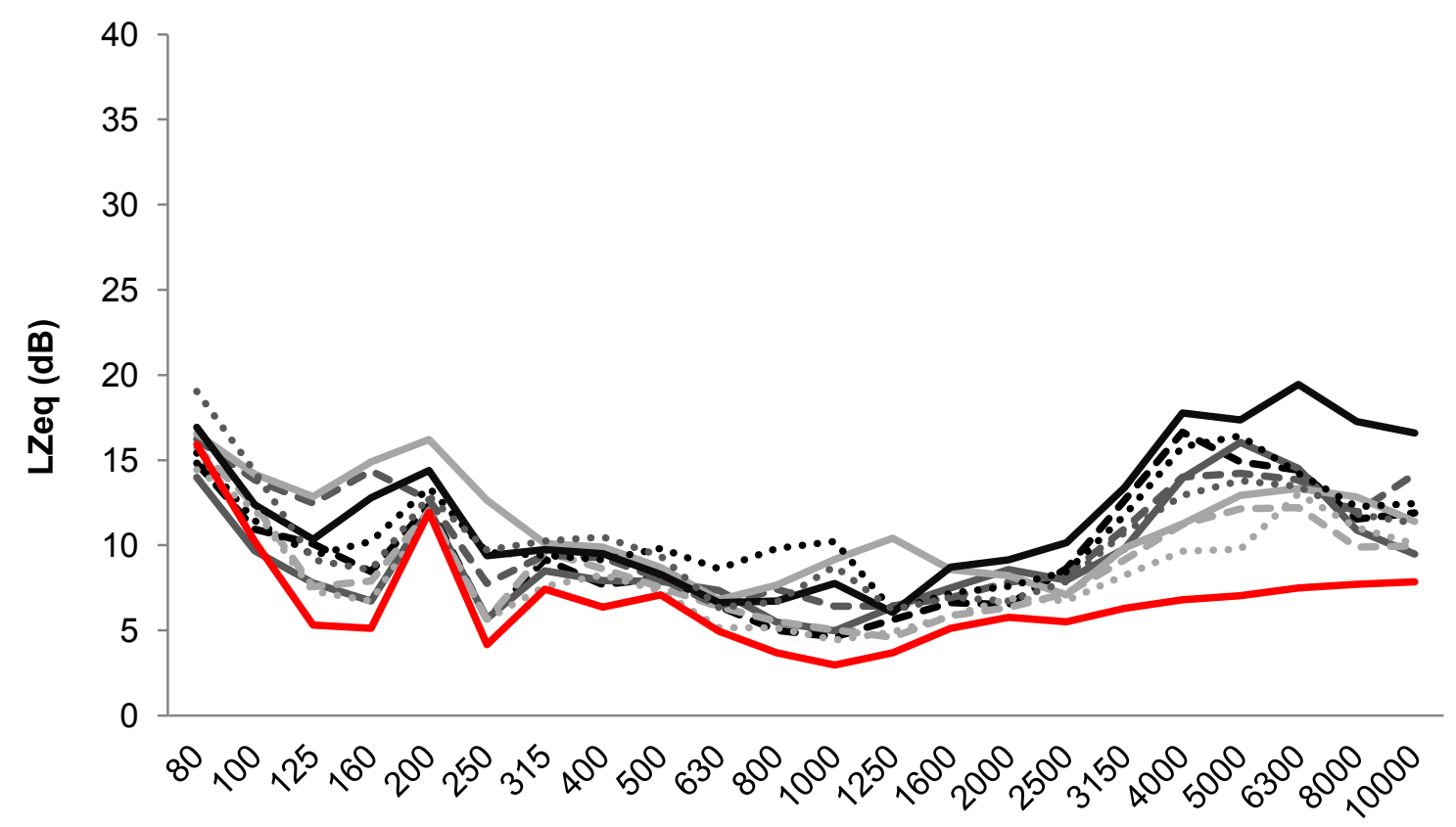

Frecuencias $(\mathrm{Hz})$

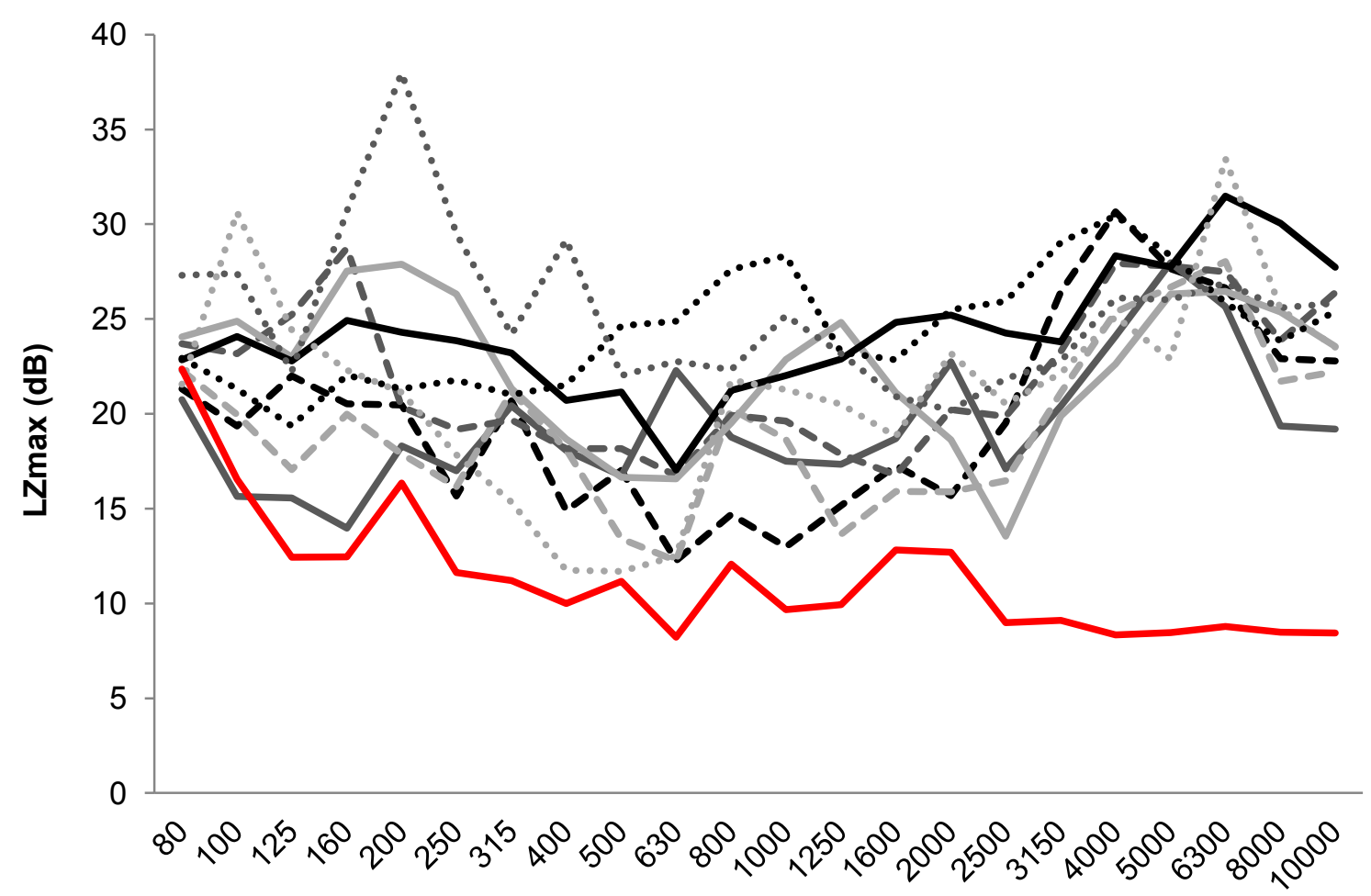

Frecuencia $(\mathrm{Hz})$

Figura 15. Espectro de los niveles sonoros de diferentes larvas en estadio 31 (líneas negras y grises) y del ruido de fondo de la cámara anecoica (línea roja). Parte superior: niveles sonoros equivalentes $\left(L Z_{\text {eq }}\right)$ en decibeles $(d B)$. Parte inferior: niveles sonoros máximos $\left(L Z_{\max } d B\right)$ 


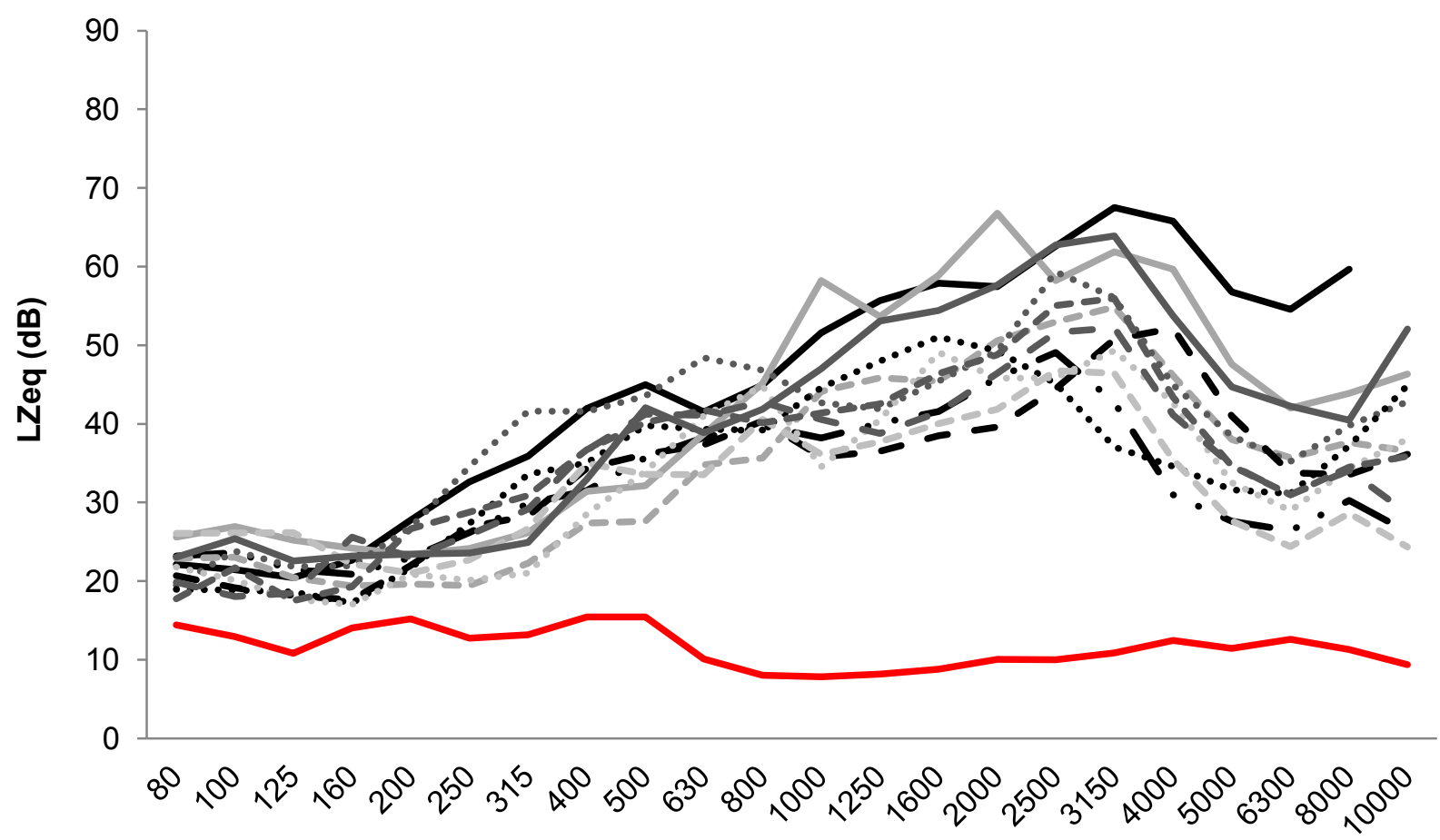

Frecuencia $(\mathrm{Hz})$

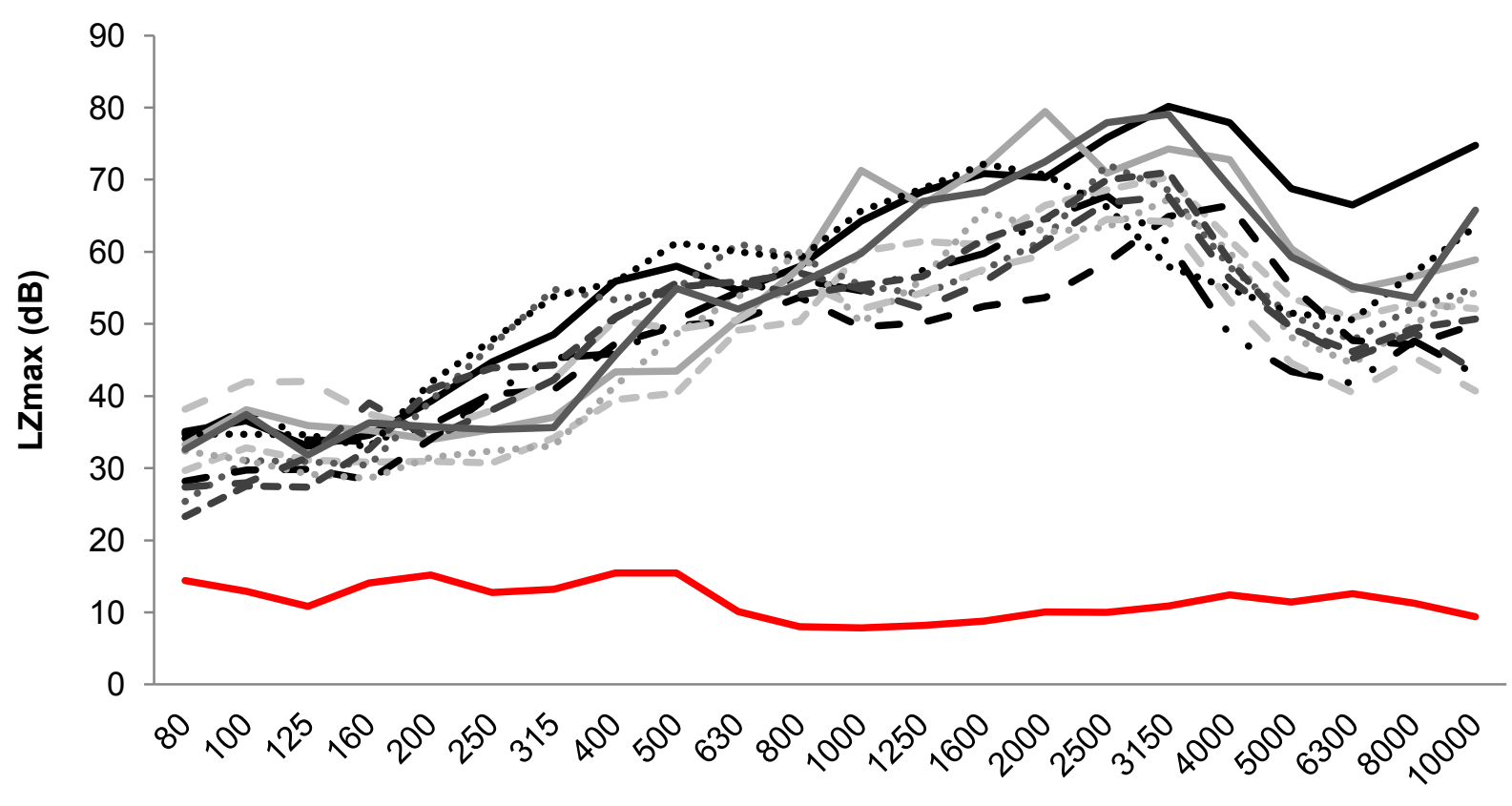

Frecuencia (Hz)

Figura 16. Espectro de los niveles sonoros de diferentes individuos juveniles de tres meses de edad (líneas negras y grises) y del ruido de fondo de la cámara anecoica (línea roja). Parte superior: niveles sonoros equivalentes $\left(L Z_{\text {eq }}\right)$ en decibeles $(d B)$. Parte inferior: niveles sonoros máximos $\left(L Z_{\max }\right.$, $\mathrm{dB})$ 
Tabla 4. Potencia sonora $(P)$ en vatio $(W)$ involucrada en la señal (sonido emitido por larvas de $C$. ornata) y el ruido de fondo (RF) del espectro de niveles sonoros equivalentes (eq) y del espectro de niveles sonoros máximos $(\max )$ antes y después de aplicar el proceso de filtrado. RSR: relación señal-ruido en decibeles $(\mathrm{dB})$

\begin{tabular}{lcc} 
& Sin filtro & Con filtro \\
\hline$P_{\text {eq señal }}(\mathrm{W})$ & 2653,9 & 216,0 \\
$P_{\text {eq } R F}(\mathrm{~W})$ & 3511,0 & 66,8 \\
$R S R(\mathrm{~dB})$ & $-1,2$ & $\mathbf{5 , 1}$ \\
\hline$P_{\text {max señal }}(\mathrm{W})$ & 11653,3 & 4102,3 \\
$P_{\text {max RF }}(\mathrm{W})$ & 8363,6 & 130,6 \\
$R S R(\mathrm{~dB})$ & $\mathbf{1 , 4}$ & $\mathbf{1 5 , 0}$ \\
\hline
\end{tabular}

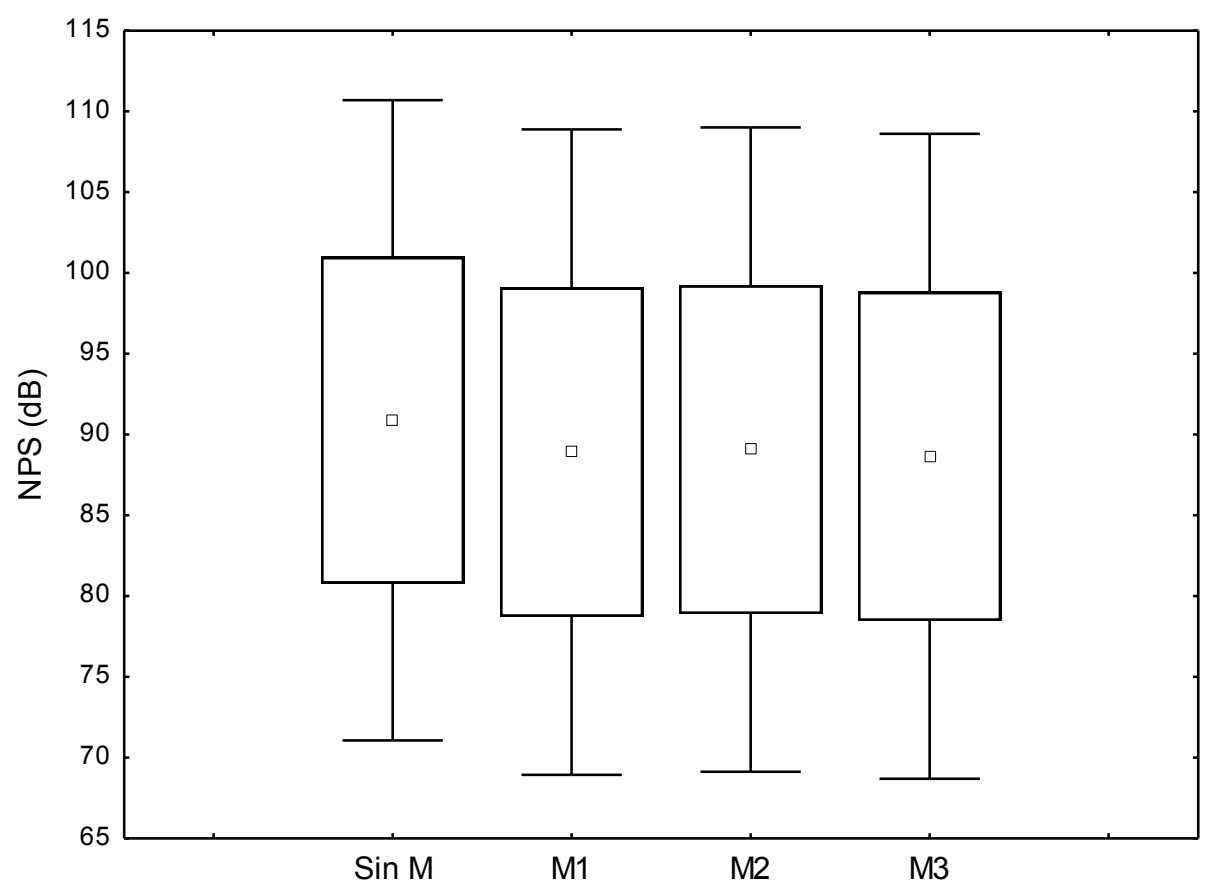

Figura 17. Comparación mediante un diagrama de caja y bigote del nivel de presión sonora (NPS) en decibeles $(\mathrm{dB})$ de la respuesta del micrófono cubierto con diferentes membranas de látex (M1, M2, M3) y $\sin$ cubrir ( $\operatorname{Sin} M)$ 


\section{Descripción del sonido emitido en un medio acuático y un medio aéreo por individuos} de C. ornata mediante variables bioacústicas

En la tabla 5 se resumen las variables bioacústicas analizadas correspondientes a 100 sonidos larvales producidos en un medio AC y AE en cuatro STD diferentes $(25,31,37$ y 41). En la misma tabla se resumen las mismas variables para 35 sonidos producidos por juveniles (STD 46) y para 12 sonidos producidos por adultos de la misma especie, en ambos casos al ser molestados tocándolos con una pipeta. Previamente, se eliminaron los valores atípicos de modo que el resumen de los datos de cada variable para cada STD resultó de diferente cantidad de datos (se indica la cantidad final de datos entre paréntesis). En las fig. 18 y 19 se muestra el oscilograma y sonograma característico para cada STD larval tanto en un medio $A C$ como $A E$, respectivamente. En las fig. 20 y 21 se muestra el oscilograma y sonograma característico de los sonidos producidos por juveniles y adultos, respectivamente. Los resultados del análisis de correlación entre las variables estimadoras del crecimiento/desarrollo y las variables bioacústicas de sonidos producidos en un medio AC por larvas de diferentes STD del desarrollo y en un medio AE por larvas de diferentes STD del desarrollo, juveniles y adultos, se resumen en las tablas 6 y 7 respectivamente. De las variables estimadoras del crecimiento medidas, se utilizó solo el peso para realizar las correlaciones por ser la variable morfométrica que mejor describe el tamaño de un organismo y porque se correlaciona positivamente y de manera perfecta con la LHC (PesoLHC de larvas grabadas en un medio AC: $r=0,9725, p<0,0005$; Peso-LHC de larvas, juveniles y adultos grabados en un medio AE: $r=0,8701, p<0,0005)$, tal como se indicó en el capítulo 1 (ver página 50). La comparación de las variables bioacústicas de sonidos producidos por las mismas larvas de $C$. ornata tanto en un medio $A C(n=10)$ como $A E(n=$ 10) indica que tanto la Ds, el Np y Nip no difieren significativamente entre sí. Por el contrario, existen diferencias significativas entre la $\mathrm{Fd}$ de sonidos grabados en un medio $\mathrm{AC}$ y $\mathrm{AE}$ (Tabla 8). Sin embargo, a partir del análisis de estadística descriptiva realizado, y teniendo en cuenta que las variables medidas a partir de sonidos grabados en un medio $A C$ y $A E$ presentan bajo coeficiente de variación, se podría predecir el valor de la $\mathrm{Fd}$ de sonidos producidos en un medio $\mathrm{AC}$ a partir de la $\mathrm{Fd}$ de sonidos producidos en un medio $\mathrm{AE}$ teniendo en cuenta que la $\mathrm{Fd}$ de los últimos es en promedio 1,6 veces mayor que la de los primeros.

Cabe destacar que, si bien se resumen las variables bioacústicas de sonidos producidos por larvas de $C$. ornata en cuatro STD larvales, las mismas emiten sonidos hasta el STD 41. Luego de este STD, momento en el cual comienzan a emerger los miembros delanteros y pierden el pico córneo, dejan de emitir sonidos hasta completar la metamorfosis, habiéndose realizado esta observación en el 100\% de 346 larvas evaluadas. Luego, vuelven a emitir 
sonidos durante el STD juvenil y adulto. Nótese que para los sonidos producidos en STD larvales solo se describe una Fd (sonido puro) mientras que para los sonidos producidos en STD juvenil y adulto se describen dos $\mathrm{Fd}$ (sonido armónico), siendo la primera un múltiplo de la segunda. Es decir, el sonido producido por individuos juveniles y adultos presenta armónicos, pudiéndose evidenciar ambas bandas de frecuencias dominantes a partir de los sonogramas (Fig. 20 y 21). Resulta evidente la modulación (cambio) en el sonido emitido por parte de juveniles y adultos de acuerdo al estado de irritación del individuo. Es decir, aquellos individuos que se encuentran más irritados emiten sonidos de mayor duración y cantidad de pulsos (Tabla 9).

Por último, si se compara el sonido producido por larvas, juveniles y adultos al ser molestados (tocándolos con una pipeta) se evidencia que es el mismo sonido cuya Ds aumenta (y consecuentemente aumenta el $\mathrm{Np}$ y $\mathrm{Nip}$ ) y su $\mathrm{Fd}$ disminuye a medida que aumenta el peso (Peso-Ds: $r=0,815, p<0,0005$; Peso-Fd: $r=-0,447, p<0,0005$ ) (Fig. 22). A partir de esta comparación se evidencia que los individuos adultos tienen mayor capacidad de modulación que los juveniles. Si dentro de tal comparación se adicionan las llamadas de anuncio de machos y de reciprocidad de hembras de C. ornata (para su descripción ver Anexo II), se evidencia que los mismos poseen menor variabilidad que sus gritos agresivos. La prueba de $t$ de diferencias entre medias de sonidos producidos por machos al ser molestados y aquellos producidos por hembras al ser molestadas, no arrojó diferencias significativas para ninguna de sus variables (Ds: $t=0,652$, g.l. $=8, p=0,532$; Np: $t=0,491$, g.l. $=10, \mathrm{p}=0,634$; Nip: $t=0,565$, g.l. $=10, \mathrm{p}=0,584 ; \mathrm{Fd}-1: t=0,556$, g.l. $=6, \mathrm{p}=$ $0,599 ; \mathrm{Fd}-2: t=0,137, \mathrm{~g} . \mathrm{I} .=8, \mathrm{p}=0,895)$. 


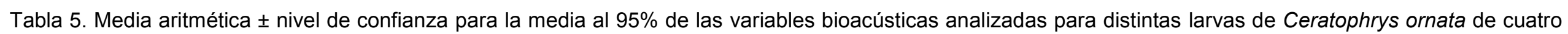

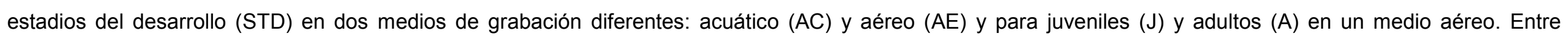

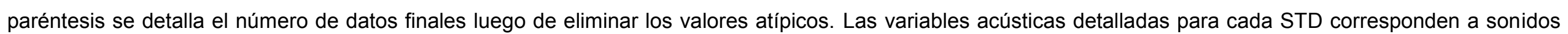

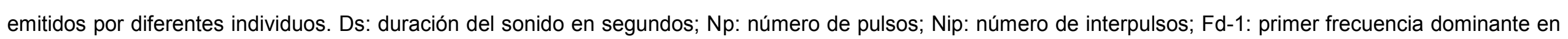
Hertz $(\mathrm{Hz})$; Fd-2: segunda frecuencia dominante $(\mathrm{Hz}) ;{ }^{(a)}$ el estadio 25 solo fue grabado en un medio acuático

\begin{tabular}{|c|c|c|c|c|c|c|}
\hline STD & Contexto & Ds & $\mathrm{Np}$ & Nip & Fd-1 & Fd-2 \\
\hline $25^{(\mathrm{a})}$ & $A C$ & $\begin{array}{c}0,048 \pm 0,003 \\
(98)\end{array}$ & $\begin{array}{c}7,490 \pm 0,404 \\
(100)\end{array}$ & $\begin{array}{c}6,490 \pm 0,404 \\
(100)\end{array}$ & $\begin{array}{c}2651,643 \pm 83,021 \\
(98)\end{array}$ & - \\
\hline 31 & $A C$ & $\begin{array}{c}0,058 \pm 0,003 \\
(88)\end{array}$ & $\begin{array}{c}8,130 \pm 0,563 \\
(100)\end{array}$ & $\begin{array}{c}7,130 \pm 0,563 \\
(100)\end{array}$ & $\begin{array}{c}2090,451 \pm 138,758 \\
(100)\end{array}$ & - \\
\hline 37 & $A C$ & $\begin{array}{c}0,087 \pm 0,004 \\
(100)\end{array}$ & $\begin{array}{c}11,870 \pm 0,838 \\
(100)\end{array}$ & $\begin{array}{c}10,870 \pm 0,838 \\
(100)\end{array}$ & $\begin{array}{c}2363,969 \pm 100,970 \\
(96)\end{array}$ & - \\
\hline 41 & $A C$ & $\begin{array}{c}0,086 \pm 0,004 \\
(98) \\
\end{array}$ & $\begin{array}{c}12,160 \pm 0,616 \\
(100)\end{array}$ & $\begin{array}{c}11,160 \pm 0,616 \\
(100)\end{array}$ & $\begin{array}{c}1937,697 \pm 64,546 \\
(99) \\
\end{array}$ & - \\
\hline 31 & $\mathrm{AE}$ & $\begin{array}{c}0,071 \pm 0,005 \\
(92)\end{array}$ & $\begin{array}{c}10,930 \pm 0,715 \\
(92)\end{array}$ & $\begin{array}{c}9,930 \pm 0,715 \\
(92)\end{array}$ & $\begin{array}{c}3778,342 \pm 128,754 \\
(92)\end{array}$ & - \\
\hline 37 & $\mathrm{AE}$ & $\begin{array}{c}0,072 \pm 0,004 \\
(91)\end{array}$ & $\begin{array}{c}11,600 \pm 0,611 \\
(90)\end{array}$ & $\begin{array}{c}10,611 \pm 0,613 \\
(90)\end{array}$ & $\begin{array}{c}3488,073 \pm 107,148 \\
(96)\end{array}$ & - \\
\hline 41 & $\mathrm{AE}$ & $\begin{array}{c}0,078 \pm 0,004 \\
(94)\end{array}$ & $\begin{array}{c}12,853 \pm 0,768 \\
(95)\end{array}$ & $\begin{array}{c}11,853 \pm 0,768 \\
(95)\end{array}$ & $\begin{array}{c}3743,435 \pm 151,327 \\
(92)\end{array}$ & - \\
\hline $\mathrm{J}$ & $\mathrm{AE}$ & $\begin{array}{c}0,332 \pm 0,068 \\
(33)\end{array}$ & $\begin{array}{c}54,019 \pm 13,889 \\
(34)\end{array}$ & $\begin{array}{c}53,019 \pm 13,889 \\
(34)\end{array}$ & $\begin{array}{c}2626,943 \pm 256,993 \\
(35)\end{array}$ & $\begin{array}{c}9599,314 \pm 386,945 \\
(35)\end{array}$ \\
\hline$A$ & $\mathrm{AE}$ & $\begin{array}{c}2,155 \pm 0,933 \\
(12)\end{array}$ & $\begin{array}{c}398,237 \pm 194,835 \\
(12)\end{array}$ & $\begin{array}{c}397,237 \pm 194,835 \\
(12)\end{array}$ & $\begin{array}{c}1892,583 \pm 229,325 \\
(12)\end{array}$ & $\begin{array}{c}6075,583 \pm 356,200 \\
(12)\end{array}$ \\
\hline
\end{tabular}


Tabla 6. Resultados del análisis de correlación ( $r$ ) entre variables bioacústicas de sonidos producidos por larvas de $C$. ornata en un medio acuático en estadio (STD) $25,31,37$ y 41 , y entre éstas y variables estimadoras del tamaño corporal (peso) y desarrollo (STD). En color rojo y con asterisco se indican los valores de correlación con $p<0,05\left(^{*}\right)$ y $p<0,005\left(^{* *}\right)$. Ds: duración del sonido en segundos; Np: número de pulsos; Nip: número de interpulsos; Fd: frecuencia dominante en Hertz; Peso en gramos

\begin{tabular}{lcccccc} 
Variables & Ds & Np & Nip & Fd & STD & Peso \\
\hline Ds & - & $0,7555^{* *}$ & $0,7546^{* *}$ & $-0,2429^{* *}$ & $0,6697^{* *}$ & $0,4870^{* *}$ \\
Np & $0,7555^{* *}$ & - & $0,9997^{* *}$ & $-0,1405^{*}$ & $0,5510^{* *}$ & $0,4708^{* *}$ \\
Nip & $0,7546^{* *}$ & $0,9997^{* *}$ & - & $-0,1388^{*}$ & $0,5507^{* *}$ & $0,4732^{* *}$ \\
Fd & $-0,2429^{* *}$ & $-0,1405^{*}$ & $-0,1388^{*}$ & - & $-0,3588^{* *}$ & $-0,1168^{*}$ \\
STD & $0,6697^{* *}$ & $0,5510^{* *}$ & $0,5507^{* *}$ & $-0,3588^{* *}$ & - & $0,9669^{* *}$ \\
Peso & $0,4870^{* *}$ & $0,4708^{* *}$ & $0,4732^{* *}$ & $-0,1168^{*}$ & $0,9669^{* *}$ & - \\
\hline
\end{tabular}

Tabla 7. Resultados del análisis de correlación ( $r$ ) entre variables bioacústicas de sonidos producidos por larvas de $C$. ornata en el medio aéreo en estadio (STD) 31,37 y 41 , juveniles y adultos, y entre éstas y variables estimadoras del tamaño corporal (peso) y desarrollo (STD). En color rojo y con asterisco se indican los valores de correlación con $p<0,05\left(^{*}\right)$ y $p<0,005\left(^{* *}\right)$. Ds: duración del sonido en segundos; Np: número de pulsos; Nip: número de interpulsos; Fd: frecuencia dominante en Hertz (para juveniles se utilizó solo la primer Fd); Peso en gramos

\begin{tabular}{lcccccc} 
Variables & Ds & Np & Nip & Fd & STD & Peso \\
\hline Ds & - & $0,7908^{* *}$ & $0,7811^{* *}$ & $-0,4178^{* *}$ & $0,6883^{* *}$ & $0,8154^{* *}$ \\
Np & $0,7908^{* *}$ & - & $0,9997^{* *}$ & $-0,5129^{* *}$ & $0,6949^{* *}$ & $0,7972^{* *}$ \\
Nip & $0,7811^{* *}$ & $0,9997^{* *}$ & - & $-0,5098^{* *}$ & $0,6866^{* *}$ & $0,7898^{* *}$ \\
Fd & $-0,4178^{* *}$ & $-0,5129^{* *}$ & $-0,5098^{* *}$ & - & $-0,3535^{* *}$ & $-0,4472^{*}$ \\
STD & $0,6883^{* *}$ & $0,6949^{* *}$ & $0,6866^{* *}$ & $-0,3535^{* *}$ & - & $0,4901^{* *}$ \\
Peso & $0,8154^{* *}$ & $0,7972^{* *}$ & $0,7898^{* *}$ & $-0,4472^{* *}$ & $0,4901^{* *}$ & - \\
\hline
\end{tabular}



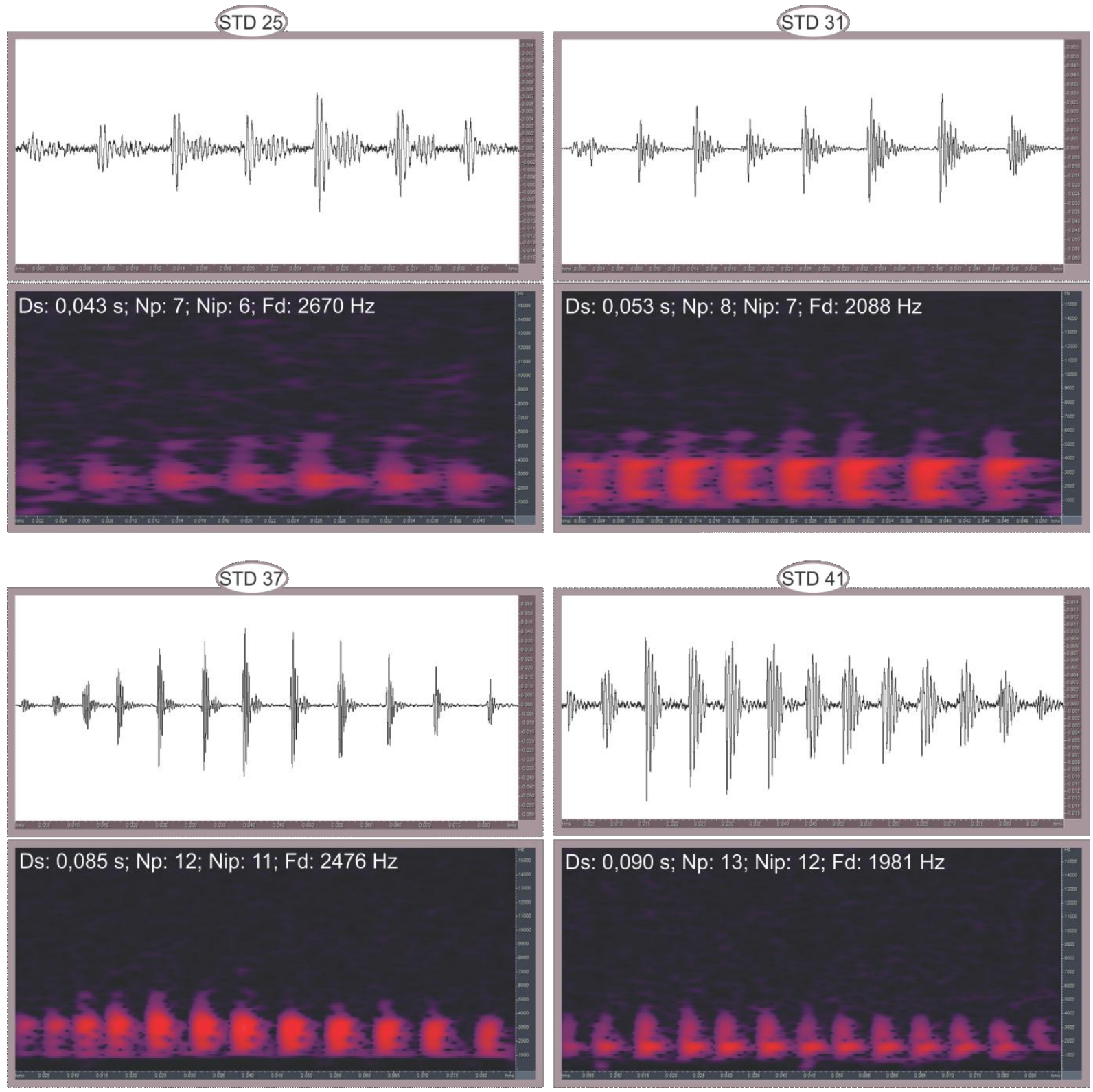

Figura 18. Oscilograma (parte superior; duración del sonido en segundos / amplitud en pascales) y sonograma (parte inferior; duración del sonido en segundos / frecuencia en Hertz) característico de los sonidos producidos por larvas de $C$. ornata en un medio acuático en diferentes estadios del desarrollo (STD). Cada gráfico corresponde al sonido emitido por una larva de un determinado STD. Ds: duración del sonido en segundos (s); Np: número de pulsos; Nip: número de interpulsos; Fd: frecuencia dominante en Hertz $(\mathrm{Hz})$ 

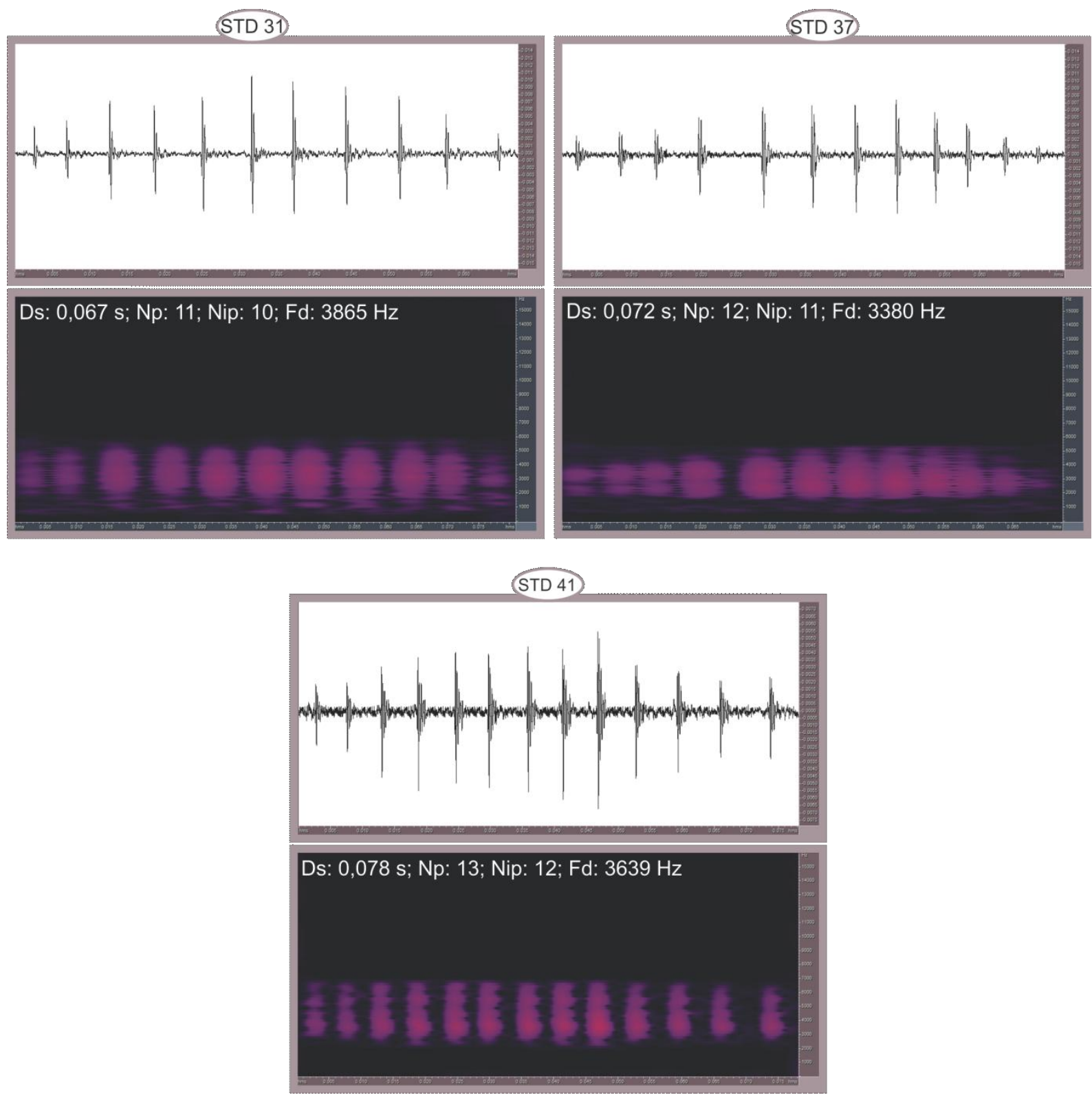

Figura 19. Oscilograma (parte superior; duración del sonido en segundos / amplitud en pascales) y sonograma (parte inferior; duración del sonido en segundos / frecuencia en Hertz) característico de los sonidos producidos por larvas de $C$. ornata en el medio aéreo en diferentes estadios del desarrollo (STD). Cada gráfico corresponde al sonido emitido por una larva de un determinado STD. Ds: duración del sonido en segundos (s); Np: número de pulsos; Nip: número de interpulsos; Fd: frecuencia dominante en $\mathrm{Hertz}(\mathrm{Hz})$ 
Tabla 8. Resultados de la comparación de las variables bioacústicas (Var, estandarizadas por el peso) de cada sonido producido por larvas de $C$. ornata tanto en un medio acuático (AC) como aéreo (AE) mediante una prueba de $t$ pareada. Ds: duración del sonido en segundos; Np: número de pulsos; Nip: número de interpulsos; Fd: frecuencia dominante en Hertz; Media: media aritmética; CV: coeficiente de variación; n: número de datos; p: probabilidad asociada a la prueba

\begin{tabular}{ccccccccc} 
STD & Var & Media-AC & CV & Media-AE & CV & $\mathbf{n}$ & $\boldsymbol{t}$ & $\mathbf{p}$ \\
\hline \multirow{3}{*}{31} & Ds & 0,174 & 0,382 & 0,165 & 0,469 & 10 & $-0,563054$ & 0,587149 \\
& Np & 5,884 & 0,264 & 5,677 & 0,314 & 10 & $-1,226799$ & 0,251023 \\
& Nip & 5,627 & 0,275 & 5,440 & 0,315 & 10 & $-1,041680$ & 0,324733 \\
& Fd & 5231,679 & 0,290 & 8195,992 & 0,214 & 10 & 5,445839 & $0,000408^{*}$ \\
\hline \multirow{3}{*}{37} & Ds & 0,053 & 0,258 & 0,052 & 0,250 & 10 & $-1,875694$ & 0,093446 \\
& Np & 1,744 & 0,185 & 1,769 & 0,176 & 10 & 0,642860 & 0,536347 \\
& Nip & 1,680 & 0,191 & 1,707 & 0,179 & 10 & 0,650726 & 0,531483 \\
& Fd & 1595,530 & 0,287 & 2518,727 & 0,182 & 10 & 12,166637 & $0,000001^{*}$ \\
\hline \multirow{2}{*}{41} & Ds & 0,044 & 0,185 & 0,045 & 0,213 & 10 & 0,274447 & 0,789937 \\
& Np & 1,222 & 0,127 & 1,321 & 0,101 & 10 & 2,140357 & 0,060986 \\
& Nip & 1,181 & 0,132 & 1,285 & 0,103 & 10 & 2,293410 & 0,047509 \\
& Fd & 1040,737 & 0,272 & 1960,601 & 0,163 & 10 & 7,029776 & $0,000061^{*}$ \\
\hline
\end{tabular}
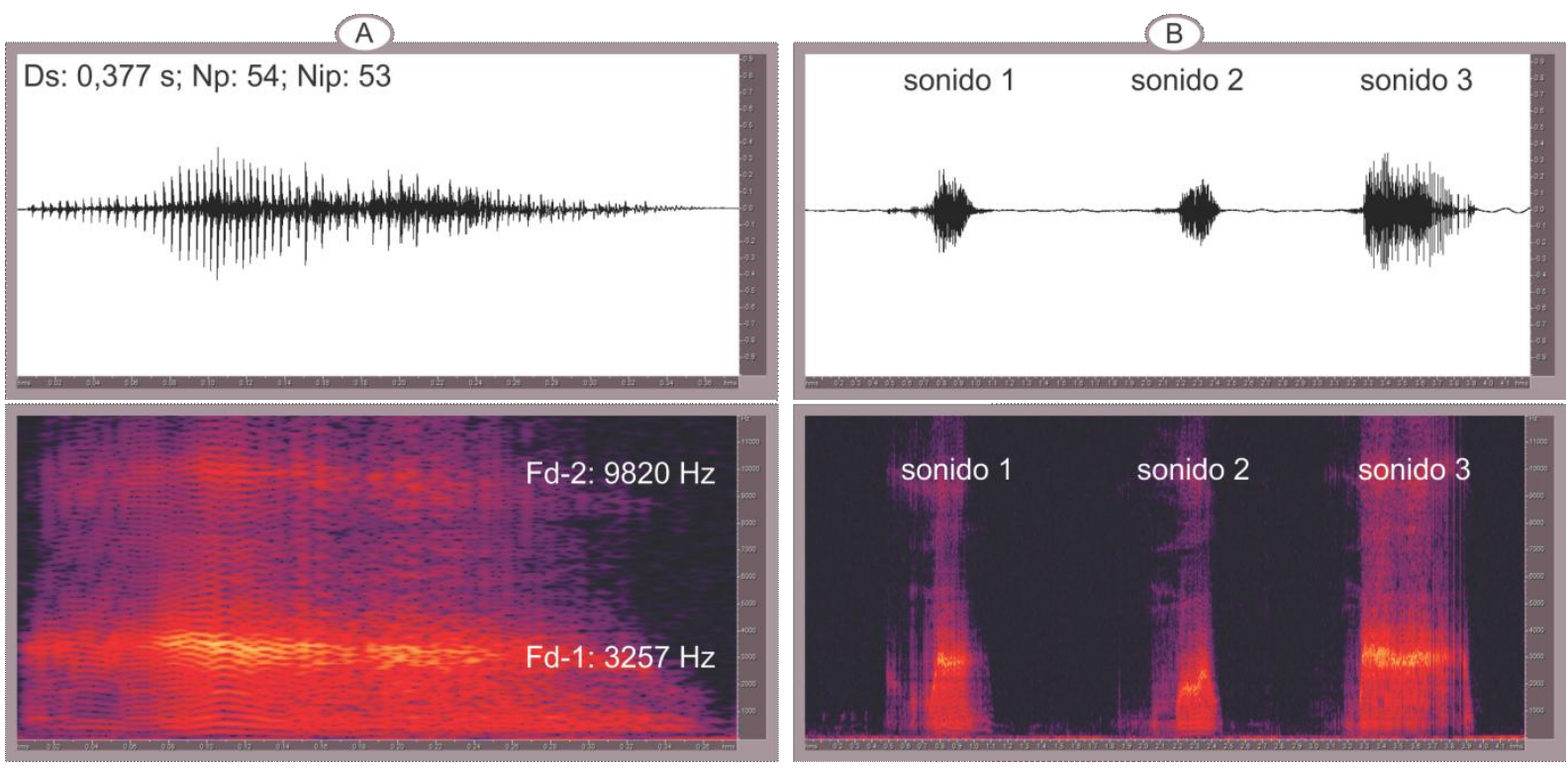

Figura 20. Oscilograma (parte superior; duración del sonido en segundos / amplitud en pascales) y sonograma (parte inferior; duración del sonido en segundos / frecuencia en Hertz) característico de los sonidos producidos por juveniles de $C$. ornata de tres meses de edad en el medio aéreo. (A) un sonido típico; (B) tres sonidos de diferente duración producidos por el mismo individuo. Ds: duración del sonido en segundos (s); Fd-1: primer frecuencia dominante en Hertz (Hz), Fd-2: segunda frecuencia dominante $(\mathrm{Hz})$ 
Tabla 9. Parámetros bioacústicos de diferentes sonidos producidos por diferentes juveniles $(\mathrm{J})$ y adultos hembra $(\mathrm{H})$ y machos $(\mathrm{M})$ de $C$. ornata. Ds: duración del sonido en segundos; Np: número de pulsos; Nip: número de interpulsos; Fd-1: primer frecuencia dominante en $\mathrm{Hertz}(\mathrm{Hz})$; $\mathrm{Fd}-2$ : segunda frecuencia dominante $(\mathrm{Hz})$; Peso en gramos

\begin{tabular}{|c|c|c|c|c|c|c|}
\hline Individuo & Ds & $\mathrm{Np}$ & Nip & Fd-1 & Fd-2 & Peso \\
\hline \multirow{4}{*}{ J1 } & 0,294 & 30 & 29 & 1441 & 9796 & \multirow{4}{*}{59,40} \\
\hline & 0,296 & 38 & 37 & 2414 & 8296 & \\
\hline & 0,163 & 16 & 15 & 1664 & 9937 & \\
\hline & 0,286 & 40 & 39 & 1898 & 7804 & \\
\hline \multirow{5}{*}{ J2 } & 0,243 & 35 & 34 & 3140 & 9656 & \multirow{5}{*}{69,38} \\
\hline & 0,377 & 54 & 53 & 3257 & 9820 & \\
\hline & 0,162 & 29 & 28 & 3726 & 9539 & \\
\hline & 0,211 & 42 & 41 & 3796 & 9046 & \\
\hline & 0,128 & 20 & 19 & 4031 & 9773 & \\
\hline \multirow{4}{*}{ J3 } & 0,247 & 34 & 33 & 2742 & 9796 & \multirow{4}{*}{75,15} \\
\hline & 0,251 & 35 & 34 & 3164 & 10350 & \\
\hline & 0,175 & 18 & 17 & 3046 & 12460 & \\
\hline & 0,192 & 22 & 21 & 2414 & 8414 & \\
\hline \multirow{3}{*}{ J4 } & 0,335 & 54 & 53 & 1710 & 11970 & \multirow{3}{*}{50,36} \\
\hline & 0,249 & 35 & 34 & 2179 & 11165 & \\
\hline & 0,407 & 71 & 70 & 2566 & 9187 & \\
\hline J5 & 0,534 & 82 & 81 & 2742 & 9281 & 56,29 \\
\hline \multirow{2}{*}{ J6 } & 0,964 & 218 & 217 & 1710 & 9351 & \multirow{2}{*}{60,65} \\
\hline & 0,825 & 163 & 162 & 1664 & 9328 & \\
\hline \multirow{4}{*}{ J7 } & 0,277 & 41 & 40 & 2953 & 8976 & \multirow{4}{*}{47,82} \\
\hline & 0,380 & 65 & 64 & 2355 & 8953 & \\
\hline & 0,393 & 68 & 67 & 2344 & 8789 & \\
\hline & 0,290 & 44 & 43 & 2718 & 10350 & \\
\hline J8 & 0,229 & 30 & 29 & 3914 & 8554 & 45,25 \\
\hline \multirow{2}{*}{ J9 } & 0,315 & 45 & 44 & 2578 & 8320 & \multirow{2}{*}{55,87} \\
\hline & 0,276 & 31 & 30 & 2929 & 8179 & \\
\hline
\end{tabular}




\begin{tabular}{|c|c|c|c|c|c|c|}
\hline & 0,313 & 49 & 48 & 3234 & 11980 & \\
\hline \multirow{5}{*}{ J10 } & 0,721 & 143 & 142 & 1710 & 9984 & \multirow{5}{*}{43,67} \\
\hline & 0,274 & 40 & 39 & 2882 & 8296 & \\
\hline & & & & & & \\
\hline & 0,810 & 163 & 162 & 1828 & 10420 & \\
\hline & 0,372 & 63 & 62 & 2625 & 9609 & \\
\hline \multirow{3}{*}{ J11 } & 0,710 & 140 & 139 & 2039 & 9140 & \multirow{3}{*}{48,06} \\
\hline & & & & & & \\
\hline & 0,310 & 49 & 48 & 3187 & 8578 & \\
\hline \multirow[t]{2}{*}{ J12 } & 0,241 & 33 & 32 & 1453 & 11270 & 50,49 \\
\hline & 2,385 & 480 & 479 & 1981 & 6912 & \multirow{3}{*}{349,89} \\
\hline \multirow[t]{2}{*}{$\mathrm{H1}$} & 0,945 & 181 & 180 & 2820 & 6589 & \\
\hline & 1,295 & 254 & 253 & 1851 & 6352 & \\
\hline \multirow{5}{*}{$\mathrm{H} 2$} & 1,931 & 387 & 386 & 1399 & 5361 & \multirow{5}{*}{460,64} \\
\hline & 0,980 & 169 & 168 & 2239 & 5469 & \\
\hline & & & & & & \\
\hline & 3,229 & 348 & 347 & 1658 & 5663 & \\
\hline & 6,170 & 1274 & 1273 & 1614 & 6158 & \\
\hline \multirow{5}{*}{ M1 } & 2,046 & 411 & 410 & 1916 & 6847 & \multirow{5}{*}{171,28} \\
\hline & 2,848 & 579 & 578 & 1959 & 6567 & \\
\hline & 1,261 & 150 & 149 & 1722 & 5663 & \\
\hline & 1,740 & 347 & 346 & 1722 & 5749 & \\
\hline & 1,028 & 198 & 197 & 1830 & 5577 & \\
\hline
\end{tabular}




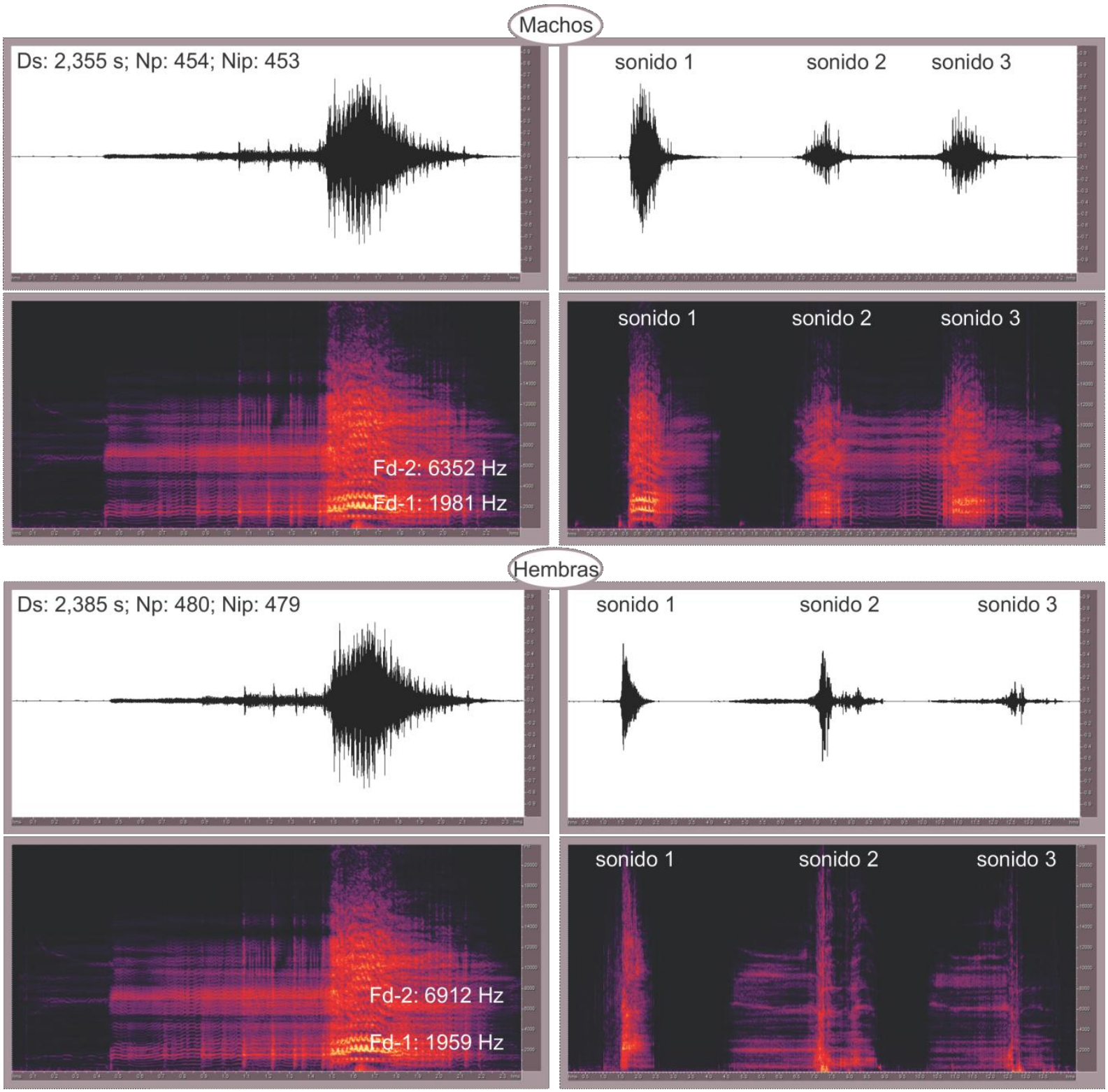

Figura 21. Oscilograma (parte superior; duración del sonido en segundos / amplitud en pascales) y sonograma (parte inferior; duración del sonido en segundos / frecuencia en Hertz) característico de los sonidos producidos por adultos de $C$. ornata en el medio aéreo. En la parte superior se observa un sonido (parte izquierda) y tres sonidos (parte derecha) típicos de un ejemplar macho. En la parte inferior se observa un sonido (parte izquierda) y tres sonidos (parte derecha) típicos de un ejemplar hembra. Ds: duración del sonido en segundos (s); Fd-1: primer frecuencia dominante en Hertz $(\mathrm{Hz})$, Fd-2: segunda frecuencia dominante $(\mathrm{Hz})$ 

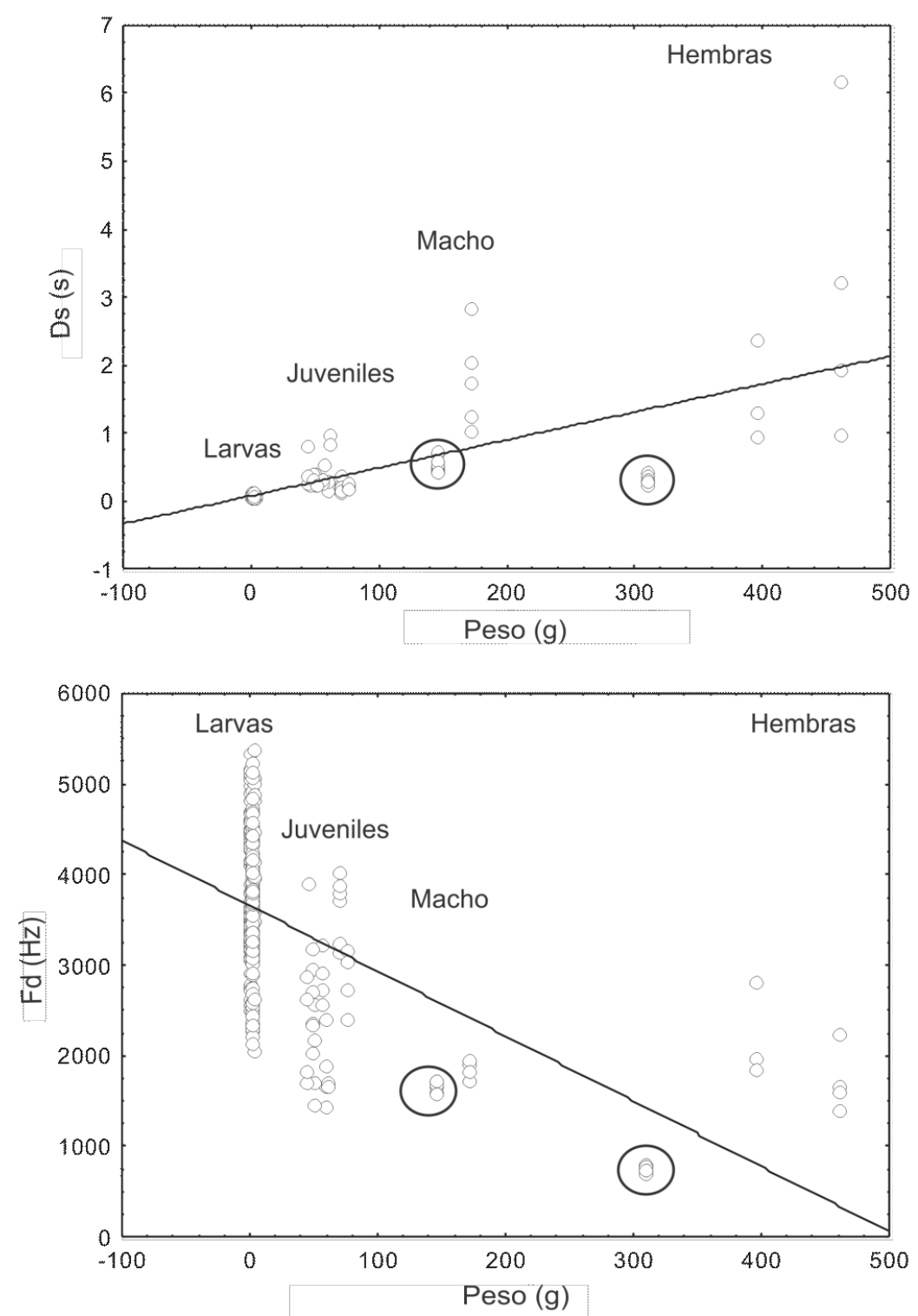

Figura 22. Análisis de correlación lineal entre la duración del sonido (Ds) en segundos (s) y la frecuencia dominante $(\mathrm{Fd})$ en Hertz $(\mathrm{Hz})$ de sonidos producidos en el medio aéreo por larvas, juveniles y adultos de $C$. ornata al ser molestados (tocados con una pipeta plástica) y el peso de los mismos. Se indican con un círculo las llamadas de anuncio de un macho y de reciprocidad de una hembra. Nótese la menor variabilidad de las variables correspondientes a sonidos reproductivos respecto a sonidos producidos al ser molestados

\section{Descripción del sonido emitido en el medio aéreo por individuos de C. ornata mediante variables acústicas}

Durante las mediciones de sonidos emitidos por larvas y juveniles de $C$. ornata, se registraron numerosas variables acústicas para la descripción de estos sonidos (Fig. 23). Teniendo en cuenta que no todas las variables resultaron adecuadas para caracterizar el sonido, en la tabla 10 se resumen los parámetros seleccionados para larvas de diferentes STD (31 a 37) y juveniles (STD 46). Por último, los análisis de correlación entre las variables 
acústicas medidas y entre éstas y variables estimadoras del tamaño corporal y desarrollo se resumen en la tabla 11. Cabe aclarar que las curvas de ponderación A fueron empleadas para la eliminación de las componentes de baja frecuencia con el objetivo de conseguir una mejor RSR.
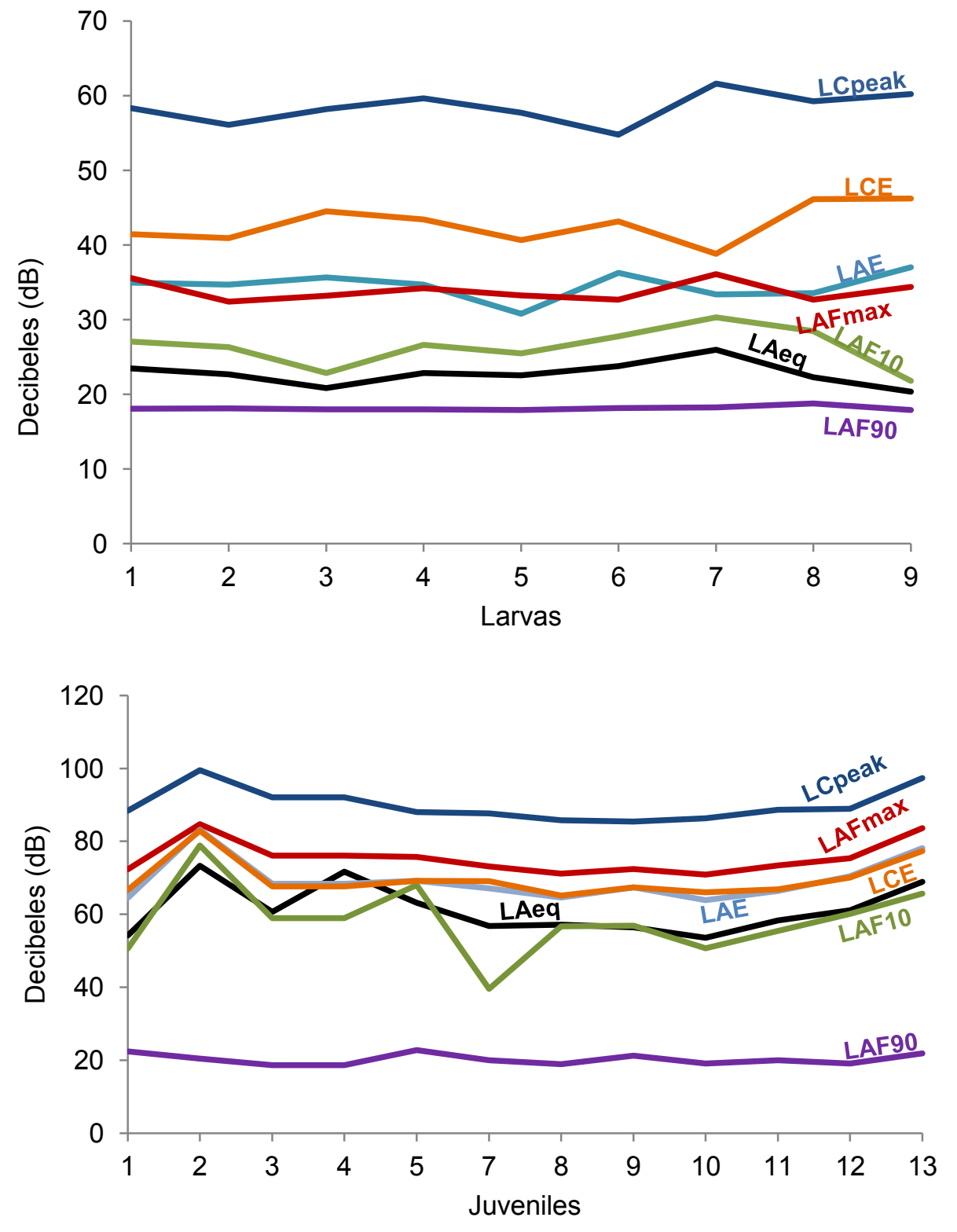

Figura 23. Variables acústicas del sonido emitido en el medio aéreo por diferentes larvas (parte superior, 1 a 9) y juveniles (parte inferior, 1 a 13) de $C$. ornata, medido mediante un sonómetro en cámara anecoica. Las letras "A" y "C" utilizadas en los nombres de los parámetros acústicos corresponden a los filtros de ponderación en frecuencias $A$ y $C$, respectivamente. $L_{\text {peak: }}$ nivel sonoro pico ponderado en C, LCE: nivel de exposición sonora ponderado en C; LAE: nivel de exposición sonora ponderado en $A ; L_{A} F_{\text {max }}$ : nivel sonoro máximo ponderado en $A ; L A F_{10}$ : nivel sonoro estadísticamente superado durante el 10\% del tiempo de medición; LAeq: nivel de presión sonora continuo equivalente ponderado en $\mathrm{A}$; $\mathrm{LAF}_{90}$ : nivel sonoro estadísticamente superado durante el $90 \%$ del tiempo de medición 
Tabla 10. Media aritmética de los parámetros acústicos $(n=3)$ medidos en larvas de diferentes estadios (STD) y juveniles (STD 46) de tres meses de edad de la especie C. ornata. LA $_{\text {eq }}$ en decibeles $(d B)$ : nivel sonoro continuo equivalente; $\operatorname{LAF}_{\max }(\mathrm{dB})$ : nivel sonoro máximo; $\mathrm{LAF}_{90}(\mathrm{~dB})$ : nivel sonoro que se ha igualado o superado durante el $90 \%$ del tiempo de medición; $A$ : con ponderación $A$ en frecuencias; Peso en gramos

\begin{tabular}{|c|c|c|c|c|}
\hline STD & $\mathrm{LA}_{\mathrm{eq}}$ & $\mathrm{LAF}_{\text {max }}$ & $\mathrm{LAF}_{90}$ & Peso \\
\hline 31 & 19,7 & 27,7 & 17,5 & 0,57 \\
\hline 32 & 22,3 & 32,3 & 17,6 & 0,69 \\
\hline 32 & 20,0 & 30,8 & 17,5 & 0,59 \\
\hline 33 & 22,4 & 31,9 & 17,5 & 0,63 \\
\hline 33 & 22,3 & 35,8 & 17,5 & 0,64 \\
\hline 33 & 29,7 & 45,3 & 18,0 & 0,67 \\
\hline 33 & 22,4 & 31,8 & 17,5 & 0,66 \\
\hline 33 & 22,3 & 32,3 & 17,5 & 0,59 \\
\hline 33 & 21,5 & 30,9 & 17,7 & 0,60 \\
\hline 33 & 26,2 & 37,4 & 18,2 & 0,61 \\
\hline 34 & 21,9 & 35,4 & 17,4 & 1,76 \\
\hline 34 & 23,4 & 35,6 & 18,1 & 0,81 \\
\hline 34 & 22,7 & 32,4 & 18,1 & 0,78 \\
\hline 34 & 20,8 & 33,2 & 18,0 & 0,86 \\
\hline 34 & 22,8 & 34,2 & 18,0 & 0,64 \\
\hline 34 & 22,5 & 33,2 & 17,9 & 1,02 \\
\hline 34 & 23,8 & 32,7 & 18,2 & 0,86 \\
\hline 34 & 26,0 & 36,1 & 18,3 & 0,75 \\
\hline 34 & 22,3 & 32,7 & 18,8 & 0,71 \\
\hline 34 & 20,4 & 34,4 & 17,9 & 0,72 \\
\hline 34 & 24,7 & 33,5 & 17,6 & 0,70 \\
\hline 35 & 21,9 & 33,5 & 17,8 & 0,72 \\
\hline 35 & 24,1 & 35,6 & 17,6 & 0,84 \\
\hline 35 & 22,0 & 31,4 & 17,7 & 0,73 \\
\hline 35 & 21,7 & 34,4 & 17,4 & 0,71 \\
\hline 35 & 20,9 & 34,8 & 17,3 & 1,43 \\
\hline 35 & 26,5 & 36,5 & 17,7 & 1,19 \\
\hline 35 & 24,9 & 35,2 & 18,0 & 1,17 \\
\hline 35 & 23,3 & 34,8 & 17,7 & 0,63 \\
\hline 36 & 23,6 & 35,7 & 17,4 & 1,92 \\
\hline 36 & 23,4 & 36,1 & 17,5 & 1,68 \\
\hline 36 & 23,0 & 35,9 & 17,7 & 1,29 \\
\hline 36 & 25,1 & 34,0 & 17,5 & 1,46 \\
\hline 37 & 23,7 & 34,1 & 17,7 & 1,39 \\
\hline 37 & 26,4 & 37,4 & 18,3 & 2,31 \\
\hline 37 & 27,4 & 39,2 & 18,0 & 2,03 \\
\hline 37 & 23,7 & 35,4 & 17,4 & 1,93 \\
\hline 37 & 23,1 & 37,8 & 17,4 & 1,85 \\
\hline 37 & 25,5 & 36,4 & 18,1 & 1,83 \\
\hline
\end{tabular}




\begin{tabular}{lllll}
46 & 54,2 & 72,3 & 22,4 & 59,40 \\
46 & 73,3 & 84,7 & 20,4 & 69,38 \\
46 & 60,7 & 76,1 & 18,7 & 75,15 \\
46 & 71,7 & 76,1 & 18,7 & 50,36 \\
46 & 63,2 & 75,7 & 22,8 & 56,29 \\
46 & 56,8 & 73,1 & 20,0 & 60,65 \\
46 & 57,1 & 71,2 & 19,0 & 53,68 \\
46 & 56,4 & 72,4 & 21,3 & 47,82 \\
46 & 53,5 & 70,9 & 19,1 & 45,25 \\
46 & 58,3 & 73,4 & 20,0 & 55,87 \\
46 & 61,1 & 75,4 & 19,1 & 43,67 \\
46 & 68,9 & 83,7 & 21,9 & 48,06 \\
\hline
\end{tabular}

Tabla 11. Resultados del análisis de correlación $(r)$ entre variables acústicas de sonidos producidos en el medio aéreo por larvas y juveniles de C. ornata desde el estadio (STD) 31 al 46, y entre éstas y variables estimadoras del tamaño corporal (peso, en gramos) y desarrollo (STD). En color rojo y con asterisco se indican los valores de correlación con $p<0,005\left(^{* *}\right)$

\begin{tabular}{lcccc} 
& LA $_{\text {eq }}$ & LAF $_{\text {max }}$ & STD & Peso \\
\hline LA $_{\text {eq }}$ & - & $0,9908^{* *}$ & $0,9520^{* *}$ & $0,9647^{* *}$ \\
LAF $_{\text {max }}$ & $0,9908^{* *}$ & - & $0,9642^{* *}$ & $0,9723^{* *}$ \\
STD & $0,9520^{* *}$ & $0,9642^{* *}$ & - & $0,9506^{* *}$ \\
Peso & $0,9647^{* *}$ & $0,9723^{* *}$ & $0,9506^{* *}$ & - \\
\hline
\end{tabular}

\section{Descripción de sonidos emitidos por larvas de otras especies de anuros autóctonos}

De las distintas especies de larvas grabadas $(n=9)$, solo aquellas pertenecientes a la familia Ceratophryidae (C. aurita, Salgado Costa y Natale, 2011; C. cranwelli, Salgado Costa y col., 2014b) emitieron sonidos tanto en el medio acuático como aéreo, a excepción de $L$. Ilanensis (Salgado Costa y col., 2015). En la tabla 12 se resumen las variables bioacústicas analizadas para larvas de C. cranwelli y C. aurita en diferentes STD. En las fig. 24 y 25 se detallan los oscilogramas y sonogramas característicos de cada STD para cada especie. Cabe aclarar que el análisis del oscilograma se utilizó como complemento del análisis del sonograma para la medición manual de variables, dado que no corresponde la utilización de éste por no haberse medido el NPS (dB) mediante un sonómetro. En la fig. 26 se muestra la falta de emisión de sonidos por parte de larvas de L. Ilanensis mediante la comparación del NPS (dB) del RF grabado antes y durante interacciones intraespecíficas entre larvas de esta especie. Las mismas son comparadas con el NPS (dB) del RF de grabaciones realizadas antes y durante interacciones intraespecíficas entre larvas de $C$. ornata. Cabe aclarar que se 
utilizó la media energética $\left(10 \log _{10}\left(1 / \mathrm{n} \sum 10^{\mathrm{SPL} / 10}\right)\right.$ para resumir los datos de NPS con la finalidad de obtener el espectro característico de cada individuo.

Tabla 12. Media aritmética \pm nivel de confianza para la media al $95 \%$ de los parámetros bioacústicos de los sonidos emitidos por larvas de $C$. cranwelli $(C c)$ y $C$. aurita $(C a)$ en diferentes estadios del desarrollo (STD). Entre paréntesis se detalla el número de datos utilizados. Sp.: especie; Ds: duración del sonido en segundos; Np: número de pulsos; Nip: número de interpulsos; Fd: frecuencia dominante en Hertz

\begin{tabular}{cccccc} 
Sp. & STD & Ds & Np & Nip & Fd \\
\hline & & $0,029 \pm 0,015$ & $8,000 \pm 3,250$ & $7,000 \pm 3,250$ & $3870,545 \pm 919,802$ \\
& 25 & $(11)$ & $(11)$ & $(11)$ & $(11)$ \\
Cc & & $0,045 \pm 0,007$ & $11,545 \pm 2,315$ & $10,545 \pm 2,315$ & $3204,273 \pm 360,487$ \\
& 28 & $(11)$ & $(11)$ & $(11)$ & $(11)$ \\
& & $0,051 \pm 0,012$ & $9,364 \pm 1,834$ & $8,364 \pm 1,834$ & $2258,182 \pm 166,787$ \\
& 37 & $(11)$ & $(11)$ & $(11)$ & $(11)$ \\
\hline & & $0,041 \pm 0,023$ & $5,500 \pm 2,054$ & $4,500 \pm 2,054$ & $3365,667 \pm 909,194$ \\
& 25 & $(4)$ & $(4)$ & $(4)$ & $(4)$ \\
Ca & & $0,046 \pm 0,017$ & $6 ., 00 \pm 1,871$ & $5,500 \pm 1,871$ & $2949,500 \pm 786,022$ \\
& 28 & $(3)$ & $(3)$ & $(3)$ & $(3)$ \\
& \multirow{4}{*}{37} & $0,047 \pm 0,007$ & $7,750 \pm 1,666$ & $6,750 \pm 1,666$ & $2771,000 \pm 658,849$ \\
& & $(5)$ & $(5)$ & $(5)$ & $(5)$ \\
\hline
\end{tabular}




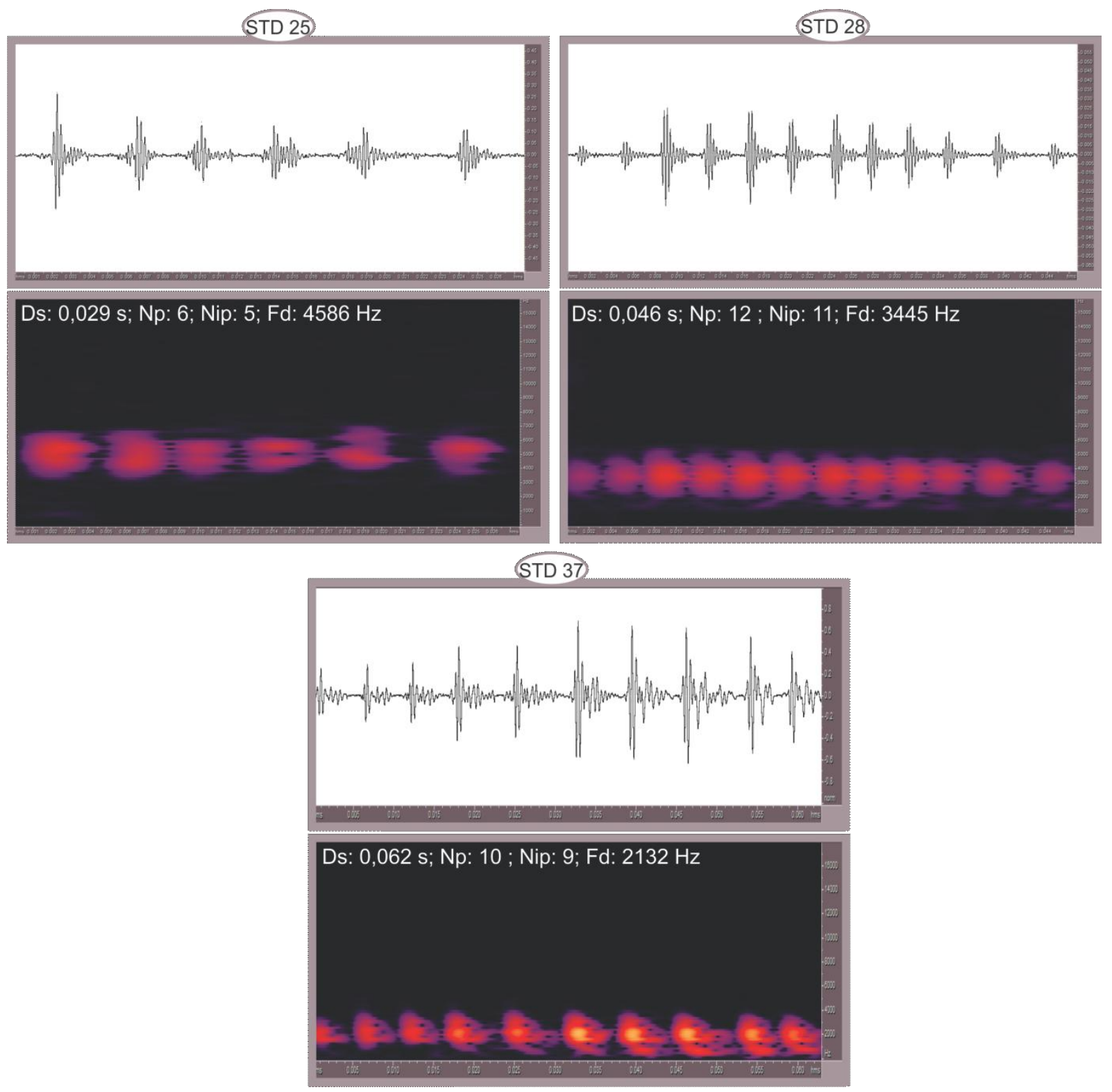

Figura 24. Oscilograma (parte superior; duración del sonido en segundos / amplitud en pascales) y sonograma (parte inferior; duración del sonido en segundos / frecuencia en Hertz) característico de los sonidos producidos por larvas de $C$. cranwelli en un medio acuático en diferentes estadios del desarrollo (STD). Cada gráfico corresponde al sonido emitido por una larva de un determinado STD. Ds: duración del sonido en segundos (s); Np: número de pulsos; Nip: número de interpulsos; Fd: frecuencia dominante en Hertz $(\mathrm{Hz})$ 


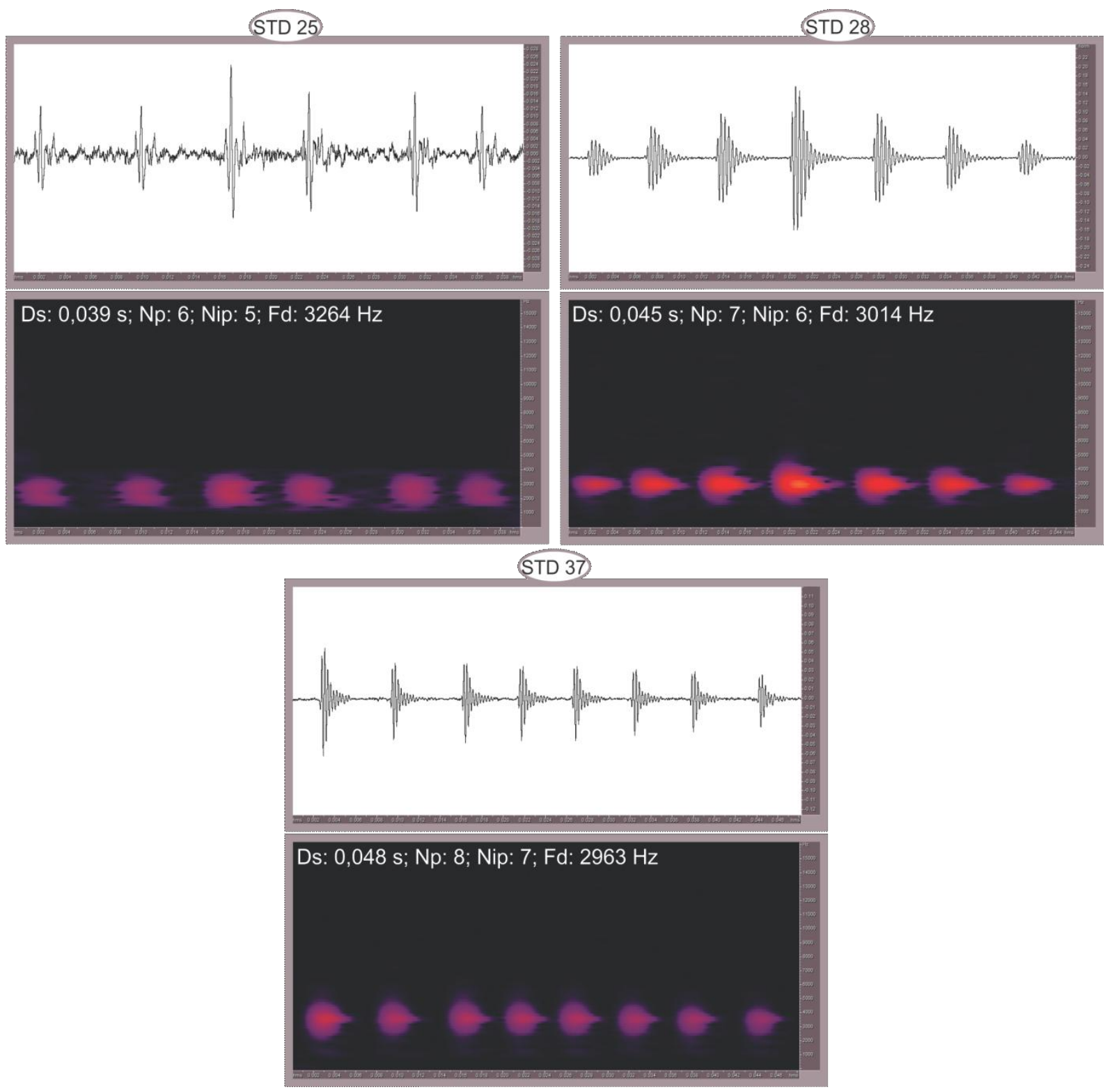

Figura 25. Oscilograma (parte superior; duración del sonido en segundos / amplitud en pascales) y sonograma (parte inferior; duración del sonido en segundos / frecuencia en Hertz) característico de los sonidos producidos por larvas de $C$. aurita en un medio acuático en diferentes estadios del desarrollo (STD). Cada gráfico corresponde al sonido emitido por una larva de un determinado STD. Ds: duración del sonido en segundos (s); Np: número de pulsos; Nip: número de interpulsos; Fd: frecuencia dominante en Hertz $(\mathrm{Hz})$ 


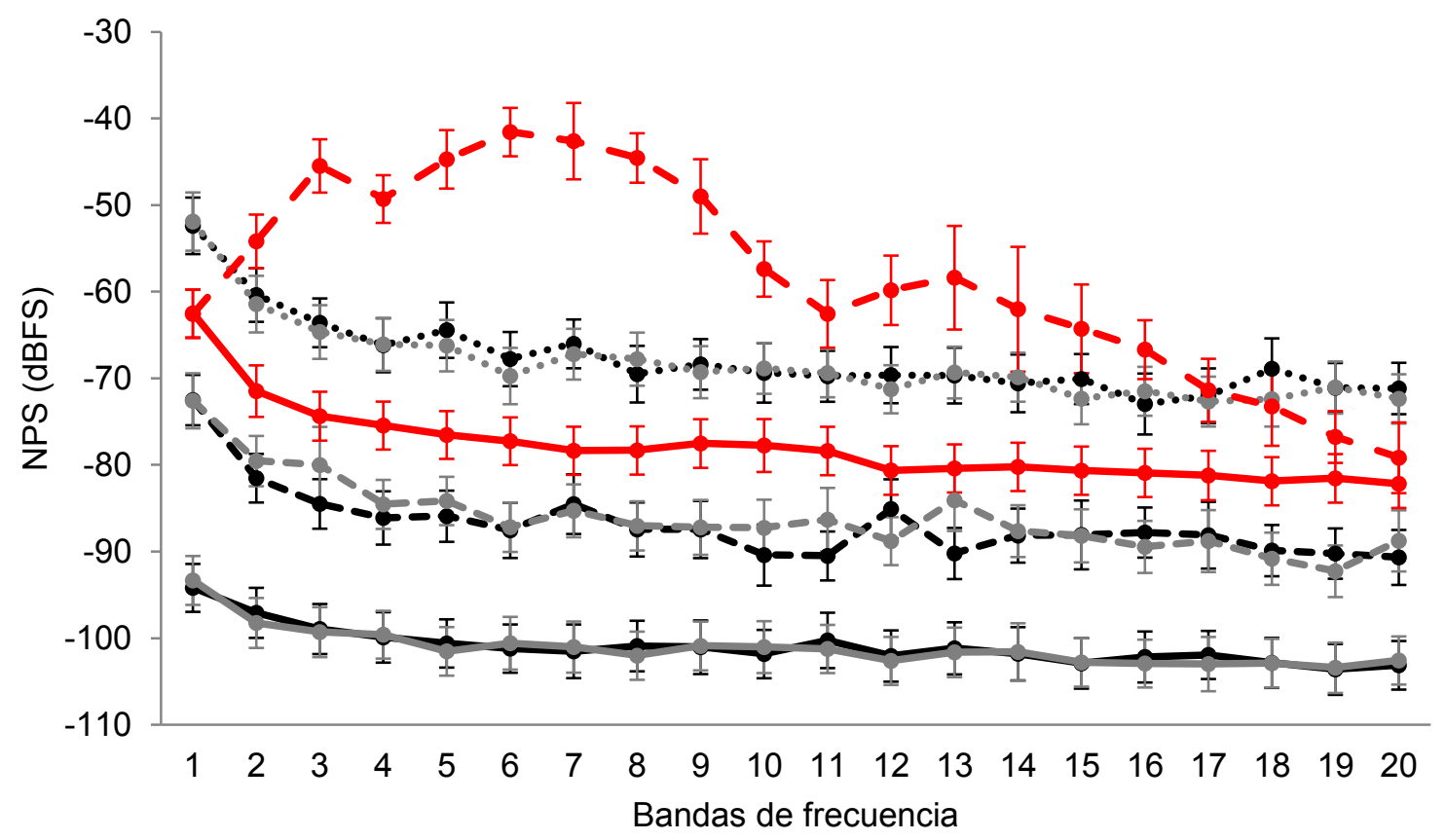

Figura 26. Media energética \pm desvío estándar del nivel de presión sonora (NPS) en decibeles referida a escala completa (dBFS) de 10 sonidos grabados antes (línea negra) y durante interacciones intraespecíficas (línea gris) de 10 larvas de Lepidobatrachus llanensis en estadio 25 (línea punteada), 28 (línea discontinua) y 37 (línea continua). A modo de comparación se muestra el NPS de 10 sonidos grabados antes (línea roja continua) y durante interacciones intraespecíficas (línea roja discontinua) de 10 larvas de Ceratophrys ornata en estadio 37. La media energética fue calculada como $10 \log _{10}\left(1 / \mathrm{n} \sum 10^{\mathrm{SPL} / 10}\right)$. Nótese el incremento prominente en el rango $3000-9000 \mathrm{~Hz}$ de C. ornata. 1-20: número de bandas de $1000 \mathrm{~Hz}$ para cada una de las cuales se midió el NPS

\section{DISCUSIÓN Y CONCLUSIONES}

Teniendo en cuenta la interacción con los Ingenieros Electrónicos del Laboratorio LAL$\mathrm{CIC}$, la misma permitió descubrir algunos aspectos a mejorar en el sistema de grabación CIMA y concluir que los sistemas de registro comúnmente utilizados en bioacústica de anfibios no brindan herramientas adecuadas para cuantificar el sonido aquí descripto (con bajo nivel de presión sonora). Es decir, para caracterizar adecuadamente este tipo de sonidos resultó necesario utilizar instrumentos calibrados con sistemas de referencia acústica. En este sentido, el procedimiento de calibrado y compensado realizado al sistema de grabación CIMA permitió obtener registros más confiables para los diferentes STD tanto en un medio AC como AE. Del mismo modo, la implementación del método de mejoramiento de la RSR, permitió obtener grabaciones con espectros más nítidos y consecuentemente más fáciles de analizar, incrementando la precisión de los registros y mediciones. Para el caso del espectro de niveles sonoros equivalentes, 
el valor obtenido de la RSR para la señal sin filtrar es un valor negativo e indica que la potencia de la señal es menor que la potencia del RF. Por el contrario, al filtrar la señal la RSR aumentó 4,3 veces (6,3 dB). Del mismo modo, el proceso de filtrado del espectro de niveles sonoros máximos aumentó el valor de la $R S R 22,5$ veces $(13,5 \mathrm{~dB})$ y consecuentemente mejoró la señal. En este sentido, las pruebas estadísticas realizadas entre distintas variables bioacústicas de sonidos recortados por debajo de los $1000 \mathrm{~Hz}$ y sin recortar demuestran que mediante el método de mejoramiento de la RSR propuesto no se pierde información de la señal, siempre y cuando el recorte se realice por debajo de la frecuencia informada. Por lo tanto, se concluye que se deben eliminar las componentes de bajas frecuencias teniendo en cuenta las bandas de frecuencias en las cuales se elevan los niveles sonoros durante la emisión de sonidos, lo cual dependerá del STD. A partir de dicha frecuencia de interés hacia abajo pueden ser eliminadas las componentes del espectro, sugiriéndose no recortar las componentes más cercanas al inicio del sonido para evitar la pérdida de información. En este sentido, para juveniles de $C$. ornata se recomienda realizar el recorte por debajo de los $100 \mathrm{~Hz}$.

El método de grabación descripto a lo largo del presente capítulo permitió caracterizar adecuadamente los sonidos producidos por larvas de $C$. ornata a lo largo de su desarrollo y determinar con precisión los estadios en los cuales son producidos, desde el STD 25 hasta el STD 41, luego del cual comienzan a emerger los miembros delanteros. En tal sentido, se concluye que las larvas de $C$. ornata no emiten sonidos desde el STD 42 al 46 debido al estrés que atraviesan los organismos durante el clímax metamórfico y a la reorganización de órganos que ocurre durante esta etapa (Duellman y Trueb, 1994). Sin embargo, una vez completado el proceso metamórfico, los juveniles vuelven a producir sonidos y esto se mantiene durante todo el ciclo vital. Tales sonidos son emitidos tanto durante el periodo juvenil como durante la adultez (independientemente del sexo) y en respuesta a una agresión o molestia (Natale y col., 2008). Tanto Barrio (1963; 1964) como Gallardo (1974) realizan una mención de este fenómeno, pero Barrio (1964) realiza una distinción entre el grito de angustia y el grito agresivo. El primero es considerado por este autor como un "distress call", el cual es emitido por ambos sexos con la boca abierta y sin inflar el saco vocal. El segundo lo describe como típico de la familia Ceratophryidae y lo relaciona con su temperamento agresivo. Más allá de tal diferenciación, cabe aclarar que en el presente trabajo de tesis se considera al grito agresivo de Ceratophrys como una llamada agonística (= distress call), la cual también es emitida por ambos sexos con la boca abierta y sin inflar el saco vocal. Sin embargo, no existían hasta el momento estudios que analicen la variación de estos sonidos desde fases tempranas del desarrollo larval y a lo largo de todo el ciclo vital. Al comparar tales sonidos con las llamadas de anuncio del macho y de reciprocidad de la hembra (Fig. 
22), resulta evidente que esos sonidos poseen un espectro completamente diferente (Fig. 19-21). Se puede observar que los sonidos reproductivos poseen menor variabilidad en la Ds y Fd que aquellos producidos por los mismos individuos al ser molestados, constituyendo los primeros cantos estereotipados y los segundos sonidos simples. Los resultados producto de las correlaciones entre las variables bioacústicas de los sonidos emitidos por larvas, juveniles y adultos de $C$. ornata indican que cuanto mayor es la Ds mayor es el $\mathrm{Np} \mathrm{y}$ Nip que contiene dicho sonido y menor es la Fd. Además, las correlaciones entre las variables bioacústicas y las distintas variables morfométricas y del desarrollo, indican que a medida que aumenta el STD, y consecuentemente aumenta el peso y la LHC, también se incrementa la Ds, el $\mathrm{Np}$ y Nip. Por lo tanto, se deduce que al aumentar el tamaño y desarrollo del organismo, también aumenta el tamaño de la caja resonante, la fuerza de las estructuras musculares y la capacidad de retener y expulsar un determinado volumen de aire, y consecuentemente las características de los sonidos. Según la hipótesis de Natale y col. (2011), más allá de cuál sea el órgano resonante durante la etapa larval, la producción de sonidos ocurre por el pasaje/salida de aire por una determinada estructura que vibra. Consecuentemente, al aumentar el tamaño de dicha estructura aumentan las características mencionadas del sonido. Por el contrario, al aumentar el tamaño y desarrollo del organismo, disminuye la frecuencia dominante tal como ocurre en la mayoría de los anuros (Gerhardt, 1994). Si se comparan los sonidos producidos por juveniles y adultos de C. ornata con aquellos producidos en STD larvales, los primeros son uno y dos órdenes de magnitud más largos, respectivamente, que aquellos producidos en STD larvales. El mecanismo de emisión de sonidos de juveniles y adultos es ampliamente conocido, estando implicado el pasaje de aire por la glotis, el cual proviene desde los pulmones (Duellman y Trueb, 1994). En consecuencia, los sonidos producidos en STD juvenil y adulto también aumentan en longitud y número de pulsos y disminuyen en frecuencia, tal como ocurre en STD larvales. En resumen, se concluye que los sonidos analizados a lo largo del presente capítulo, de características similares, cuya Ds, Np y Nip aumenta y su Fd disminuye a medida que aumenta el STD y consecuentemente el peso de los individuos, pertenecen a la categoría de "llamada agonística" ("distress call") de Duellman y Trueb (1994).

En relación con los distintos contextos en los cuales se realizaron las grabaciones de sonidos (en un medio $\mathrm{AC}$ y $\mathrm{AE}$ ), se concluye que los parámetros de tales sonidos difieren entre sí debido a las características de ambos medios donde fueron grabados. Teniendo en cuenta que la velocidad de propagación de un determinado sonido depende de las características del medio, aquellos que se propagan en un medio líquido lo hacen a mayor velocidad que en un medio gaseoso como la atmósfera (1505 m/s versus $344 \mathrm{~m} / \mathrm{s}$ a $22^{\circ} \mathrm{C}$; Everest y Pohlmann, 2001). Por lo tanto, resulta esperable que la Fd de un sonido grabado en un medio $\mathrm{AE}$ sea mayor que la $\mathrm{Fd}$ de un sonido grabado en un medio 
AC. Teniendo en cuenta que el sonido se propaga a diferente velocidad según el medio, y si se mantienen constantes la condiciones de grabación en ambos medios (agua y aire), se pueden predecir las características de los sonidos de $C$. ornata grabados en un medio $A C$, a partir de las características de los mismos sonidos grabados en un medio AE. Más allá de las diferencias del medio, el método de grabación utilizado permitió caracterizar satisfactoriamente los sonidos producidos por larvas de $C$. ornata tanto en un medio AC como AE.

La interacción con los profesionales del laboratorio LAL-CIC permitió además, mediante su sistema de medición, caracterizar satisfactoriamente los sonidos emitidos en un medio $A E$ por larvas y juveniles de $C$. ornata tanto cuali como cuantitativamente mediante variables acústicas. Se debe tener en cuenta que tales variables acústicas son frecuentemente utilizadas para caracterizar sonidos humanos, las cuales en conjunto con el enfoque bioacústico generaron un conjunto de variables. Estas variables, luego de ser analizadas estadísticamente permitieron establecer criterios de selección. Es decir, no todas las variables obtenidas resultaron informativas para caracterizar acústicamente los sonidos aquí estudiados. En tal sentido, dado que la señal de los sonidos estudiados está fundamentalmente contenida en las componentes del espectro con frecuencias superiores a los $1500 \mathrm{~Hz}$, la curva de ponderación C, la cual apenas reduce las componentes de baja frecuencia, fue descartada para todas las variables. Para el caso particular del $L C_{\text {peak }}$, se debe considerar que el mismo es un parámetro muy sensible a las variaciones instantáneas del ruido dada la capacidad del instrumento para medir con una respuesta temporal de $50 \mu \mathrm{s}$. Tal parámetro fue descartado por varias razones, entre ellas que las señales medidas son de muy bajo nivel sonoro y muy corta duración, y que se requirió la presencia de los operadores de medición dentro de la cámara de ensayos. Es decir, tal nivel pico puede no haber sido generado por el renacuajo sino por otra fuente de ruido. EI LAE pareciera ser el más adecuado para la caracterización de un sonido larval debido a que se trata de un evento sonoro discreto. Sin embargo, este parámetro requiere que sean medidos varios sonidos seguidos para poder registrarlos correctamente, por lo tanto fue descartado. Para el caso de los niveles sonoros estadísticos, el $\mathrm{LAF}_{10}$ fue descartado por no encontrarlo representativo de ninguna característica del sonido a evaluar ni del ruido de fondo. Por lo anteriormente expuesto, se concluye que las variables acústicas que mejor caracterizan el sonido producido por larvas de $C$. ornata son $L F_{\text {máx }}$ y $L_{\text {eq, }} y$ aquella que mejor caracteriza al RF es $\mathrm{LAF}_{90}$.

Por último, en lo que respecta a la emisión de sonidos en estadios larvales por otras larvas de anuros, solo se constató emisión en aquellas especies que poseen hábitos carnívoros, entre ellas C. cranwelli (Salgado Costa y col., 2014b) y C. aurita (Salgado Costa y Natale, 2011). Sin embargo, la especie Lepidobatrachus llanensis 
constituye una excepción a esta regla (Salgado Costa y col., 2015). En consecuencia, la hipótesis original (Natale y col., 2011) que plantea que la emisión de sonidos está presente en todas las larvas de anuros macrófagas y carnívoras de la familia Ceratophryidae debe ser rechazada. Respecto al mecanismo de emisión de sonidos por parte de larvas, podría interpretarse que la emisión se relaciona con la producción de sonidos mediante piezas bucales de las larvas tal como postulan Reeve y col. (2011). Tales autores, describieron una probable coincidencia entre la producción de sonido y un rápido cierre de las vainas mandibulares. Teniendo en cuenta que tales piezas son vestigiales en larvas de L. llanensis (Ruibal y Thomas, 1988), resulta esperable que esta especie no produzca sonidos en estadios larvales. Sin embargo, las evidencias que sostienen tal hipótesis de producción de sonidos resultan escasas. Se recomienda examinar el potencial de producción de sonidos en las restantes cinco especies de Ceratophrys y demás miembros de la familia Ceratophryidae, con la finalidad de determinar el estado del carácter "producción de sonidos" a lo largo del árbol filogenético de los anuros. En lo que respecta al mecanismo de emisión de sonidos, las hipótesis concernientes al mismo son planteadas y puestas a prueba en el próximo capítulo. 
Capítulo 3

Explorando el contexto y mecanismo de emisión de sonidos de larvas de la familia Ceratoprhyidae y las interacciones biológicas de las mismas 
En el capítulo se describen interacciones tanto intraespecíficas como interespecíficas entre larvas macrófagas y carnívoras de Ceratophrys ornata y entre éstas y larvas que forman parte de su dieta habitual. En tal sentido, se describe su producción de sonidos en diferentes contextos, entre ellos producto de interacciones intraespecíficas. Además, se ponen a prueba hipótesis relativas a la función de la señal acústica y de señales visuales y químicas. La descripción de la variabilidad de los sonidos realizada en el capítulo anterior, sumada al contexto de producción de sonidos descripto en el presente capítulo, permitió desarrollar un modelo experimental para su aplicación en estudios ecotoxicológicos de evaluación de efectos de plaguicidas. Por último, se describen interacciones intra e interespecíficas entre larvas macrófagas y carnívoras filogenéticamente cercanas a C. ornata (C. cranwelli, C. aurita, L. Ilanensis) y entre éstas y larvas que forman parte de su dieta habitual. Para estas tres especies se evaluó además la emisión de sonidos en estadios larvales.

\section{INTRODUCCIÓN}

\section{Interacciones biológicas en anfibios}

Una interacción biológica es una relación entre organismos de la misma u otra especie. Tales interacciones son muy diversas, desde aquellas que involucran a organismos que se alimentan de un recurso que dejará de estar disponible para otro organismo, ya sea de la misma u otra especie (competencia intra e interespecífica, respectivamente), especies que se alimentan de la misma u otra especie (predación intra e interespecífica, respectivamente), pasando por aquellas donde ambas especies obtienen un beneficio (mutualismo) o donde una especie es beneficiada mientras la otra no se beneficia ni se perjudica (comensalismo), hasta interacciones en donde una especie depende de la otra para vivir, beneficiándose de ella y perjudicándola al mismo tiempo (parasitismo) (Begon y col., 2006).

Particularmente, la predación intra e interespecífica implica un tipo de interacción predador-presa que involucra a un predador de una determinada especie y a una presa de la misma especie que el predador (Polis, 1981) o a una presa de otra especie (Walters, 1975), respectivamente. En lo que respecta a predación interespecífica, para el caso de anuros juveniles se han reportado varias estrategias de defensa cuya principal función es evitar convertirse en la presa de un determinado predador (Duellman y Trueb, 1994). Tales estrategias han sido resumidas y clasificadas por Toledo y col. (2011) en 30 categorías, siendo las más frecuentes la huida y el permanecer inmóvil. Éstas estrategias no son utilizadas de forma aislada en un individuo sino complementariamente, aumentado así las probabilidades de escapar de un predador. Las funciones particulares de las mismas son 
evitar ser identificado, visualizado, subyugado o ingerido, formando parte de una respuesta antipredatoria (Toledo y col., 2011). Para larvas de anuros, se ha reportado mayormente como estrategia antipredatoria la disminución de la actividad natatoria, la cual se ve afectada ante la presencia de señales químicas de un determinado predador (Stauffer y Semlitsch,1993; Kiesecker y col., 1996; Van Buskirk, 2001; Hettyey y col., 2012). La utilización de señales visuales por larvas de anuros en tal contexto defensivo es considerada de menor importancia, ya que la mayoría de las larvas poseen una visión de corto alcance (Hoff y col., 1999) y su hábitat consiste mayormente y a modo de generalización, de agua turbia y/o vegetación densa (Stauffer y Semlitsch,1993; Kiesecker y col., 1996; Saidapur y col., 2009). Sin embargo, Hettyey y col. (2012) demostraron una disminución en la actividad larval ante la presencia de tales señales, debiéndose quizás a ciertas mejoras introducidas en sus experimentos respecto a otros autores. Tales mejoras incluyen la utilización de recipientes de menor tamaño para facilitar la captación de la señal visual (dada la corta visión larval) y la utilización de larvas de estadios superiores a otros experimentos ya que su visión mejora a mayores estadios (Lannoo, 1999). En lo que respecta a señales hidráulicas (también conocidas como táctiles), las cuales consisten en movimientos del agua detectados por mecano-receptores alojados en el sistema de la línea lateral, si bien no se han informado diferencias significativas respecto al control, no se cuenta con tantos registros al respecto en la literatura científica (Stauffer y Semlitsch, 1993; Jara y Perotti, 2010; Hettyey y col., 2012). Por otro lado, se puede mencionar el caso particular de la agregación de larvas (un tipo de comportamiento), ya sea por reconocimiento intraespecífico o por una respuesta individual a gradientes de temperatura del agua. Éstas han sido interpretadas como un mecanismo antipredatorio ya que los individuos en grandes agregaciones son menos vulnerables a potenciales predadores pequeños que aquellos que viven aislados (Duellman y Trueb, 1994).

\section{Interacciones predador-presa intraespecíficas en larvas de anfibios}

Otro tipo de interacción predador-presa es la predación intraespecífica, también conocida como canibalismo. Es un proceso bien conocido que consiste tanto en matar como ingerir a un individuo de la misma especie, pudiendo esto influenciar la historia de vida, la estructura poblacional, el comportamiento y la competencia por los recursos. El canibalismo ha sido informado en una gran cantidad de especies, desde protozoos hasta mamíferos, y ocurre frecuentemente en repuesta a una baja disponibilidad de alimento, aumento del estrés y/o alta densidad poblacional (Fox, 1975; Crump, 1992). Mediante análisis del contenido estomacal de diferentes taxones del reino animal, se podría generalizar que los animales en estadio adulto son caníbales más voraces que aquellos en estadio juvenil, siendo además los ejemplares pequeños más frecuentemente ingeridos que aquellos de mayor tamaño. 
Cabe destacar, por supuesto, que existen excepciones a tal generalización. También se han reportado casos de canibalismo de manera grupal para atacar a individuos más grandes (Polis, 1981). En algunos casos, el canibalismo ha sido interpretado como una forma de predación oportunista que ocurre naturalmente en distintos taxones, sin estar implicado un reconocimiento intraespecífico (Duellman y Trueb, 1994). En otros, se postula que la existencia de reconocimiento en organismos caníbales confiere beneficios a su aptitud inclusiva (Pfennig, 1997). En lo que respecta a anfibios anuros, algunos autores postulan que las larvas de hábitos carnívoros pasan más tiempo alejadas de sus conespecíficos que las larvas de hábitos omnívoros. Es decir, que las larvas carnívoras evitan estar cerca de un conespecífico, rompiéndose esta tendencia en casos de apetito alto, indicando que el nivel de reconocimiento es contexto-dependiente (Pfennig, 1997; 1999). Específicamente, dentro de este grupo de animales se han reportado casos de canibalismo para 36 especies, tratándose la mayoría de ellos de adultos o juveniles que predan sobre juveniles de la misma especie, o larvas que predan sobre huevos de la misma especie (Polis y Myers, 1985). Cuando se analizan los casos de canibalismo de larvas por parte de larvas, si bien los mismos se verían favorecidos en ambientes acuáticos temporarios por las condiciones de alta densidad y bajos recursos alimenticios, y por la utilización de tal estrategia para acelerar el crecimiento y desarrollo, los mismos son menos numerosos de lo esperado, al menos para larvas de anuros (Crump 1992). Quizás pueda deberse a que cuando se describe el hábito alimenticio de una especie, se hace referencia al/los ítem/s más frecuentemente consumidos mediante análisis del contenido estomacal, no siendo todos fácilmente identificables y/o diferenciables ya que depende de su grado de descomposición. Siguiendo con esta línea de pensamiento, toda especie herbívora podría ser carnívora y/o carroñera facultativa ante la falta de alimento o condiciones de alta densidad (Heyer y col., 1975). En lo que refiere a especies autóctonas, han sido reportados casos de canibalismo larval por parte de larvas solamente para tres especies pertenecientes a la familia Ceratophryidae, Ceratophrys ornata (Cei, 1980), C. cranwelli (Gallardo y Varela de Olmedo, 1992) y Chacophrys pierotti (Cei, 1955), y una especie perteneciente a la familia Leptodactylidae, Pleurodema nebulosum (Cei, 1979). Si bien en la literatura científica se afirma en reiteradas ocasiones que todos los adultos pertenecientes a la familia Ceratophryidae poseen hábitos caníbales, y consecuentemente se asume tal situación para sus larvas, no hay evidencias al respecto sino para las tres especies antes citadas. Tales generalizaciones generalmente provienen de simples reportes producto de la cría de algunas especies en cautiverio, donde pueden ocurrir situaciones artificiales no coincidentes con aquellas que ocurren en la naturaleza. Sin embargo, tal como se mencionó en el primer capítulo, se debe diferenciar entre lo que un organismo es capaz de comer en cautiverio 
(condicionado por aquello que se le ofrece) y lo que realmente come en la naturaleza dado su nicho ecológico (Schalk y col., 2014).

En lo que respecta a señales involucradas en la interacción predador-presa intraespecífica, se ha descripto la utilización de señales químicas, las cuales pueden ser detectadas ya sea producto de una presa herida (situación en la cual se detecta sangre y/o restos de conespecífico, siendo ésta la señal más frecuentemente evaluada en la literatura científica mediante un macerado de conespecífico) o de una presa que está siendo predada y emite una señal. En esta última situación, las señales son emitidas por una presa que resultó predada y alerta a sus conespecíficos de la presencia de un predador. Es decir, las larvas pueden detectar la presencia de un predador a través de señales intraespecíficas, ya sea provenientes de un conespecífico dañado o de una señal hormonal específica la cual es emitida ante situaciones de miedo. Si bien estas últimas han sido poco estudiadas hasta el momento, son también consideradas una estrategia de defensa que desencadenará la posterior huida (Blaustein, 1988; Fraker y col., 2009). Además, se describió la utilización de señales acústicas por primera vez para larvas de la especie C. ornata (Natale y col., 2011). En dicho trabajo se describió la emisión de sonidos por parte de una larva (en el rol de presa) al ser atacada por un conespecífico (en el rol de predador) o al ser tocada por un objeto (espátula metálica o pipeta plástica). En este sentido, se hipotetizó que el conespecífico en el rol de predador reconoce esa señal acústica y evita el canibalismo soltando a su presa. Además, se hipotetizó que la producción de sonidos estaría presente en todas las larvas de anuros macrófagas y carnívoras con la posible función de evitar el canibalismo. Por último, se describió un posible mecanismo de emisión de sonidos, el cual se asemeja al ya conocido mecanismo de individuos adultos, consistiendo el mismo en el pasaje de aire desde los pulmones hacia la glotis. No obstante, en las larvas no habría un saco vocal que actúe como estructura amplificadora del sonido. Una segunda publicación (Reeve y col., 2011), indicó la utilización de señales acústicas durante interacciones intraespecíficas por parte de larvas de Gephyromantis azzurrae. Sin embargo, fueron descriptas en un contexto competitivo, habiéndose interpretado tal emisión como una señal agresiva hacia otros conespecíficos. Es decir, en la primera publicación mencionada la señal acústica es emitida por la presa y en la segunda publicación la señal es emitida por el predador, aunque ambos involucran interacciones intraespecíficas.

Con este contexto teórico específico (dos publicaciones existentes) y el marco teórico que constituye en sí el paradigma ecológico actual, se plantearon las siguientes preguntas de investigación, algunas de las cuales pudieron ser contestadas a lo largo del capítulo: 1) ¿cuándo emiten sonidos las larvas de C. ornata?, 2) ¿quién emite el sonido, el predador o la presa?, 3) ¿cómo emiten tales sonidos? , 4) ¿qué tipo de señales intraespecíficas utilizan las larvas de $C$. ornata para evaluar el riesgo de predación?, 5) ¿poseen las larvas de $C$. ornata 
un mecanismo antipredador?, 6) ¿la emisión de sonidos forma parte del mecanismo antipredador?, 7) ¿es efectiva?. A lo largo del capítulo, se adopta la hipótesis de trabajo original y más parsimoniosa (principio de parsimonia de Ockham), que postula que el sonido forma parte de un mecanismo antipredador, siendo éste el único componente. Sin embargo, se considera posible que otro tipo de señales también estén involucradas y formen parte del mecanismo, siendo la emisión de sonidos tan importante como otras señales no acústicas. Con la intención de comprender el mecanismo antipredatorio, se utilizaron no solo larvas de C. ornata sino también larvas de otras especies autóctonas, macrófagas y carnívoras, para la evaluación de sus interacciones predador-presa y las señales involucradas en las mismas.

\section{Hipótesis}

* Las larvas de C. ornata emiten un sonido audible (señal acústica) en diferentes contextos (interacción intraespecífica o con un objeto), el cual forma parte de un mecanismo antipredador, siendo la señal acústica la única componente.

* El aire empleado para la emisión de sonidos por larvas de C. ornata es almacenado en el estómago y mediante su pasaje por la cavidad bucofaríngea se produce el sonido.

* A mayor densidad de larvas macrófagas y carnívoras (total de larvas/L) ante una proporción predador-presa fija, las larvas carnívoras exhiben mayor cantidad de eventos de canibalismo (hipótesis del efecto de la densidad, HED).

* El número de eventos de canibalismo se incrementa al aumentar la proporción predador-presa (mayor proporción de predadores y menor proporción de presas) y al mantenerse constante la densidad de larvas macrófagas y carnívoras (hipótesis de la disponibilidad relativa de presas, HDRP).

* El mecanismo antipredatorio antes mencionado, disminuye la frecuencia de predación entre organismos conespecíficos.

* Otras larvas macrófagas y carnívoras pertenecientes a la familia Ceratophryidae también emiten sonidos en relación con un mecanismo antipredatorio.

\section{Objetivos}

* Caracterizar el contexto de emisión de sonidos emitidos por larvas de C. ornata, ya sea producto de interacciones intraespecíficas, de ser tocadas experimentalmente (molestadas) o de otra perturbación (ej. choque contra el micrófono).

* Evaluar el mecanismo de emisión de sonidos de larvas de C. ornata

* Evaluar el comportamiento de larvas de C. ornata ante distintas señales (acústicas, químicas y visuales) para determinar la función de las mismas. 
* Evaluar las interacciones predador-presa intra e interespecíficas entre larvas de C. ornata y entre éstas y larvas de anuros que forman parte de su dieta habitual, en diferentes condiciones experimentales de densidad y disponibilidad relativa de presas.

* Evaluar las interacciones predador-presa intra e interespecíficas entre larvas macrófagas y carnívoras de otras especies de la familia Ceratophryidae, y entre éstas y larvas de anuros que forman parte de su dieta habitual, en diferentes condiciones experimentales de densidad y disponibilidad relativa de presas.

* Evaluar la existencia de emisión de sonidos en relación con un mecanismo antipredatorio en larvas macrófagas y carnívoras de otras especies de la familia Ceratophryidae.

\section{MATERIALES Y MÉTODOS}

Para responder las siguientes preguntas: ¿cuándo emiten sonidos las larvas de $C$. ornata?, ¿quién emite el sonido, el predador o la presa?, ¿cómo emiten tales sonidos?, ¿qué tipo de señales intraespecíficas utilizan las larvas de $C$. ornata para evaluar el riesgo de predación?, ¿poseen las larvas de C. ornata un mecanismo antipredador?, ¿la emisión de sonidos forma parte del mecanismo antipredador?, ¿es efectiva?, se realizaron varios experimentos específicos (evaluación del contexto y del mecanismo de emisión de sonidos, evaluación de distintas señales comportamentales y evaluación de interacciones predadorpresa; ver más adelante) y se consideraron todas las grabaciones de audio y video realizadas durante el año 2010 en relación con la primera publicación que registra la emisión de sonidos por larvas de C. ornata (Natale y col., 2011), sumado a las grabaciones de audio y video realizadas en el marco de este trabajo de tesis. Cabe aclarar, que la existencia del mecanismo antipredador fue evaluada mediante experimentos específicos, no solo en larvas de $C$. ornata sino de otras especies filogenéticamente cercanas a ésta (ver más adelante). Complementariamente, se realizaron observaciones producto de la cría de tales larvas en cautiverio y de la grabación de sus sonidos producto de interacciones intra e interespecíficas y producto de tocarlas experimentalmente con una pipeta. A continuación se detallan todos los experimentos, pruebas y observaciones realizadas para responder las preguntas antes enunciadas. 


\section{Evaluación del contexto y del mecanismo de emisión de sonidos por larvas de C. ornata}

Para evaluar el contexto de emisión de sonidos (¿cuándo emiten sonidos las larvas de $C$. ornata?, y ¿quién emite el sonido, el predador o la presa?), se utilizaron larvas producto de la inducción realizada en el año 2014 (ver capítulo 1, página 48). Se dispusieron cinco larvas de C. ornata de STD 37 en una bandeja de $45,5 \times 32,5 \times 26,0 \mathrm{~cm}$ junto a una larva de Hypsiboas pulchellus. Se realizaron simultáneamente observaciones visuales y grabaciones de audio a lo largo de todo el experimento con la metodología detallada en el capítulo 2 (ver página 71). El experimento consistió en observar y anotar el comportamiento de las larvas durante sesiones de $15 \mathrm{~min}$, realizándose en total cuatro sesiones. De esta manera, se registró la cantidad de interacciones intra e interespecíficas, el modo de la interacción (ej. boca con cola: una larva ataca a otra larva por la cola) y la presencia/ausencia de emisión de sonidos durante las interacciones. Asimismo, se registraron todos los contextos de emisión de sonidos, no solo aquellos que implicaron una interacción intraespecífica sino aquellos que implicaron una perturbación (ej. choque contra el micrófono). También se realizaron observaciones producto de la cría de larvas de esta especie en cautiverio y de la grabación de sus sonidos durante interacciones intra e interespecíficas y durante el tocado de las mismas con una pipeta. Tanto las grabaciones de audio y video antes mencionadas como las observaciones presenciales, aumentaron considerablemente el número de datos a evaluar para responder las preguntas anteriormente enunciadas.

Para evaluar el mecanismo de emisión de sonidos (¿cómo emiten sonidos?), se realizaron una serie de pruebas morfo-funcionales con el objetivo de obturar ciertas estructuras y determinar la presencia/ausencia de emisión de sonidos en esas circunstancias. Previo a los procedimientos detallados, se anestesió a cada larva con una solución de benzocaína $(250 \mathrm{ml} / \mathrm{L})$ de acuerdo a las recomendaciones de la Comisión Europea (Close y col., 1996). Se realizaron las siguientes pruebas con distintas larvas y bajo lupa binocular: inmovilización del pico corneo (pegando la partes superior e inferior), obturación de la cavidad bucal con algodón, obturación de la glotis con un tubo rígido que no permitió la variación de la luz del tubo (jeringa Hamilton), colapso de pulmones por ruptura de tejidos (pared pulmonar), pasaje de aire forzado desde el estómago hacia la glotis a través de una cánula y llenado del estómago con gelatina mediante una jeringa punzada desde la cavidad abdominal a nivel anterior derecho. En todos los casos se utilizaron larvas de STD 37 (por su tamaño) para facilitar los procedimientos dado el pequeño tamaño de las estructuras a obturar. Cada intervención se realizó con un control en el cual una larva fue sometida a los mismos procedimientos (anestesia, manipulación quirúrgica) pero sin bloqueo de estructuras. Una vez recuperadas de la operación, tanto las larvas control como las larvas obturadas fueron grabadas y observadas para evaluar la emisión/no emisión de 
sonidos. Por último, se mantuvieron otras dos larvas por separado, cada una en una

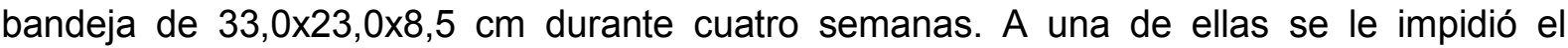
acceso a la superficie para tomar aire atmosférico. Diariamente se las molestó con una pipeta plástica y se evaluó la emisión/no emisión de sonidos. Cabe aclarar que todas estas pruebas carecen de un diseño experimental ya que fueron realizadas con los materiales que se tuvieron al alcance y con el simple objetivo de distinguir el mecanismo de emisión de sonidos. Teniendo en cuenta que la mayoría de las intervenciones quirúrgicas implican la posterior muerte de los individuos, no fue la intención de este trabajo de tesis realizar pruebas con cientos de larvas sino que se utilizó la menor cantidad posible de individuos con el objetivo de aportar evidencias que permitieran generar nuevas hipótesis acerca del mecanismo de emisión de sonidos.

\section{Experimentos de comportamiento: evaluación del comportamiento de larvas de C. ornata ante señales acústicas, visuales y químicas}

Para responder la pregunta ¿qué tipo de señales intraespecíficas utilizan las larvas de $C$. ornata para evaluar el riesgo de predación?, se evaluó su respuesta comportamental a diferentes señales: acústica $(A)$, química $(Q)$ y visual $(V)$ mediante la realización de tres experimentos diferentes, uno por cada señal, siguiendo la metodología propuesta por Pueta y col. (2016). Se utilizaron larvas de C. ornata de STD 37 producto de la inducción del año 2013 (ver capítulo 1, página 48). En términos generales, se dispusieron larvas de $C$. ornata en recipientes cilíndricos de polipropileno de $500 \mathrm{ml}(8,50 \times 8,50 \times 8,00 \mathrm{~cm})$ con agua declorinada (ver parámetros de calidad del agua en capítulo 1, página 54). Antes de evaluar cada señal las larvas fueron individualmente alimentadas y habituadas al recipiente de experimentación durante 5 minutos ( $\mathrm{min}$ ). Se realizaron grabaciones de video de cada larva con una cámara Sony DCR-HC28. Cada larva fue filmada durante un tiempo previo a la adición de la señal (tiempo pre-señal) y un tiempo de igual duración posterior a la adición de la señal (tiempo post-señal). Se utilizaron 15 larvas de $C$. ornata por cada tratamiento y su respectivo control (= 30 larvas por experimento), habiéndose asignado cada larva a cada tratamiento y réplica de manera aleatoria. Se analizaron las filmaciones y se cuantificó como variable respuesta el tiempo total que las larvas estuvieron en actividad tanto en el periodo pre como post-señal. Se consideró a una larva en actividad siempre que ésta realizó algún tipo de movimiento, ya sea de desplazamiento de un punto hacia otro del recipiente o en el lugar. Los análisis de las filmaciones fueron realizados por un experimentador sin conocimiento previo del tratamiento de la larva que se estaba observando (a ciegas) mediante la utilización del programa Fox-Pro 2.0 (Fox Holdings) para registrar las variables antes enunciadas. Durante todos los experimentos se realizaron grabaciones de audio con la metodología detallada en el capítulo 2 (ver página 71). 
Para evaluar la señal acústica (A) se realizó un tratamiento, cuya señal consistió en un sonido de conespecífico (A-Cn, sonido de $C$. ornata) y un grupo control $(A-C)$ cuya señal consistió en un sonido de igual duración pero diferente frecuencia y número de pulsos. Los respectivos sonidos fueron reproducidos mediante un auricular, el cual fue aislado del agua con un film y testado por el grupo del LAL. El periodo pre-señal duró $5 \mathrm{~min}$, luego del cual se reprodujo el sonido de conespecífico o control según correspondiera y se dejaron pasar otros 5 min post-señal (Fig. 27A).

Para evaluar la señal química $(Q)$ se realizó un tratamiento, cuya señal consistió en un macerado de larva de conespecífico (Q-Cn) y un grupo control (Q-C) cuya señal consistió en introducir agua destilada. A partir de $2,10 \mathrm{~g}$ de larvas de $C$. ornata del mismo estadio se realizó un macerado mediante un homogeneizador marca PRO Scientific ${ }^{\circledR}$ modelo PRO200. El mismo fue diluido en agua destilada llevándolo a un volumen de $30 \mathrm{ml}$ (manteniendo una relación $0,07 \mathrm{mg} / \mathrm{ml}$ ), filtrado dos veces mediante filtro de tela de $45 \mu \mathrm{m}$, fraccionado en eppendorf de $1,5 \mathrm{ml}$ y mantenido en freezer hasta su utilización (Pueta y col., 2016). Para este experimento el periodo pre-señal duró $10 \mathrm{~min}$, luego del cual se introdujo en cada recipiente $1,5 \mathrm{ml}$ de cada señal (conespecífica o agua, según correspondiera) mediante una pipeta Pasteur y se dejaron pasar 10 min post-señal. Se seleccionaron 10 min de prueba ya que una señal química puede durar más tiempo en el agua que las demás señales consideradas (Fig. 27B).

Para evaluar la señal visual $(V)$ se realizó un tratamiento cuya señal consistió en una larva conespecífica ( $\mathrm{V}-\mathrm{Cn})$ y un grupo control cuya señal consistió en una larva heteroespecífica $(\mathrm{V}-\mathrm{Ht})$. Con la finalidad de utilizar como señal heteroespecífica a una larva de similar tamaño y STD se colectaron en campo larvas de Leptodactylus latrans. EI experimento consistió en colocar una larva (señal conespecífica o heteroespecífica, según correspondiera) dentro de un vaso de precipitado, el cual a su vez fue colocado dentro del recipiente de polipropileno. El período pre-señal duró $5 \mathrm{~min}$, luego del cual se colocó la señal durante $1 \mathrm{~min}$. A continuación, se retiró el vaso con la larva y se colocó otro vaso de precipitado de iguales características y tamaño pero vacío y se dejaron pasar 10 min postseñal (Fig. 27C). Debido al estrés (observado en las filmaciones) que generaba la manipulación del vaso de precipitado, en este experimento se decidió analizar 1 min preseñal y 1 min post-señal (considerando tal tiempo mientras se encontraba la señal en el vaso). 


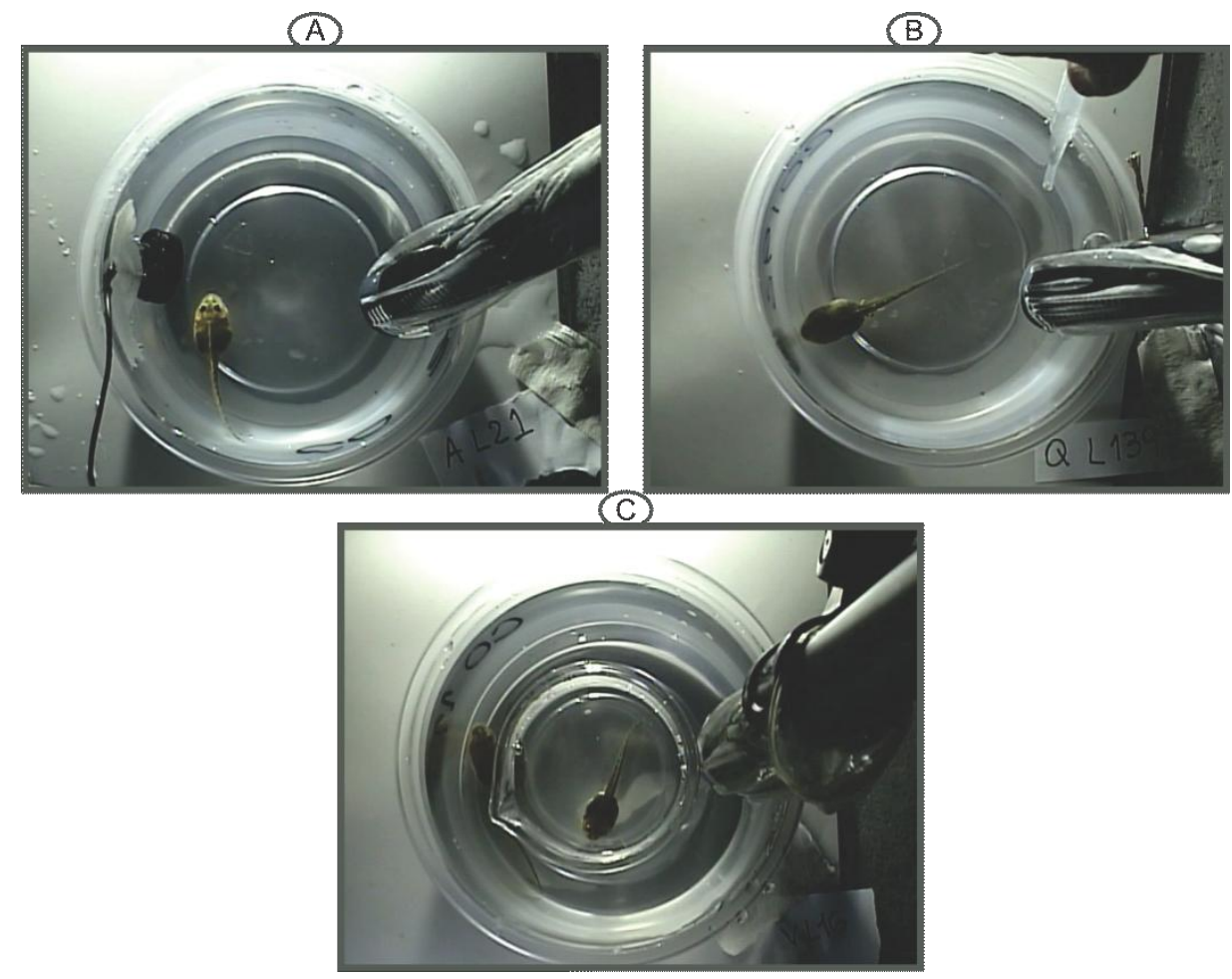

Figura 27. Método de introducción de la señal acústica (A), química (B) y visual (C) durante los experimentos realizados para evaluar el comportamiento de larvas de $C$. ornata

\section{Experimentos de interacción: evaluación de interacciones predador-presa entre larvas de la familia Ceratophryidae y otras larvas de anuros}

Con el propósito de determinar la existencia de un mecanismo antipredatorio y de evaluar interacciones intra e interespecíficas entre larvas carnívoras y otras larvas que forman parte de su dieta habitual, se seleccionaron cuatro especies de la familia Ceratophryidae: C. ornata, C. cranwelli, C. aurita y Lepidobatrachus llanensis. Para ello se utilizaron las larvas obtenidas producto de las inducciones realizadas en 2012 (ver capítulo 1). En términos generales, cada experimento realizado con cada especie consistió en disponer larvas macrófagas y carnívoras (predador, $P$ ) en STD 25, en bandejas de polipropileno de $1 \mathrm{~L}$ de $21,5 \times 15,5 \times 3,5 \mathrm{~cm}$ junto a larvas herbívoras (presa, $p$ ) del mismo STD, en distintas densidades (4 larvas $/ L=2 P-2 p, 10$ larvas $/ L=5 P-5 p, 20$ larvas $/ L=10 P-10 p$ ) y distintas proporciones predador-presa $(0=0 P-10 p, 1 / 4=2 P-8 p, 2 / 3=4 P-6 p, 11 / 2=6 P-4 p, 8 / 2=8 P$ $2 p, 10=10 P-0 p)$, todos por cuadruplicado. De este modo, se evaluaron las hipótesis del efecto de la densidad (HED) e hipótesis de la disponibilidad relativa de presas (HDRP), respectivamente (Fig. 28). Todos los experimentos fueron realizados en condiciones controladas de laboratorio (temperatura: $22 \pm 1{ }^{\circ} \mathrm{C}$; alcalinidad: 181,3 $\pm 42,2 \mathrm{mgCaCO}_{3} / \mathrm{L}$; dureza: $142,0 \pm 2,3 \mathrm{mgCaCO}_{3} / \mathrm{L} ; \mathrm{pH}: 8,05 \pm 0,05 ;$ conductividad: $\left.754 \pm 9 \mu \mathrm{S} / \mathrm{cm}\right)$. Se registró la cantidad de predadores y presas vivos de cada especie cada hora durante $48 \mathrm{~h}$, 
considerando las siguientes variables: tiempo que tardan en comer la primera presa en minutos $\left(1^{\circ} \mathrm{p}, \min \right)$, tiempo que tardan en comer la segunda presa $\left(2^{\circ} \mathrm{p}\right.$, min), tiempo que tardan en comer todas las presas (Tp, min), tiempo sin comer, luego de comerse a todas las presas (Sc, $\mathrm{min}$ ), tiempo en el cual ocurren eventos de canibalismo (Conesp, min), número de eventos de canibalismo (C). Se espera que a mayor densidad de larvas macrófagas y carnívoras (total de larvas/L) ante una proporción predador-presa constante, las larvas carnívoras exhiban mayor cantidad de eventos de canibalismo (HED); y que el número de eventos de canibalismo aumente al aumentar la proporción predador-presa (mayor proporción de predadores) ante una densidad constante (HDRP). Por último, se describió en detalle la interacción tanto intra como interespecífica no solo a partir de observaciones visuales sino también de grabaciones de audio (ver capítulo 2) y video realizadas aleatoriamente con una Sony DCR-HC28. Tales grabaciones permitieron responder si la emisión de sonidos forma parte del mecanismo antipredador y si tal emisión es efectiva. A continuación se detalla cada experimento y las diferencias respecto al esquema general presentado:

\section{Ceratophrys ornata}

Se realizaron dos experimentos (E1 y E2) independientes con los tres tratamientos antes propuestos para testear HED y los seis tratamientos propuestos para testear HDRP. Para E1 se dispusieron larvas de $C$. ornata $(C o, P)$ en STD 25 (promedio $\mathrm{LHC} \pm \mathrm{DE}=5,855 \pm$ $0,157 \mathrm{~mm}$; promedio peso $\pm \mathrm{DE}=0,051 \pm 0,005 \mathrm{~g}, \mathrm{n}=10$ ), junto a larvas de Hypsiboas pulchellus $(H p, p)$ del mismo STD (promedio LHC $\pm \mathrm{DE}=4,609 \pm 0,648 \mathrm{~mm}$; promedio peso $\pm \mathrm{DE}=0,023 \pm 0,004 \mathrm{~g}, \mathrm{n}=10$ ) en las distintas densidades y proporciones predador-presa antes enunciadas. Para E2 el único cambio introducido es que se utilizaron como presas larvas de Rhinella fernandezae ( $R f$ : promedio $\mathrm{LHC} \pm \mathrm{DE}=4,462 \pm 0,204 \mathrm{~mm}$; promedio peso $\pm \mathrm{DE}=0,018 \pm 0,005 \mathrm{~g}, \mathrm{n}=10)$.

\section{Ceratophrys cranwelli}

Se realizó un experimento (E3) con los tres tratamientos antes propuestos para testear HED y cuatro de los seis tratamientos propuestos para testear HDRP (2Cc-8Ra; 4Cc-6Ra; 6Cc-4Ra; 8Cc-2Ra), todos con cinco replicados. Se dispusieron larvas de C. cranwelli (Cc, $P$ ) de STD 37 (promedio LHC $\pm \mathrm{DE}=17,210 \pm 1,166$; promedio peso $\pm \mathrm{DE}=1,032 \pm 0,192$ $\mathrm{g}, \mathrm{n}=10)$ junto a larvas de $R$. arenarum $(R a, p)$ del mismo STD (promedio LHC $\pm \mathrm{DE}=$ $11,870 \pm 0,856 \mathrm{~mm}$; promedio peso $\pm \mathrm{DE}=0,715 \mathrm{~g} \pm 0,131, \mathrm{n}=10)$. Se registró la cantidad de predadores y presas vivos de cada especie durante $72 \mathrm{~h}$, habiéndose realizado registros cada hora durante las primeras seis horas y luego cada $3 \mathrm{~h}$ hasta el final del experimento. 

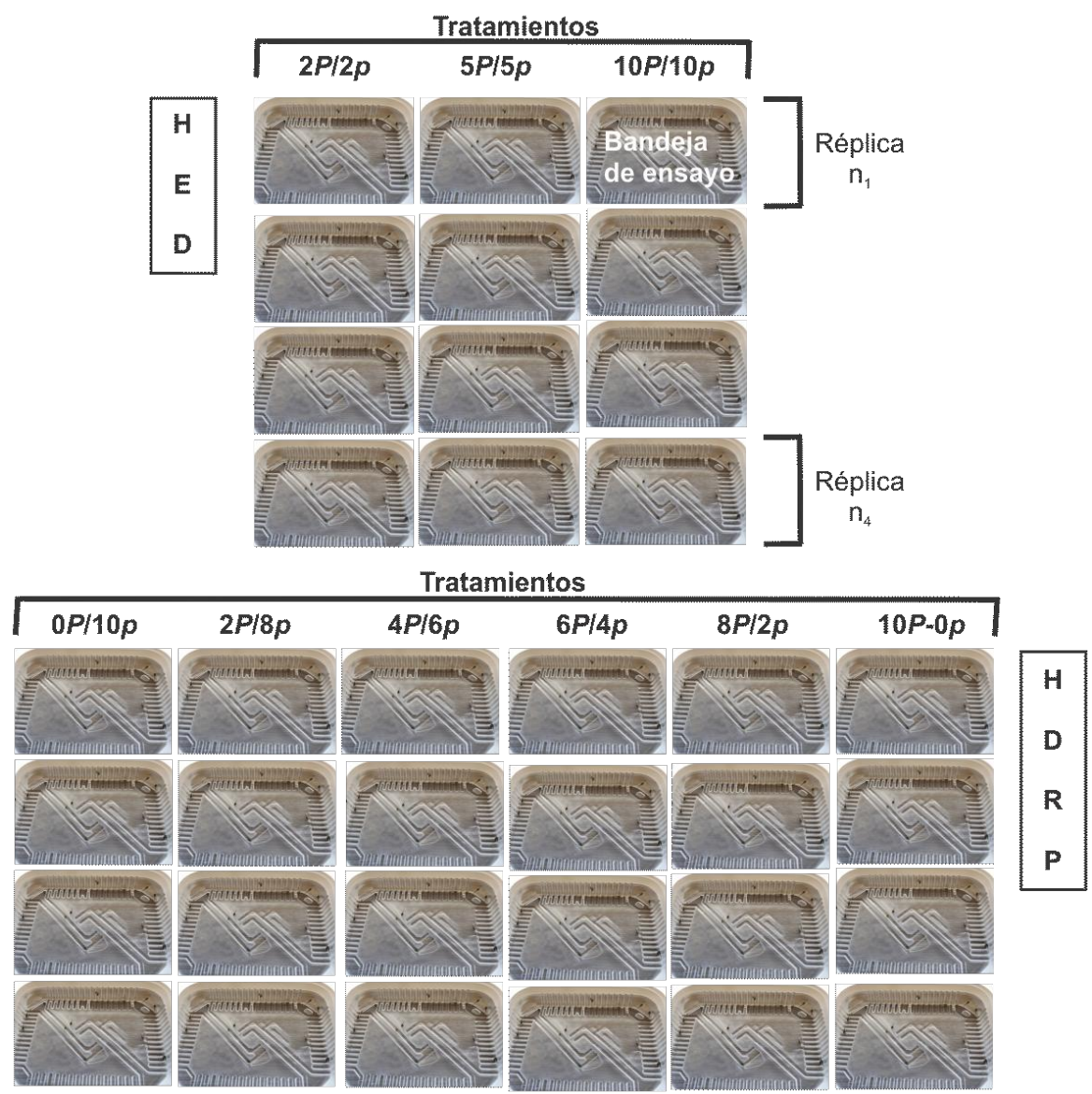

Figura 28. Esquema general de los experimentos realizados para evaluar la hipótesis del efecto de la densidad (HED) y la hipótesis de la disponibilidad relativa de presas (HDRP), indicando los tratamientos y réplicas $\left(\mathrm{n}_{1}\right.$ a $\left.\mathrm{n}_{4}\right)$. $P$ : predador; $p$ : presa

\section{Lepidobatrachus Ilanensis}

Se realizó un experimento (E4) con los seis tratamientos propuestos para testear HDRP pero no se testeó la HED por falta de larvas. Se dispusieron larvas de $L$. llanesis $(L I, P)$ en STD 25 (promedio LHC $\pm \mathrm{DE}=0,88 \pm 0,17 \mathrm{~mm}$; promedio peso $\pm \mathrm{DE}=0,0202 \pm 0,0055 \mathrm{~g}, \mathrm{n}$ = 6) junto a larvas de $H p(p)$ del mismo STD (promedio LHC $\pm \mathrm{DE}=0,46 \pm 0,06 \mathrm{~mm}$; promedio peso $=0,0227 \pm 0,0042 \mathrm{mg}, \mathrm{n}=10$ ). Se registró la cantidad de predadores $\mathrm{y}$ presas vivos de cada especie cada media hora durante $48 \mathrm{~h}$.

\section{Ceratophrys aurita}

Se realizaron grabaciones de audio y video de larvas de $C$. aurita $(\mathrm{Ca}, P)$ junto a larvas de distintas especies $(H p, R a)$ en distintas densidades y proporciones predador-presa con el objetivo de evaluar la existencia de un mecanismo antipredatorio. Además, se realizaron observaciones visuales producto de la cría de la especie en cautiverio. Para el caso particular de $C$. aurita, la evaluación de la existencia de un mecanismo antipredatorio se 
realizó solamente a partir de las grabaciones de audio y video, no habiéndose realizado experimentos que evalúen la HED y la HDRP con esta especie.

\section{Análisis estadístico}

Los datos resultantes del experimento realizado para determinar el contexto de emisión de sonidos fueron resumidos en una tabla de frecuencias. Se realizó una prueba de chicuadrado para evaluar la independencia de la emisión de sonidos durante las distintas interacciones intraespecíficas observadas (B-Bpo, B-C, B-B). El mismo análisis fue realizado para evaluar la independencia de la emisión de sonidos durante interacciones intra e interespecíficas. Los datos producto de los experimentos realizados con la finalidad de determinar el mecanismo de emisión de sonidos fueron analizados descriptivamente.

Respecto a la evaluación del comportamiento de $C$. ornata ante diferentes señales, se seleccionaron los valores atípicos teniendo en cuenta el primero y tercer cuartil, eliminando aquellos valores menores al valor de $Q_{25 \%}-1,5$ y mayores al valor de $Q_{75 \%}+1,5$ (Alperin, 2013). Luego, se realizó una prueba de $t$ pareada entre la duración del tiempo en movimiento de cada larva pre-señal y post-señal para cada tratamiento de cada experimento. Se realizó también una prueba de $t$ de diferencia entre medias para la diferencia en la duración post-pre señal entre los distintos tratamientos por ser el análisis frecuente que se realiza en los estudios de comportamiento.

Las distintas variables medidas $\left(1^{\circ} \mathrm{p}, 2^{\circ} \mathrm{p}, \mathrm{Tp}\right.$, Sc, Conesp, C) para evaluar HED y la HDRP fueron resumidas mediante medidas de resumen de posición \pm desvío estándar. EI número de eventos de canibalismo para cada tratamiento ocurridos durante el periodo de apetito normal se comparó con el número de eventos de canibalismo ocurridos durante el periodo de apetito alto mediante una prueba $U$ de Mann-Whitney. De manera similar, se realizó una prueba de $t$ de diferencias entre medias para comparar el tiempo que tardan en comer la primera presa de cada tratamiento con el tiempo que tardan en comer un conespecífico de cada tratamiento. Se evaluó la existencia de correlación lineal entre las distintas variables medidas y las distintas densidades y proporciones predador-presa. Por último, se comparó el tiempo en el cual ocurren eventos de canibalismo y el número de eventos de canibalismo de las especies evaluadas mediante un ANOVA.

Para la realización de todas las pruebas estadísticas se utilizó el programa Statistica 7.0 $\left(\right.$ Statsoft ${ }^{\circledR}$ ) y se eligió un nivel de significancia de 0,05 . Además, todas las pruebas realizadas cumplen con sus respectivos supuestos (Zar, 2010). 


\section{RESULTADOS}

\section{Contexto y mecanismo de emisión de sonidos por larvas de C. ornata}

Durante el experimento realizado se observaron 78 interacciones diferentes, las cuales fueron clasificadas en cinco tipos. La más frecuente (58\%) implicó una interacción predadorpresa intraespecífica mediante la cual una larva de $C$. ornata (predador) ataca con su boca (B) a otra de su misma especie (presa) por el cuerpo (Cpo). De ese 58\%, el 93\% (= 42) de las larvas que fueron atacadas emitieron un sonido y lograron escapar del predador y solo el $7 \%$ (= 3) no emitió sonidos pero logró escapar del predador. Las dos siguientes interacciones más frecuentes (aunque menores en ocurrencia) también implicaron una interacción intraespecífica pero mediante el ataque a la cola $(19 \%)$ o a la boca $(15 \%)$ de la presa. De la interacción boca-cola $(B-C)$, el $73 \%(=11)$ de las larvas atacadas emitieron un sonido y lograron escapar del predador y solo el $27 \%$ (= $)$ no emitió un sonido pero logró escapar del predador. De la interacción boca-boca (B-B), el 58\% (=7) de las larvas atacadas emitieron un sonido y lograron escapar del predador y el $42 \%$ restante $(=5)$ no emitió un sonido pero logró escapar del predador. Los dos tipos restantes de interacciones menos frecuentes implicaron una interacción interespecífica, mediante la cual una larva de $C$. ornata atacó a una larva de $H$. pulchellus por el cuerpo (6\%) sin emisión de sonidos en el $100 \%$ de los casos, y la interacción con un objeto (1\%, choque de una larva de C. ornata contra el micrófono) seguido de la emisión de sonidos en el $100 \%$ de los casos. Por último, del total del interacciones observadas, el $78 \%(=61)$ de las larvas en el rol de presa emitieron un sonido y lograron escapar del predador mientras que solo el $22 \%$ restante no emitió un sonido pero logró escapar del predador (Tabla 13A). Además, a partir de los resultados de esta tabla se puede inferir que las larvas de $C$. ornata interaccionan más veces entre sí que con un individuo heteroespecífico.

El análisis de datos de la tabla de contingencia para las categorías emisión/no emisión de sonidos durante los distintos tipos de interacciones intraespecíficas (B-Cpo, B-C, B-B; tabla $1 A)$ arrojó diferencias significativas $\left(X^{2}=9,720, p=0,007\right)$, indicando una dependencia de la interacción con la emisión de sonidos. El análisis de datos de la tabla de contingencia para las categorías emisión/no emisión de sonidos durante las interacciones intra e interespecíficas (tabla 1A) arrojó diferencias significativas $\left(X^{2}=18,873, p<0,0005\right)$, indicando una dependencia del tipo de interacción con la emisión de sonidos. El análisis de datos de la tabla de contingencia para las categorías emisión/no emisión durante distintas interacciones (intra e interespecíficas, tocada con pipeta, choque contra micrófono; tabla 13B), construida a partir de observaciones realizadas durante la cría en cautiverio de larvas de esta especie y de la grabación de sus sonidos, arrojó diferencias significativas $\left(X^{2}=\right.$ 
$5376,952, p<0,0005)$. También se obtuvieron diferencias significativas para las categorías emisión/no emisión de sonidos durante interacciones intra e interespecíficas $\left(X^{2}=4966,196\right.$, $p<0,0005)$. En resumen, se puede afirmar que cada vez que se observó una interacción intraespecífica entre larvas de $C$. ornata, cada vez que se molestó a una larva tocándola con una pipeta plástica y cada vez que se observó a una larva chocarse contra el micrófono, las mismas emitieron sonidos en el $87 \%$ de los casos para las dos primeras situaciones y en el $91 \%$ de los casos para la última situación. Sin embargo, cada vez que se observó a una larva de $C$. ornata comiéndose a una larva heteroespecífica el predador (Co) no emitió sonidos en el $100 \%$ de los casos.

Por último, los resultados de la serie de pruebas morfo-funcionales realizadas con dos larvas por prueba para determinar el mecanismo de emisión de sonidos indican que: las larvas emiten sonidos aún con el pico córneo inmovilizado, con la cavidad bucal obturada y con los pulmones colapsados. Sin embargo, dejan de emitir sonidos cuando la glotis se encuentra obturada, revelando la necesidad de pasaje de aire por la misma para la emisión de sonidos. En el mismo sentido, se pudo comprobar que cuando se fuerza el pasaje de aire desde el estómago hacia la glotis a través de una cánula, se producen sonidos de similares características al que producen las larvas de C. ornata. Estos últimos resultados permiten aceptar la hipótesis que plantea que el aire empleado para la emisión de sonidos es almacenado en el estomago y mediante un pasaje del mismo por la glotis hacia la cavidad bucal y luego hacia la cavidad oral produce el sonido. En el mismo sentido, y siguiendo con las pruebas morfo-funcionales, si bien la larva a la cual se le llenó el estómago con gelatina nunca dejó de emitir sonidos, tal prueba no se considera concluyente ya que no se pudo comprobar el total llenado del estómago dada la dificultad para realizar esta tarea manteniendo al individuo con vida luego de la anestesia. Otra evidencia que permite aceptar la hipótesis del aire estomacal es la frecuente observación (a simple vista y por transparencia de la zona ventral) de la presencia de una burbuja de aire alojada en el estómago de las larvas. Por último, se comprobó que las larvas de $C$. ornata no necesitan de la toma de aire atmosférico para la emisión de sonidos, ya que tanto la larva sin acceso a la superficie como aquella con acceso a la misma, emitieron sonidos cada vez que fueron molestadas. En la fig. 29, se muestra una fotografía electrónica de barrido (Natale y col., 2011) mediante la cual se pudo comprobar la presencia de las supuestas estructuras involucradas en la emisión de sonidos. Para todas las pruebas realizadas las larvas del grupo control emitieron sonidos luego de los procedimientos quirúrgicos sin obturación de estructuras. Cabe recordar que estas pruebas carecen de diseño y del posterior análisis estadístico riguroso, sin que ese hecho invalide las hipótesis planteadas al respecto (ver más adelante). 
Tabla 13. Frecuencia absoluta de interacciones observadas en larvas de Ceratophrys ornata seguidas por la emisión/no emisión de sonidos. A: número de observaciones producto del experimento realizado para evaluar el contexto de emisión de sonidos; B: número de observaciones producto de la cría de la especie en cautiverio y de la grabación de sonidos; B: boca; C: cola; Cpo: cuerpo

A

\begin{tabular}{c|cc|cc} 
& Con sonido & Sin sonido & Con sonido & Sin sonido \\
\cline { 1 - 3 } B-Cpo & 42 & 3 & \multirow{2}{*}{2982} & 447 \\
\hline B-C & 11 & 4 & & \\
\hline B-B & 7 & 5 & 0 & 3104 \\
\hline Hetero & 0 & 5 & 400 & 60 \\
\hline Pipeta & -- & -- & 198 & 19 \\
\hline Micrófono & 1 & 0 & &
\end{tabular}

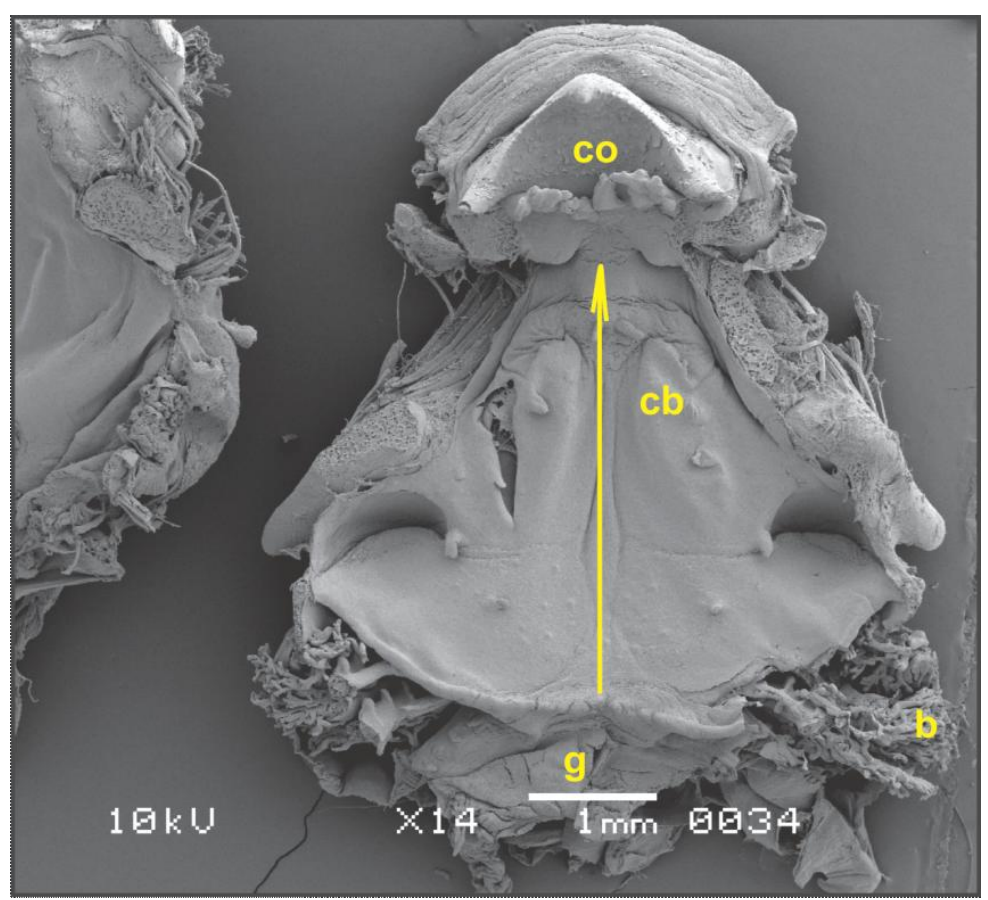

Figura 29. Fotografía electrónica de barrido mostrando las estructuras de una larva de Ceratophrys ornata de estadio 31. Con una flecha se indica el hipotético pasaje de aire para la producción de sonidos; co: cavidad oral; cb: cavidad bucal; g: glotis; b: branquias

\section{Comportamiento de larvas de C. ornata ante señales acústicas, químicas y visuales}

Los resultados de la evaluación de cada señal se resumen en la fig. 30 mediante la diferencia de la duración total post-pre señal. Específicamente, la prueba de $t$ de diferencia entre medias para la señal acústica no arrojó diferencias significativas $(p=0,282)$ para la diferencia en la duración post-pre señal entre los distintos tratamientos. Sin embargo, la prueba de $t$ pareada arrojó diferencias significativas a cola inferior para el tratamiento 
conespecífico $(t=1,961$, g.l. $=14, \mathrm{p}=0,035)$ indicando una disminución de la actividad de cada larva luego de la señal acústica (Fig. 31). Respecto a la señal química, la prueba de $t$ de diferencia entre medias para la diferencia en la duración post-pre señal entre los distintos tratamientos no arrojó diferencias significativas $(p=0,106)$, como tampoco la prueba de $t$ pareada arrojó diferencias significativas para ninguno de los tratamientos evaluados (agua: $p$ $=0,071$; conespecífico: $p=0,716$ ) (Fig. 31). Por último, para el caso de la señal visual la prueba de $t$ de diferencia entre medias para la diferencia en la duración post-pre señal entre los distintos tratamientos arrojó diferencias significativas a cola inferior $(p=0,021)$ siendo menor la duración del tiempo en movimiento post-señal. La prueba de $t$ pareada también arrojó diferencias significativas a cola inferior $(p=0,018)$ entre la duración del tiempo en movimiento pre y post-señal para la señal conespecífica, siendo menor la duración del tiempo en movimiento post-señal (Fig. 31). 


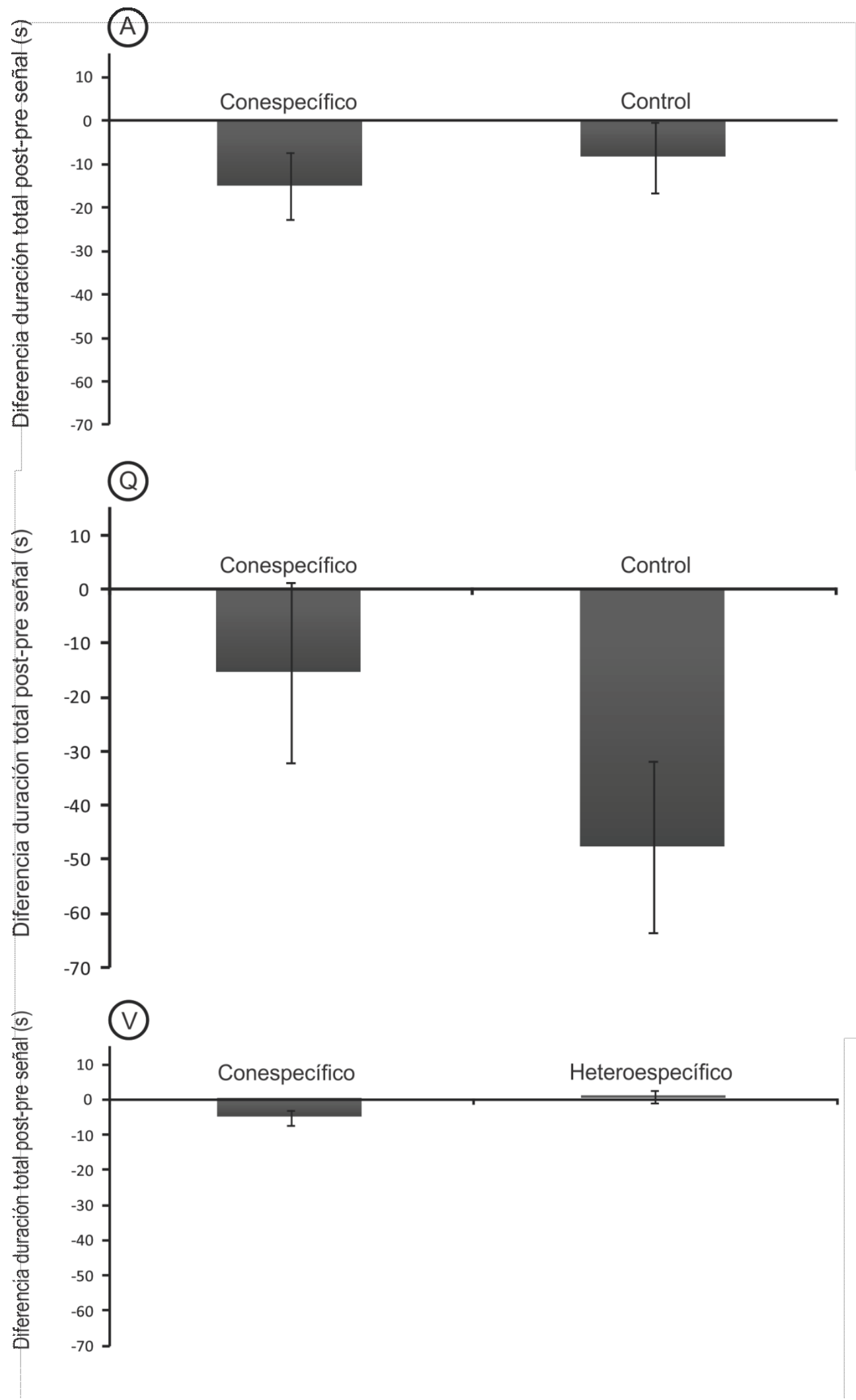

Figura 30. Diferencia de la duración total en movimiento post-pre señal en segundos (s) para cada tratamiento realizado para evaluar el comportamiento de larvas de $C$. ornata ante una señal acústica $(A)$, química $(Q)$ y visual $(V)$ 

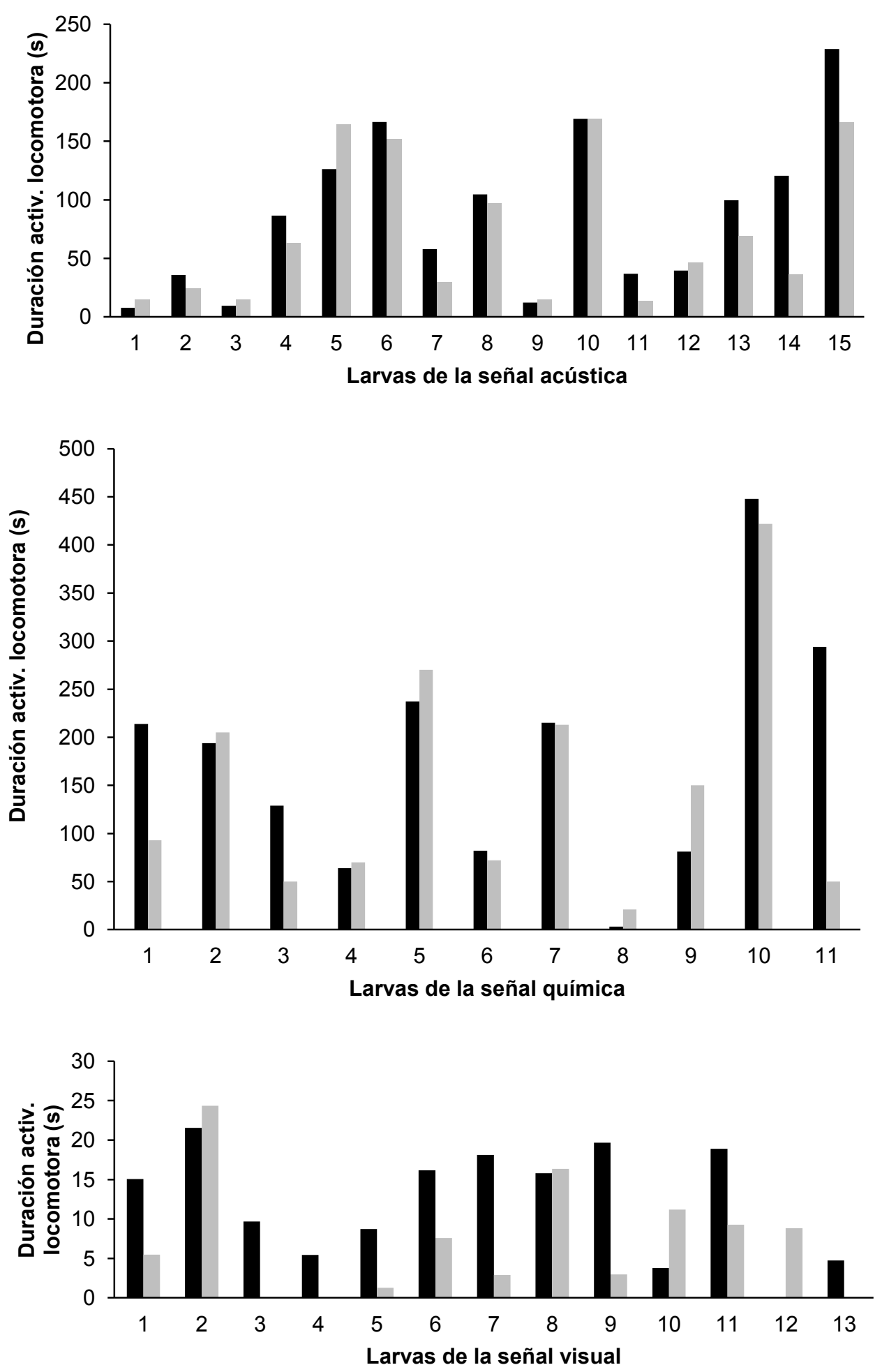

Figura 31. Duración del tiempo total de la actividad locomotora en segundos (s) de cada larva ensayada (1 a 15) de C. ornata previo a la inserción de la señal (columna color negro) y posterior a la misma (columna color gris) para la señal acústica, química y visual 


\section{Interacciones predador-presa con larvas de C. ornata}

Los resultados de los experimentos de interacciones (E1 y E2) realizados para testear la HED se resumen en las tablas 14 y 16 . Considerando todos los tratamientos, para E1 no se observaron eventos de canibalismo durante el periodo de apetito normal ( 0 a $3 \mathrm{~h}$, ver capítulo 1) perteneciendo el $100 \%$ (=8) de los eventos de canibalismo observados al periodo de apetito alto (a partir de las $3 \mathrm{~h}$, ver capítulo 1). Estos casos ocurrieron siempre luego de comerse a todas las presas heteroespecíficas (tiempo promedio $2130 \mathrm{~min}$, período de apetito alto). Para E2, tampoco se observaron eventos de canibalismo durante el periodo de apetito normal perteneciendo el $100 \%(=7)$ de los eventos registrados al periodo de apetito alto. La prueba de $t$ de diferencia entre medias arrojó diferencias significativas (E1: $t=-$ 6,596 , g.l. $=2, p=0,022 ; E 2: t=-6,430$, g.l. $=2, p=0,023$ ) entre el tiempo que tardan en comer la primera presa (tiempo promedio $=438 \mathrm{~min}$, periodo de apetito alto) y el tiempo que tardan en comer a un conespecífico (tiempo promedio $=2658 \mathrm{~min}$, periodo de apetito alto). En todos los tratamientos de ambos experimentos se registró el consumo total de presas heteroespecíficas y una primera elección de las mismas en lugar de un conespecífico, habiéndose consumido el $100 \%$ de las presas y solo un $12 \%$ y $10 \%$ de conespecíficos en $\mathrm{E} 1$ y E2, respectivamente. Para el caso particular de E1, todas las presas fueron consumidas a un promedio de 1 presa en 150 minutos y en el 100\% de los casos durante el período de apetito alto. En E2, las presas fueron consumidas a un promedio de 1 presa en 90 minutos en el $8 \%$ de las casos durante el periodo de apetito normal mientras que el $92 \%$ restante consumió sus presas durante el periodo de apetito alto (promedio de consumo $=1$ presa en $184 \mathrm{~min})$. Teniendo en cuenta los análisis de correlación lineal realizados, los mismos arrojaron una correlación negativa entre el tiempo que tardan en comer la primera presa y las distintas densidades evaluadas ( $E 1: r=-0,263, p=0,030$; $E 2: r=-0,291, p=0,016$ ). Para E2 existe además correlación positiva entre el número de eventos de canibalismo y las distintas densidades evaluadas $(r=0,999, p=0,018)$.

Los resultados de los experimentos de interacciones (E1 y E2) realizados para testear la HDRP se resumen en las tablas 15 y 17 . Considerando todos los tratamientos, para E1 se registraron ocho eventos de canibalismo, $87 \%(=7)$ de los cuales ocurrieron durante el periodo de apetito alto y solo el $13 \%(=1)$ durante el periodo de apetito normal. La prueba de U de Mann-Whitney entre el número de eventos de canibalismo ocurridos durante el periodo de apetito normal y el periodo de apetito alto arrojó diferencias significativas a una cola $(U=$ 4721, $p=0,027$ ). Todos los eventos de canibalismo ocurrieron luego de comerse a todas las presas (tiempo promedio $=1410 \mathrm{~min}$, periodo de apetito alto). Para E2, se registraron 13 eventos de canibalismo, $8 \%(=1)$ de los cuales ocurrió durante el periodo de apetito normal y el $92 \%$ restante $(=12)$ ocurrió durante el periodo de apetito alto. La prueba de $U$ de MannWhitney entre el número de eventos de canibalismo ocurridos durante el periodo de apetito 
normal y el periodo de apetito alto arrojó diferencias significativas tanto a una cola $(U=$ 4,492, $p=0,006)$ como a dos colas $(U=3,054, p=0,011)$. Todos los eventos de canibalismo ocurrieron luego de comerse a todas las presas (tiempo promedio $=2172 \mathrm{~min}$, periodo de apetito alto). La prueba de $t$ de diferencia entre medias arrojó diferencias significativas para E2 $(t=-10,247$, g.l. $=3, \mathrm{p}=0,002)$ entre el tiempo que tardan en comer la primera presa (tiempo promedio $=38 \mathrm{~min}$, periodo de apetito normal) y el tiempo que tardan en comer a un conespecífico (tiempo promedio $=2754 \mathrm{~min}$, periodo de apetito alto). En todos los tratamientos de E1 y casi la totalidad de los tratamientos de E2 se registró el consumo total de presas y una primera elección de las mismas en lugar de un conespecífico, habiéndose consumido el $100 \%$ y $88 \%$ de las presas y el $7 \%$ y $11 \%$ de conespecíficos en $\mathrm{E} 1$ y E2, respectivamente. En E1, todas las presas fueron consumidas a un promedio de 1 presa en 30 minutos en el 12,5\% de los casos durante el período de apetito normal, mientras que el $87,5 \%$ restante consumió todas sus presas durante el período de apetito alto (promedio de consumo = 1 presa en $179 \mathrm{~min}$ ). En E2, todas las presas fueron consumidas a un promedio de 1 presa en 90 minutos en el $12,5 \%$ de los casos durante el período de apetito normal, mientras que el $75 \%$ consumió todas sus presas durante el período de apetito alto (promedio de consumo $=1$ presa en $149 \mathrm{~min}$ ) y el $12,5 \%$ no consumió todas sus presas hacia el final del experimento. Teniendo en cuenta los análisis de correlación lineal realizados, para E1 arrojaron una correlación positiva entre el tiempo sin comer y las distintas densidades evaluadas $(r=0,490, p=0,046)$ y entre el número de eventos de canibalismo y las distintas densidades evaluadas $(r=0,8620, p=$ 0,027). Para E2, los análisis arrojaron una correlación negativa entre el tiempo que tardan en comer todo $(r=-0,555, p=0,040)$ y las distintas proporciones evaluadas. Por último, las pruebas de $t$ pareadas realizadas para comparar cada variable de cada tratamiento entre ambos experimentos (E1 y E2) no arrojaron diferencias significativas ( $p>0,05)$, para ninguno de los tratamientos realizados para testear HED y HDRP.

Teniendo en cuenta las grabaciones de video y las observaciones visuales producto de la cría de la especie en cautiverio, se puede afirmar que cuando una larva en el rol de predador se encuentra cercana a una potencial presa heteroespecífica, ataca a la misma y la muerde hasta su total ingestión. Por el contrario, cuando una larva en el rol de predador (C. ornata) interacciona con una larva de la misma especie y la ataca (=interacción intraespecífica), la larva mordida emite un sonido y realiza un rápido movimiento corporal seguido del alejamiento (escape) de la presa del predador. Esta observación se hizo en el $100 \%$ de 2000 registros e indica que los conespecíficos se evitan entre sí mediante un mecanismo antipredatorio. 
Tabla 14. Media aritmética \pm desvío estándar (en minutos) de cada variable para cada tratamiento que evalúa la hipótesis del efecto de la densidad mediante interacciones entre larvas de Ceratophrys ornata (Co) e Hypsiboas pulchellus (Hp). Entre paréntesis se informa el número de eventos para cada variable. $1^{\circ} \mathrm{p}$ : tiempo que tardan en comer la primera presa; Tp: tiempo que tardan en comer todas las presas; Sc: tiempo sin comer; Conesp: tiempo que tardan en comer un conespecífico, entre paréntesis se indica además el número de tratamientos respecto al total en los cuales ocurrieron eventos de canibalismo; C: número de eventos de canibalismo

\begin{tabular}{lccc}
\multicolumn{1}{c}{$\begin{array}{c}\text { Variables/ } \\
\text { Tratamientos }\end{array}$} & 2Co/2Hp & 5Co/5Hp & 10Co/10Hp \\
\hline $\mathbf{1}^{\circ} \mathbf{p}$ & $636 \pm 528(8)$ & $504 \pm 342(20)$ & $378 \pm 282(40)$ \\
Tp & $942 \pm 690(4)$ & $942 \pm 252(4)$ & $900 \pm 138(4)$ \\
Sc & $1920 \pm 570(4)$ & $1632 \pm 480(6)$ & $1200 \pm 624(4)$ \\
Conesp & -- & $2328 \pm 450(4,2 / 4)$ & $1938 \pm 198(4,3 / 4)$ \\
C & 0 & 4 & 4 \\
\hline
\end{tabular}

Tabla 15. Media aritmética \pm desvío estándar (en minutos) de cada variable para cada tratamiento que evalúa la hipótesis de la disponibilidad relativa de presas mediante interacciones entre larvas de Ceratophrys ornata $(\mathrm{Co})$ e Hypsiboas pulchellus $(H p)$. Entre paréntesis se informa el número de eventos para cada variable. $1^{\circ} \mathrm{p}$ : tiempo que tardan en comer la primera presa; $2^{\circ} \mathrm{p}$ : tiempo que tardan en comer la segunda presa; Tp: tiempo que tardan en comer todas las presas; Sc: tiempo sin comer; Conesp: tiempo que tardan en comer un conespecífico, entre paréntesis se indica además el número de tratamientos respecto al total en los cuales ocurrieron eventos de canibalismo; C: número de eventos de canibalismo

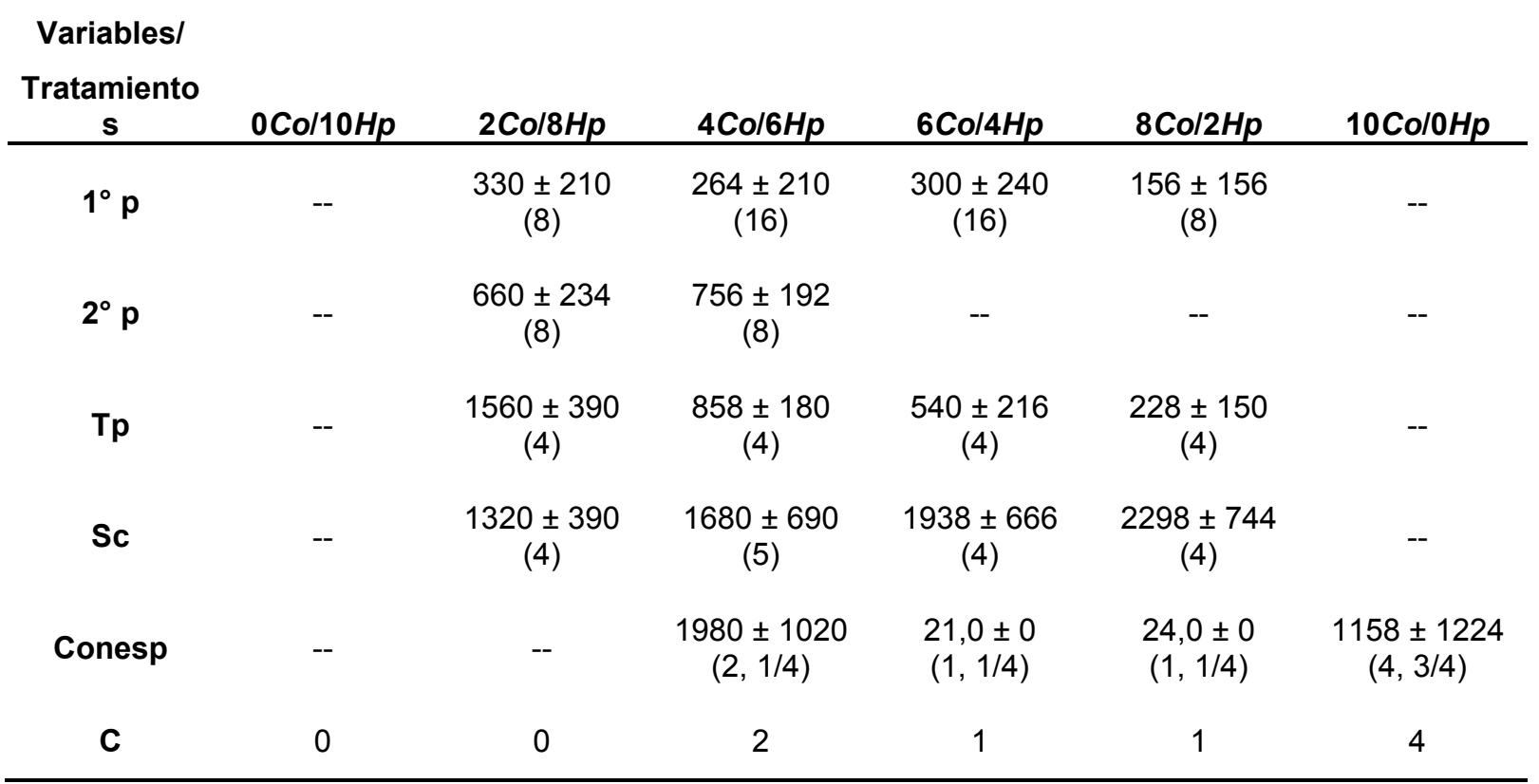


Tabla 16. Media aritmética \pm desvío estándar (en minutos) de cada variable para cada tratamiento que evalúa la hipótesis del efecto de la densidad mediante interacciones entre larvas de Ceratophrys ornata $(\mathrm{Co})$ y Rhinella fernandezae $(R a)$. Entre paréntesis se informa el número de eventos para cada variable. $1^{\circ} \mathrm{p}$ : tiempo que tardan en comer la primera presa; Tp: tiempo que tardan en comer todas las presas; Sc: tiempo sin comer; Conesp: tiempo que tardan en comer un conespecífico, entre paréntesis se indica además el número de tratamientos respecto al total en los cuales ocurrieron eventos de canibalismo; C: número de eventos de canibalismo

\begin{tabular}{lccc}
\multicolumn{1}{c}{$\begin{array}{c}\text { Variables } / \\
\text { Tratamientos }\end{array}$} & 2Co/2Ra & 5Co/5Ra & 10Co/10Ra \\
\hline $\mathbf{1}^{\circ} \mathbf{p}$ & $660 \pm 276(8)$ & $540 \pm 420(20)$ & $330 \pm 258(40)$ \\
Tp & $1080 \pm 306(4)$ & $1128 \pm 456(4)$ & $870 \pm 144(4)$ \\
Sc & $1800 \pm 1146(4)-$ & $1530 \pm 702(4)$ & $1308 \pm 552(4)$ \\
Conesp & -- & $2460 \pm 0(2,2 / 4)$ & $2064 \pm 432(5,3 / 4)$ \\
C & 0 & 2 & 5 \\
\hline
\end{tabular}

Tabla 17. Media aritmética \pm desvío estándar (en minutos) de cada variable para cada tratamiento que evalúa la hipótesis de la disponibilidad relativa de presas mediante interacciones entre larvas de Ceratophrys ornata $(\mathrm{Co})$ y Rhinella fernandezae $(R a)$. Entre paréntesis se informa el número de eventos para cada variable. $1^{\circ} \mathrm{p}$ : tiempo que tardan en comer la primera presa; $2^{\circ} \mathrm{p}$ : tiempo que tardan en comer la segunda presa; Tp: tiempo que tardan en comer todas las presas; Sc: tiempo sin comer; Conesp: tiempo que tardan en comer un conespecífico, entre paréntesis se indica además el número de tratamientos respecto al total en los cuales ocurrieron eventos de canibalismo; C: número de eventos de canibalismo

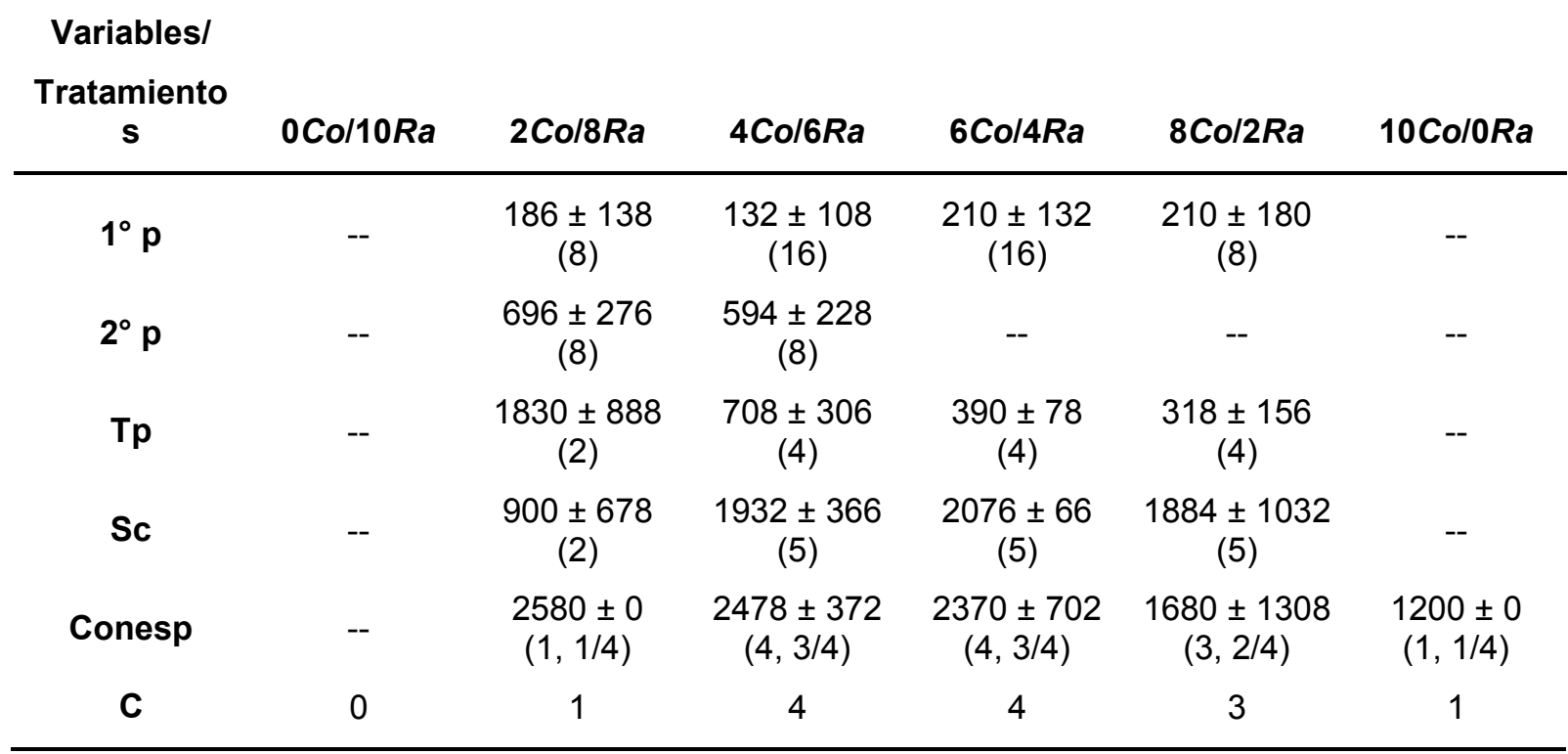




\section{Interacciones predador-presa con larvas de C. cranwelli}

Los resultados del experimento de interacciones (E3) realizado para testear la HED se resumen en la tabla 18. Considerando todos los tratamientos, no se observaron eventos de canibalismo durante el periodo de apetito normal ( 0 a $12 \mathrm{~h}$, ver capítulo 1 ), perteneciendo los únicos dos casos registrados al periodo de apetito alto (a partir de las $12 \mathrm{~h}$ ) de los tratamientos $2 C c-2 R a$ y $5 C c-5 R a$. Tales casos ocurrieron siempre luego de comerse a todas las presas (tiempo promedio 2375 min, período de apetito alto). La prueba de $t$ de diferencia entre medias arrojó diferencias significativas $(t=-8,457, \mathrm{~g} . \mathrm{I} .=2, \mathrm{p}=0,014)$ entre el tiempo que tardan en comer la primera presa (tiempo promedio $=296 \mathrm{~min}$, periodo de apetito normal) y el tiempo que tardan en comer a un conespecífico (tiempo promedio $=2375 \mathrm{~min}$, periodo de apetito alto). En todos los tratamientos se registró el consumo total de presas y una primera elección de las mismas en lugar de un conespecífico, habiéndose consumido el $100 \%$ de las presas y solo un $0,02 \%$ de conespecíficos. Todas las presas fueron consumidas a un promedio de 1 presa en 64 minutos en el $73 \%$ de los casos durante el período de apetito normal, mientras que el $27 \%$ restante consumió todas sus presas durante el período de apetito alto (promedio de consumo = 1 presa en $347 \mathrm{~min}$ ). Teniendo en cuenta los análisis de correlación lineal realizados, los mismos no arrojaron diferencias significativas entre las distintas densidades y las siguientes variables: tiempo que tardan en comer todas las presas $(p=0,176)$, tiempo sin comer $(p=0,176)$ y número de eventos de canibalismo ( $p$ $=0,242)$. Sin embargo, existe una correlación negativa $(r=-0,2624, p=0,015)$ entre el tiempo que tardan en comer la primera presa y todas las densidades usadas para testear la HED (Salgado Costa y col., 2014b).

En relación con los tratamientos realizados para testear HDRP, los resultados se resumen en la tabla 19. Considerando todos los tratamientos, se registraron seis casos de canibalismo, los cuales ocurrieron durante el periodo de apetito alto y en el $100 \%$ de los casos luego de comerse a todas las presas (tiempo promedio $1553 \mathrm{~min}$, periodo de apetito alto). La prueba de $t$ de diferencia entre medias arrojó diferencias significativas $(t=-5,106$, g.l. $=3, p=0,014$ ) entre el tiempo que tardan en comer la primera presa (tiempo promedio $=$ $160 \mathrm{~min}$, periodo de apetito normal) y el tiempo que tardan en comer a un conespecífico (tiempo promedio $=900 \mathrm{~min}$, alto periodo de apetito). En todos los tratamientos se registró el consumo total de presas y una primera elección de las mismas en lugar de un conespecífico, habiéndose consumido el $100 \%$ de las presas y solo un $4 \%$ de conespecíficos. Todas las presas fueron consumidas a un promedio de 1 presa en 95 minutos en el $63 \%$ de los casos durante el período de apetito normal, mientras que el $37 \%$ restante consumió todas sus presas durante el período de apetito alto (promedio de consumo $=1$ presa en $314 \mathrm{~min}$ ) (Salgado Costa y col., 2014b). Teniendo en cuenta los análisis de correlación lineal realizados, los mismos no arrojaron diferencias significativas 
entre las distintas proporciones predador-presa y el tiempo que tardan en comer la primera presa $(p=0,070)$ y la segunda presa $(p=0,448)$. Sin embargo, existe una correlación negativa entre el tiempo que tardan en comer todas las presas $(r=-0,6303, p=0,004)$ y todas las proporciones testeadas, y una correlación positiva entre el tiempo que están sin comer $(r=0,5839, p=0,004)$ y el número de eventos de canibalismo $(r=0,9837, p=0,049)$ $\mathrm{y}$ todas las proporciones testeadas.

Teniendo en cuenta las grabaciones de video y las observaciones visuales producto de la cría de la especie en cautiverio, se puede afirmar que cuando una larva en el rol de predador se encuentra cercana a una potencial presa heteroespecífica, ataca a la misma y la muerde hasta ingerirla de manera completa. Por el contrario, cuando una larva en el rol de predador interacciona con una larva de la misma especie y la ataca (=interacción intraespecífica), la larva mordida emite un sonido y realiza un rápido movimiento corporal seguido del alejamiento (escape) de la presa del predador. Esta observación se hizo en el $100 \%$ de 1500 registros e indica que cuando se encuentran dos conespecíficos los mismos se evitan entre sí mediante un comportamiento antipredatorio (Salgado Costa y col., 2014b).

Tabla 18. Media aritmética \pm desvío estándar (en minutos) de cada variable para cada tratamiento que evalúa la hipótesis del efecto de la densidad mediante interacciones entre larvas de Ceratophrys cranwelli $(C c)$ y Rhinella arenarum $(R a)$. Entre paréntesis se informa el número de eventos para cada variable. $1^{\circ} \mathrm{p}$ : tiempo que tardan en comer la primera presa; Tp: tiempo que tardan en comer a todas las presas; Sc: tiempo sin comer; Conesp: tiempo que tardan en comer un conespecífico, entre paréntesis se indica además el número de tratamientos respecto al total en los cuales ocurrieron eventos de canibalismo; C: número de eventos de canibalismo

\begin{tabular}{cccc}
$\begin{array}{c}\text { Variables } / \\
\text { Tratamientos }\end{array}$ & 2Cc/2Ra & 5Cc/5Ra & 10Cc/10Ra \\
\hline $\mathbf{1}^{\circ} \mathbf{p}$ & $395 \pm 244(5)$ & $197 \pm 72(5)$ & $149 \pm 33(5)$ \\
Tp & $760 \pm 489(5)$ & $612 \pm 321(5)$ & $450 \pm 181(5)$ \\
Sc & $3220 \pm 489(5)$ & $3368 \pm 321(5)$ & $3530 \pm 181(5)$ \\
Conesp & $2600 \pm 0(1,1 / 5)$ & $2150 \pm 0(1,1 / 5)$ & -- \\
C & 1 & 1 & 0 \\
\hline
\end{tabular}


Tabla 19. Media aritmética \pm desvío estándar (en minutos) de cada variable para cada tratamiento que evalúa la hipótesis de la disponibilidad relativa de presas mediante interacciones entre Ceratophrys cranwelli $(C c)$ y Rhinella arenarum $(R a)$. Entre paréntesis se informa el número de casos para cada variable. $1^{\circ} \mathrm{p}$ : tiempo que tardan en comer la primera presa; $2^{\circ} \mathrm{p}$ : tiempo que tardan en comer la segunda presa; Tp: tiempo que tardan en comer a todas las presas; Sc: tiempo sin comer; Conesp: tiempo que tardan en comer un conespecífico, entre paréntesis se indica además el número de tratamientos respecto al total en los cuales ocurrieron eventos de canibalismo; C: número de eventos de canibalismo

\begin{tabular}{ccccc}
$\begin{array}{c}\text { Variables/ } \\
\text { Tratamientos }\end{array}$ & 2Cc/8Ra & 4Cc/6Ra & 6Cc/4Ra & 8Cc/2Ra \\
\hline $\mathbf{1}^{\circ} \mathbf{p}$ & $109 \pm 57(4)$ & $134 \pm 71(5)$ & $77 \pm 16(5)$ & $60 \pm 44(5)$ \\
$\mathbf{2}^{\circ} \mathbf{p}$ & $461 \pm 206(8)$ & $402 \pm 139(10)$ & -- & -- \\
Tp & $3038 \pm 691(4)$ & $808 \pm 293(5)$ & $144 \pm 68(5)$ & $84 \pm 17(5)$ \\
Sc & $943 \pm 691(4)$ & $3172 \pm 293(5)$ & $3836 \pm 68(5)$ & $3896 \pm 88(5)$ \\
Conesp & -- & -- & -- & $1553 \pm 768(4,3 / 5)$ \\
$\mathbf{C}$ & 0 & 0 & 0 & 4 \\
\hline
\end{tabular}

\section{Interacciones predador-presa con larvas de L. Ilanensis}

Los resultados del experimento de interacciones (E4) realizado para testear la HDRP se resumen en la tabla 20. Considerando todos los tratamientos, se registraron 14 casos de canibalismo, de los cuales solo el $7 \%(=1)$ ocurrió durante el periodo de apetito normal $(0$ a 4 h, ver capítulo 1) en el tratamiento sin disponibilidad de presas $(10 \mathrm{LI}-\mathrm{OHp})$ y el $93 \%(=13)$ restante ocurrió durante el periodo de apetito alto (a partir de las $4 \mathrm{~h}$ ). Teniendo en cuenta esos 13 casos, el $85 \%(=11)$ de ellos ocurrió luego de comerse a todas las presas (tiempo promedio $=1476 \mathrm{~min}$, periodo de apetito alto) y el 15\% (=2) restante ocurrió antes de terminarse a todas las presas (tiempo promedio $=600 \mathrm{~min}$, periodo de apetito alto). $\mathrm{La}$ prueba $U$ de Mann-Whitney realizada con la finalidad de comparar el numero de eventos de canibalismo ocurridos durante el periodo de apetito normal (tiempo promedio $=30 \mathrm{~min}$ ) con aquellos que ocurrieron durante el periodo de apetito alto (tiempo promedio $=1452 \mathrm{~min}$ ) arrojó diferencias significativas $(U=3,327, p=0,032)$. La prueba de $t$ de diferencia entre medias arrojó diferencias significativas $(t=-3,230$, g.l. $=4, p=0,032)$ entre el tiempo que tardan en comer la primera presa (tiempo promedio $=156 \mathrm{~min}$, periodo de apetito normal) $\mathrm{y}$ el tiempo que tardan en comer un conespecífico (tiempo promedio $=1140 \mathrm{~min}$, periodo de apetito alto). En todos los tratamientos se registró el consumo total de presas y una primera elección de las mismas en lugar de un conespecífico, habiéndose consumido un $60 \%$ de las 
presas y solo un $12 \%$ de conespecíficos. Todas las presas fueron consumidas a un promedio de 1 presa en 40 minutos en el $38 \%$ de los casos durante el período de apetito normal, mientras que el $44 \%$ consumió todas sus presas durante el período de apetito alto (promedio de consumo $=1$ presa en $230 \mathrm{~min}$ ) y el $18 \%$ restante no consumió todas sus presas antes de las $48 \mathrm{~h}$ (= final del experimento). Teniendo en cuenta los análisis de correlación lineal realizados, los mismos no arrojaron diferencias significativas entre las distintas proporciones predador-presa y las siguientes variables: tiempo que tardan en comer la primera presa $(p=0,133)$, tiempo que tardan en comer la segunda presa $(p=$ $0,622)$, tiempo sin comer $(p=0,298)$ y tiempo que tardan en comer un conespecífico $(p=$ $0,465)$. Sin embargo, los análisis arrojaron una correlación positiva $(r=0,9552, p=0,003)$ entre el número de eventos de canibalismo y las proporciones predador-presa y una correlación negativa $(r=-0,7533, p=0,003)$ entre el tiempo que tardan en comer todas las presas y las distintas proporciones predador-presa evaluadas.

Teniendo en cuenta las grabaciones de vídeo y las observaciones visuales producto de la cría de la especie en cautiverio, se puede afirmar que cuando una larva en el rol de predador se encuentra cercana a una potencial presa heteroespecífica, ataca a la misma y se la traga entera. Por el contrario, cuando una larva en el rol de predador interacciona con una larva de la misma especie y la ataca (=interacción intraespecífica), la larva mordida realiza un rápido movimiento corporal seguido del alejamiento (escape) de la presa del predador. Esta observación se hizo en el $100 \%$ de 400 registros e indica que cuando se encuentran dos conespecíficos los mismos se evitan entre sí mediante un comportamiento antipredatorio (Salgado Costa y col. 2015).

\section{Interacciones predador-presa con larvas de C. aurita}

A partir de las grabaciones de audio y video realizadas y de las observaciones visuales producto de la cría de la especie en cautiverio, al igual que para las otras tres especies antes descriptas, se puede afirmar que cuando una larva de $C$. aurita en el rol de predador se encuentra cercana a una potencial presa heteroespecífica, ataca a la misma y la muerde hasta ingerirla de manera completa. Por el contrario, cuando una larva de $C$. aurita en el rol de predador interacciona con una larva de la misma especie y la ataca (=interacción intraespecífica), la larva mordida emite un sonido seguido de un rápido movimiento corporal y del alejamiento (escape) de la presa del predador. Esta observación se hizo en el 100\% de 200 registros e indica que cuando se encuentran dos conespecíficos los mismos se evitan entre sí mediante un comportamiento antipredatorio (Salgado Costa y Natale, 2011). 
Tabla 20. Media aritmética \pm desvío estándar (en minutos) de cada variable para cada tratamiento que evalúa la hipótesis de la disponibilidad relativa de presas mediante interacciones entre larvas de Lepidobatrachus llanensis $(L I)$ e Hypsiboas pulchellus $(H p)$. Entre paréntesis se informa el número de eventos para cada variable. $1^{\circ} \mathrm{p}$ : tiempo que tardan en comer la primera presa; $2^{\circ} \mathrm{p}$ : tiempo que tardan en comer la segunda presa; Tp: tiempo que tardan en comer a todas las presas; Sc: tiempo sin comer luego de comer a todas las presas; Conesp: tiempo que tardan en comer un conespecífico, entre paréntesis se indica además el número de tratamientos respecto al total en los cuales ocurrieron eventos de canibalismo; C: número de eventos de canibalismo

\begin{tabular}{|c|c|c|c|c|c|c|}
\hline $\begin{array}{c}\text { Variables/ } \\
\text { Tratamientos }\end{array}$ & $0 L / / 10 H p$ & $2 L / / 8 H p$ & $4 L / / 6 H p$ & $6 L / / 4 H p$ & $8 L / / 2 H p$ & $10 L / / 0 H p$ \\
\hline $1^{\circ} \mathrm{p}$ & -- & $\begin{array}{c}120 \pm 162 \\
(5)\end{array}$ & $\begin{array}{c}204 \pm 246 \\
(14)\end{array}$ & $\begin{array}{c}210 \pm 204 \\
(16)\end{array}$ & $\begin{array}{c}48 \pm 66 \\
(8)\end{array}$ & -- \\
\hline $2^{\circ} \mathrm{p}$ & -- & $\begin{array}{c}1068 \pm 624 \\
(6)\end{array}$ & $\begin{array}{c}912 \pm 450 \\
(6)\end{array}$ & -- & -- & -- \\
\hline Tp & -- & $\begin{array}{c}2502 \pm 30 \\
(2)\end{array}$ & $\begin{array}{c}1134 \pm 450 \\
\text { (3) }\end{array}$ & $\begin{array}{c}426 \pm 276 \\
(4)\end{array}$ & $\begin{array}{c}84 \pm 84 \\
(4)\end{array}$ & -- \\
\hline Sc & -- & $\begin{array}{c}384 \pm 30 \\
(2)\end{array}$ & $1746 \pm 450$ & $\begin{array}{c}1998 \pm 930 \\
(5)\end{array}$ & $\begin{array}{c}1920 \pm 1104 \\
(4)\end{array}$ & -- \\
\hline Conesp & -- & -- & $\begin{array}{c}600 \pm 84 \\
(2,1 / 4)\end{array}$ & $\begin{array}{c}1638 \pm 1440 \\
(2,1 / 4)\end{array}$ & $\begin{array}{c}1182 \pm 540 \\
(2,2 / 4)\end{array}$ & $\begin{array}{c}1506 \pm 1068 \\
(8,3 / 4)\end{array}$ \\
\hline C & 0 & 0 & 2 & 2 & 2 & 8 \\
\hline
\end{tabular}

\section{Comparación de los ensayos de interacciones realizados}

La comparación de los ensayos de interacciones predador-presa realizados con larvas de la familia Ceratophryidae, debe realizarse eliminando del análisis a la especie $C$. aurita por no contar con esos datos. Si se compara el tiempo en el cual ocurren eventos de canibalismo entre las tres especies restantes (Co, Cc, $L l)$, el ANOVA no arroja diferencias significativas $(F(2,36)=1,412, p=0,256)$. Del mismo modo, la comparación mediante un ANOVA del número de eventos de canibalismo tampoco arroja diferencias significativas entre las tres especies $(F(2,19)=0,487, p=0,622)$ (Fig. 32). Más allá de las diferencias metodológicas (diferentes STD y tratamientos), si se comparan los tres mecanismos teniendo en cuenta el total de eventos de canibalismo ocurridos durante el periodo de apetito normal/apetito alto y el tiempo en el cual ocurren tales eventos de canibalismo se puede concluir que los mismos presentan el siguiente grado de eficiencia de mayor a menor: C. ornata, C. cranwelli, L. Ilanensis. 


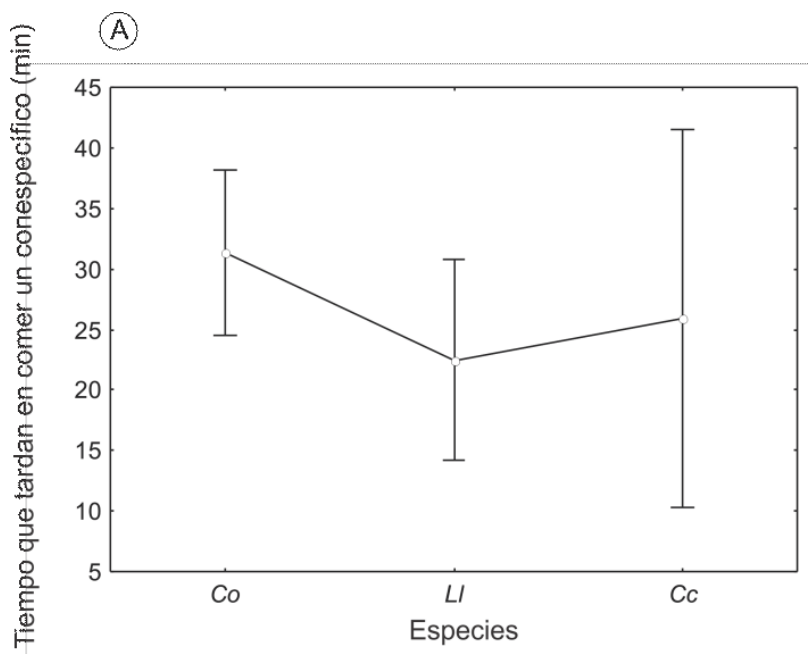

(B)

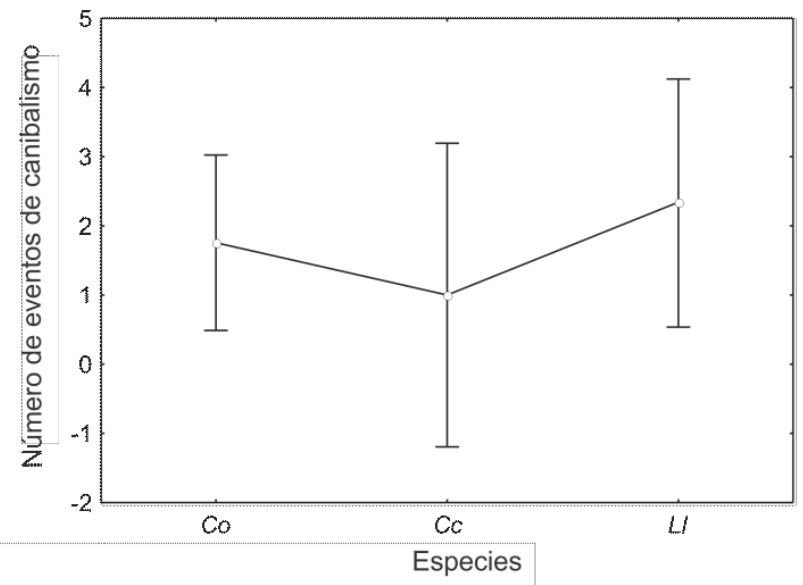

Figura 32. Comparación del tiempo que tardan en comer un individuo conespecífico en minutos (A) y del número de eventos de canibalismo $(B)$ entre larvas de Ceratophrys ornata $(C o)$, C. cranwelli $(C c)$ y Lepidobatrachus llanensis (LI)

\section{DISCUSIÓN Y CONCLUSIONES}

Como se mencionó en la introducción de este capítulo, el canibalismo ha sido mayormente descripto como una forma de predación oportunista, sin estar implicado un reconocimiento intraespecífico (Duellman y Trueb, 1994). Sin embargo, deben estar presentes ciertos factores para que el canibalismo ocurra, entre ellos: 1) una morfología del aparato bucal adecuada que permita la captura, manipulación e ingesta de la presa; 2) vulnerabilidad de la presa en ciertos estadios o momentos, como el estadio de huevo, el estadio premetamórfico caracterizado por individuos casi inmóviles con las cuatro patas bien desarrolladas que no les permiten nadar adecuadamente (como lo hacen en la etapa larval) ni saltar (como lo hacen en la etapa juvenil), y/o organismos con alguna herida o enfermedad; y/o 3) bajos niveles de comida disponible y alta densidad de conespecíficos (Crump, 1992). Además, se han descripto varios casos de canibalismo en los cuales las larvas caníbales adoptan un morfotipo particular, el cual lleva asociado un desarrollo larval más lento que el morfotipo típico (Crump, 1992). Sin embargo, la diminución de la tasa de desarrollo y aumento del tiempo en alcanzar la metamorfosis no es un patrón común para todas la larvas ya que algunos autores hay reportado la situación opuesta (Bragg, 1964; Lannoo, 1989). En comparación con las descripciones de esos autores, todos los casos de canibalismo reportados para las distintas especies evaluadas no tienen asociado un morfotipo particular y el desarrollo de las larvas es muy acelerado en comparación con larvas de otras especies autóctonas (Natale, 2006). Si bien en la literatura científica se afirma en reiteradas ocasiones que todos los adultos pertenecientes a la familia 
Ceratophryidae poseen hábitos caníbales, y consecuentemente se asume tal situación para sus larvas, no hay evidencias que soporten dichas aseveraciones al respecto sino para $C$. ornata (Cei, 1980), C. cranwelli (Gallardo y Varela de Olmedo, 1992) y Chacophrys pierotti (Cei, 1955). Por lo tanto, tales afirmaciones deben ser consideradas hipótesis sin constatar. Del total de casos de canibalismo registrados para especies autóctonas $(n=4)$, se reafirma la condición de caníbal para larvas de $C$. ornata y $C$. cranwelli y se adicionan reportes de comportamiento caníbal para larvas de $C$. aurita (producto de observaciones relativas a su cría en cautiverio y de grabaciones de audio y video) y de $L$. llanensis producto de observaciones relativas a su cría en cautiverio y de experimentos de interacción intraespecífica bajo las condiciones experimentales antes descriptas.

En lo que respecta a señales involucradas en la interacción intraespecífica, se describió por primera vez en el año 2011 la utilización de señales acústicas por larvas de C. ornata (Natale y col., 2011). En tal publicación, se describió la emisión de sonidos por parte de una larva (en el rol de presa) al ser atacada por un conespecífico (en el rol de predador) o al ser tocada por un objeto (espátula metálica o pipeta plástica). En tal sentido, se hipotetizó que el conespecífico en el rol de predador reconoce esa señal acústica y evita el canibalismo, habiéndose asociado la emisión de sonidos con un mecanismo de reconocimiento que actuaría disminuyendo la frecuencia de predación entre organismos conespecíficos. Tal contexto de emisión difiere del propuesto por Reeve y col. (2011) para larvas de G. azzurrae, quienes postulan un contexto competitivo habiéndose interpretado tal emisión como una señal agresiva hacia otros conespecíficos. Teniendo en cuenta lo antedicho, recientemente hemos reformulado la hipótesis acerca del contexto de emisión de sonidos considerando que el mismo podría asociarse con una respuesta antipredatoria sin estar implicado el reconocimiento intraespecífico sensu stricto, tal como se postula para $C$. cranwelli (Salgado Costa y col., 2014b). A partir de los experimentos que evalúan el contexto de emisión de sonidos por larvas de esta especie, de observaciones producto de la cría en cautiverio y de la grabación de cientos de sonidos de la misma, se concluye que $C$. ornata emite sonidos ante una interacción intraespecífica o con un objeto. Es decir, C. ornata emite sonidos no solo cuando una larva en el rol de presa es atacada por una larva conespecífica en el rol de predador sino también cuando es tocada por algún objeto (ej. pipeta) o cuando se choca contra algún objeto (ej. micrófono). Tal como se mencionó previamente, los resultados del ensayo realizado para evaluar el contexto de emisión de sonidos (Tabla 13A) indican una mayor frecuencia de interacción entre larvas de C. ornata que entre éstas y una larva heterospecífica, siendo una evidencia a favor de que la señal visual per se no es importante como parte del mecanismo antipredatorio. Se concluye que las larvas que emiten sonidos son aquellas en el rol de presa ya que siempre que 
se observó a una larva de $\boldsymbol{C}$. ornata en el rol de predador interaccionando con una presa heteroespecífica o con una presa conespecífica, la misma (el predador) no emitió sonidos. Además, la emisión de sonidos resulta $100 \%$ efectiva ya que siempre que la presa conespecífica emitió sonidos pudo escaparse del predador. Sin embargo, esto no sucede cuando el ataque se produce sobre una larva que no posee dicho mecanismo (ej. larvas heteroespecíficas ofrecidas como presas).

En relación con los experimentos realizados para evaluar el mecanismo de emisión de sonidos, se concluye que el mismo difiere del característico mecanismo de emisión de individuos juveniles y adultos, ya que no intervienen los pulmones como reservorio de aire. Si bien resulta necesario realizar más experimentos para contribuir con más evidencias que permitan concluir al respecto, a partir de los resultados obtenidos se descarta que el volumen de aire necesario para emitir sonidos provenga de los pulmones. Esta conclusión abarca a los estadios tempranos del desarrollo, teniendo en cuenta que los pulmones no se encuentran bien desarrollados y las larvas igual emiten sonidos, como para STD más avanzados, ya que por medio de experimentación se registró emisión de sonidos aun estando colapsados los pulmones. Producto de la frecuente observación de una burbuja de aire alojada en el estómago de las larvas de $C$. ornata (pudiéndose observar a simple vista por transparencia de la zona ventral) y de experimentos morfo-funcionales, se sostiene la hipótesis que postula que el estómago actúa como reservorio de aire, el cual al ser forzado a pasar por la cavidad bucofaríngea a través de la glotis produce sonidos similares a los descriptos para larvas de esta especie. Además, teniendo en cuenta que en disecciones previas se observó que la porción posterior del músculo rectus abdominis podría tener injerencia en el movimiento del estómago en sentido antero-posterior, se deberá evaluar en futuras disecciones su función en la emisión de sonidos. Para ello, se propone realizar anestesias locales a nivel de este elemento y de otros músculos que puedan estar involucrados (complejo de músculos angulares, orbitohioideo y suspensorio-hioideo) con el objetivo de verificar si bajo el efecto de determinados elementos anestesiados las larvas dejan de emitir sonidos. Cabe recordar que todas estas pruebas carecen de un diseño experimental robusto ya que fueron realizadas con el mínimo número de organismos posible y con los materiales que se tuvieron al alcance con el simple objetivo de explorar el mecanismo de emisión de sonidos. De todas formas, resulta evidente que el acceso a un endoscopio del tamaño de la cavidad bucal de una larva de C. ornata o a técnicas de ecografía/tomografía, las cuales no estuvieron a nuestro alcance, nos permitiría concluir con más certeza acerca del mecanismo de emisión.

Respecto a la evaluación del comportamiento de larvas de $C$. ornata ante diferentes señales, a partir de los resultados obtenidos se podría concluir que tanto la señal acústica como la visual disminuyen la actividad locomotora de las larvas ante la presencia de una 
señal conespecífica. Cabe destacar que se consideró a la disminución en la actividad locomotora como una respuesta antipredatoria (Jara y Perotti, 2010; Hettyey y col., 2012; Pueta y col., 2016). Sin embargo, la re-evaluación de la señal química se deberá realizar en futuros ensayos agregando un grupo con una señal heteroespecífica, dado que si bien no se hallaron diferencias significativas entre el grupo control (agua) y el tratamiento conespecífico, se observó mayor disminución de la actividad de las larvas al introducir el agua. Por lo tanto, para poder descartar un error experimental, es decir el hecho de que se asusten simplemente por introducir el agua con una pipeta, se deberá evaluar la respuesta ante un macerado de larva heteroespecífica. En lo que respecta a la señal visual, si bien se describe una diminución de la actividad larval ante la presencia de una larva conespecífica, también se deberá re-evaluar tal señal ya que el modo de introducción de la misma (entrada y salida de un vaso de precipitado) podría asustar a las larvas. Adicionalmente, el hecho de que las larvas de $C$. ornata interaccionen continuamente entre sí (observación realizada a partir del ensayo realizado para evaluar el contexto de emisión de sonidos), indicaría que la señal visual no cumple una función importante en larvas de esta especie. Por lo tanto, deberá mejorarse el diseño experimental para re-evaluar esa señal. Resumiendo lo antedicho, se concluye con estos experimentos que la única señal confirmada como señal de alarma es la acústica, disminuyendo la actividad de las larvas de $C$. ornata. Cabe aclarar que estos experimentos no evalúan tales señales en el contexto de la interacción intraespecífica sino como señales de alarma que disminuyen la actividad locomotora de las larvas evaluadas.

En relación con los experimentos realizados para evaluar las interacciones predadorpresa, para los dos experimentos realizados con larvas de $C$. ornata $(E 1, E 2)$ se registraron eventos de canibalismo siempre luego de comer a todas las presas. En el $90 \%$ de las observaciones realizadas siempre que una larva ataca a un conespecífico este último emite un sonido y posteriormente emprende la huida escapando del predador, concluyéndose que existe un eficiente mecanismo antipredatorio. El mismo disminuye significativamente la frecuencia de predación entre organismos conespecíficos ante la presencia de presas. El análisis de la variable tiempo en el cual ocurren eventos de canibalismo, relativo al tiempo que tardan en comer la totalidad de las presas, da sustento a los resultados en tal sentido. Teniendo en cuenta todos los experimentos de interacciones realizados con larvas de C. ornata, C. cranwelli y L. llanensis (E1-E2, E3 y E4, respectivamente), se puede concluir que no se rechazan las hipótesis planteadas en este capítulo (HED, HDRP). Es decir, a medida que aumenta la densidad de larvas/L y la proporción de predadores respecto a las presas, se incrementa el número de eventos de canibalismo. Estos resultados son concordantes con las condiciones usualmente descriptas, bajo las cuales ocurren eventos de canibalismo en otros grupos de animales (Fox, 1975; Crump, 1992). Se 
concluye que las cuatro especies descriptas (C. ornata, C. cranwelli, C. aurita y $L$. llanesis) poseen un mecanismo antipredatorio que disminuye la frecuencia de predación entre organismos conespecíficos ante la presencia de presas heteroespecíficas. Si se elimina de este análisis a $C$. aurita (dado que no se realizaron ensayos de interacciones predador-presa tal como para las otras tres especies), no se obtienen diferencias significativas entre el tiempo en el cual ocurren eventos de canibalismo ni entre el número de eventos de canibalismo entre las tres especies. A modo de comparación, para las larvas de $C$. ornata en rol de presa se describió un rápido movimiento de la cola acompañado por la emisión de sonidos subacuáticos, seguido del escape de la presa del predador (Natale y col., 2011). Para larvas de C. cranwelli, también se describió un mecanismo antipredador en el contexto de interacciones intraespecíficas. El movimiento de la cola y la emisión de sonidos también acompañan a dicho mecanismo. Sin embargo, en $C$. cranwelli el sonido fue interpretado como parte de un conjunto de señales que podrían estar involucradas en tal mecanismo (Salgado Costa y col., 2014b). Para C. aurita, se describió el mismo tipo de mecanismo antipredatorio, el cual consiste en un rápido movimiento de la cola acompañado por la emisión de sonidos por parte de una larva que está siendo atacada por un organismo conespecífico, seguido del escape de la presa del predador. En cambio, si bien para $L$. Ilanensis también se describió un rápido movimiento de la cola seguido del escape del predador durante interacciones intraespecíficas, no se registró la emisión de sonidos asociada, al menos en el rango de frecuencias evaluado (Salgado Costa y col., 2015). Más allá de las diferencias metodológicas (STD, tratamientos), si se comparan los tres mecanismos teniendo en cuenta el total de eventos de canibalismo ocurridos durante el periodo de apetito normal y de apetito alto y el tiempo en el cual ocurren tales eventos de canibalismo se puede concluir que los mismos presentan el siguiente grado de eficiencia de mayor a menor: C. ornata, C. cranwelli, L. Ilanensis.

Retomando la hipótesis planteada en el año 2011 (Natale y col., 2011), la cual postula que la producción de sonidos estaría presente en todas las larvas de anuros macrófagas y carnívoras como parte fundamental de un mecanismo antipredatorio que disminuiría la frecuencia de ocurrencia de eventos de canibalismo, la misma debe ser rechazada. La falta de emisión de sonidos por larvas de L. Ilanensis permite falsear dicha hipótesis. Incluso, el hecho de que las larvas de L. Ilanensis se eviten eficientemente sin emitir sonidos audibles, invita a pensar en numerosas hipótesis acerca de las posibles señales que componen el complejo mecanismo antipredatorio. En resumen, las larvas de $C$. ornata, C. cranwelli, C. aurita y L. llanensis poseen un mecanismo antipredador que disminuye la frecuencia de predación entre organismos conespecíficos. Sin embargo, en el mecanismo de $L$. Ilanensis no hay señales acústicas involucradas. Quizás sea ésta la razón por la cual el mecanismo de L. Ilanensis resulta menos eficiente que aquel descripto para 
especies del género Ceratophrys. Al respecto, pueden considerarse varias explicaciones. En primer lugar, si bien son varias las hipótesis propuestas acerca de cómo es exactamente el mecanismo de emisión de sonidos, aún quedan algunas preguntas por responder (limitadas en gran parte por falta de acceso a la tecnología adecuada). Por lo tanto, no podemos concluir al respecto ni descartar los posibles mecanismo de emisión. Al respecto, Reeve y col. (2011) postulan que la producción de sonidos podría estar relacionada con piezas bucales pesadas ya que describen una probable coincidencia entre la producción de sonidos y el cierre rápido de las vainas de la mandíbula. Tales piezas bucales queratinizadas son vestigiales en larvas de L. Ilanensis por lo que resultaría esperable, de ser ese el mecanismo de emisión, que esta especie no produzca sonidos. Sin embargo, no se puede concluir lo mismo para larvas de Ceratophrys. De todas formas, se debe estudiar en mayor detalle cómo funcionan las vainas del aparato bucal ya que la hipótesis de tales autores aún no ha sido probada.

En segundo lugar, las diferencias en el mecanismo antipredador pueden coincidir con los diferentes mecanismos de alimentación de ambos géneros (Ceratophrys y Lepidobatrachus). En tal sentido, poseen varias estructuras diferentes del condrocráneo involucradas en el mecanismo de alimentación (Wild, 1997; Fabrezi, 2011). Las larvas de Ceratophrys primero muerden a las presas de menor tamaño y luego las ingieren enteras, o mastican a las presas más grandes convirtiéndolas en pedazos más pequeños antes de la ingestión. Por el contrario, las larvas de Lepidobatrachus tienen un aparato bucal único entre los renacuajos de anuros, con piezas bucales vestigiales que les permiten tragar presas enteras y de gran tamaño (megalofagia; Ruibal y Thomas, 1988).

En tercer lugar, hay que considerar cómo fueron interpretadas las señales acústicas para cada especie. En un principio, tales señales fueron consideradas las únicas involucradas en las interacciones intraespecíficas entre larvas de C. ornata (Natale y col., 2011). Hoy día, y luego de la ejecución y análisis de experimentos específicos, se considera que tanto las larvas de $C$. ornata como de $C$. cranwelli utilizan señales acústicas junto con otras para evitar la predación (Salgado Costa y col., 2014b). Tal afirmación resulta válida también para larvas de C. aurita como se mencionó previamente. Por lo tanto, las tres especies del género Ceratophrys aquí estudiadas utilizan las mismas estrategias antipredatorias. Sin embargo, si bien en la literatura se asume en reiteradas ocasiones que todas las especies del género Ceratophrys cazan al acecho, es decir que permanecen semienterradas e inmóviles y atacan rápidamente a sus presas cuando las mismas se encuentran cercanas (predadores sit-and-wait; Duellman y Lizana, 1994), esta generalización no es válida al menos para su larvas. En este sentido, a partir de observaciones producto de la cría de estas especies en cautiverio se puede re-afirmar que tanto $C$. ornata como $C$. cranwelli cazan al acecho y postular que $C$. aurita y L. llanensis son cazadores activos que buscan y 
persiguen a sus presas. Esta aparente diferencia en la estrategia de predación podría ser un motivo por el cual el mecanismo de predación de L. Ilanensis resulta ser menos eficiente que el de $C$. ornata y $C$. cranwelli, ya que tal estrategia disminuye las probabilidades de huida de la presa del predador.

Por otro lado, considerando que la monofilia de la familia Ceratophryidae ha sido recientemente corroborada (Faivovich y col., 2014), se debe tener en cuenta que el conjunto de características que comparten estos géneros (inmunología, macrocefalia, megalofagia y comportamiento agresivo; Maxson y Ruibal, 1988, Wassersug y Heyer, 1988; Haas, 2003) aparecen después de la metamorfosis. Si bien muestran diferencias intergenéricas notables, las mismas están presentes durante las etapas premetamórficas. Así, tanto adultos como larvas del género Lepidobatrachus poseen caracteres distintivos y únicos que divergen de sus parientes (Ceratophrys, Chacophrys), siendo considerado el extremo de la morfología Ceratophryinae (Fabrezi, 2011). Su crecimiento rápido y la adquisición temprana de las características del adulto implican solo cambios sutiles en la transformación de larva a adulto. Además, la morfología de las larvas recién metamórficas de Lepidobatrachus define un plan corporal peramórfico, lo que sugiere que la etapa larval de alimentación libre puede considerarse equivalente a estadios larvales posteriores (metamórficos) de la mayoría de los anuros (Fabrezi, 2011). Una tercera posible explicación es que las señales acústicas que participan en el mecanismo antipredador divergieron primero, por lo que resulta esperable encontrarlas en Ceratophrys pero no en su pariente Lepidobatrachus. En decir, L. Ilanensis debe utilizar otro tipo de señales para evitar el canibalismo.

Por último, se sabe que existe producción de sonidos en larvas de C. ornata (Natale y col., 2011), C. cranwelli (Salgado Costa y col., 2014b) y C. aurita (Salgado Costa y col., 2011). Por el contrario, no se han podido detectar sonidos en larvas de Lepidobatrachus bajo las condiciones experimentales descriptas. Los estudios futuros, por lo tanto, deberán examinar el potencial de producción de sonidos en las restantes cinco especies de Ceratophrys y otros miembros de grupos hermanos estrechamente relacionados (por ejemplo, Lepidobatrachus y Chacophrys). Si bien se han logrado avances relevantes en el área de la bioecología de larvas de anuros, aún queda por describir el etograma completo de la interacción tanto intra como interespecífica, así como las distintas señales que intervienen en las mismas (en caso que intervengan más señales que la acústica). Para ello, como se mencionó anteriormente se deberán realizar estudios ulteriores de comportamiento con diseños específicos que permitan contrastar todas las hipótesis antes planteadas, entre ellas la función de cada señal interviniente en el mecanismo antipredador. 
Segunda parte: aplicación del modelo experimental en estudios ecotoxicológicos de evaluación de efectos de plaguicidas 
Capítulo 4

Efectos agudos y crónicos del clorpirifós durante la etapa larval de Ceratophrys ornata 
A partir del desarrollo de un protocolo de cría de individuos de C. ornata, se pudieron obtener larvas de esta especie en distintos estadios del desarrollo y evaluar los efectos letales y subletales producidos por su exposición aguda y crónica a un determinado plaguicida organofosforado. A lo largo del presente capítulo se describen respuestas ecotoxicológicas convencionales, entre ellas mortalidad, alteraciones en la natación y presencia de anormalidades. Los aquí descriptos, resultan ser los primeros bioensayos de exposición de larvas de C. ornata a un determinado contaminante ambiental. Por sus características biológicas y su manejo en laboratorio, la especie resulta de gran interés como modelo de estudio en Ecotoxicología.

\section{INTRODUCCIÓN}

\section{Impactos ambientales de la agricultura con énfasis en el modelo intensivo y extensivo}

Los impactos de las actividades humanas sobre los ecosistemas dependen mayormente de su intensidad, extensión, duración y de las tecnologías empleadas. Si bien todos los grupos humanos han transformado el entorno para satisfacer sus necesidades y demandas, en las sociedades modernas tales transformaciones ocurren a gran velocidad, con consecuencias ambientales, sociales y económicas alarmantes (Manuel-Navarrete y col., 2005; Leguizamón, 2014). De todas las actividades humanas, la agrícola es la que se aplica a una mayor superficie terrestre, generando un conflicto creciente entre las formas de hacer agricultura, la satisfacción de las necesidades básicas y la sustentabilidad del ambiente (Pengue, 2005; Leguizamón, 2014). Esta actividad generalmente implica un fuerte proceso de transformación del paisaje con cambios en el flujo energético. Sin embargo, lo especialmente alarmante es que tales impactos negativos se han multiplicado de la mano de la agricultura moderna. Dicho modelo se caracteriza por la siembra directa, la utilización de variedades transgénicas resistentes a herbicidas o plagas y la producción intensiva en capital, maquinarias y agroquímicos. Tal intensificación agrícola, presentada como la más viable alternativa productiva, ha generado algunos beneficios sectoriales pero también transformaciones importantes, tanto en la estructura agraria Pampeana como Extrapampeana. Entre ellas, la degradación y erosión de los suelos, eutrofización de los cuerpos de agua, agotamiento de los acuíferos, deforestación, desaparición de paisajes enteros, pérdida de biodiversidad e inaccesibilidad al modelo seguido del desalojo de muchos pobladores, campesinos e indígenas (Pengue, 2009; Carrasco y col., 2012; WWF, 2014). Particularmente en Argentina, el desarrollo que ha tenido la agricultura en los últimos años, principalmente con relación al cultivo de soja transgénica, llevó a una expansión desmedida 
de la superficie cultivada. Actualmente, la soja ocupa casi 20.000 .000 ha y representa al $57 \%$ del total de la superficie cultivada (SubAgr, 2014). De la mano de tal expansión, no solo surge el consecuente incremento en el uso de agroquímicos, sino también la reducción de otros cultivos, el confinamiento de la ganadería, la deforestación y la pérdida de hábitats por alteración irreversible y/o fragmentación (Pengue, 2009). Ante tal panorama desalentador, resulta imprescindible un plan estratégico que modere el avance no integrado de la agricultura y la incorporación de técnicas sustentables a largo plazo.

En el capítulo se evalúan los efectos de un plaguicida organofosforado ampliamente utilizado por el actual modelo agrícola intensivo, sobre un determinado grupo de la fauna asociado a los ambientes perturbados por dicha actividad. En tal sentido, en varias oportunidades se ha propuesto a los anfibios como buenos bioindicadores de las condiciones ambientales locales. A continuación se discute el uso de tal término y se presenta luego un resumen de los estudios realizados con anfibios autóctonos en el ámbito de la Ecotoxicología.

\section{Los anfibios como bioindicadores}

La mayoría de los anfibios poseen un ciclo de vida bifásico, con larvas acuáticas que sufren un proceso denominado metamorfosis para originar un organismo terrestre. El mismo implica un modo de vida acuático durante las etapas larvales, seguido de otro mayormente terrestre asociado con la culminación del proceso metamórfico, con individuos juveniles y posteriormente adultos (Duellman y Trueb, 1994). Siendo vertebrados ectotérmicos, su actividad se encuentra estrechamente relacionada con las variables físicas de los ambientes acuáticos y terrestres. Su tegumento es altamente permeable, con una estructura que resulta fundamental para el intercambio gaseoso y la osmorregulación, haciéndolos particularmente sensibles a sufrir efectos por la exposición a distintos contaminantes (Duellman y Trueb, 1994; Stebbins y Cohen, 1995). A dicha sensibilidad se le suma el hecho de que los individuos adultos no emigran de los sitios donde oviponen, donde también eclosionan sus huevos y se desarrollan sus larvas (Blaustein y col., 1994). Todas estas características hacen de los anfibios un grupo de especial interés para su estudio en el marco de la Ecotoxicología, permitiendo no solo evaluar efectos nocivos sobre ambientes acuáticos que funcionan como sumideros de contaminantes sino también sobre ambientes terrestres directamente expuestos a los mismos. En este contexto, se ha propuesto a los anfibios como buenos bioindicadores o centinelas de las condiciones locales desde finales del siglo XX hasta la actualidad (Power, 1989; Blaustein y Wake, 1995; Stebbins y Cohen, 1995; Guzy y col., 2012).

En lo que respecta al concepto de bioindicador, se han publicado diferentes definiciones y criterios que han generado bastante controversia (Sewell y Griffiths, 2009). El uso 
mayoritario del término al considerar al grupo de los anfibios, hace referencia a aquella especie o grupo de especies que reflejan fácilmente el estado abiótico o biótico de un ambiente, siendo su potencial el de proporcionar una alerta temprana de respuestas naturales a los impactos ambientales. Sin embargo, aún es discutido el hecho de considerar a un grupo de especies en vez de una sola especie como bioindicadora. Si bien se han realizado estudios con diferentes especies de anfibios proponiéndolos como bioindicadores en la evaluación de la contaminación de un determinado ambiente, los resultados no han sido concluyentes al respecto (DeGarady y Halbrook, 2006; Lebboroni y col., 2006; Calderon y col., 2014). En tal sentido, si bien es ampliamente aceptado por la comunidad herpetológica que la disminución de las poblaciones de anfibios puede ser indicativa de la degradación del ambiente, su rol como bioindicadores es aún controvertido (Muenz y col., 2006; Sewell y Griffiths, 2009).

En este trabajo de tesis, se desarrolla un protocolo de cría en cautiverio de la especie seleccionada (Ceratophrys ornata) y un modelo experimental para su aplicación en estudios ecotoxicológicos de plaguicidas. Del factible desarrollo de ambos, surge el proponer a la especie como modelo para la temprana detección de impactos ambientales, correspondiéndose con el popular concepto de bioindicador. Sin embargo, se enfatiza también la importancia de contar con múltiples bioindicadores ambientales complementarios y correlacionables para poder realizar estudios ambientales integrados y más realistas tal como indica Salibián (2015).

\section{Los plaguicidas y sus efectos sobre los anfibios}

La Organización Mundial de la Salud (OMS), define a los plaguicidas como aquellas sustancias o mezcla de sustancias destinadas a prevenir, controlar o destruir vectores de enfermedades humanas y no humanas que puedan resultar perjudiciales para la salud y la agricultura, siendo estas especies consideradas plaga si causan perjuicio o interfieren negativamente en la producción, elaboración, almacenamiento, transporte o comercialización de alimentos y productos agrícolas o sus derivados (WHO, 2010). Particularmente en Argentina, los tipos de plaguicidas más utilizados en orden decreciente son herbicidas, insecticidas y fungicidas, siendo el glifosato y el clorpirifós los productos más utilizados de los dos primeros tipos, respectivamente (CASAFE, 2012). Estudios previos han demostrado que los plaguicidas alcanzan los ecosistemas acuáticos superficiales (Rovedatti y col., 2001; Marino y Ronco, 2005; Aparicio y col., 2013; De Gerónimo y col., 2014), afectando en consecuencia a los organismos que los componen. Entre ellos, invertebrados (Jergentz y col., 2005; Di Marzio y col., 2010), peces (Carriquiriborde y col., 2009; Crupkin y col., 2013) y larvas de anuros. En relación con este último grupo, se ha demostrado el impacto de los plaguicidas a nivel individual (Brodeur y col., 2009; Agostini y col., 2010; Ruiz 
de Arcaute y col., 2012; Svartz y col., 2012; Brodeur y col., 2014; Svartz y col., 2016), y subindividual, a nivel bioquímico (Venturino y col., 2001; Attademo y col., 2011; Lajmanovich y col., 2011) y genético (Cabagna y col., 2006; Vera Candioti y col., 2010; Lajmanovich y col., 2014; Pérez Iglesias y col., 2014; 2015). Cabe aclarar que solo se proveen algunas citas de diferentes grupos de investigación locales a modo de sustentar lo antedicho, existiendo en la bibliografía cuantiosa información al respecto. No obstante, sigue resultando necesario evaluar los efectos subletales de plaguicidas a bajas concentraciones pero mediante estudios que provean más realismo, a través de la utilización de especies nativas, la incorporación de variabilidad genética, el estudio de distintos estadios del desarrollo y la utilización de concentraciones ambientalmente relevantes. En tal sentido, durante el desarrollo del presente trabajo de tesis se intentaron abordar algunos de tales aspectos, mediante la realización de bioensayos de toxicidad.

\section{Uso del bioensayo de toxicidad como herramienta bioanalítica en la evaluación de efectos sobre anfibios anuros}

Los ensayos biológicos o bioensayos son herramientas de diagnóstico adecuadas para determinar el efecto de agentes físicos y químicos sobre organismos de prueba, bajo condiciones experimentales específicas y controladas. Específicamente, los bioensayos de toxicidad son potentes herramientas que poseen ventajas sobre las clásicas pruebas químicas y físicas, ya que no solo permiten evaluar la calidad del agua sino también estimar las concentraciones de los contaminantes que causan potenciales efectos adversos sobre las biota acuática (USEPA, 1998). Tal uso de los bioensayos permite considerarlos herramientas bioanalíticas, siendo importante utilizar metodologías estandarizadas con especies validadas por comparación de resultados tanto intra como inter-laboratorios. La finalidad de estas metodologías es maximizar la reproducibilidad y confiabilidad de los datos obtenidos (Buikema y col., 1982). Teniendo en cuenta la duración de los efectos medidos en estos bioensayos, los mismos pueden clasificarse en dos grandes categorías: agudos y crónicos. Un efecto agudo involucra un estímulo lo suficientemente severo para inducir una respuesta rápida, mientras que un efecto crónico involucra un estímulo que permanece o continúa por períodos prolongados de al menos la décima parte del ciclo de vida (USEPA, 1989).

Específicamente en anuros, la utilización de los bioensayos a modo de evaluación ecotoxicológica se ha difundido como herramienta válida para determinar la calidad de las aguas (Ferrari y col., 1997; De la Torre, 2001; Demichelis y col. 2001; Salibián, 2006). No obstante, en lo que respecta a protocolos solo contamos a nivel internacional con el protocolo de bioensayo estandarizado para embriones de anfibios para medir toxicidad y teratogenicidad de sustancias puras, mezclas, efluentes y cursos de agua contaminados 
(ASTM, 1991; Bantle, 1995). A nivel local, se desarrolló un protocolo con embriones de anuros de Rhinella arenarum denominado AMPHITOX (Herkovits y Pérez Coll, 1999a-b), que permite evaluar la toxicidad de sustancias químicas, mezclas y muestras ambientales. Sin embargo, esta especie es solo una de las 168 especies de anuros descriptas para Argentina, siendo necesario contar con más protocolos estandarizados para evaluar efectos biológicos sobre otras especies autóctonas, para su aplicación como herramienta bioanalítica en la evaluación de fuentes puntuales y difusas de contaminación. Particularmente en el CIMA, se ha trabajado en el desarrollo de protocolos de bioensayos estandarizados con larvas de anuros autóctonos, estando tales investigaciones a cargo del Dr. Natale. En tal sentido, el presente trabajo de tesis contribuye con un protocolo de cría y reproducción en cautiverio de una especie autóctona, y con el desarrollo de un modelo experimental con esta especie para su aplicación en estudios ecotoxicológicos de plaguicidas. Particularmente, se propone un diseño experimental novedoso con larvas expuestas de forma individual, con la finalidad de evaluar la hipótesis de la existencia de una progresión de efectos negativos, tal como postulan Ruiz de Arcaute y col. (2012).

\section{Evaluación del riesgo ecológico}

Teniendo en cuenta que a comienzos de la década del 90 la información proveniente de estudios toxicológicos comenzó a integrarse en esquemas de clasificación de sensibilidades (Birge y col., 2000) y posteriormente en perfiles de efectos en evaluaciones de riesgo ecotoxicológico (Westerman y col., 2003), para tales evaluaciones resulta necesario contar con información de base. Dicha información se encuentra disponible para escasos lugares del planeta, particularmente en América del Sur. Un interesante aporte al respecto lo realiza Demetrio (2012) mediante la evaluación del riesgo para invertebrados acuáticos asociado a eventos de aplicación de cipermetrina, clorpirifós y glifosato para la región Pampeana. En tal sentido, con el objetivo de contextualizar la información toxicológica se utilizó la herramienta de evaluación del riesgo ecológico, siendo éste un proceso por el cual se define la probabilidad de que un determinado estresor pueda inducir efectos ecológicamente adversos (USEPA, 1998). Las evaluaciones de riesgo ecológico utilizan como insumo datos de distribución de las concentraciones de tóxicos (perfil de exposición) y de distribución de sensibilidades de especies, para calcular una medida del riesgo ecológico asociado a dichos escenarios de exposición (Suter II, 1999). Específicamente, una distribución de sensibilidades de especies (DSE) es una distribución de frecuencias que describe la variación de la toxicidad entre un conjunto de especies para un determinado compuesto o mezcla (van Straalen, 2002). El modelo de la DSE se ha utilizado tradicionalmente en la evaluación de riesgos prospectivos para el cálculo de concentraciones peligrosas (su sigla en inglés es HC: hazardous concentration), indicándose la concentración de la sustancia en 
el agua que afecta a una proporción de las especies. El valor de corte del $5 \%$ de especies a cola inferior de la distribución $\left(\mathrm{HC}_{5}\right)$, ha sido utilizado tradicionalmente para obtener concentraciones ambientales potencialmente seguras, bajo el supuesto de que los ecosistemas pueden tolerar un cierto grado de estrés químico (Posthuma y col., 2002). En el eje vertical $(y)$ se indica la potencial fracción afectada (PAF), la cual es utilizada como una medida del riesgo ecológico, correspondiéndose con la fracción de especies que resulta esperable (potencialmente) ver afectada por encima de su nivel de no-efecto a una concentración ambiental determinada (Aldenberg y col., 2002). La distribución de concentraciones de exposición (DCE) se define como la función de distribución acumulativa de la concentración de cada uno de los plaguicidas en un cuerpo de agua "típico" posterior a eventos de aplicaciones o escorrentías posteriores a la misma en un área dada. El modelo asume una distribución log-normal de los parámetros evaluados (ej. CL-50) y las concentraciones ambientales consideradas.

\section{Hipótesis}

* Las larvas de Ceratophrys ornata son organismos adecuados para la realización de bioensayos de toxicidad en laboratorio.

* La exposición de larvas de C. ornata a bajas concentraciones de clorpirifós (CPF) influye negativamente sobre el sistema de estudio, provocando efectos letales (mortalidad) como subletales (alteraciones en la natación, presencia de anormalidades e inhibición del crecimiento).

* Existe un incremento de los efectos perjudiciales producidos por el CPF sobre las larvas de $C$. ornata, los cuales se incrementan con el aumento de la concentración del tóxico en el agua y con el aumento del tiempo de exposición.

* El CPF posee un efecto negativo de carácter progresivo (efectos en la natación seguidos de presencia de anormalidades y culminando con la muerte) sobre las larvas de C. ornata.

\section{Objetivos}

* Evaluar la sensibilidad de larvas de C. ornata, en diferentes estadios del desarrollo, a diferentes tiempos de exposición y concentraciones del plaguicida organofosforado CPF mediante bioensayos de toxicidad, midiendo efectos a nivel individual tanto letales (mortalidad) como subletales (alteraciones en la natación, presencia de anormalidades e inhibición del crecimiento).

* Evaluar el efecto negativo de carácter progresivo del CPF sobre larvas de C. ornata mediante su exposición de forma individual. 
* Resumir e integrar la información existente sobre efectos y exposición del CPF mediante la herramienta de evaluación del riesgo ecológico, contextualizando los resultados obtenidos.

\section{MATERIALES Y MÉTODOS}

\section{Condiciones controladas de laboratorio y preparación del material utilizado}

Se mantuvieron condiciones controladas de laboratorio en un cuarto aclimatado a una temperatura de $25^{\circ} \mathrm{C} \pm 1$ con un fotoperiodo de $16: 8 \mathrm{~h}$ de luz y oscuridad. Se seleccionaron tres STD de Gosner (1960) representativos de la fase de vida acuática. EI STD 25 se seleccionó por ser el primero de vida libre con la morfología larval completa y que comienza a alimentarse pero que aún posee reservas energéticas del vitelo que le permiten sobrevivir algunos días sin comer (LHC: 6,586 $\pm 0,776 \mathrm{~mm}$; peso: 0,069 $\pm 0,011 \mathrm{~g}$ ). EI STD 31 fue seleccionado por ser intermedio y caracterizarse por larvas de mayor tamaño (LHC: 13,748 $\pm 1,063 \mathrm{~mm}$; peso: $0,413 \pm 0,104 \mathrm{~g}$ ), con las extremidades posteriores en crecimiento y en forma de pala. EI STD 37 fue seleccionado por estar caracterizado por larvas de gran tamaño (LHC: 21,430 \pm 2,054 mm; peso: 1,538 \pm 0,375 g) con los 5 dedos de las extremidades posteriores separados y todas las características larvales ya desarrolladas antes del comienzo de la metamorfosis (Duellman y Trueb, 1994). Los bioensayos se realizaron con agua de red filtrada con los parámetros fisicoquímicos ya detallados en el capítulo 1 (ver página 54). Todo el material utilizado fue lavado siguiendo un procedimiento estandarizado antes de cada bioensayo (APHA, 1998), con pequeñas modificaciones, consistiendo en un tren de lavado con una solución de hipoclorito de sodio diluida al $10 \%$, seguido del lavado con alcohol etílico $96^{\circ}$, posterior enjuague con agua de red y finalmente enjuague con agua destilada.

\section{Selección de plaguicidas organofosforados de uso frecuente en la región Pampeana}

Para la ejecución del presente trabajo de tesis se seleccionó al CPF (O, O-dietil O-3,5,6trichloropyridin-2-il fosforotioato) por ser un insecticida organofosforado de uso frecuente en la región Pampeana. Es utilizado en productos de uso veterinario para control de pulgas y garrapatas, de aplicación frecuente en la producción de hortalizas de hoja y fruto, de aplicación muy frecuente en frutas de carozo y cítricos y de aplicación sistemática en la producción agrícola extensiva. Es el insecticida que sigue en importancia de empleo en soja a la cipermetrina. Normalmente, no se emplea preventivamente dado su elevado costo sino a partir de observar la presencia de la plaga (Cappello y Fortunato, 2013). Posee acción 
neurotóxica por inhibición de la aceticolinesterasa, provocando la acumulación de acetilcolina y consecuentemente una hiperexcitación del sistema nervioso (Hill, 1995). Además, posee una persistencia superior a los dos meses en agua y a los seis meses en sedimento, siendo aún mayor en condiciones de baja temperatura, luminosidad y pH (Watts, 2012).

\section{Diseño experimental - Efectos letales y subletales}

Se siguieron los protocolos de la EPA con algunas modificaciones propuestas para especies locales (Natale, 2006, Ruiz de Arcaute y col., 2012). Se realizaron bioensayos de toxicidad aguda (96 h) y los mismos fueron continuados a exposición crónica (336 h) en condiciones controladas de laboratorio. La solución madre fue preparada a partir de CPF $95,1 \%$ diluido en etanol absoluto $(\mathrm{EtOH})$ y las diluciones se realizaron con agua de calidad (ver parámetros en página 54), siendo la concentración final de etanol en la solución de ensayo inferior al $0,01 \%$. El control negativo en agua de dilución con agregado de etanol absoluto se preparó con la máxima concentración del solvente empleada en las diluciones del tóxico. De manera general, para cada bioensayo se utilizaron nueve concentraciones del plaguicida en el rango de $0,01-0,5 \mathrm{mg} / \mathrm{L}$ y dos grupos control negativo: un control con agua de bioensayo sin plaguicida $(C)$ y un control de dilución $\left(C_{d}\right)$ (Fig.33). Las distintas concentraciones de plaguicida fueron seleccionadas a partir de bioensayos previos, en los que se determinó el intervalo $0-100 \%$ de efecto. Como recipientes de bioensayo se utilizaron frascos de vidrio de $100 \mathrm{ml}$ para larvas de STD 25 y de 1,5 L para larvas de STD posteriores, colocándose una larva por frasco. Los frascos no fueron tapados en su totalidad para permitir el intercambio gaseoso de la fase agua-aire. Teniendo en cuenta el diseño propuesto, la unidad experimental fue cada frasco en el que se colocó una larva y el factor evaluado fue el plaguicida con diferentes niveles de concentración (mg de CPF/L). Todas las soluciones fueron renovadas en su totalidad cada $24 \mathrm{~h}$ durante las exposiciones agudas y cada $48 \mathrm{~h}$ durante las exposiciones crónicas siguiendo el criterio de Ruiz Arcaute y col., (2012). Durante las exposiciones agudas no se les proveyó alimento, pero fueron luego alimentadas durante la exposición crónica (antes de cada renovación del medio) con una larva de otra especie ( $R$. arenarum, $H$. pulchellus) o un individuo de la especie Tubifex, dependiendo de la disponibilidad de alimento. Cabe destacar que las larvas comen cada ítem alimentario instantáneamente, por lo tanto el mismo no es considerado vía de ingreso de la sustancia a ensayar (CPF). 
Tratamientos

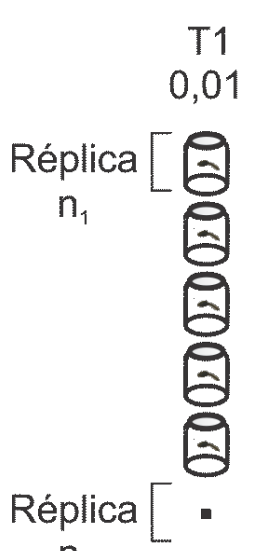

$\begin{array}{lllll}\text { T2 } & \text { T3 } & \text { T4 } & \text { T5 } & \text { T6 }\end{array}$
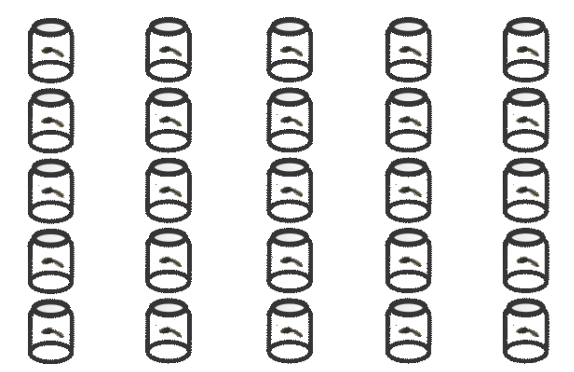

$$
\begin{aligned}
& \text { T9 } \\
& 0,5
\end{aligned}
$$

\section{Controles}
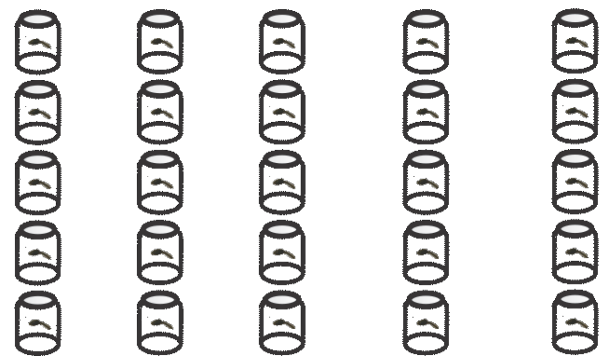

$\mathrm{n}_{\mathrm{x}}$

Figura 33. Diseño experimental general de los bioensayos de toxicidad realizados, detallando los tratamientos $(\mathrm{T})$ con sus concentraciones en $\mathrm{mg} / \mathrm{L}$, grupos control (C: control con agua de bioensayo; $\mathrm{C}_{\mathrm{d}}$ : control de dilución con etanol) y réplicas $\left(\mathrm{n}_{1}\right.$ a $\left.\mathrm{n}_{\mathrm{x}}\right)$

Se registraron las siguientes variables de respuesta (puntos finales) letales y subletales a nivel individual:

* Mortalidad: se determinó por observación visual de inmovilidad sumado al aspecto cadavérico (color blanquecino producto de la rápida descomposición del cuerpo). Esto permitió distinguir claramente a los individuos que se encontraban inmóviles por efecto del plaguicida de aquellos muertos. En caso que surgieran dudas, se corroboró la presencia de actividad cardíaca mediante observación directa en una pipeta Pasteur. Los individuos muertos fueron fijados durante $24 \mathrm{~h}$ en una solución Bouin (75\% ácido pícrico $+25 \%$ formol $40 \%+5 \%$ ácido acético) y posteriormente conservados en etanol $70 \%$ para su posterior cuantificación de anormalidades y medición de la longitud hocico cloaca (LHC). Se siguió el mismo procedimiento con todos los individuos al finalizar cada bioensayo. Las muertes en los grupos control $(C)$ debieron ser menores al 10\% (USEPA, 1989).

* Alteraciones en la natación: se registraron por comparación con el grupo control (con agua de bioensayo, C) luego de un estímulo mecánico que consistió en realizar suaves movimientos del agua con una pipeta plástica cercanos a la larva en posición de reposo, hasta provocar la natación (huida) de la misma.

* Presencia de anormalidades: se determinó y cuantificó por observación visual y posterior corroboración bajo lupa siguiendo la clasificación propuesta por Bantle y col. (1996).

* Inhibición del crecimiento: se determinó por fotografía digital y posterior medición de LHC (en milímetros) con el programa Image $J^{\circledR}$ versión 1.46r (ver capítulo 1, página 33). 
A partir del análisis de tales puntos finales se obtuvieron parámetros convencionales, entre ellos CL-50, CE-50, NOEC y LOEC a 96, 168, 240 y 336 h y TL-50 a 336 h. El diseño experimental propuesto con larvas expuestas de forma individual, tiene como finalidad evaluar la hipótesis de la existencia de una progresión de efectos negativos, tal como postulan Ruiz de Arcaute y col., (2012), desde la aparición de alteraciones en la natación pasando por la presencia de anormalidades leves y luego severas hasta llegar a la muerte. Para ello se asignaron valores al estado de cada larva al finalizar la exposición aguda y crónica de cada bioensayo. Tales estados $(0$ = larva viva y sin efectos negativos, $1=$ larva con alteraciones en la natación, 2 = larva con una anormalidad leve, 3 = larva con una anormalidad severa, 4 = larva muerta), fueron asignados teniendo en cuenta el máximo estado que poseía la larva al momento de la lectura (ej. a una larva viva con alteraciones en la natación y anormalidades leves se le asignó el estado 2.

Se realizaron en total cinco bioensayos de toxicidad: dos agudos con su continuación a crónicos en STD 25 (E1-E2), uno agudo continuado a crónico en STD 31 (E3) y dos agudos en STD 37 (E4-E5). A continuación se detallan las diferencias respecto al diseño general para cada bioensayo (Fig. 34):

\section{Bioensayos con clorpirifós en STD 25}

Se utilizaron las larvas producto de la inducción de la pareja 4 y 5 (ver capítulo 1) para la ejecución de dos bioensayos de toxicidad (E1, E2, respectivamente) bajo exposiciones agudas y crónicas. Para el E1, en vez de colocar una larva por frasco se colocaron 5 larvas por frasco de 1,5 L. Se les proveyó alimentación diaria (cada 24 h) para evitar el canibalismo dada la alta voracidad de la especie, garantizándose que todas las larvas coman la misma cantidad de alimento. Se utilizaron 13 concentraciones en el intervalo de 0,0075 a 0,9 mg CPF/L $(0,0075 ; 0,01 ; 0,025 ; 0,05 ; 0,075 ; 0,1 ; 0,25 ; 0,5 ; 0,6 ; 0,7 ; 0,8 ; 0,9 ; n=300)$ con cuatro réplicas, dos grupos control con agua de bioensayo $(C)$ y un control de dilución $\left(\mathrm{C}_{\mathrm{d}}\right)$. Este diseño fue mejorado en los subsiguientes bioensayos dado que la especie posee comportamiento caníbal en condiciones de alto apetito. Por lo tanto, en este bioensayo se registró la cantidad de larvas vivas por frasco de manera más frecuente (cada 2 h), permitiendo distinguir las muertes por canibalismo de aquellas muertes producto de la exposición al CPF al completar las planillas definitivas de datos.

Considerando la experiencia adquirida en E1, para la ejecución de E2 se realizaron algunos cambios o mejoras: (1) se colocó una larva por frasco de $100 \mathrm{ml}$ sin alimentación hasta las $96 \mathrm{~h}$ con la finalidad de cumplimentar con recomendaciones de protocolos (USEPA, 1989), (2) se redujo el intervalo de concentraciones, dejando solamente las concentraciones efectivas, y (3) se utilizó un solo grupo control con agua de bioensayo (C) en vez de dos. Se utilizaron las nueve concentraciones planteadas en el diseño general en 
el intervalo de 0,01 a $0,5 \mathrm{mg} C P F / L$ con 15 réplicas $(n=165)$. El bioensayo no se pudo continuar hasta el día 14 por falta de alimento y debió finalizarse el día 7 (168 h).

\section{* Bioensayos con clorpirifós en STD 31}

Se utilizaron las larvas producto de la inducción de la pareja 5 (ver capítulo 1) para la ejecución de un bioensayo de toxicidad (E3) bajo exposición aguda y crónica. Teniendo en cuenta los diseños experimentales de E1-E2, y partiendo de la hipótesis frecuentemente corroborada en el ámbito de la ecotoxicología de anfibios que plantea que a mayores STD aumenta la tolerancia al CPF, para la realización de E3 se utilizaron ocho concentraciones en el rango de 0,025 a $0,7 \mathrm{mg} \mathrm{CPF/L}(0,025 ; 0,075 ; 0,15 ; 0,2 ; 0,25 ; 0,3 ; 0,5 ; 0,7 ; \mathrm{n}=200)$, con 20 réplicas por tratamiento.

\section{* Bioensayos con clorpirifós en STD 37}

Se utilizaron las larvas producto de la inducción de la pareja 5 (ver capítulo 1) para la ejecución de dos bioensayos de toxicidad (E4-E5) bajo exposición aguda. Para el bioensayo E4, se utilizaron tres concentraciones en el intervalo de 0,05 a $0,2 \mathrm{mg} / \mathrm{L}(0,05 ; 0,01 ; 0,02 ; \mathrm{n}$ $=40$ ) y 10 réplicas por tratamiento. Para el bioensayo E5 se utilizaron cinco concentraciones en el intervalo de 0,025 a $0,5 \mathrm{mg} \operatorname{CPF} / \mathrm{L}(0,025 ; 0,1 ; 02 ; 0,3 ; 05 ; \mathrm{n}=70)$ y 10 réplicas por tratamiento. Es evidente la reducción en el número de individuos que componen estos diseños experimentales respecto al de los demás bioensayos, encontrándose asociado a la cría de los mismos hasta STD avanzados para poner a punto el protocolo de cría en cautiverio desarrollado en el capítulo 1 . Se realizó solamente la exposición aguda con el objetivo principal de evaluar respuestas en el sonido a bajas concentraciones.

\section{Aplicación de la herramienta de evaluación del riesgo ecológico}

En relación a la evaluación del riesgo ecológico del CPF, para la construcción del perfil de exposición se consideraron las concentraciones medidas en la región Pampeana en escenarios post-aplicación o asociados a escorrentías posteriores a los mismos (Marino y Ronco, 2005; Jergenzt y col., 2005; Mugni y col., 2011). El perfil de efectos fue construido teniendo en cuenta datos de CL-50/CE-50 a $96 \mathrm{~h}$ publicados para otras especies de anfibios anuros. El análisis de DSE se realizó siguiendo el método de Aldenberg y Jaworska (2000) mediante el software ETX 2.0 (van Vlaardingen y col., 2005). El resultado se presenta gráficamente como una curva de probabilidad conjunta (CPC) de la distribución acumulativa de la toxicidad del CPF para un conjunto de especies de anuros y de la distribución acumulativa de las concentraciones de CPF en el ambiente. El riesgo ecológico esperado promedio se calculó como la fracción potencialmente afectada de las especies consideradas, correspondiendo al área bajo la curva en la CPC. 


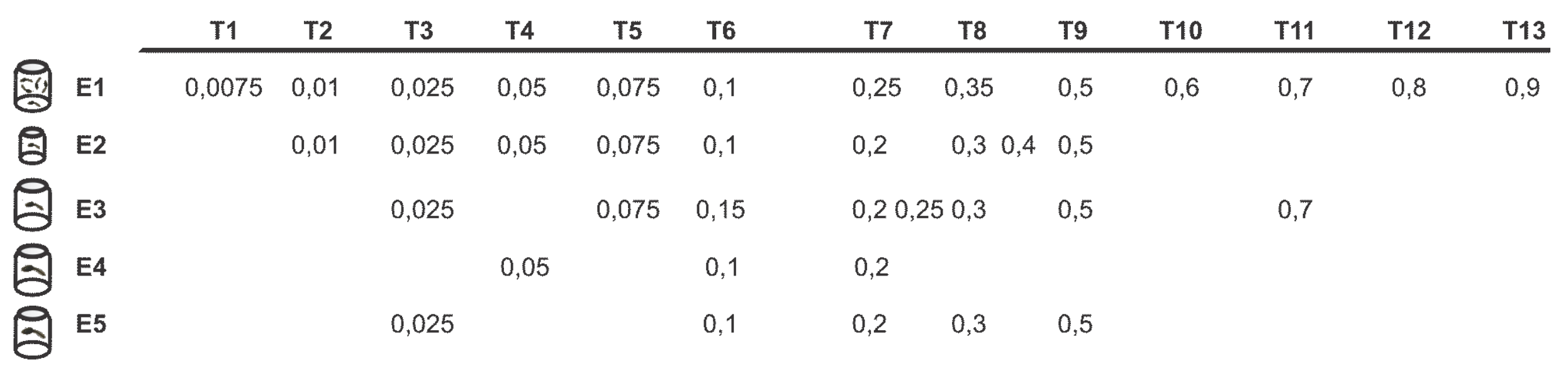

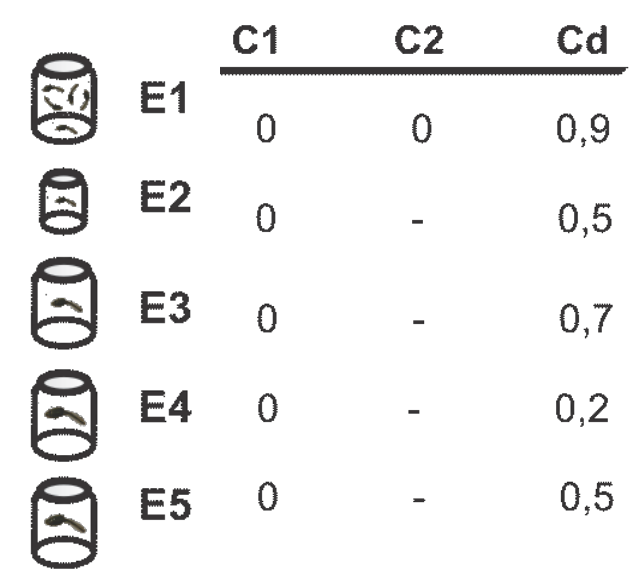

Figura 34. Detalle de los tratamientos $(T)$ con sus concentraciones en $\mathrm{mg} / \mathrm{L}$ y grupos control ( $\mathrm{C} 1$ y $\mathrm{C2}$ : control con agua de bioensayo, $\mathrm{C}_{\mathrm{d}}$ : control de dilución) utilizados para cada bioensayo (E) de exposición a clorpirifós. E1-E2: bioensayo en estadio 25; E3: bioensayo en estadio 31; E4-E5: bioensayo en estadio 37 


\section{Análisis estadístico}

La CL-50/CE-50 y sus límites de confianza al 95\% se obtuvieron por análisis Probit, tanto mediante la utilización del programa de análisis Probit versión 1.5 como siguiendo el método de intersección lineal cuando el probit no pudo ser aplicado (USEPA, 1989) para estimar las curvas concentración-respuesta para diferentes tiempos y STD. Con el objetivo de obtener los TL-50 al final de los bioensayos crónicos (168 h / 336 h) se construyeron las curvas de supervivencia por el método de Kaplan-Meier, método que además permitió calcular el tiempo de sobrevida para cada individuo de cada STD y bioensayo. Se calcularon los NOEC y LOEC mediante ANOVA con prueba a posteriori de Dunnett para cada tiempo de exposición para la mortalidad, alteraciones en la natación, presencia de anormalidades e inhibición del crecimiento.

Con el objetivo de evaluar la existencia de inhibición del crecimiento, se realizó una ANOVA de una vía para cada bioensayo al final de la exposición aguda y al final de la exposición crónica. Se evaluó la existencia de correlación lineal entre la LHC y los distintos tratamientos al final de la exposición aguda y al final de la exposición crónica de cada bioensayo realizado. Siempre que fue posible se realizó un ANOVA de medidas repetidas para cada bioensayo para evaluar el crecimiento individual al final de la exposición aguda respecto del mismo al final de la exposición crónica.

Las curvas correspondientes a cada bioensayo para cada punto final fueron comparadas mediante una prueba de $t$ o ANOVA (según correspondiera) para la pendiente y ordenada al origen, tanto al final de los bioensayos agudos como al final de los bioensayos crónicos.

Para evaluar la existencia de una progresión de efectos negativos se realizó un análisis de correlación entre el $0-100 \%$ de efectos de cada punto final (alteraciones en la natación, presencia de anormalidades y mortalidad) y las concentraciones en las cuales se observaron tales efectos al final de la exposición aguda y crónica. Se realizó una prueba de chi-cuadrado entre las distintas combinaciones de estados que implican presencia/ausencia de progresión y los distintos tratamientos. Luego, se realizó un análisis de correlación entre la frecuencia de estados que indican progresión de efectos y el logaritmo de las distintas concentraciones de CPF (mg/L) en la cual se dan tales efectos, a un tiempo fijo de exposición (final del bioensayo agudo/crónico) y entre la frecuencia de estados que indican progresión de efectos a una concentración fija y los distintos tiempos de exposición. Se realizó un análisis descriptivo mediante gráficos de torta de los estados asignados a lo largo del tiempo. Por último, se realizó un análisis de correlación entre la proporción de efectos negativos de los distintos puntos finales evaluados (mortalidad, alteraciones en la natación, presencia de anormalidades) y las distintas concentraciones a un tiempo constante. 
Para la realización de todas las pruebas estadísticas se utilizó el programa Statistica 7.0 $\left(\right.$ Statsoft ${ }^{\circledR}$ ) y se eligió un nivel de significancia de 0,05 . Además, todas las pruebas realizadas cumplen con sus respectivos supuestos (Zar, 2010).

\section{RESULTADOS}

\section{Bioensayos con clorpirifós - Efectos letales}

Las CL-50, NOEC y LOEC de la mortalidad registrada bajo exposiciones agudas y crónicas para cada bioensayo realizado (E1-5) se resumen en la tabla 21. En la fig. 35 se muestran los gráficos de regresión entre el logaritmo de la concentración de CPF y las unidades probit, por medio de los cuales se corroboraron los datos de CL-50 obtenidos mediante el programa Probit. Cabe destacar que se registró total ausencia de mortalidad en los grupos control. La comparación de curvas a 96 h y 168 h de los bioensayos realizados en STD 25 (E1, E2) no arrojó diferencias significativas para los pendientes (96 h: $t=1,804$, g.l. $=7, \mathrm{p}>0,05 ; 168 \mathrm{~h}: t=-0,738$, g.l. $=6, \mathrm{p}>0,05)$ ni para las ordenadas al origen $(96 \mathrm{~h}: t$ $=-1,665$, g.l. $=8, p>0,05 ; 168 \mathrm{~h}: t=2,084$, g.I. $=7, \mathrm{p}>0,05)$. Del mismo modo, la comparación de curvas a $96 \mathrm{~h}$ de los bioensayos realizados en STD 37 (E4, E5) tampoco arrojó diferencias significativas para las pendientes $(t=-0,813$, g.l. $=1, p>0,05)$ ni para las ordenadas al origen $(t=0,410, \mathrm{~g} . \mathrm{I} .=2, \mathrm{p}>0,05)$. El análisis de comparaciones múltiples realizado a $96 \mathrm{~h}(\mathrm{E} 1, \mathrm{E} 2, \mathrm{E} 3, \mathrm{E} 4, \mathrm{E} 5)$ arrojó diferencias significativas entre las pendientes $(F(4,13)=4,47, p=0,017)$ y ordenadas al origen $(F(4,17)=8,33, p=0,001)$. La prueba de Tukey arrojó diferencias significativas entre las pendientes de E1-E3 y las ordenadas al origen de E1-E5, E2-E4 y E2-E5. El análisis de comparaciones múltiples realizado a $168 \mathrm{~h}$ (E1, E2, E3) no arrojó diferencias significativas entre las pendientes $(F(2,10)=3,35, p=$ $0,077)$ ni ordenadas al origen $(F(2,12)=2,02, p=0,176)$. Por último, la comparación de curvas a 336 h de los bioensayos realizados en STD 25 y 31 (E1, E3) no arrojó diferencias significativas entre las pendientes $(t=0,470$, g.l. $=8, p>0,05)$ pero sí entre las ordenadas al origen $(t=4,200$, g.l. $=9, p<0,005)$. Las curvas de supervivencia crónica de Kaplan-Meier realizadas para todos los bioensayos crónicos (E1, E2, E3) a las mismas concentraciones se muestran en la fig. 36. Estas curvas permitieron obtener los TL-50 para cada bioensayo a determinadas concentraciones (Tabla 21).

Por último, en la fig. 37 se muestra la DSE de anuros al CPF. Dicha curva se estimó mediante 22 valores de Log (CL-50), teniendo una media de -0,234 y un D.E. de 0,706. La $\mathrm{HC}_{5}$ estimada es $0,039 \mathrm{mg} / \mathrm{L}$ (límite inferior al $90 \%=0,013 \mathrm{mg} / \mathrm{L}$ - límite superior al $90 \%=$ 0,084 mg/L) y la $\mathrm{HC}_{50}$ estimada es 0,583 mg/L (límite inferior al $90 \%=0,321 \mathrm{mg} / \mathrm{L}$ - límite 
superior al $90 \%=1,059 \mathrm{mg} / \mathrm{L})$. En la fig. 37 se muestra además la CPC de la distribución acumulativa de la toxicidad del CPF para diferentes especies de anuros $(n=22)$ y de la distribución acumulativa de las concentraciones de CPF en el ambiente ( $n=21)$, siendo el riesgo ecológico esperado promedio menor al $1 \%$.

Tabla 21. Resumen de los parámetros obtenidos (en $\mathrm{mg} / \mathrm{L}$ ) a partir de la mortalidad registrada bajo exposiciones agudas y crónicas para cada bioensayo realizado (E1-E5). Entre paréntesis se detallan los límites de confianza al 95\% para la CL-50. Para los TL-50 en días (d) se indica entre paréntesis la hora a la cual se evaluó tal parámetro para cada concentración (c) de cada cada bioensayo. E1-E2: bioensayos en estadio 25; E3: bioensayo en estadio 31; E4-E5: bioensayos en estadio 37; " mínima y máxima concentración en las cuales se observó efectos (rango de efectos); c: concentración de clorpirifós en mg/L; c1: 0,025 mg/L; c2: 0,075 mg/L; c3: 0,2 mg/L; c4: 0,3 mg/L; c5: 0,5 mg/L

\begin{tabular}{|c|c|c|c|c|c|c|}
\hline & & E1 & E2 & E3 & E4 & E5 \\
\hline \multirow{4}{*}{ 동 } & CL -50 & 0,229 & 0,185 & 0,121 & - & - \\
\hline & & $(0,188-0,268)$ & $(0,143-0,234)$ & $(0,079-0,173)$ & $\left(0,05^{\mathrm{a}}-0,2^{\mathrm{a}}\right)$ & $\left(0,5^{\mathrm{a}}->0,5^{\mathrm{a}}\right)$ \\
\hline & NOEC & 0,1 & 0,1 & 0,025 & - & - \\
\hline & LOEC & 0,25 & 0,2 & 0,075 & - & - \\
\hline \multirow{4}{*}{ 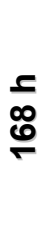 } & CI 50 & 0,083 & 0,138 & 0,114 & -- & -- \\
\hline & & $(0,064-0,110)$ & $(0,107-0,181)$ & $(0,074-0,160)$ & & \\
\hline & NOEC & 0,075 & 0,1 & 0,025 & -- & -- \\
\hline & LOEC & 0,1 & 0,2 & 0,075 & -- & -- \\
\hline \multirow{4}{*}{ 웜 } & CI 50 & 0,043 & -- & 0,102 & -- & -- \\
\hline & CLEOT & $(0,031-0,060)$ & & $(0,064-0,144)$ & & \\
\hline & NOEC & 0,01 & -- & 0,025 & -- & -- \\
\hline & LOEC & 0,025 & -- & 0,075 & -- & -- \\
\hline \multirow{4}{*}{ క్ } & CL-50 & 0,030 & -- & 0,100 & -- & -- \\
\hline & & $(0,021-0,043)$ & & $(0,064-0,138)$ & & \\
\hline & NOEC & 0,01 & -- & 0,025 & -- & -- \\
\hline & LOEC & 0,025 & -- & 0,075 & -- & -- \\
\hline \multirow{5}{*}{ 号 } & c1 & $7 \mathrm{~d}(336 \mathrm{~h})$ & -- & $>14 \mathrm{~d}(336 \mathrm{~h})$ & -- & -- \\
\hline & c2 & $4 \mathrm{~d}(336 \mathrm{~h})$ & $>14 \mathrm{~d}(168 \mathrm{~h})$ & $3-10 d(336 h)$ & -- & -- \\
\hline & c3 & -- & $7 \mathrm{~d}(168 \mathrm{~h})$ & -- & -- & -- \\
\hline & c4 & -- & $4 \mathrm{~d}(168 \mathrm{~h})$ & $3 d$ & -- & -- \\
\hline & c5 & $1 \mathrm{~d}(336 \mathrm{~h})$ & $2 \mathrm{~d}(168 \mathrm{~h})$ & -- & -- & -- \\
\hline
\end{tabular}



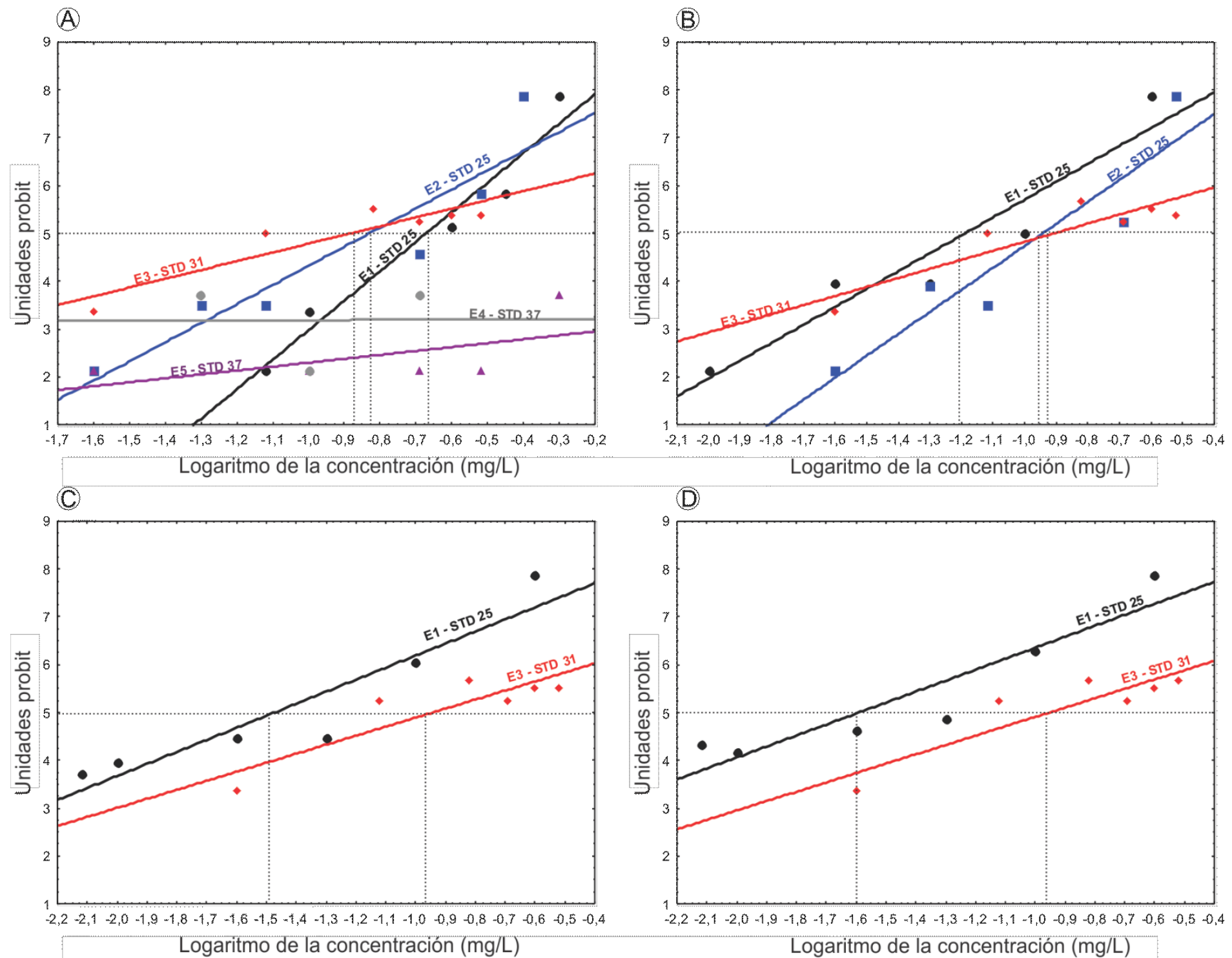

Figura 35. Estimación de la concentración letal 50 para cada bioensayo realizado (E) en los distintos estadios del desarrollo (STD) a 96 h (A), 168 h (B), 240 h (C) y 336 h (D) mediante un análisis de regresión. Con línea punteada se indica la intersección de cada curva con la unidad probit 5 (eje vertical) y el logaritmo de la concentración en mg/L (eje horizontal) 

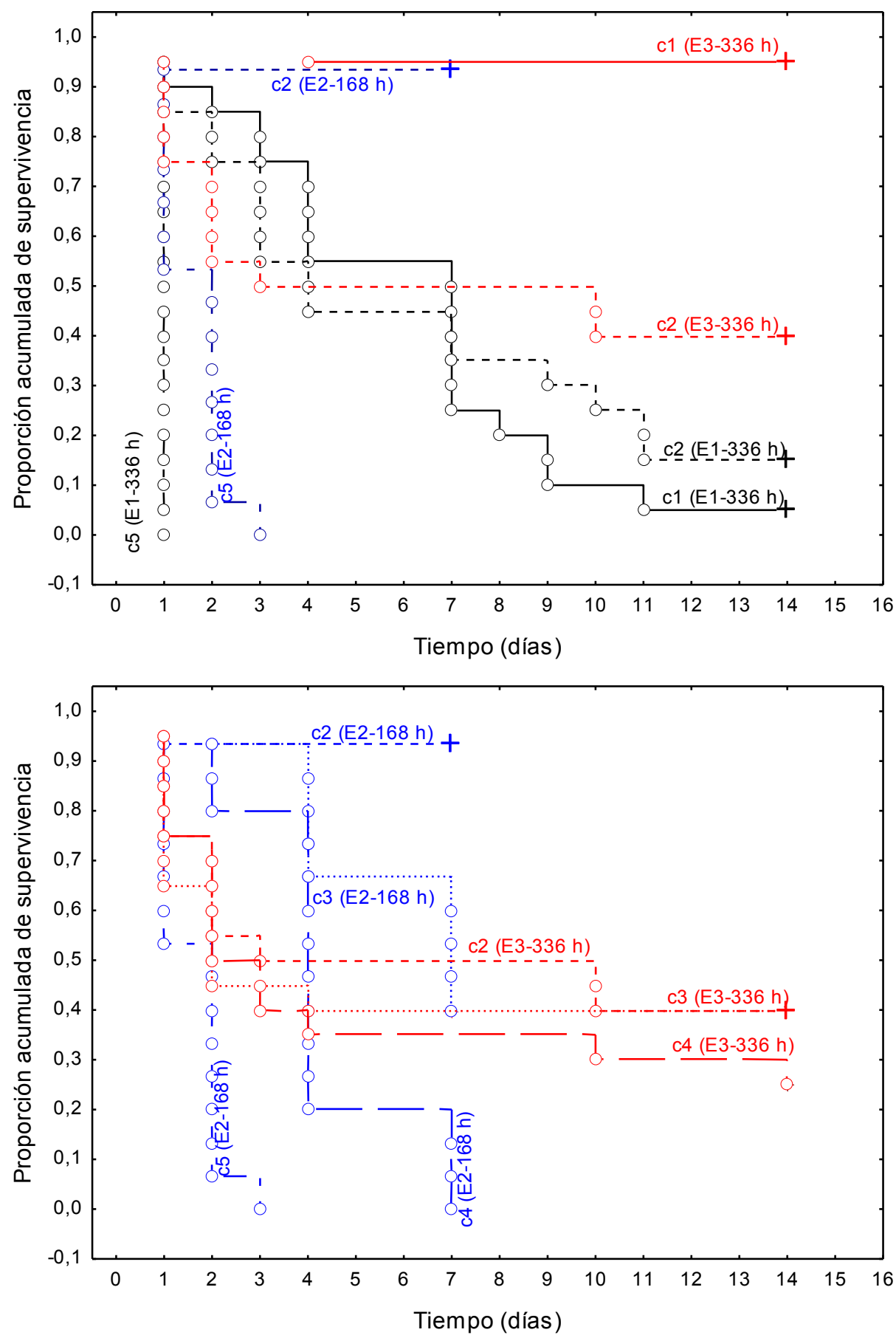

Figura 36. Curvas de supervivencia crónica de Kaplan-Meier considerando los bioensayos crónicos realizados. Parte superior: se comparan las curvas de supervivencia de los bioensayos E1-E2 (estadio 25) y E3 (estadio 31). Parte inferior: se comparan las curvas de supervivencia de los bioensayos E2 y E3. c: concentración de clorpirifós en mg/L; c1: 0,025 mg/L; c2: 0,075 mg/L; c3: 0,2 $\mathrm{mg} / \mathrm{L}$; c4: 0,3 mg/L; c5: 0,5 mg/L; círculo: dato observado; cruz: dato estimado por el método de Kaplan-Meier 

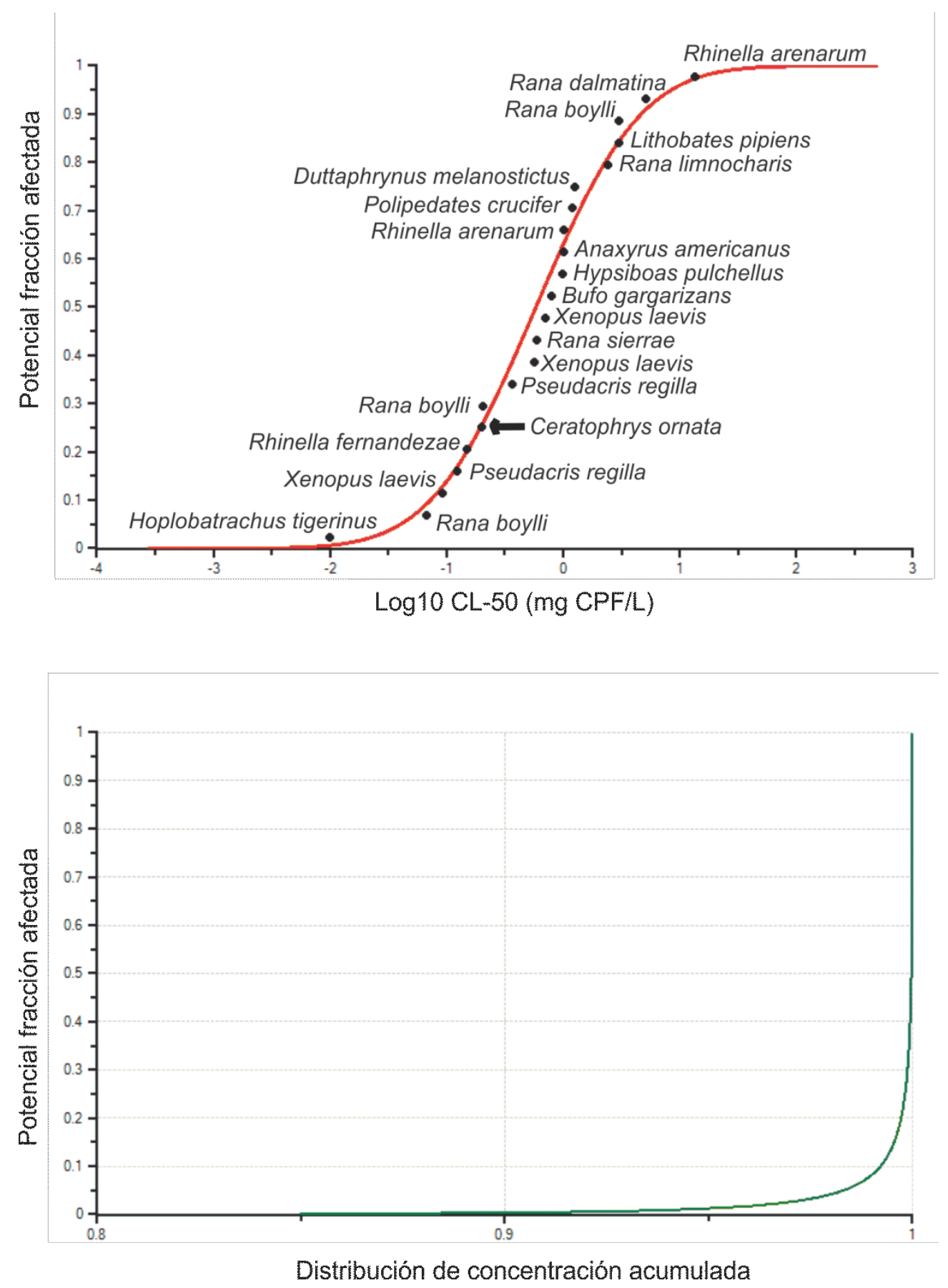

Figura 37. Parte superior: Distribución de sensibilidad de especies de anfibios según valores de CL50 (mg/L) para el clorpirifós (CPF). Con una flecha se indica el dato de CL-50 para la especie Ceratophrys ornata. Parte inferior: Curva de probabilidad conjunta entre la fracción de especies afectadas y la distribución de concentración acumulada para el clorpirifós 


\section{Bioensayos con clorpirifós - Efectos subletales}

Las CE-50, NOEC y LOEC de las alteraciones en la natación y presencia de anormalidades registradas bajo exposiciones agudas y crónicas se resumen en las tablas 22 y 23 , respectivamente.

Las alteraciones en la natación fueron registradas en el $95 \%$ de los tratamientos con individuos expuestos a CPF considerando todos los STD evaluados (25, 31 у 37), habiéndose registrado total ausencia de tal efecto en los grupos control. Para el caso particular de E1, las mismas fueron registradas solo hasta las $96 \mathrm{~h}$ dada la dificultad para evaluar este punto final visualmente al haber 5 larvas por frasco. Esta dificultad fue superada en el E2 al tener una sola larva por frasco. En la fig. 38 se muestran los gráficos de regresión entre el logaritmo de la concentración de CPF y las unidades probit, por medio de los cuales se corroboraron los datos de CE-50 obtenidos mediante el programa Probit. La comparación de curvas a 96 h de los bioensayos realizados en STD 25 (E1, E2) no arrojó diferencias significativas para las pendientes $(t=-0,141$, g.l. $=9, p>0,05)$ ni para las ordenadas al origen $(t=-0,727$, g.I. $=10, p>0,05)$. La comparación de curvas a $96 \mathrm{~h}$ de los bioensayos realizados en STD 37 (E4, E5) no se pudo realizar por no contar con suficiente cantidad de puntos del $0-100 \%$ de efectos para E4. Respecto al análisis de comparaciones múltiples realizado a $96 \mathrm{~h}(\mathrm{E} 1, \mathrm{E} 2, \mathrm{E} 3, \mathrm{E} 5)$, el mismo no arrojó diferencias significativas entre las pendientes $(F(3,10)=2,03, p=0,173)$ ni entre las ordenadas al origen $(F(3,13)=$ $2,34, p=0,121)$. Por último, la comparación de curvas a $168 \mathrm{~h}$ de los bioensayos E2 y E3, no arrojó diferencias significativas entre las pendientes $(t=-1,352$, g.l. $=2, p>0,05)$ pero sí entre las ordenadas al origen $(t=6,624$, g.I. $=3, p<0,005)$.

Respecto a la presencia de anormalidades, se registró leve flexión lateral de la cola (LFLC) y severa flexión lateral de la cola (SFLC). Las mismas fueron registradas más frecuentemente para los STD 25 y 31, habiéndose observado LFLC en tan solo 5 individuos de STD 37 pertenecientes al bioensayo E4 y la total ausencia de SFLC tanto para E4 como para E5. Al igual para que el punto final anterior, se registró total ausencia de anormalidades en los grupos control. En la fig. 39 y 40 se muestran los gráficos de regresión entre el logaritmo de la concentración de CPF y las unidades probit, por medio de los cuales se corroboraron los datos de CE-50 obtenidos mediante el programa Probit. Respecto a la presencia de LFLC, la comparación de curvas a $96 \mathrm{~h}$ de los bioensayos realizados en STD 25 (E1, E2) no arrojó diferencias significativas para los pendientes $(t=-0,152$, g.l. $=8, p>$ $0,05)$ ni para las ordenadas al origen $(t=0,039$, g.l. $=9, p>0,05)$. Respecto al análisis de comparaciones múltiples realizado a 96 h (E1, E2, E3, E4), el mismo no arrojó diferencias significativas entre las pendientes $(F(3,9)=0,91, p=0,474)$ pero sí entre las ordenadas al origen $(F(3,12)=6,51, p=0,007)$, habiéndose detectado tales diferencias, mediante la prueba de Tukey, entre los bioensayos E1-E4, E2-E3 y E2-E4. Por último, la comparación 
de curvas a $168 \mathrm{~h}$ de los bioensayos E2 y E3, no arrojó diferencias significativas entre las pendientes $(t=-1,389$, g.I. $=5, p>0,05)$ pero sí entre las ordenadas al origen $(t=3,022$, g.l. $=6, p<0,005)$. Respecto a la presencia de SFLC, la comparación de curvas a $96 \mathrm{~h}$ de los bioensayos realizados en STD 25 (E1, E2) no arrojó diferencias significativas para los pendientes $(t=-3,723$, g.l. $=8, \mathrm{p}>0,05)$ ni para las ordenadas al origen $(t=0,317, \mathrm{~g} . \mathrm{I} .=9, \mathrm{p}$ $>0,05)$.

Con relación al crecimiento, para el STD 25 (E2) el ANOVA de una vía arrojó diferencias significativas, siendo la concentración $0,4 \mathrm{mg} \mathrm{CPF/L} \mathrm{(=T8)} \mathrm{significativamente} \mathrm{menor} \mathrm{que} \mathrm{el}$ grupo control (prueba de Dunnett) para las $96 \mathrm{~h}(\mathrm{~F}(8,105)=6,833, \mathrm{p}=0,001)$ y para las 168 h $(F(9,135)=7,389, p=0,0009)$. Además, existe correlación negativa entre la LHC y los distintos tratamientos tanto para las $96 \mathrm{~h}(r=-0,4809, p<0,0005)$ como para las $168 \mathrm{~h}(r=-$ 0,4237, $p<0,0005$ ) (Fig. 41A). Para el STD 31 (E3), el ANOVA de una vía arrojó diferencias significativas para las $96 \mathrm{~h}(\mathrm{~F}(7,152)=3,253, \mathrm{p}=0,003)$ pero no respecto al grupo control (prueba de Dunnett) sino entre los tratamientos superiores respecto a los inferiores (prueba de Fisher; Fig. 41B). Para las 336 h, el ANOVA de una vía arrojó diferencias significativas entre las concentraciones $0,5 \mathrm{mg} C P F / L(=T 7)$ y $0,7 \mathrm{mg} C P F / L(=T 8)$ y el grupo control $(\mathrm{F}(8$, $171)=3,213, p=0,002$ ) (Fig. $41 \mathrm{C}$ ). Al igual que para las $96 \mathrm{~h}$, si se comparan todos los tratamientos entre sí mediante la prueba de Fisher, existen diferencias significativas entre los tratamientos superiores respecto a los inferiores $(F(7,152)=2,993, p=0,006)$ (Fig. 41D). Además, existe correlación negativa entre la LHC y los distintos tratamientos para las $96 \mathrm{~h}(r=-0,3220, p<0,0005)$ como para las $336 \mathrm{~h}(r=-0,3096, p<0,0005)$. Si se analizan los datos de LHC del E3 para las 96 y $336 \mathrm{~h}$ mediante un ANOVA de medidas repetidas, el mismo arroja diferencias significativas producto del efecto del tratamiento $(F(8,171)=3,123$, $p=0,002)$, del tiempo $(F(1,171)=8,120, p=0,004)$ y del tratamiento con el tiempo $(F(8$, $171)=3,329, p=0,001)$. Sin embargo, la prueba de Dunnett arroja diferencias significativamente mayores entre las $96 \mathrm{~h}$ y $336 \mathrm{~h}$ para el grupo control $(p=0,002)$, no existiendo diferencias significativamente menores entre los distintos tratamientos y el grupo control (Fig. 42). Si se elimina al grupo control de este análisis, el ANOVA de medidas repetidas solo arroja diferencias significativas producto del efecto del tratamiento $(F(7,152)$ $=3,208, p=0,003)$ y del tiempo $(F(1,152)=20,914, p<0,0005)$ pero no del efecto del tratamiento con el tiempo $(F(7,152)=0,488, p=0,842)$ (Fig. 42). Para el STD 37 (E4, E5) el ANOVA de una vía no arrojó diferencias significativas $(E 4: F(3,34)=2,613, p=0,067$; $E 5$ : $F(5,54)=2,349, p=0,053)$. Para este STD, tampoco existe correlación entre la LHC y los distintos tratamientos a $96 \mathrm{~h}(\mathrm{E} 4: \mathrm{p}=0,067$; $E 5: p=0,087)$. Cabe aclarar que todas las pruebas fueron realizadas con el control con agua de bioensayo (C) ya que no existen diferencias significativas entre este control y el control de dilución $\left(C_{d}\right)(E 2-96 \mathrm{~h}$ y $168 \mathrm{~h}: t=-$ 1,827, g.I. $=28, \mathrm{p}=0,078$; E3-96 h: $t=0,551$, g.I. $=38, \mathrm{p}=0,585$; E3-336 h: $t=-1,774$, g.I. $=$ 
38, $\mathrm{p}=0,084$; E4-96 h: $t=-1,767$, g.I. $=16, \mathrm{p}=0,096$; E5-96 h: $t=0,983$, g.I. $=18, \mathrm{p}=$ $0,339)$.

Para evaluar la progresión de efectos negativos se muestra en la fig. 43 el análisis de correlación realizado entre el $0-100 \%$ de efectos de cada punto final (alteraciones en la natación, LFLC, SFLC y mortalidad) y las concentraciones en las cuales se observan tales efectos. El análisis fue realizado al final de la exposición aguda y al final de la exposición crónica arrojando una correlación positiva tanto para E1 (96 h: $r=0,711, p=0,003$ ) como para E2 (96 h: $r=0,734, p=0,001 ; 168 h: r=0,859, p<0,0005)$. Cabe aclarar que las curvas para E1 a 336 h, E3 a 96 h y 336 h y E5 a 96 h no pudieron ser calculadas por falta de datos. Teniendo en cuenta los valores asignados al estado de cada larva al finalizar la exposición aguda y crónica, tal como se mencionó anteriormente $(0$ = larva viva y sin efectos negativos, 1 = larva con alteraciones en la natación, 2 = larva con una anormalidad leve, 3 = larva con una anormalidad severa, 4 = larva muerta), se obtuvieron distintas combinaciones de estado para cada tratamiento de cada bioensayo (ej. 0110: larva viva con alteraciones en la natación y anormalidades leves). Los estados obtenidos para cada bioensayo a un determinado tiempo de exposición fueron clasificados según la presencia/ausencia de progresión. La prueba de chi-cuadrado arrojó diferencias significativas entre los tratamientos y la presencia/ausencia de progresión para E2 (96 h: $X^{2}=40,255, \mathrm{p}<0,0005 ; 168$ h: $X^{2}=$ $41,114, p<0,0005)$ y E3 (96 h: $\left.X^{2}=21,217, p=0,003 ; 336 \mathrm{~h}: X^{2}=31,668, p<0,0005\right)$. En el mismo sentido, si se realiza una prueba de chi-cuadrado entre todos los estados (sin clasificar) y todos los tratamientos se obtienen diferencias significativas para E1 (96 h: $X^{2}=$ 137,359, p < 0,0005), E2 (96 h: $\left.X^{2}=220,085, p<0,0005 ; 168 \mathrm{~h}: X^{2}=265,896, p<0,0005\right)$, E3 (96 h: $\left.X^{2}=162,583, p<0,0005 ; 336 \mathrm{~h}: X^{2}=257,311, \mathrm{p}<0,0005\right)$ y E4 (96 h: $X^{2}=$ $56,913, p<0,0005)$. Con la intención de complementar los análisis anteriores y con el objetivo de demostrar la existencia de progresión de efectos negativos, se realizaron para los distintos bioensayos correlaciones entre la frecuencia de estados que indican progresión de efectos y el logaritmo de las distintas concentraciones de CPF ( $\mathrm{mg} / \mathrm{L})$ en la cual se dan tales efectos, a un tiempo fijo de exposición (final del bioensayo agudo/crónico), obteniéndose una correlación positiva para E2 (96 h: $r=0,8317, p=0,005 ; 168 \mathrm{~h}: \mathrm{r}=$ 0,7952, $p=0,010$ ) y para E3 (96 $h: r=0,8089, p=0,015 ; 336 h: r=0,9453, p<0,0005$ ) (Fig. 44). En el mismo sentido, se realizaron análisis de correlación entre todos los estados asignados a una concentración fija y los distintos tiempos de exposición, arrojando los mismos diferencias significativas para E2 (T2: $r=0,9773, p=0,004 ; T 5: r=0,9359, p=$ 0,019; T6: $r=0,9310, p=0,021 ; T 7: r=0,9163, p=0,029)$ y para E3 (T3: $r=0,7651, p=$ 0,045; T6: $r=0,8308, p=0,021 ; T 7: r=0,930, p=0,002 ; T 8: r=0,852, p=0,015)$ (Fig. 45). Complementariamente, en la fig. 46 se detallan los gráficos de torta empleados para evaluar tal progresión de efectos negativos desde el STD 25 al 37, pudiéndose distinguir hacia el 
inicio de los bioensayos mayor porcentaje de individuos sanos sin alteraciones, seguido por la aparición de alteraciones en la natación, luego por la presencia de anormalidades leves y a continuación severas, culminando con la muerte de los individuos afectados hacia el final de los bioensayos. En la tabla 24 se detallan los resultados del análisis de correlación lineal realizado entre la proporción de efectos negativos de los distintos puntos finales evaluados para todos los bioensayos (mortalidad, alteraciones en la natación, LFLC y SFLC) y las distintas concentraciones a un tiempo constante $(h)$.

Por último, en la fig. 47 se muestra la DSE de anfibios anuros al CPF. Dicha curva se estimó mediante 10 valores de Log (CE-50), teniendo una media de $-1,015$ y un desvío estándar de 0,430. La $\mathrm{HC}_{5}$ estimada es $0,018 \mathrm{mg} / \mathrm{L}$ (límite inferior al 90\% $=0,005 \mathrm{mg} / \mathrm{L}$ límite superior al $90 \%=0,035 \mathrm{mg} / \mathrm{L}$ ) y la $\mathrm{HC}_{50}$ estimada es $0,097 \mathrm{mg} / \mathrm{L}$ (límite inferior al $90 \%=0,054 \mathrm{mg} / \mathrm{L}$ - límite superior al $90 \%=0,171 \mathrm{mg} / \mathrm{L})$. En la fig. 47 se muestra además la CPC de la distribución acumulativa de la toxicidad del CPF para diferentes especies de anfibios anuros $(n=10)$ y de la distribución acumulativa de las concentraciones de CPF en el ambiente $(n=21)$, siendo el riesgo ecológico esperado promedio menor al $2 \%$. 
Tabla 22. Resumen de los parámetros obtenidos (en $\mathrm{mg} / \mathrm{L}$ ) a partir de las alteraciones en la natación bajo exposiciones agudas y crónicas para cada bioensayo realizado (E1-E5). Entre paréntesis se detallan los límites de confianza al 95\% para la CE-50. E1-E2: bioensayos en estadio 25; E3: bioensayo en estadio 31; E4-E5: bioensayos en estadio 37; ' ${ }^{2}$ mínima y máxima concentración en las cuales se observó efectos (rango de efectos); ' valores calculados por el método de intersección lineal cuando el método probit no se pudo aplicar

\begin{tabular}{|c|c|c|c|c|c|c|}
\hline & & E1 & E2 & E3 & E4 & E5 \\
\hline \multirow{3}{*}{$\frac{5}{8}$} & CE-50 & $\begin{array}{c}0,027^{\mathrm{b}} \\
\left(0,01^{\mathrm{a}}-0,35^{\mathrm{a}}\right)\end{array}$ & $\begin{array}{c}0,021 \\
(0,011-0,030)\end{array}$ & $\begin{array}{c}0,069^{\mathrm{b}} \\
\left(0,075^{\mathrm{a}}-0,7^{\mathrm{a}}\right)\end{array}$ & $\left(0,05^{-}-0,2^{a}\right)$ & $\begin{array}{c}0,008^{\mathrm{b}}- \\
\left(<0,025^{\mathrm{a}}-0,5^{\mathrm{a}}\right)\end{array}$ \\
\hline & NOEC & 0,0075 & 0,01 & - & $<0,05$ & $<0,025$ \\
\hline & LOEC & 0,01 & $<0,025$ & - & 0,05 & 0,025 \\
\hline \multirow{4}{*}{ ᄃ } & & & 0,015 & $0,068^{b}$ & & \\
\hline & CE-50 & -- & $(0,011-0,019)$ & $\left(0,075^{\mathrm{a}}-0,7^{\mathrm{a}}\right)$ & -- & -- \\
\hline & NOEC & -- & 0,01 & - & -- & -- \\
\hline & LOEC & -- & $<0,025$ & - & -- & -- \\
\hline \multirow{3}{*}{ 守 } & CE-50 & -- & -- & $\begin{array}{c}0,066^{\mathrm{b}} \\
\left(0,075^{\mathrm{a}}-0,7^{\mathrm{a}}\right)\end{array}$ & -- & -- \\
\hline & NOEC & -- & -- & - & -- & -- \\
\hline & LOEC & -- & -- & - & -- & -- \\
\hline \multirow{3}{*}{ 孚 } & CE-50 & -- & -- & $\begin{array}{c}0,066^{\mathrm{b}} \\
\left(0,075^{\mathrm{a}}-0,7^{\mathrm{a}}\right)\end{array}$ & -- & -- \\
\hline & NOEC & -- & -- & - & -- & -- \\
\hline & LOEC & -- & -- & - & -- & -- \\
\hline
\end{tabular}



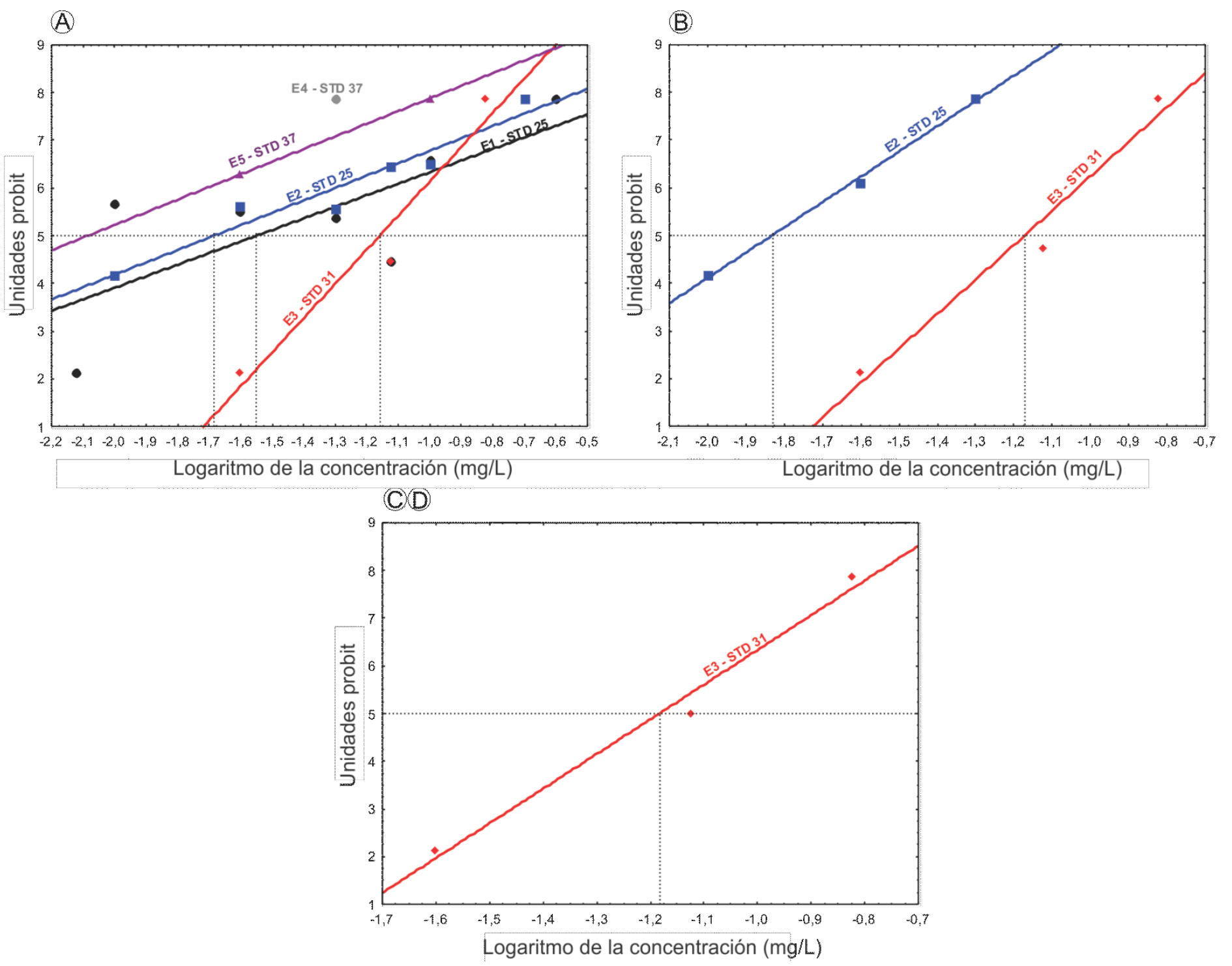

Figura 38. Estimación de la concentración efectiva 50 a 96 h de la alteración en la natación para cada bioensayo realizado (E) en los distintos estadios del desarrollo (STD) a 96 h (A), 168 h (B), 240 h (C) y 336 h (D) mediante un análisis de regresión. Con línea punteada se indica la intersección de cada curva con la unidad probit 5 (eje vertical) y el logaritmo de la concentración en $\mathrm{mg} / \mathrm{L}$ (eje horizontal) 
Tabla 23. Resumen de los parámetros obtenidos (en $\mathrm{mg} / \mathrm{L}$ ) a partir de la presencia de anormalidades bajo exposiciones agudas y crónicas para cada bioensayo realizado (E1-E5). Entre paréntesis se detallan los límites de confianza al 95\% para la CE-50. E1-E2: bioensayos en estadio 25; E3: bioensayo en estadio 31; E4-E5: bioensayos en estadio 37; ' ${ }^{2}$ mínima y máxima concentración en las cuales se observó efectos (rango de efectos); ${ }^{b}$ valores calculados por el método de intersección lineal cuando el método probit no se pudo aplicar

\begin{tabular}{|c|c|c|c|c|c|c|c|}
\hline & & & E1 & E2 & E3 & E4 & E5 \\
\hline \multirow{12}{*}{ 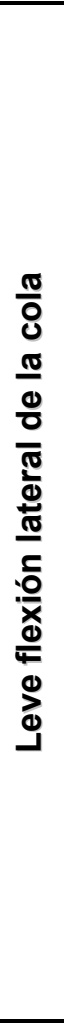 } & \multirow{3}{*}{$\frac{5}{8}$} & CE-50 & $\begin{array}{c}0,096 \\
(0,065-0,272)\end{array}$ & $\begin{array}{c}0,128 \\
(0,078-347)\end{array}$ & $\begin{array}{c}0,295^{\mathrm{b}} \\
\left(0,2^{\mathrm{a}}-0,25^{\mathrm{a}}\right)\end{array}$ & $\begin{array}{c}0,240^{\mathrm{b}} \\
\left(0,1^{\mathrm{a}}-0,2^{\mathrm{a}}\right)\end{array}$ & -- \\
\hline & & NOEC & 0,075 & 0,05 & -- & -- & -- \\
\hline & & LOEC & 0,1 & 0,075 & -- & -- & -- \\
\hline & \multirow{3}{*}{ 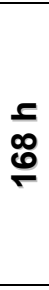 } & 0550 & -- & $\begin{array}{c}0,102 \\
(0,066-0,261)\end{array}$ & $\begin{array}{c}0,219^{\mathrm{b}} \\
\left(0,2^{\mathrm{a}}-0,25^{\mathrm{a}}\right)\end{array}$ & -- & -- \\
\hline & & NOEC & -- & 0,05 & -- & -- & -- \\
\hline & & LOEC & -- & 0,075 & -- & -- & -- \\
\hline & \multirow{3}{*}{ 辛 } & CE-50 & -- & -- & $\left(0,2^{\mathrm{a}-}-0,25^{\mathrm{a}}\right)$ & -- & -- \\
\hline & & NOEC & -- & -- & -- & -- & -- \\
\hline & & LOEC & -- & -- & -- & -- & -- \\
\hline & \multirow{3}{*}{ 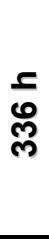 } & CE-50 & -- & -- & $\left(0,2^{\mathrm{a}-}-0,25^{\mathrm{a}}\right)$ & -- & -- \\
\hline & & NOEC & -- & -- & -- & -- & -- \\
\hline & & LOEC & -- & -- & -- & -- & -- \\
\hline \multirow{12}{*}{ 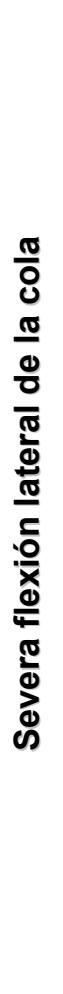 } & \multirow{3}{*}{$\frac{1}{8}$} & CE-50 & $\begin{array}{c}\left(0,0075^{\mathrm{a}}-\right. \\
\left.0,25^{\mathrm{a}}\right)\end{array}$ & $\begin{array}{c}0,127 \\
(0,093-0,248)\end{array}$ & $\left(0,2^{--}-0,7^{a}\right)$ & -- & -- \\
\hline & & NOEC & 0,01 & 0,1 & -- & -- & -- \\
\hline & & LOEC & 0,025 & 0,2 & -- & -- & -- \\
\hline & \multirow{3}{*}{$\begin{array}{l}\text { c } \\
\infty \\
0\end{array}$} & CE-50 & -- & $\begin{array}{c}0,078 \\
(0,058-0,127)\end{array}$ & $\left(0,2^{--}-0,7^{a}\right)$ & -- & -- \\
\hline & & NOEC & -- & 0,025 & -- & -- & -- \\
\hline & & LOEC & -- & 0,05 & -- & -- & -- \\
\hline & \multirow{3}{*}{ व } & CE-50 & -- & -- & $\left(0,2^{\mathrm{a}-0}, 7^{\mathrm{a}}\right)$ & -- & -- \\
\hline & & NOEC & -- & -- & -- & -- & -- \\
\hline & & LOEC & -- & -- & -- & -- & -- \\
\hline & \multirow{3}{*}{ 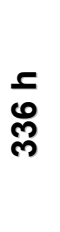 } & CE-50 & -- & -- & $\left(0,2^{\left.-\bar{a}-0,7^{a}\right)}\right.$ & -- & -- \\
\hline & & NOEC & -- & -- & -- & -- & -- \\
\hline & & LOEC & -- & -- & -- & -- & -- \\
\hline
\end{tabular}



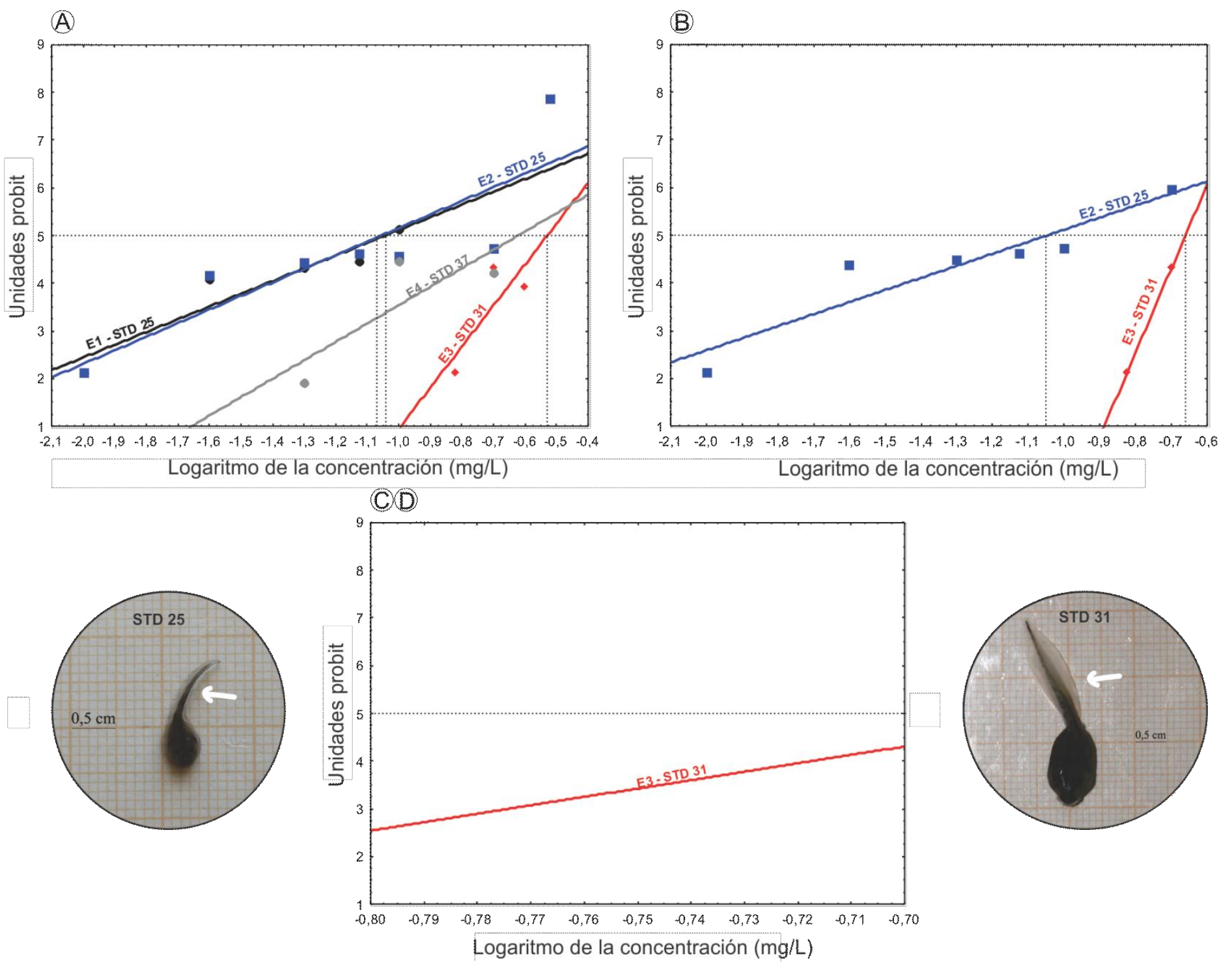

Figura 39. Estimación de la concentración efectiva 50 de la presencia de leve flexión lateral de la cola (se indica con una flecha) para cada bioensayo realizado (E) en los distintos estadios del desarrollo (STD) a 96 h (A), 168 h (B), 240 h (C) y 336 h (D) mediante un análisis de regresión. Con línea punteada se indica la intersección de cada curva con la unidad probit 5 (eje vertical) y el logaritmo de la concentración en $\mathrm{mg} / \mathrm{L}$ (eje horizontal) 

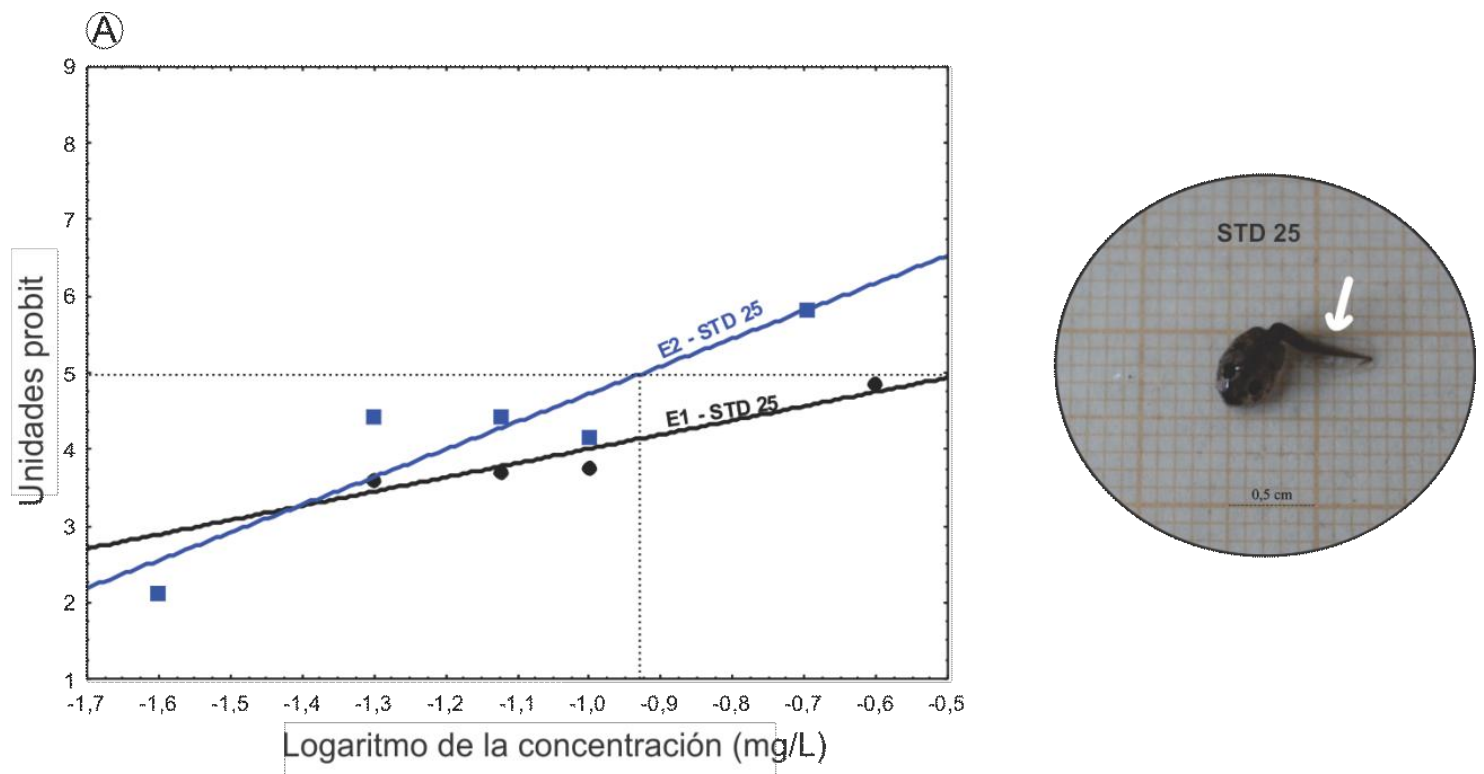

(B)
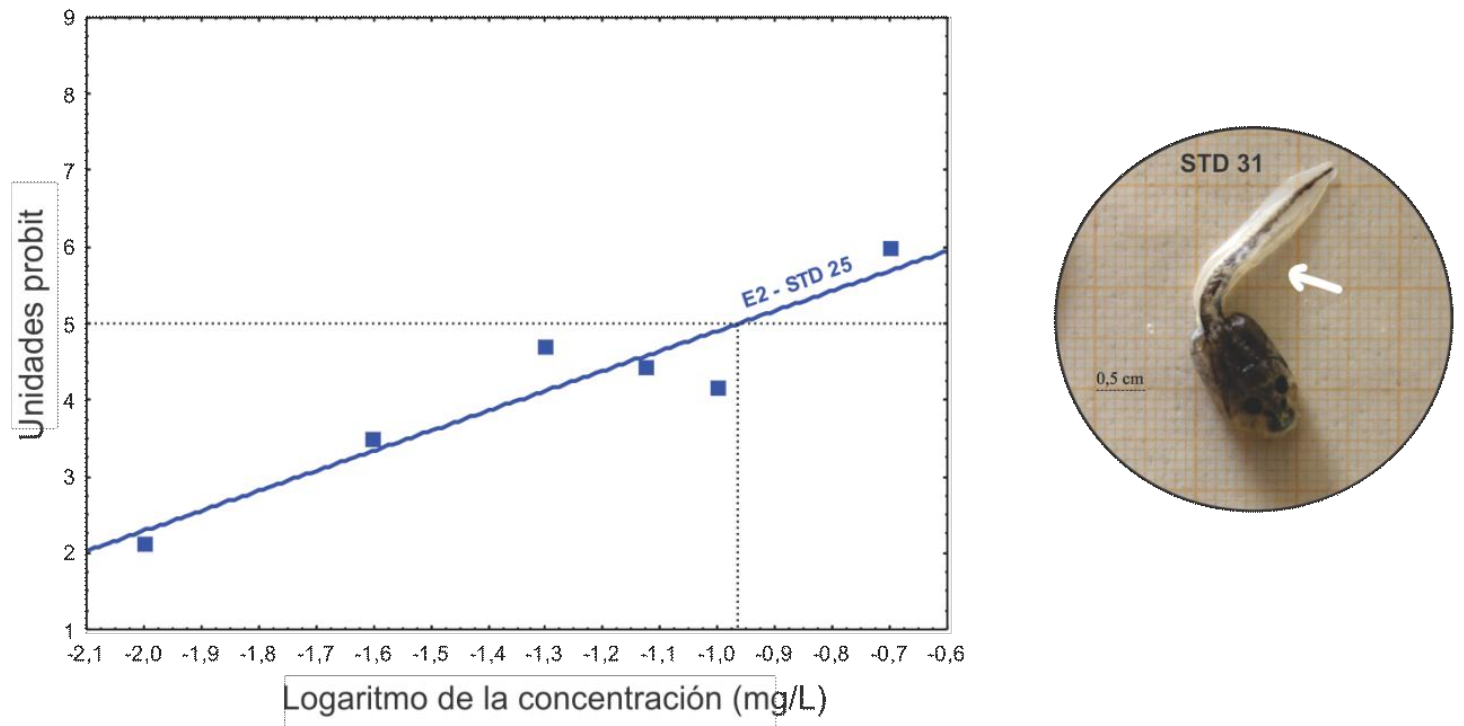

Figura 40. Estimación de la concentración efectiva 50 de la presencia de severa flexión lateral de la cola (se indica con una flecha) para cada bioensayo realizado $(E)$ en los distintos estadios del desarrollo (STD) a 96 h (A) y 168 h (B) mediante una curva de regresión. Con línea punteada se indica la intersección de cada curva con la unidad probit 5 (eje vertical) y el logaritmo de la concentración en $\mathrm{mg} / \mathrm{L}$ (eje horizontal) 

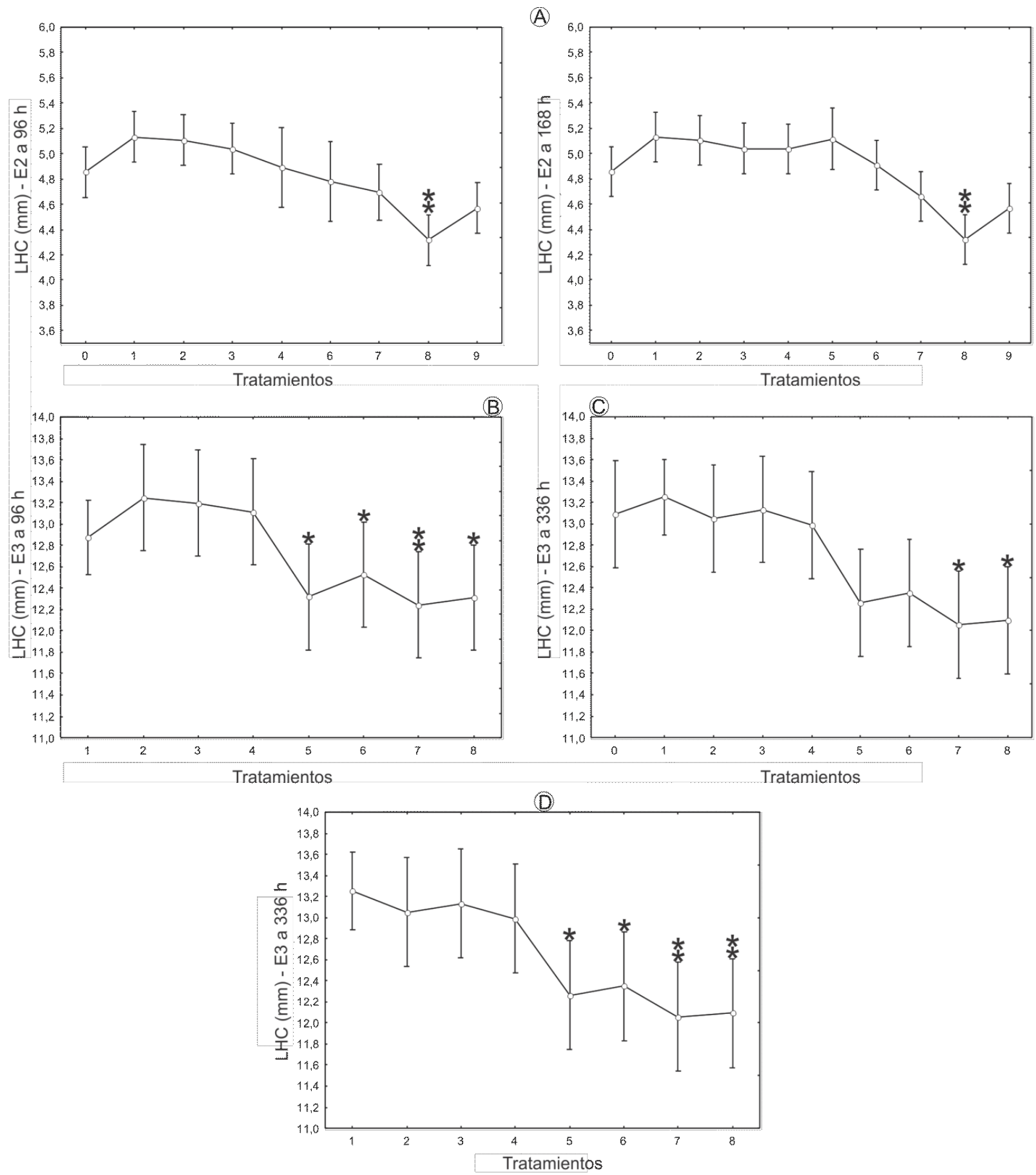

Figura 41. Análisis de la varianza de una vía entre la longitud hocico-cloaca (LHC) y los distintos tratamientos (0-9) para distintos bioensayos. A: análisis realizado para el bioensayo 2 (E2) a 96 h y 168 h; B: análisis realizado para el bioensayo 3 a $96 \mathrm{~h}$ sin considerar al grupo control (0); C-D: análisis realizado para el bioensayo 3 a $336 \mathrm{~h}$ considerando y sin considerar al grupo control, respectivamente; $\left({ }^{*}\right)=p<0,05 ;\left(^{* *}\right)=p<$ 0,005 

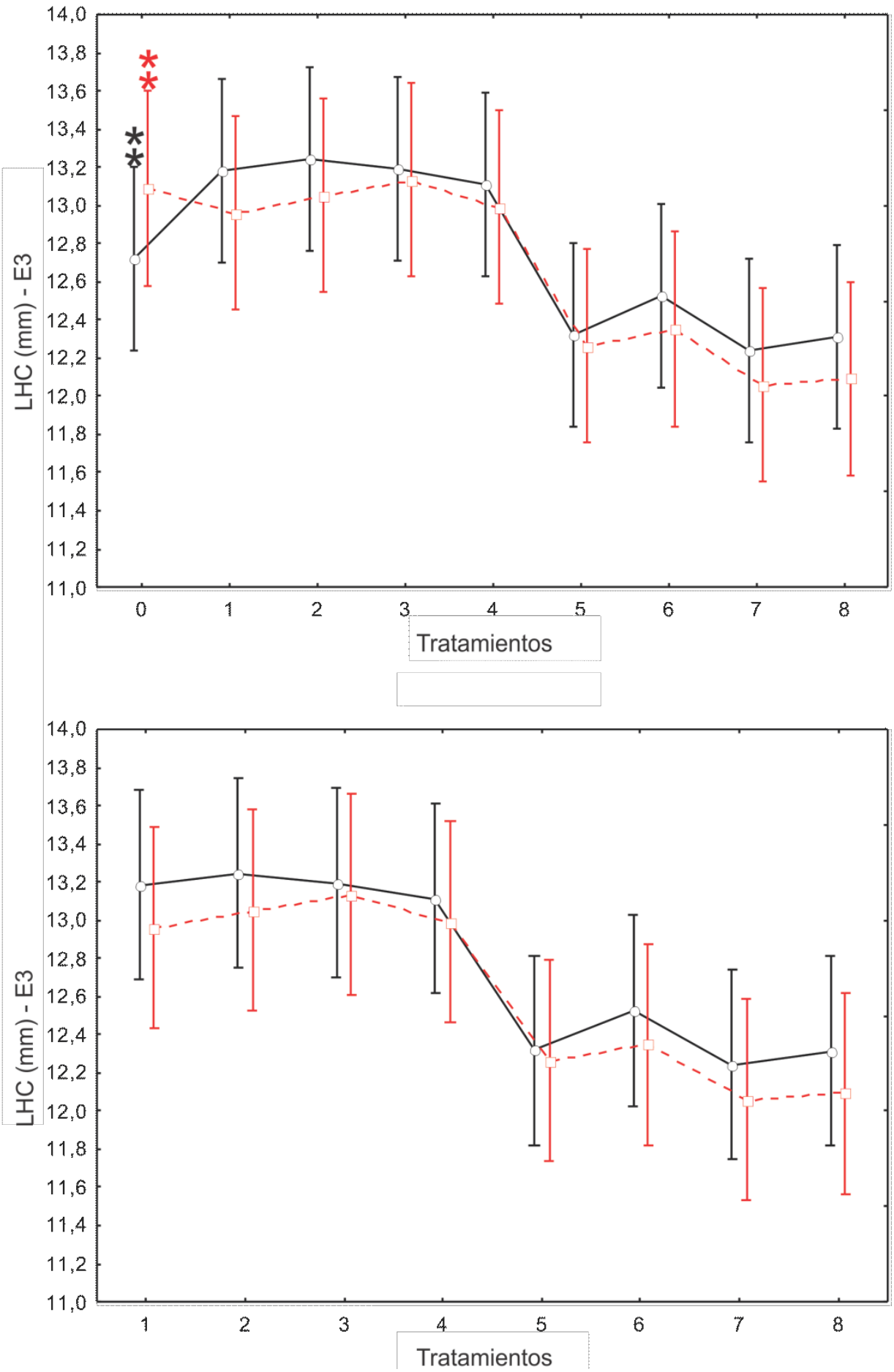

Figura 42. Análisis de la varianza de medidas repetidas entre la longitud hocico cloaca y los distintos tratamientos a 96 h (línea continua color negro) y 336 h (línea discontinua color rojo) para el bioensayo 3 realizado con larvas de $C$. ornata en estadio 31. Parte superior: análisis considerando el grupo control (0), para el cual existen diferencias significativas $\left(^{* *}=p<0,005\right.$ ) entre las $96 \mathrm{~h}$ y $336 \mathrm{~h}$. Parte inferior: análisis sin considerar al grupo control, no existiendo diferencias significativas entre las $96 \mathrm{~h}$ y $336 \mathrm{~h}$ para ninguno de los tratamientos (1-8) 

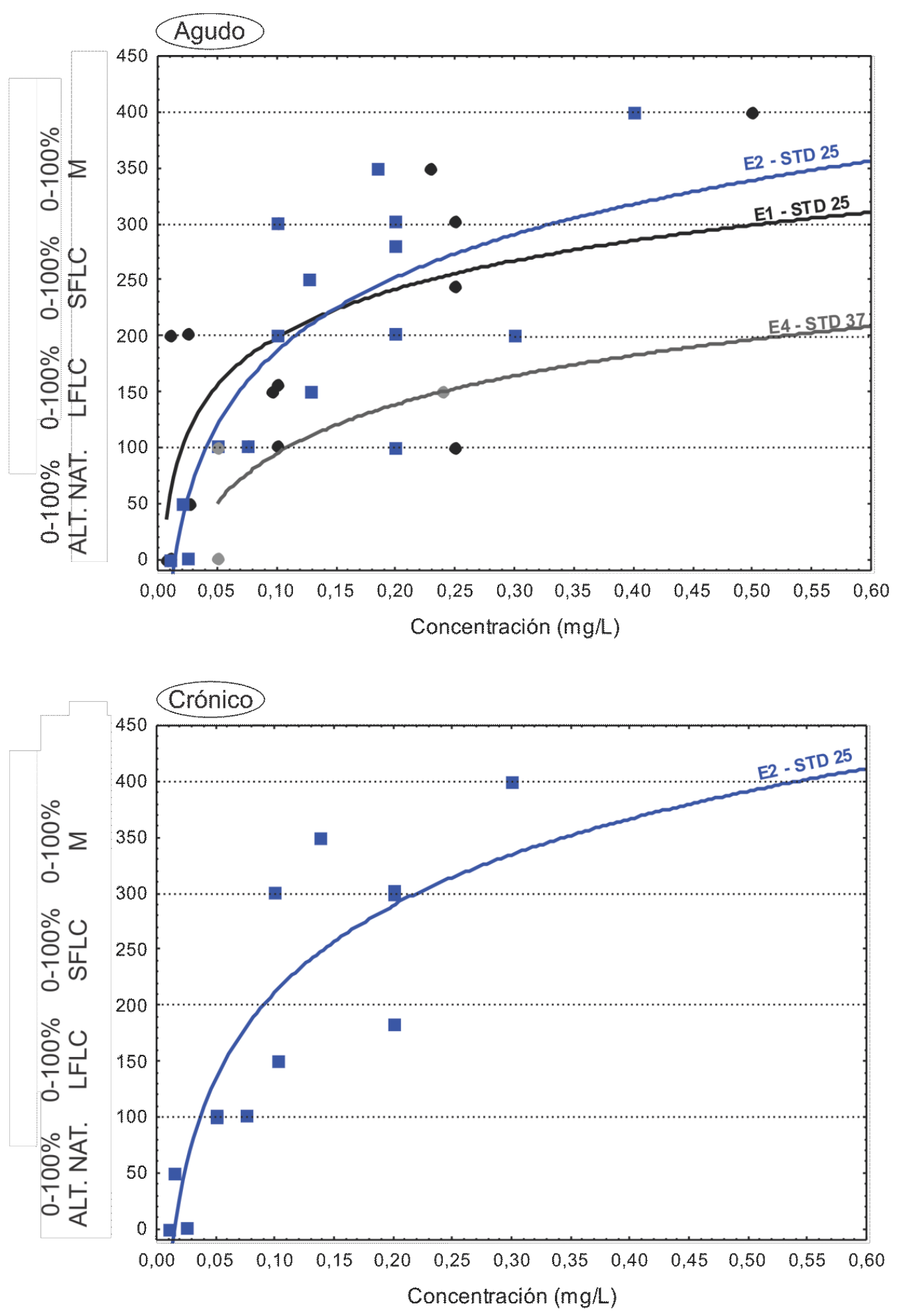

Figura 43. Análisis de correlación realizado para demostrar la progresión de efectos negativos del 0 al 100\%, desde la la aparición de alteraciones en la natación (ALT. NAT.), pasando por la presencia de una leve flexión lateral de la cola (LFLC), seguido por una severa flexión lateral de la cola (SFLC) y culminando con la muerte (M) de los individuos, para los bioensayos (E) realizados en estadio (STD) 25,31 y 37 bajo exposiciones agudas y crónicas. Solo se muestran las correlaciones significativas ( $p$ $<0,05)$ 

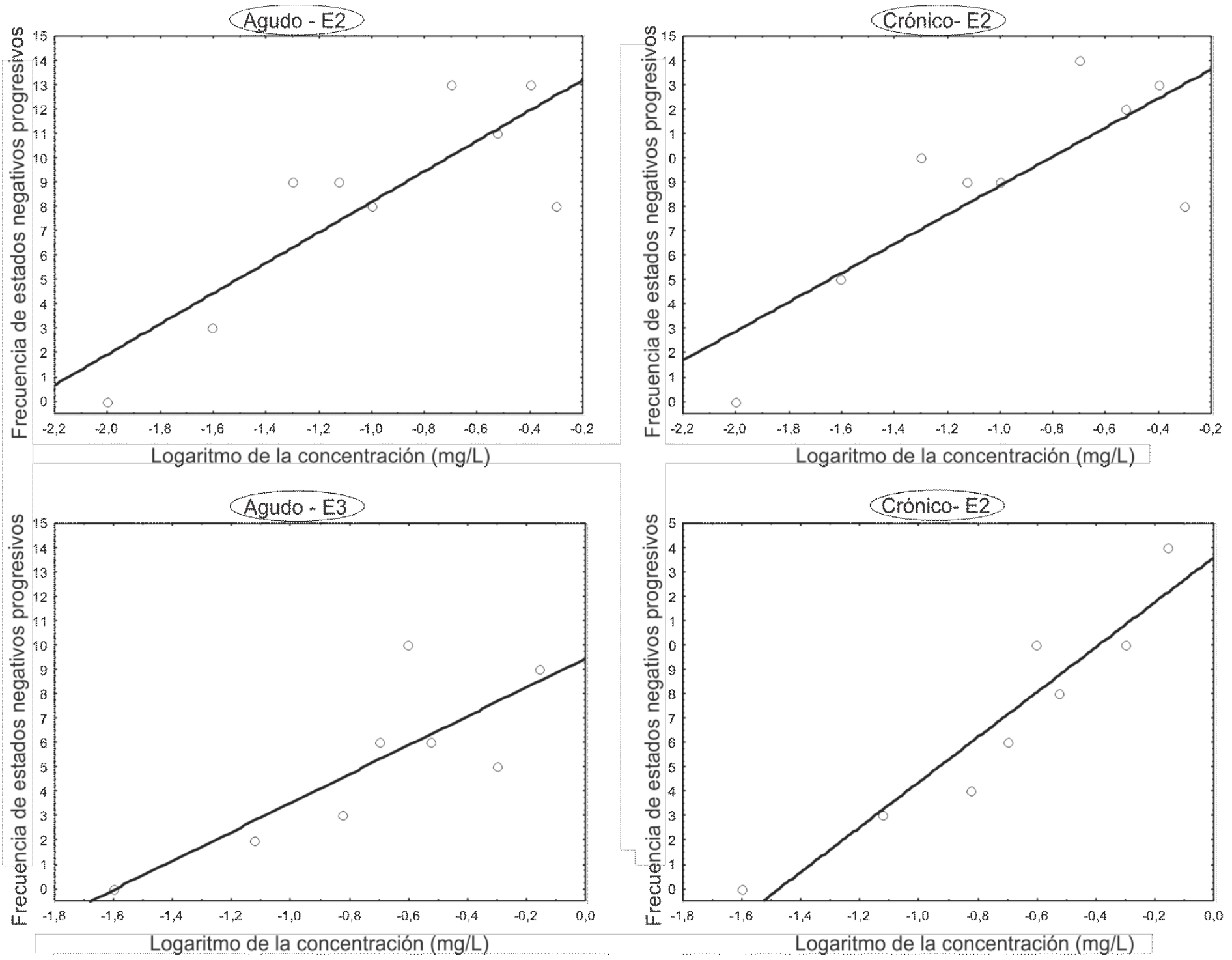

Figura 44. Análisis de correlación lineal entre la frecuencia de estados que indican progresión de efectos negativos (eje vertical) y el logaritmo de las distintas concentraciones de clorpirifós (mg/L; eje horizontal) en las cuales ocurren tales efectos para el bioensayo 2 (E2) a $96 \mathrm{~h}$ (agudo) y $168 \mathrm{~h}$ (crónico) y para el bioensayo 3 (E3) a $96 \mathrm{~h}$ (agudo) y $336 \mathrm{~h}$ (crónico). Solo se muestran las correlaciones significativas $(\mathrm{p}<0,05)$ 

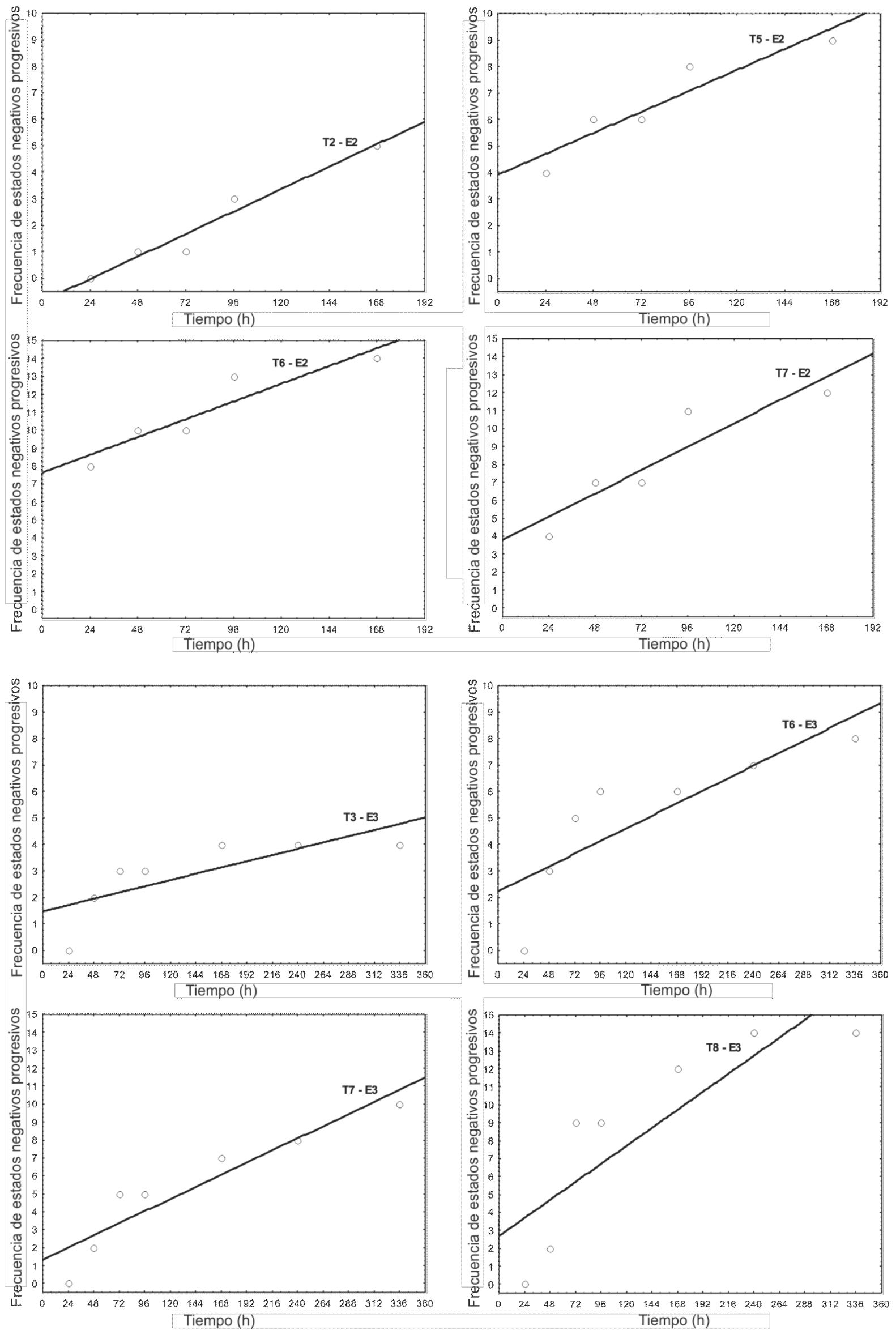

Figura 45. Análisis de correlación lineal entre la frecuencia de estados asignados (eje vertical) a un determinado tratamiento $(\mathrm{T})$ y los distintos tiempos de exposición (h; eje horizontal) para el bioensayo 2 (E2) y 3 (E3). Solo se muestran las correlaciones significativas $(p<0,05)$ 


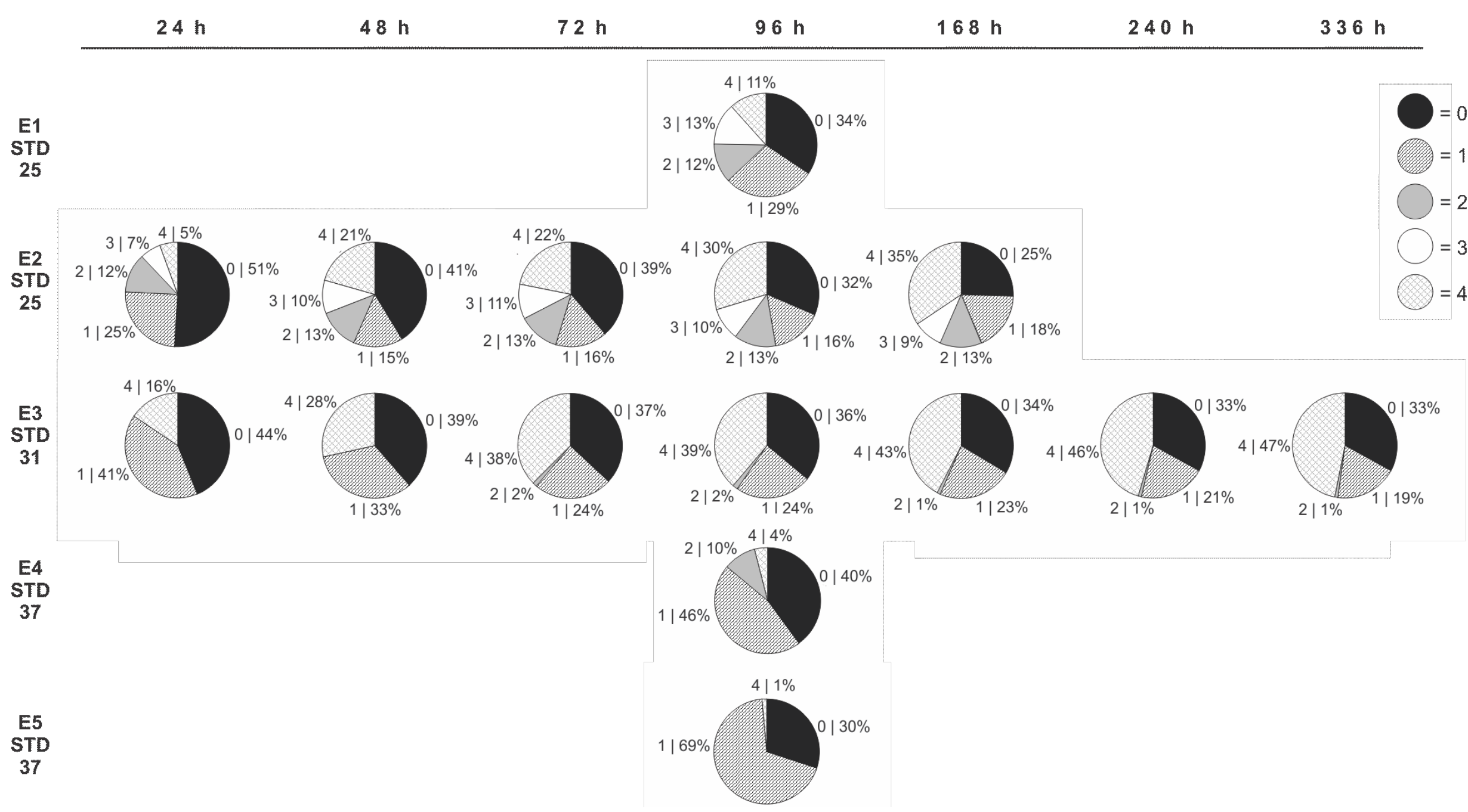

Figura 46. Gráficos de torta realizados para cada tiempo evaluado de cada bioensayo realizado (E1-E5) mostrando la progresión de efectos negativos, desde un individuo sano sin alteraciones (estado 0), seguido por la aparición de alteraciones en la natación (estado 1), luego por la presencia de anormalidades leves (estado 2) y a continuación severas (estado 3) y culminando con la muerte de los individuos afectados (4). Se indica el porcentaje de individuos afectados por estado para cada tiempo evaluado (24 h a $336 \mathrm{~h}$ ) 
Tabla 24. Resultados del análisis de correlación lineal ( $r$ ) entre la proporción de efectos negativos de mortalidad (M), alteraciones en la natación (ALT. NAT.), presencia de leve flexión lateral de la cola (LFLC) y severa flexión lateral de la cola (SFLC) y las distintas concentraciones a un tiempo constante (h). En color rojo y con asterisco se indican los valores de correlación con $p<0,05\left(^{*}\right), p<0,005\left(^{* *}\right)$ y $\mathrm{p}<0,0005\left({ }^{* * *}\right)$

\begin{tabular}{|c|c|c|c|c|c|}
\hline & Tiempo & M & ALT. NAT. & LFLC & SFLC \\
\hline \multirow{7}{*}{ 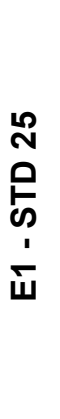 } & $24 \mathrm{~h}$ & $0,9452^{* * *}$ & 0,7190 & -- & -- \\
\hline & $48 \mathrm{~h}$ & $0,9555^{* * *}$ & $0,9634^{* *}$ & -- & -- \\
\hline & $72 \mathrm{~h}$ & $0,9462^{* * *}$ & 0,8452 & -- & -- \\
\hline & $96 \mathrm{~h}$ & $0,9348^{* * *}$ & $0,7891^{*}$ & $0,9666^{* *}$ & 0,3203 \\
\hline & $168 \mathrm{~h}$ & $0,8577^{* * *}$ & -- & -- & -- \\
\hline & $240 \mathrm{~h}$ & $0,8057^{* *}$ & -- & -- & -- \\
\hline & $336 \mathrm{~h}$ & $0,7986^{* *}$ & -- & -- & -- \\
\hline \multirow{5}{*}{ 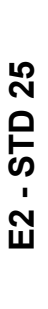 } & $24 \mathrm{~h}$ & $0,7106^{*}$ & $0,7717^{*}$ & $0,9374^{* * *}$ & $0,9489^{* *}$ \\
\hline & $48 \mathrm{~h}$ & $0,9053^{* *}$ & $0,7135^{\star}$ & $0,9374^{* * *}$ & $0,8656^{*}$ \\
\hline & $72 \mathrm{~h}$ & $0,9020^{* *}$ & $0,6852^{*}$ & $0,8956^{* *}$ & $0,8656^{*}$ \\
\hline & $96 \mathrm{~h}$ & $0,9711^{* * *}$ & 0,6244 & $0,9385^{\star * *}$ & $0,9439^{* *}$ \\
\hline & $168 \mathrm{~h}$ & $0,9412^{* * *}$ & 0,4271 & $0,9195^{* * *}$ & $0,9203^{*}$ \\
\hline \multirow{7}{*}{$\begin{array}{l}\bar{m} \\
0 \\
\underline{5} \\
1 \\
\dot{m}\end{array}$} & $24 \mathrm{~h}$ & $0,9978^{*}$ & $0,8326^{*}$ & -- & -- \\
\hline & $48 \mathrm{~h}$ & $0,8127^{*}$ & $0,8091^{*}$ & -- & -- \\
\hline & $72 \mathrm{~h}$ & $0,8882^{*}$ & $0,7630^{*}$ & 0,7505 & -- \\
\hline & $96 \mathrm{~h}$ & $0,9204^{*}$ & 0,6150 & 0,7505 & -- \\
\hline & $168 \mathrm{~h}$ & $0,9075^{*}$ & 0,6079 & 0,7505 & -- \\
\hline & $240 \mathrm{~h}$ & $0,8643^{*}$ & 0,5958 & -- & -- \\
\hline & $336 \mathrm{~h}$ & $0,8631^{*}$ & 0,5958 & -- & -- \\
\hline \multirow{4}{*}{ 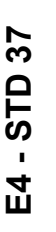 } & $24 \mathrm{~h}$ & 0,1890 & $0,9972^{*}$ & -- & -- \\
\hline & $48 \mathrm{~h}$ & 0,1890 & 0,9538 & -- & -- \\
\hline & $72 \mathrm{~h}$ & 0,1890 & 0,7017 & 0,8660 & -- \\
\hline & $96 \mathrm{~h}$ & 0,1890 & -- & 0,7137 & -- \\
\hline \multirow{4}{*}{$\begin{array}{l}\hat{m} \\
0 \\
\text { s } \\
1 \\
\text { in }\end{array}$} & $24 \mathrm{~h}$ & 0,8292 & $0,9490^{*}$ & -- & -- \\
\hline & $48 \mathrm{~h}$ & 0,8292 & 0,8619 & -- & -- \\
\hline & $72 \mathrm{~h}$ & 0,8292 & 0,8619 & -- & -- \\
\hline & $96 \mathrm{~h}$ & 0,8292 & 0,8619 & -- & -- \\
\hline
\end{tabular}



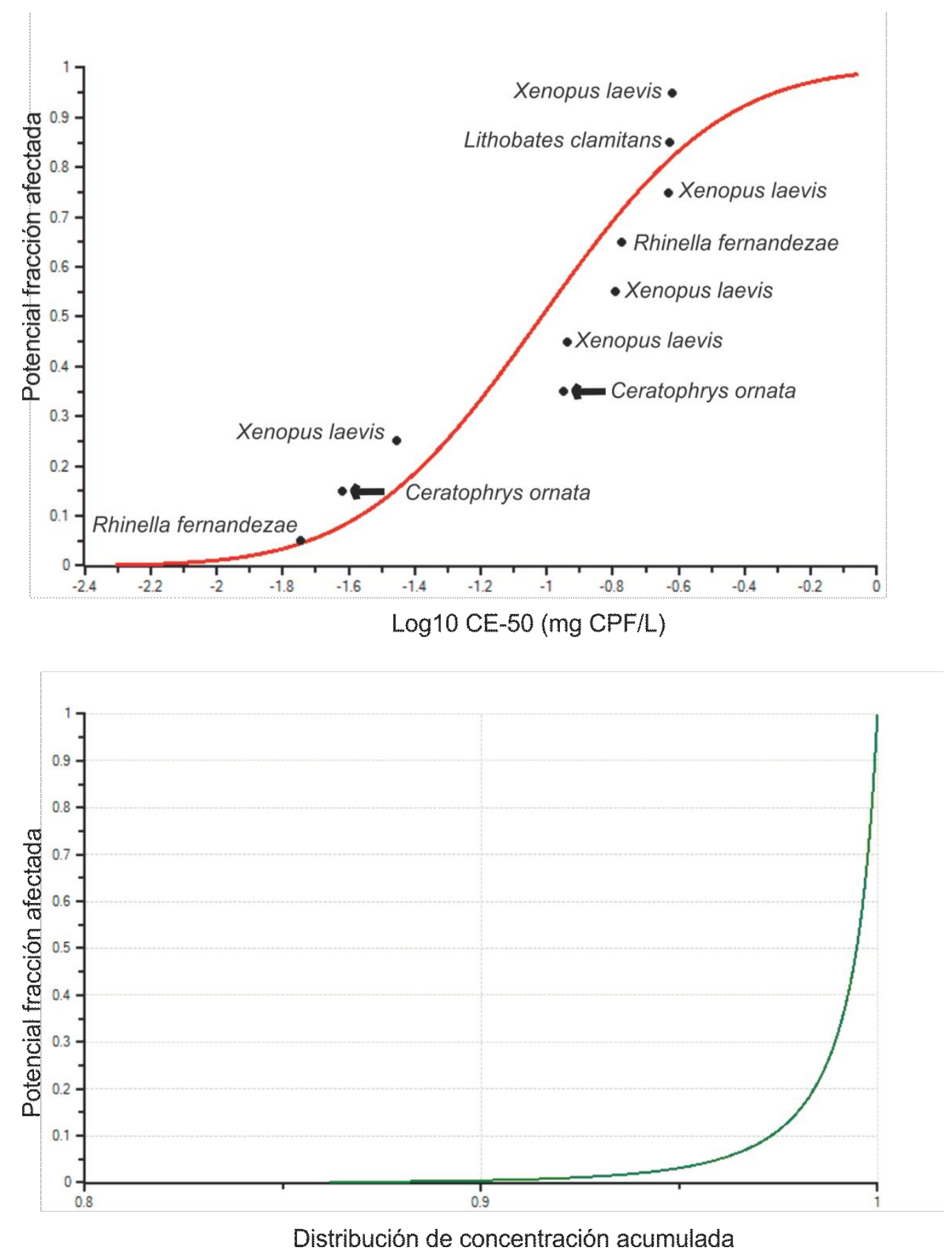

Figura 47. Parte superior: Distribución de sensibilidad de especies de anfibios según valores de CE50 (mg/L) para el clorpirifós (CPF). Con una flecha se indican los datos de CE-50 para la especie Ceratophrys ornata. Parte inferior: Curva de probabilidad conjunta entre la fracción de especies afectadas y la distribución de concentración acumulada para el clorpirifós 


\section{DISCUSIÓN Y CONCLUSIONES}

Tal como se mencionó en la introducción general, Sparling y col. (2000) realizaron una investigación sobre los trabajos publicados entre 1972 y 1998 relacionados con ecotoxicología de vertebrados. Una década después, los autores realizan una nueva búsqueda y concluyen que se había logrado un gran desarrollo de la información ecotoxicológica de anfibios y remarcan que el incremento en el número de trabajos publicados se encuentra asociado a la aceptación del fenómeno denominado declinación mundial de las poblaciones de anfibios. Además, reconocen la necesidad de realizar más trabajos para poder entender de manera global los efectos de los contaminantes tanto en anfibios como en reptiles. En tal sentido, el presente capítulo contribuye con información de base acerca de la sensibilidad de la especie $C$. ornata al CPF en distintos estadios del desarrollo larval. Según PNUMA (1998), el CPF es bioacumulable y tóxico, dos de los tres atributos que identifican a una sustancia como peligrosa. Si además se tiene en cuenta que el CPF es uno de los insecticidas más utilizados en Argentina (CASAFE, 2012), el riesgo para la salud humana y la biota de los ecosistemas de la región se incrementa.

Respecto a las larvas de la especie utilizada, se concluye que las mismas son organismos adecuados para la realización de bioensayos de toxicidad en laboratorio, tanto por su facilidad para criarlas en condiciones controladas como por su sensibilidad al plaguicida organofosforado evaluado, permitiendo así obtener las curvas concentración-respuesta a lo largo del desarrollo larval. Otras características que hacen interesante a la especie como modelo de estudio, son su rápida tasa de desarrollo y crecimiento, su rol en la cadena trófica y su gran tamaño (el cual permite contar con varios tipos de muestras biológicas). A partir de los resultados obtenidos producto de la exposición de larvas de $C$. ornata a bajas concentraciones de CPF, se concluye que el mismo influye negativamente sobre el sistema de estudio, habiéndose registrado efectos letales y subletales. Además, las correlaciones realizadas entre la proporción de efectos para cada punto final evaluado y las distintas concentraciones, indican que los efectos negativos se incrementan con el aumento de la concentración del tóxico en el agua a un tiempo constante. En el mismo sentido, si se analizan los parámetros ecotoxicológicos convencionales reportados (CL-50, TL-50, CE-50, NOEC y LOEC) para cada STD y punto final, se acepta la hipótesis de la existencia de un incremento de los efectos perjudiciales con el aumento del tiempo de exposición. Es decir, cuando los efectos negativos son analizados a un tiempo de exposición constante (a diferentes concentraciones) o a concentraciones constantes (a diferentes tiempos de exposición), los mismos se incrementan a medida que aumenta la concentración y el tiempo de exposición, respectivamente. Si bien esto último ha sido observado a lo largo de todo el 
desarrollo larval, también debe tenerse en cuenta que la sensibilidad de las larvas de $C$. ornata al CPF disminuye a medida que aumenta su STD. Teniendo en cuenta que se logró una supervivencia aceptable de distintos STD debido a la implementación del protocolo de cría, garantizando que no hubo selección al realizar los bioensayos en STD superiores, se corrobora la hipótesis mencionada acerca la disminución de la sensibilidad con el aumento del STD. En este sentido, a partir de las curvas de supervivencia crónica (14 d) de KaplanMeier para los bioensayos realizados en STD 25 y 31 (E1-E3) (Fig. 36), se concluye que el STD 25 es el más sensible a la exposición al CPF ya que la proporción de individuos que sobreviven disminuye más rápidamente y a menores tiempos de exposición que en STD superiores. Si bien no se pudieron incluir en tales curvas los datos de supervivencia para el STD 37 por no haberse realizado exposiciones crónicas, a partir de los valores de CL-50 para larvas de STD 25 y 31 (0,1 y 0,2 mg CPF/L, respectivamente) se puede concluir que el STD 37 resulta ser el STD evaluado menos sensible al CPF. Mientras los valores reportados para el STD 25 y 31 poseen efectos letales en el 50\% de los individuos expuestos, tales concentraciones en el STD 37 solo poseen efectos letales en menos del $1 \%$ de los individuos expuestos.

En el presente capítulo se registraron efectos letales y subletales del CPF a lo largo del desarrollo larval de C. ornata. Específicamente, para efectos letales se reportaron las CL-50 al final de la exposición aguda y a distintos tiempos de exposición crónica. Si se compara la sensibilidad de $C$. ornata al CPF, la misma se encuentra cercana al percentil 26 teniendo en cuenta datos de CL-50 a $96 \mathrm{~h}$ publicados para otras especies de anfibios anuros (Abbasi y Soni, 1991; Pan y Liang, 1993; Cowman y Manzanti, 2000; Richards, 2000; Gaizick y col., 2001; Richards y Kendall, 2002; El-Merhibi y col., 2004; Kerby, 2006; Sparling y Fellers 2007; 2009; Yin y col., 2009; Jayawardena y col., 2010; Bernabó y col., 2011; Wijesinghe y col., 2011; Ruiz de Arcaute y col., 2012, Sotomayor y col., 2012; Watson y col., 2014). Tal comparación se considera válida ya que si bien es conocido que las variaciones en la sensibilidad de una determinada especie a un determinado tóxico podrían deberse a diferencias metodológicas de los bioensayos (Sprague, 1995), las bases de datos ecotoxicológicos y demás herramientas ecotoxicológicas (ej. la evaluación del riesgo ambiental) consideran tales diferencias como no significativas. Cabe destacar que a futuro se deberán realizar más bioensayos en STD 31 y 37 (teniendo en cuenta los resultados obtenidos) para poder estimar mejor las curvas concentración-respuesta. El resumen e integración de la información toxicológica existente para anfibios mediante la herramienta de evaluación del riesgo ecológico y la contextualización de los resultados obtenidos, permite observar a partir de la CPC el percentil en el cual se encuentra la sensibilidad de la especie evaluada y el riesgo que implica el CPF para las distintas especies de anuros, siendo el mismo muy bajo. Si se compara la DSE 
aquí reportada para anuros con aquella publicada para invertebrados acuáticos de la región Pampeana (Demetrio, 2012), estos últimos resultan ser más sensibles.

En relación con los efectos subletales, si se compara la sensibilidad de $C$. ornata al CPF, la misma se encuentra cercana al percentil 5 (alteraciones en la natación) y 33 (presencia de anormalidades) teniendo en cuenta datos de CE-50 a $96 \mathrm{~h}$ publicados para otras especies de anfibios anuros (Richards, 2000; Richards y Kendall, 2002; Bonfanti y col., 2004; El-Merhibi y col., 2004; Wacksman y col., 2006; Ruiz de Arcaute y col., 2012). Se concluye que el CPF produce alteraciones en la natación tal como reportaron otros autores tanto para el CPF (Widder y Bidwell, 2008; Ruiz de Arcaute y col., 2012) como para otros plaguicidas (Brunelli y col., 2009; Agostini y col., 2010; Vera Candioti y col., 2010; Svartz y col. 2016). Respecto a la presencia de anormalidades, se registraron dos tipos: LFLC y SFLC. Teniendo en cuenta que se registró total ausencia de las mismas en los grupos control, se concluye que las mismas son producidas por efecto del CPF tal como reportaron otros autores tanto para anormalidades provocadas por el CPF (Britson y Threlkeld, 1998; Bernabó y col., 2011; Sotomayor y col., 2012) como por otros plaguicidas (Peltzer y col., 2011; Svartz y col. 2012; Agostini, 2013; Svartz y col., 2016). Respecto al crecimiento, se concluye que el CPF inhibe el mismo a medida que aumenta la concentración del tóxico, habiéndose registrado los menores valores de LHC a las mayores concentraciones de CPF. Este resultado es concordante con el de otros autores para el mismo tóxico (Widder y Bidwell, 2008; Ruiz de Arcaute y col., 2012) como para otros plaguicidas (Svartz y col., 2012; 2016). Si bien la inhibición del crecimiento solo pudo ser corroborada para el STD 25 y 31, resulta esperable que también se manifieste en individuos de STD 37. Para ello, se deberán realizar a futuro bioensayos a concentraciones mayores de las ensayadas. Se concluye que el punto final alteraciones en la natación resulta ser un buen biomarcador ya que se anticipa a los demás puntos finales evaluados. El resumen e integración de la información toxicológica existente para anfibios mediante la herramienta de evaluación del riesgo ecológico y la contextualización de los resultados obtenidos, permite observar a partir de la CPC el percentil en el cual se encuentra la sensibilidad de la especie evaluada y el riesgo que implica el CPF para las distintas especies de anuros, siendo el mismo muy bajo.

Si se tienen en cuenta los niveles de CPF medidos en el medio ambiente (Jergentz y col., 2005; Marino y Ronco, 2005; Mugni y col., 2011), los mismos se encuentran dentro del intervalo de concentraciones que inducen efectos subletales en el laboratorio en larvas de $C$. ornata. Teniendo en cuenta tales trabajos, la mayor concentración medida en agua se encuentra dentro del intervalo de confianza al $95 \%$ de la concentración que induce efectos en la natación en el $50 \%$ de los organismos en STD 25 a 96 h. Asimismo, la mayor concentración medida en material particulado se encuentra dentro del intervalo de confianza 
al 95\% de la concentración que induce la muerte del 50\% de los organismos en STD 25 a 96 $\mathrm{h}$, es un orden de magnitud mayor que las concentraciones que inducen alteraciones en la natación en los organismos evaluados y se encuentra dentro del intervalo de confianza al 95\% de la concentración que induce la presencia de anormalidades en el $50 \%$ de los organismos en STD 25 y 31 a $96 \mathrm{~h}$. De todas formas, se debe tener en cuenta que los efectos letales y subletales en campo pueden deberse también a las mezclas de plaguicidas (incluyendo al CPF), tal como informaron Ronco y col. (2008) para $H$. pulchellus y $R$. arenarum (especies que habitan en ambientes modificados por cultivos de soja dentro de la región Pampeana), constituyendo tales reportes los primeros acerca del efecto del CPF sobre anuros autóctonos. En las evaluaciones del riesgo de este insecticida, se debe considerar además que las aplicaciones de CPF en campo a menudo coinciden con el período reproductivo de los anfibios, siendo los estadios embrionarios y larvales los más sensibles de su ciclo de vida (Linder y col., 2003).

A partir del diseño individualizado utilizado para exponer larvas de C. ornata, se concluye que el mismo no solo permite evitar el canibalismo sino también ver efectos de manera individual y seguirlos en el tiempo. En tal sentido, el diseño experimental propuesto permitió demostrar que los efectos negativos del CPF, en el intervalo de concentraciones ensayadas, se mantienen constantes en el $26 \%$ y $53 \%$ de los casos para el STD 25 y 31 , respectivamente, y/o aumentan en el $74 \%$ y $47 \%$ de los casos para el STD 25 y 31 , respectivamente. A diferencia de los diseños que involucran a varias larvas por frasco, a partir del diseño experimental propuesto con larvas expuestas de manera individual se puede concluir que los efectos del CPF en larvas de $C$. ornata nunca revierten. Además, se comprobó la hipótesis de la progresión de efectos negativos del CPF, desde alteraciones en la natación seguidas por la presencia de anormalidades leves y luego severas hasta la muerte. Si bien este resultado pudo comprobarse solamente para larvas de STD 25 y 31, es esperable que tal progresión también exista para larvas de STD 37. Esto podrá comprobarse cuando a futuro se realicen más bioensayos en STD 37 a mayores concentraciones que las ensayadas. La progresión de efectos negativos aquí reportada es concordante con los resultados del trabajo de Ruiz de Arcaute y col. (2012). EI

presente constituye el primer bioensayo de exposición de larvas de C. ornata a agroquímicos de uso frecuente de la región Pampeana. Por sus características biológicas y su manejo en laboratorio, la especie resulta de gran interés como modelo de estudio en Ecotoxicología. 
Capítulo 5

Efectos del clorpirifós sobre el sonido emitido por larvas de Ceratophrys ornata 
A partir del desarrollo de un protocolo de cría de individuos de C. ornata desde la etapa de huevo hasta la etapa adulta (capítulo 1), del estudio de la variabilidad de los sonidos producidos por individuos de esta especie a lo largo de su desarrollo (capítulo 2), del estudio del contexto de emisión de tales sonidos (capítulo 3) y de la realización de bioensayos de exposición de larvas de esta especie a concentraciones subletales del plaguicida organofosforado clorpirifós (capítulo 4 = aplicación del modelo), en este capítulo se evalúa el efecto de ese plaguicida sobre el sonido emitido por larvas de C. ornata en distintos estadios del desarrollo. Esta variable de respuesta resulta novedosa dentro del ámbito de la Ecotoxicología y Etología de anfibios. Se reafirma la utilidad de la especie como modelo de estudio ecotoxicológico.

\section{INTRODUCCIÓN}

\section{Biomarcadores utilizados en Ecotoxicología de anfibios}

Una herramienta que en los últimos años ha sido ampliamente utilizada como señal de alerta temprana para detectar efectos adversos inducidos por un tóxico a tiempos cortos de exposición y bajas concentraciones, son los biomarcadores. Éstos, han sido inicialmente definidos como respuestas biológicas a nivel sub-individual (molecular, bioquímico, fisiológico, histológico) por exposición a un tóxico, las cuales pueden ser mensurables y contribuyen a fundamentar la toma de decisiones para la gestión y protección ambiental (McCarthy y Shugart, 1990). Tal concepto clásico de biomarcador fue posteriormente ampliado para incluir a los niveles ecológicos de individuo, población y ecosistema (Markert, 1994). Desde la Ecotoxicología se ha trabajado en la búsqueda de respuestas de alerta temprana en los organismos evaluados mediante la utilización de biomarcadores en algunos de los niveles ecológicos jerárquicos (ej. comunidad, población e individuo) (McCarthy y Shugart, 1990). En particular, la utilización de baterías de biomarcadores ha demostrado ser de gran utilidad en la evaluación de la contaminación ambiental, permitiendo detectar problemas de calidad de aguas asociados a fuentes complejas de contaminación (Galloway y col., 2004). El estudio de biomarcadores a nivel sub-individual en el ámbito de la Ecotoxicología Herpetológica, ha sido abordado en los últimos años en Argentina por diferentes grupos de investigación. Entre ellos, un grupo de relevante importancia se encuentra en la Universidad Nacional de Luján, cuyos investigadores llevaron a cabo un gran número de estudios pioneros sobre la Toxicología acuática con especies de anuros autóctonos, principalmente larvas y adultos de la especie $R$. arenarum. Si bien la mayoría de sus publicaciones reportan respuestas a nivel individual, también han colaborado con otros 
investigadores buscando respuestas a nivel sub-individual (Arrieta y col., 2000; Rosenberg y col., 2002, Mastrángelo y col., 2011). Otro grupo que también ha utilizado como modelo de estudio a la especie $R$. arenarum se encuentra en la Universidad Nacional del Comahue, cuyos investigadores han realizado numerosos aportes acerca de los efectos bioquímicos específicos de insecticidas organoclorados y organofosforados en embriones y larvas de esta especie (Venturino y col., 2003; Lascano y col., 2011; Liendro y col., 2015; Sotomayor y col., 2015). Además, un grupo de investigación de la Universidad Nacional del Litoral ha publicado varios trabajos sobre los efectos en la actividad de diferentes enzimas por exposición de anuros autóctonos a plaguicidas y herbicidas de uso frecuente en los agroecosistemas que tales especies habitan (Attademo y col., 2007; Peltzer y col., 2013; Attademo y col., 2014; 2015). También han realizado varios estudios de genotoxicidad por exposición de anuros autóctonos a plaguicidas y herbicidas de uso frecuente en agroecosistemas pampeanos (Cabagna y col., 2006; Lajmanovich y col., 2014). En relación a este último tema, el grupo de investigación del laboratorio de citogenética de la UNLP también ha publicado varios trabajos (Vera Candioti y col., 2010; Pérez Iglesias y col., 2014; 2015). Destacan también las investigaciones en ésta área de un grupo del Instituto Nacional de Tecnología Agropecuaria, que desde hace algunos años realiza investigaciones evaluando el impacto de los plaguicidas frecuentemente utilizados en Argentina en los sectores agrícola y forestal, sobre la calidad del agua y los anfibios que habitan tales sectores (Brodeur y col., 2011; 2012).

Para seleccionar una respuesta biológica a un determinado nivel y por exposición a un tóxico, es deseable que la misma sea lo suficientemente sensible y específica. Los biomarcadores a nivel sub-individual han sido ampliamente aceptados dentro del ámbito de la Ecotoxicología Herpetológica, contando con bastante información al respecto. De todas formas, con la finalidad de complementar estudios en los que se evaluaba letalidad, se han buscado y sugerido otras respuestas a nivel individual. En tal sentido, dos investigadores destacados de la Fundación Pro Salud y Medio Ambiente y la Universidad Nacional de San Martín, han realizado varios trabajos en conjunto, utilizando como modelo larvas de $R$. arenarum mediante la evaluación de efectos a este nivel de diferentes contaminantes, entre ellos metales pesados y plaguicidas (Pérez Coll y col., 1986; 1988; Pérez Coll y Herkovits, 1990; Svartz y col., 2012; 2016). Estos mismos investigadores son los que publicaron el ya mencionado protocolo para desarrollar bioensayos de toxicidad con embriones de anfibios de $R$. arenarum denominado AMPHITOX (Herkovits y Pérez Coll, 1999a-b), que permite evaluar la toxicidad de sustancias químicas, mezclas y muestras ambientales. Sin embargo, este protocolo ha sido realizado con solo una de las 168 especies de anuros descriptas para nuestro país, siendo deseable desarrollar más protocolos que involucren otras especies autóctonas. En este sentido, desde el CIMA hemos estado y continuamos trabajando en el 
desarrollo de protocolos de bioensayos estandarizados con larvas de anuros autóctonos, habiéndose evaluado efectos a nivel individual provocados por metales pesados y plaguicidas de uso frecuente en la región Pampeana (Natale, 2006; Natale y col., 2006; Agostini y col., 2010; Vera Candioti y col., 2010; Ruiz de Arcaute y col., 2012).

Específicamente, y siguiendo con este nivel de estudio, se han propuesto para anuros distintos biomarcadores de comportamiento, anormalidades morfológicas e índices de condición corporal. Entre ellos, los biomarcadores de comportamiento incluyen mediciones en larvas de la distancia recorrida, la actividad natatoria y la velocidad promedio de natación (Brunelli y col., 2009; Denoël y col., 2012; Ruiz de Arcaute y col., 2012; Peltzer y col., 2013; Svartz y col., 2016). La cuantificación de la frecuencia de distintos tipos de anormalidades morfológicas ha sido reportada tanto para anfibios adultos como larvas (Pérez Coll y col., 1986; 1988; Bantle y col., 1996; Blaustein y Johnson, 2003; Brunelli y col., 2009; Agostini, 2013; Svartz y col., 2016). Por último, en relación a los índices de condición corporal se cuenta con bastante información al respecto tanto para individuos adultos como larvas (Nebeker y col., 1998; Brodeur y col., 2011, Agostini, 2013; Brodeur y col., 2013; Svartz y col., 2016). Por último, un grupo de la Universidad Nacional de Río Cuarto ha comenzado hace pocos años a realizar estudios acerca del impacto de los agroecosistemas sobre los anfibios de su región, siendo quizás esta diversificación de su campo disciplinar un indicio de la problemática regional (Pollo y col., 2013; Babini y col., 2015). El gran número de trabajos publicados dentro del área de la Ecotoxicología Herpetológica, el cual se puede vislumbrar a partir de las citas anteriores, se encuentra asociado a la aceptación del fenómeno denominado declinación mundial de las poblaciones de anfibios (Sparling y col., 2010; Vaira y col., 2012; Alroy, 2015).

Se propone la utilización de un biomarcador de comportamiento novedoso, no utilizado hasta el momento (los sonidos producidos por larvas de C. ornata), como parte del modelo experimental desarrollado con larvas de esta especie (ver capítulos 1 a 3), para su aplicación en la evaluación de efectos producidos por plaguicidas organofosforados frecuentemente utilizados en la región Pampeana. Específicamente, se evalúan los efectos sobre el sonido producidos por el insecticida CPF.

\section{Hipótesis}

* Los sonidos emitidos por larvas de C. ornata se ven tempranamente alterados mediante la modificación de sus parámetros normales por efecto del CPF a bajas concentraciones.

* Existe un incremento de los efectos perjudiciales producidos por el CPF sobre los parámetros normales del sonido con el aumento de la concentración del tóxico en el agua a un tiempo constante de exposición. 
* Los parámetros que caracterizan al sonido emitido por larvas de C. ornata expuestas a CPF se correlacionan con los diferentes puntos subletales convencionales medidos (alteraciones en la natación, presencia de anormalidades morfológicas y crecimiento) en función de la concentración-respuesta.

\section{Objetivos}

* Evaluar los efectos producidos por el CPF mediante el modelo propuesto, sobre los parámetros normales del sonido emitido por larvas de $C$. ornata en distintos estadios del desarrollo, mediante la realización de bioensayos de toxicidad aguda y crónica.

* Correlacionar los parámetros de los sonidos emitidos por larvas de C. ornata expuestas a CPF con las diferentes concentraciones (a un tiempo constante de exposición) y con los diferentes puntos subletales convencionales (alteraciones en la natación, presencia de anormalidades morfológicas y crecimiento) medidos en función de la concentración-respuesta.

\section{MATERIALES Y MÉTODOS}

\section{Grabación de sonidos de larvas de C. ornata expuestas a clorpirifós}

Se utilizaron las larvas expuestas de los bioensayos realizados bajo exposiciones agudas y crónicas (E3, E5) para la grabación y posterior análisis de los sonidos emitidos en un medio AE (Fig. 48). Cabe aclarar que solo se realizó la grabación y análisis de sonidos correspondientes a larvas de STD 31 (E3) y 37 (E5) por poseer mayor NPS (dB) que aquellos en STD 25, facilitándose el análisis dado que el espectro se diferencia fácilmente del RF de la cámara de grabación. El sistema de grabación utilizado y la metodología de grabación coinciden con la anteriormente descripta (ver capítulo 2, página 71). Cada larva fue grabada aleatoriamente e individualmente durante 30 segundos. De cada grabación (= cada larva) se seleccionaron tres sonidos, siendo éstos los sonidos emitidos a los 5,10 y 20 segundos de grabación. En caso que en los tiempos indicados no se estuviera en presencia de un sonido, se seleccionó el más cercano a cada tiempo ya sea anterior o posterior al mismo (Fig. 49). Esta metodología permite obtener sonidos emitidos por una misma larva a lo largo de toda la grabación y considerar la variabilidad individual producto del efecto del CPF. Para cada sonido se midieron todas las variables ya detalladas para larvas no expuestas (Ds (s), Np, Nip y Fd (Hz); ver capítulo 2, página 72). Las variables extraídas de cada sonido fueron comparadas estadísticamente entre individuos expuestos y no expuestos (grupo control con agua de bioensayo; C). Además, las variables de los sonidos 
correspondientes a larvas del control de dilución (etanol; Cd) fueron comparadas estadísticamente con aquellas correspondientes a sonidos de larvas del control con agua de bioensayo (C), con el objetivo de demostrar que la dilución de la solución madre en etanol absoluto no añade efectos negativos. Todas las variables de los sonidos correspondientes a larvas del grupo control (C) y larvas expuestas fueron comparadas con aquellas variables correspondientes a sonidos normales $(\mathrm{N})$ utilizados para caracterizar el sonido, grabado en un medio $A E$, en cada STD larval (ver capítulo 2).

\begin{tabular}{|c|c|c|c|c|c|c|c|c|c|c|}
\hline & T1 & T2 & T3 & $\mathrm{T} 4$ & T5 & T6 & T7 & $\mathrm{T} 8$ & C & $\mathrm{Cd}$ \\
\hline E3 & 0,025 & 0,075 & 0,15 & 0,2 & 0,25 & 0,3 & 0,5 & 0,7 & 0 & 0,7 \\
\hline E5 & 0,025 & 0,1 & 0,2 & 0,3 & 0,5 & & & & 0 & 0,5 \\
\hline
\end{tabular}

Figura 48. Detalle de los tratamientos $(\mathrm{T})$ con sus concentraciones en $\mathrm{mg} / \mathrm{L}$ y grupos control (C: control con agua de bioensayo, Cd: control de dilución) utilizados para cada bioensayo (E) de exposición a clorpirifós. E3: estadio 31; E5: estadio 37

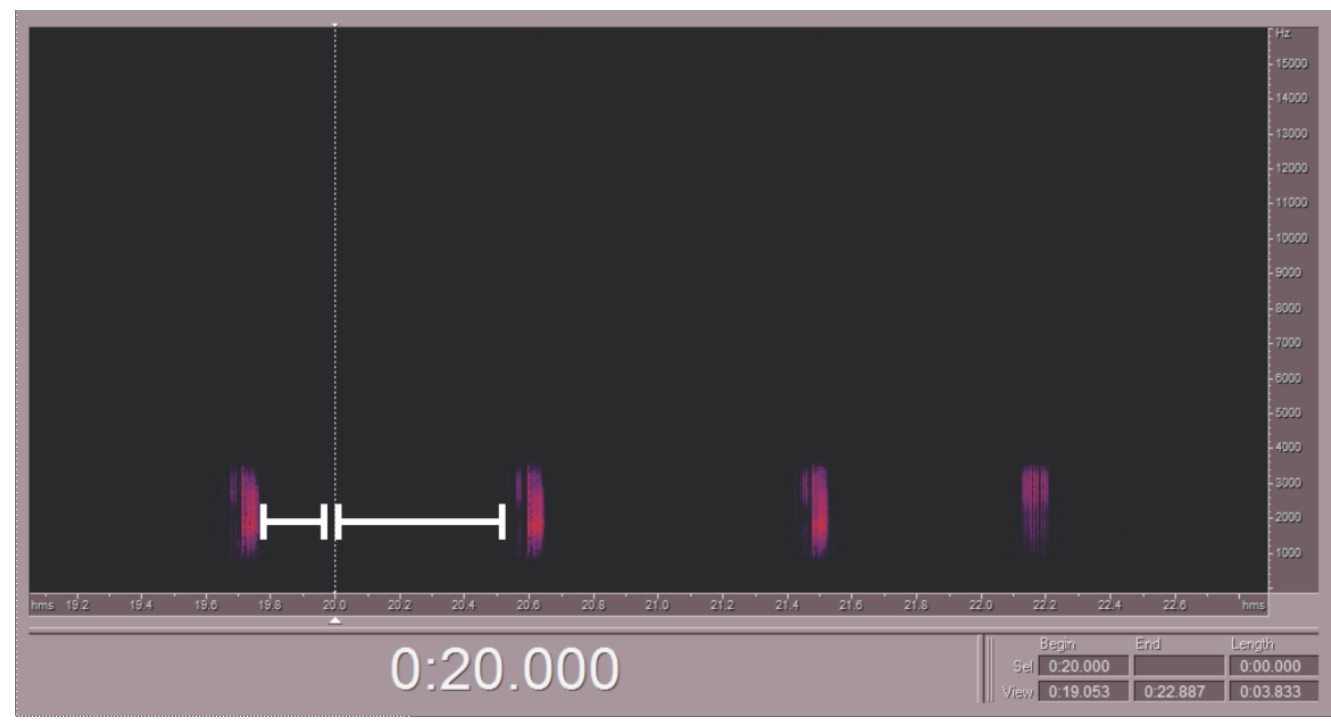

Figura 49. Esquema representativo del modo de selección del sonido más cercano a un tiempo determinado. Para el caso mostrado se seleccionó el sonido más cercano a los 20 segundos de grabación

\section{Análisis estadístico}

Para cada bioensayo, se realizó una prueba de $t$ de diferencia entre medias entre las variables bioacústicas (Ds, Np, Nip y Fd) de los sonidos producidos por larvas del control con agua de bioensayo $(\mathrm{C})$ y las mismas variables correspondientes a sonidos producidos 
por larvas del control de dilución con etanol (Cd). Luego, se realizó para cada bioensayo una prueba de comparación múltiple (ANOVA o Kruskal-Wallis, según correspondiera) para las variables bioacústicas medidas ( $\mathrm{Ds}, \mathrm{Np}$, Nip y $\mathrm{Fd}$ ) de los sonidos grabados durante los bioensayos E3 y E5, con la prueba a posteriori correspondiente para comparar los tratamientos contra el control con agua de bioensayo $(\mathrm{C})$. Estos análisis fueron realizados tanto al finalizar la exposición aguda como al finalizar la exposición crónica.

Se realizaron las mismas pruebas de comparación múltiple antes detalladas pero utilizando como grupo control a los sonidos normales $(\mathrm{N})$ mediante los cuales se caracterizó el sonido emitido por larvas de C. ornata. Por lo tanto, se contrastaron previamente las variables bioacústicas de tales sonidos $(\mathrm{N})$ con los del grupo control $(\mathrm{C})$ de cada bioensayo realizado mediante una prueba de $t$ de diferencia entre medias.

Además, se realizaron análisis de correlación lineal entre las distintas variables bioacústicas medidas (Ds, Np, Nip y Fd) y los tratamientos correspondientes a cada bioensayo. Por último, se realizaron análisis de correlación lineal entre las variables bioacústicas medidas (Ds, Np, Nip, Fd) y los distintos puntos ecotoxicológicos subletales (alteraciones en la natación, presencia de anormalidades morfológicas e inhibición del crecimiento).

Para la realización de todas las pruebas estadísticas se utilizó el programa Statistica 7.0 $\left(\right.$ Statsoft ${ }^{\circledR}$ ) y se eligió un nivel de significancia de 0,05 . Además, todas las pruebas realizadas cumplen con sus respectivos supuestos (Zar, 2010).

\section{RESULTADOS}

\section{Efectos del clorpirifós sobre el sonido emitido por larvas de C. ornata}

Se registró y analizó el sonido emitido en un medio AE por larvas de C. ornata en STD 31 y 37. Específicamente para el STD 31, en la tabla 25 se resumen las variables bioacústicas medidas al finalizar la exposición aguda y crónica para los distintos tratamientos del bioensayo E3. La comparación de las variables bioacústicas de los sonidos emitidos por larvas pertenecientes al grupo control con agua de bioensayo $(\mathrm{C})$ y al control de dilución con etanol (Cd) no arrojó diferencias significativas para las 96 h ni para las 336 h (Tabla 26). En relación a los análisis de comparación múltiple realizados para este STD a las 96 h, los ANOVA/Kruskal-Wallis (según correspondiera) realizados para comparar las distintas variables bioacústicas entre sus correspondientes tratamientos y el grupo control con agua de bioensayo $(C)$ no arrojaron diferencias significativas para la Ds $(F(8,292)=1,866, p=$ $0,065)$ ni para la $F d(F(8,292)=0,928, p=0,493)$ pero sí arrojaron diferencias significativas 
para el Np $(H(8,301)=29,078, p<0,0005)$ y el Nip $(H(8,301)=29,078, p<0,0005)$ (Fig. 50). Cabe recordar que las variables discretas $\mathrm{Np}$ y Nip fueron transformadas a variables continuas mediante el logaritmo natural de cada valor más uno ( $\operatorname{Ln} X+1)$. El análisis de correlación lineal entre las variables bioacústicas medidas a $96 \mathrm{~h}$ y los tratamientos solo arrojó una correlación significativa para el $\mathrm{Np}(r=-0,140, \mathrm{p}=0,015)$ y el $\mathrm{Nip}(r=-0,136, p=$ $0,018)$. Los mismos análisis de comparación múltiple realizados a las $336 \mathrm{~h}$ arrojaron diferencias significativas entre los tratamientos y el grupo control $(C)$ para la Ds $(H(8,253)=$ 58,796, $p<0,0005)$, el Np $(H(8,253)=97,179, p=0,0005)$, el $N i p(H(8,253)=97,837, p<$ $0,0005)$ y la $\mathrm{Fd}(\mathrm{H}(8,253)=37,765, \mathrm{p}<0,0005)$ (Fig. 51). El análisis de correlación lineal entre las distintas variables bioacústicas medidas a $336 \mathrm{~h}$ y los tratamientos, arrojó una correlación significativa para la Ds $(r=-0,374, p<0,0005)$, el $N p(r=-0,540, p<0,0005)$, el Nip $(r=-0,540, p<0,0005)$ y la $F d(r=0,359, p<0,0005)$.

Si en los análisis se incluye como grupo control a los sonidos emitidos por larvas de $C$. ornata que caracterizan al STD 31 (N; ver capítulo 2), la comparación de estas variables con las variables del grupo control con agua de bioensayo $(C)$ no arroja diferencias significativas para las 96 h ni para las 336 h (Tabla 26). El análisis de comparaciones múltiples tampoco arroja diferencias significativas $(p>0,05)$ para las $96 \mathrm{~h}$ entre los tratamientos y el grupo control $(N)$ para la Ds $(H(9,393)=16,885)$ y la $F d(H(9,393)=18,859)$ pero sí se arroja diferencias significativas entre los tratamientos y el grupo control $(\mathrm{N})$ para el $\mathrm{Np}(\mathrm{H}(9,393)=$ 61,325, $\mathrm{p}<0,0005)$ y el Nip $(\mathrm{H}(9,393)=61,325, \mathrm{p}<0,0005)$ (Fig. 52). El análisis de correlación lineal entre las distintas variables bioacústicas solo arrojó una correlación significativa para el Np $(r=-0,223, p<0,0005)$ y el Nip $(r=-0,215, p<0,0005)$. El mismo análisis de comparaciones múltiples para las $336 \mathrm{~h}$, realizado incluyendo como grupo control a los sonidos emitidos por larvas de $C$. ornata que caracterizan al STD 31 ( $\mathrm{N}$; ver capítulo 2), arroja diferencias significativas entre los tratamientos y el grupo control $(N)$ para la Ds $(H)$, $345)=75,309, p<0,0005)$, el Np $(H(9,345)=146,205, p<0,0005)$, el $N i p(H(9,345)=$ 146,757, $\mathrm{p}<0,0005)$ y la Fd $(\mathrm{H}(9,345)=54,110, \mathrm{p}<0,0005)$ (Fig. 53). El análisis de correlación lineal entre las distintas variables bioacústicas medidas a $336 \mathrm{~h}$ y los tratamientos también arrojó una correlación significativa para la Ds $(r=-0,377, p<0,0005)$, el $N p(r=-0,606, p<0,0005)$, el Nip $(r=-0,608, p<0,0005)$ y la $F d(r=0,427, p<0,0005)$. Por último, en la fig. 54 se muestra el oscilograma y sonograma característico de los sonidos producidos por larvas de $C$. ornata en un medio AE en STD 31 bajo los efectos del CPF. Cabe recordar que el análisis del oscilograma se utilizó como complemento del análisis del sonograma para la medición manual de variables, dado que no corresponde la utilización de éste por no haberse medido el NPS $(\mathrm{dB})$ mediante un sonómetro (ver capítulo 2 para más detalle). 
Específicamente para el STD 37, en la tabla 27 se resumen las variables bioacústicas medidas al finalizar la exposición aguda para los distintos tratamientos del bioensayo E5. La comparación de las variables bioacústicas de los sonidos emitidos por larvas pertenecientes al grupo control con agua de bioensayo $(\mathrm{C})$ y al control de dilución con etanol (Cd) no arrojó diferencias significativas (Tabla 28). En relación a los análisis de comparación múltiple para este STD, los ANOVA/Kruskal-Wallis (según correspondiera) realizados para comparar las distintas variables bioacústicas entre sus correspondientes tratamientos y el grupo control (C) no arrojaron diferencias significativas para la $\mathrm{Ds}(\mathrm{F}(5,169)=1,910, \mathrm{p}=0,095)$ y la $\mathrm{Fd}(\mathrm{H}$ $(5,175)=2,862, p=0,721)$ pero sí arrojaron diferencias significativas para el $\mathrm{Np}(\mathrm{H}(5,175)$ $=32,004, p<0,0005)$ y el Nip $(H(5,175)=32,004, p<0,0005)$ (Fig. 55). El análisis de correlación lineal entre las distintas variables bioacústicas medidas y los tratamientos solo arrojó una correlación significativa para el $\mathrm{Np}(r=-0,208, \mathrm{p}=0,006)$ y el $\mathrm{Nip}(r=-0,188, p=$ 0,013).

Si en los análisis se incluye como grupo control a los sonidos emitidos por larvas de $C$. ornata que caracterizan al STD 37 (N; ver capítulo 2), la comparación de éstas variables con las variables del grupo control con agua de bioensayo $(C)$ no arroja diferencias significativas para las 96 h (Tabla 28). El análisis de comparaciones múltiples tampoco arroja diferencias significativas para las $96 \mathrm{~h}$ entre los tratamientos y el grupo control $(\mathrm{N})$ para la Ds $(H(6,266)$ $=13,580, p=0,035)$ y la $\mathrm{Fd}(\mathrm{H}(6,271)=7,140, \mathrm{p}=0,308)$ pero sí arroja diferencias significativas para el $\mathrm{Np}(\mathrm{H}(6,265)=68,101, \mathrm{p}<0,0005)$ y el $\mathrm{Nip}(\mathrm{H}(6,265)=68,101, \mathrm{p}<$ 0,0005) (Fig. 56). El análisis de correlación lineal entre las distintas variables bioacústicas y los tratamientos solo arrojó una correlación significativa para el $\mathrm{Np}(r=-0,397, \mathrm{p}<0,0005)$, el Nip $(r=-0,381, p<0,0005)$ y la Fd $(r=0,175, p=0,004)$. Por último, en la fig. 57 se muestra el oscilograma y sonograma característico de los sonidos producidos por larvas de C. ornata en un medio AE en STD 37 bajo los efectos del CPF.

Respecto a los análisis de correlación lineal realizados entre las variables bioacústicas medidas (Ds, Np, Nip, Fd), producto de sonidos emitidos por larvas expuestas a CPF, y los distintos puntos ecotoxicológicos subletales medidos en el capítulo precedente (alteraciones en la natación, presencia de anormalidades morfológicas e inhibición del crecimiento), los resultados se resumen en la tabla 29. Tales resultados indican que a medida que disminuye la LHC de los individuos, aumenta la proporción de individuos con alteraciones en la natación y disminuye la Ds. Asimismo, a medida que aumenta la LHC, aumenta el Np y Nip y a su vez a medida que aumenta el $\mathrm{Np}$ disminuye la proporción de individuos con alteraciones en la natación. Por último, a medida que aumenta la Fd se incrementa la proporción de individuos con alteraciones en la natación. 
Tabla 25. Media aritmética \pm nivel de confianza para la media al $95 \%$ de las variables bioacústicas analizadas para cada bioensayo $(E)$ realizado en estadio 31. Entre paréntesis se indica el número de datos involucrados en las medidas de resumen. Ds: duración del sonido en segundos; Np: número de pulsos; Nip: número de interpulsos; Fd: frecuencia dominante en Hertz; Tratamientos (1-8) en mg CPF/L; C: control con agua de bioensayo (0 mg CPF/L); Cd: control de dilución con etanol en $\mathrm{mg}$ Etanol/L

\begin{tabular}{|c|c|c|c|c|c|}
\hline STD & Tratamientos & Ds & $\mathrm{Np}$ & Nip & Fd \\
\hline \multirow{10}{*}{ 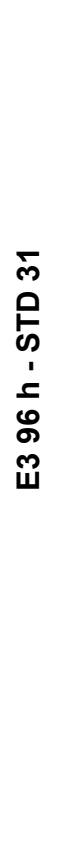 } & $C(0)$ & $\begin{array}{c}0,076 \pm 0,008 \\
(59)\end{array}$ & $\begin{array}{c}9,967 \pm 0,836 \\
(59)\end{array}$ & $\begin{array}{c}8,967 \pm 0,836 \\
(59)\end{array}$ & $\begin{array}{c}3532,729 \pm 268,915 \\
(59)\end{array}$ \\
\hline & $\mathrm{Cd}(0,7)$ & $\begin{array}{c}0,077 \pm 0,006 \\
(56)\end{array}$ & $\begin{array}{c}9,964 \pm 0,750 \\
(56)\end{array}$ & $\begin{array}{c}8,964 \pm 0,750 \\
(56)\end{array}$ & $\begin{array}{c}3521,393 \pm 267,162 \\
(56)\end{array}$ \\
\hline & $1(0,025)$ & $\begin{array}{c}0,075 \pm 0,010 \\
(54)\end{array}$ & $\begin{array}{c}7,037 \pm 1,089 \\
(54)\end{array}$ & $\begin{array}{c}6,037 \pm 1,089 \\
(54)\end{array}$ & $\begin{array}{c}3814,815 \pm 230,290 \\
(54)\end{array}$ \\
\hline & $2(0,075)$ & $\begin{array}{c}0,085 \pm 0,012 \\
(30)\end{array}$ & $\begin{array}{c}7,367 \pm 1,677 \\
(30)\end{array}$ & $\begin{array}{c}6,367 \pm 1,677 \\
(30)\end{array}$ & $\begin{array}{c}3454,867 \pm 341,981 \\
(30)\end{array}$ \\
\hline & $3(0,15)$ & $\begin{array}{c}0,094 \pm 0,021 \\
(18)\end{array}$ & $\begin{array}{c}9,167 \pm 1,783 \\
(18)\end{array}$ & $\begin{array}{c}8,167 \pm 1,783 \\
(18)\end{array}$ & $\begin{array}{c}3648,167 \pm 397,511 \\
(18)\end{array}$ \\
\hline & $4(0,2)$ & $\begin{array}{c}0,070 \pm 0,012 \\
(23)\end{array}$ & $\begin{array}{c}7,304 \pm 1,958 \\
(23)\end{array}$ & $\begin{array}{l}6,304 \pm 1,958 \\
(23)\end{array}$ & $\begin{array}{c}3824,957 \pm 387,381 \\
(23)\end{array}$ \\
\hline & $5(0,25)$ & $\begin{array}{c}0,082 \pm 0,014 \\
(21)\end{array}$ & $\begin{array}{c}10,095 \pm 2,115 \\
(21)\end{array}$ & $\begin{array}{c}9,095 \pm 2,115 \\
(21)\end{array}$ & $\begin{array}{c}3454,095 \pm 437,700 \\
(21)\end{array}$ \\
\hline & $6(0,3)$ & $\begin{array}{c}0,060 \pm 0,012 \\
(21)\end{array}$ & $\begin{array}{c}6,619 \pm 1,638 \\
(21)\end{array}$ & $\begin{array}{c}5,619 \pm 1,638 \\
(21)\end{array}$ & $\begin{array}{c}3524,810 \pm 320,139 \\
(21)\end{array}$ \\
\hline & $7(0,5)$ & $\begin{array}{l}0,071 \pm 0,010 \\
\quad(42)\end{array}$ & $\begin{array}{c}7,190 \pm 1,397 \\
(42)\end{array}$ & $\begin{array}{c}6,190 \pm 1,397 \\
(42)\end{array}$ & $\begin{array}{c}3451,833 \pm 277,957 \\
(42)\end{array}$ \\
\hline & $8(0,7)$ & $\begin{array}{c}0,075 \pm 0,011 \\
\quad(33)\end{array}$ & $\begin{array}{c}7,182 \pm 1,123 \\
(33)\end{array}$ & $\begin{array}{c}6,182 \pm 1,123 \\
(33)\end{array}$ & $\begin{array}{c}3548,000 \pm 320,628 \\
(33)\end{array}$ \\
\hline \multirow{10}{*}{ 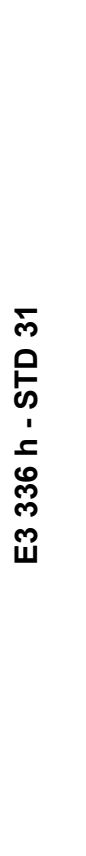 } & $C(0)$ & $\begin{array}{c}0,077 \pm 0,006 \\
(55)\end{array}$ & $\begin{array}{c}11,455 \pm 1,264 \\
(55)\end{array}$ & $\begin{array}{c}10,455 \pm 1,264 \\
(55)\end{array}$ & $\begin{array}{c}3786,218 \pm 254,934 \\
(55)\end{array}$ \\
\hline & $\mathrm{Cd}(0,7)$ & $\begin{array}{c}0,074 \pm 0,006 \\
(50)\end{array}$ & $\begin{array}{c}11,340 \pm 1,380 \\
(50)\end{array}$ & $\begin{array}{c}10,340 \pm 1,380 \\
(50)\end{array}$ & $\begin{array}{c}3758,320 \pm 309,147 \\
(50)\end{array}$ \\
\hline & $1(0,025)$ & $\begin{array}{l}0,071 \pm 0,008 \\
\quad(57)\end{array}$ & $\begin{array}{c}8,684 \pm 1,410 \\
(57)\end{array}$ & $\begin{array}{c}7,684 \pm 1,410 \\
(57)\end{array}$ & $\begin{array}{c}4960,175 \pm 531,099 \\
(57)\end{array}$ \\
\hline & $2(0,075)$ & $\begin{array}{c}0,076 \pm 0,015 \\
(24)\end{array}$ & $\begin{array}{c}9,583 \pm 2,618 \\
(24)\end{array}$ & $\begin{array}{c}8,583 \pm 2,618 \\
(24)\end{array}$ & $\begin{array}{c}3878,167 \pm 627,689 \\
(24)\end{array}$ \\
\hline & $3(0,15)$ & $\begin{array}{c}0,055 \pm 0,023 \\
(15)\end{array}$ & $\begin{array}{c}5,267 \pm 2,524 \\
(15)\end{array}$ & $\begin{array}{c}4,267 \pm 2,524 \\
(15)\end{array}$ & $\begin{array}{c}4893,333 \pm 1276,413 \\
(15)\end{array}$ \\
\hline & $4(0,2)$ & $\begin{array}{c}0,038 \pm 0,010 \\
(24)\end{array}$ & $\begin{array}{c}3,292 \pm 1,297 \\
(24)\end{array}$ & $\begin{array}{c}2,292 \pm 1,297 \\
(24)\end{array}$ & $\begin{array}{c}5401,292 \pm 863,964 \\
(24)\end{array}$ \\
\hline & $5(0,25)$ & $\begin{array}{c}0,044 \pm 0,014 \\
(18)\end{array}$ & $\begin{array}{c}4,056 \pm 1,511 \\
(18)\end{array}$ & $\begin{array}{c}3,056 \pm 1,511 \\
(18)\end{array}$ & $\begin{array}{c}6069,111 \pm 1294,506 \\
(18)\end{array}$ \\
\hline & $6(0,3)$ & $\begin{array}{c}0,054 \pm 0,014 \\
(15)\end{array}$ & $\begin{array}{c}4,333 \pm 1,696 \\
(15)\end{array}$ & $\begin{array}{c}3,333 \pm 1,696 \\
(15)\end{array}$ & $\begin{array}{c}5453,200 \pm 1305,473 \\
(15)\end{array}$ \\
\hline & $7(0,5)$ & $\begin{array}{l}0,051 \pm 0,009 \\
(27)\end{array}$ & $\begin{array}{c}3,741 \pm 0,935 \\
(27)\end{array}$ & $\begin{array}{c}2,741 \pm 0,935 \\
(27)\end{array}$ & $\begin{array}{c}5762,333 \pm 808,240 \\
(27)\end{array}$ \\
\hline & $8(0,7)$ & $\begin{array}{c}0,049 \pm 0,012 \\
(18)\end{array}$ & $\begin{array}{c}4,111 \pm 1,426 \\
(18)\end{array}$ & $\begin{array}{c}3,111 \pm 1,426 \\
(18)\end{array}$ & $\begin{array}{c}6817,611 \pm 1843,370 \\
(18)\end{array}$ \\
\hline
\end{tabular}


Tabla 26. Resultados de la comparación mediante una prueba de $t$ de las variables bioacústicas de los sonidos emitidos por larvas pertenecientes a diferentes grupos control del ensayo 3 (E3) tanto a 96 h como a 336 h. C: grupo control con agua de bioensayo; Cd: grupo control de dilución con etanol; $\mathrm{N}$ : grupo control de los sonidos característicos de larvas de $C$. ornata en STD 31; Ds: duración del sonido en segundos; Np: número de pulsos; Nip: número de interpulsos; Fd: frecuencia dominante en Hertz; g.l: grados de libertad; F: varianza $1^{\circ}$ muestra / varianza $2^{\circ}$ muestra; p: probabilidad asociada a la prueba realizada

\begin{tabular}{|c|c|c|c|c|c|c|c|}
\hline & & Variables & $t$ & g.l. & $p(t)$ & $\mathbf{F}$ & $p(F)$ \\
\hline \multirow{4}{*}{$\begin{array}{l}\frac{1}{\circ} \\
\mathscr{8} \\
m \\
m\end{array}$} & \multirow{4}{*}{$\begin{array}{l}\text { J } \\
0 \\
0 \\
0\end{array}$} & Ds & $-0,073$ & 113 & 0,941 & 2,049 & 0,008 \\
\hline & & $\mathrm{Np}$ & $-0,333$ & 113 & 0,740 & 1,297 & 0,334 \\
\hline & & Nip & $-0,352$ & 113 & 0,725 & 1,302 & 0,326 \\
\hline & & $\mathrm{Fd}$ & 0,059 & 113 & 0,953 & 1,102 & 0,719 \\
\hline \multirow{4}{*}{$\begin{array}{l}\text { 足 } \\
\text { ల్ } \\
\tilde{m}\end{array}$} & \multirow{4}{*}{\begin{tabular}{l} 
ठ \\
\multirow{0}{\infty}{} \\
0
\end{tabular}} & Ds & 0,566 & 103 & 0,573 & 1,157 & 0,607 \\
\hline & & $\mathrm{Np}$ & 0,166 & 103 & 0,868 & 1,012 & 0,963 \\
\hline & & Nip & 0,164 & 103 & 0,870 & 1,003 & 0,988 \\
\hline & & $\mathrm{Fd}$ & 0,141 & 103 & 0,888 & 1,331 & 0,306 \\
\hline \multirow{4}{*}{$\begin{array}{l}\text { c } \\
\mathscr{8} \\
\tilde{m} \\
\ddot{w}\end{array}$} & \multirow{4}{*}{$\begin{array}{l}z \\
0 \\
0\end{array}$} & Ds & $-1,327$ & 149 & 0,186 & 4,097 & $<0,0005$ \\
\hline & & $\mathrm{Np}$ & 1,765 & 149 & 0,080 & 1,228 & 0,376 \\
\hline & & Nip & 1,778 & 149 & 0,077 & 1,260 & 0,320 \\
\hline & & $\mathrm{Fd}$ & 1,809 & 149 & 0,073 & 2,837 & $<0,0005$ \\
\hline \multirow{4}{*}{$\begin{array}{l}\text { 它 } \\
\mathscr{ల} \\
\tilde{m} \\
\tilde{w}\end{array}$} & \multirow{4}{*}{$\begin{array}{l}z \\
0 \\
0\end{array}$} & Ds & $-1,784$ & 145 & 0,077 & 1,925 & 0,006 \\
\hline & & $\mathrm{Np}$ & $-0,531$ & 145 & 0,596 & 1,728 & 0,021 \\
\hline & & Nip & $-0,483$ & 145 & 0,630 & 1,708 & 0,024 \\
\hline & & $\mathrm{Fd}$ & $-0,061$ & 145 & 0,951 & 2,301 & $<0,0005$ \\
\hline
\end{tabular}



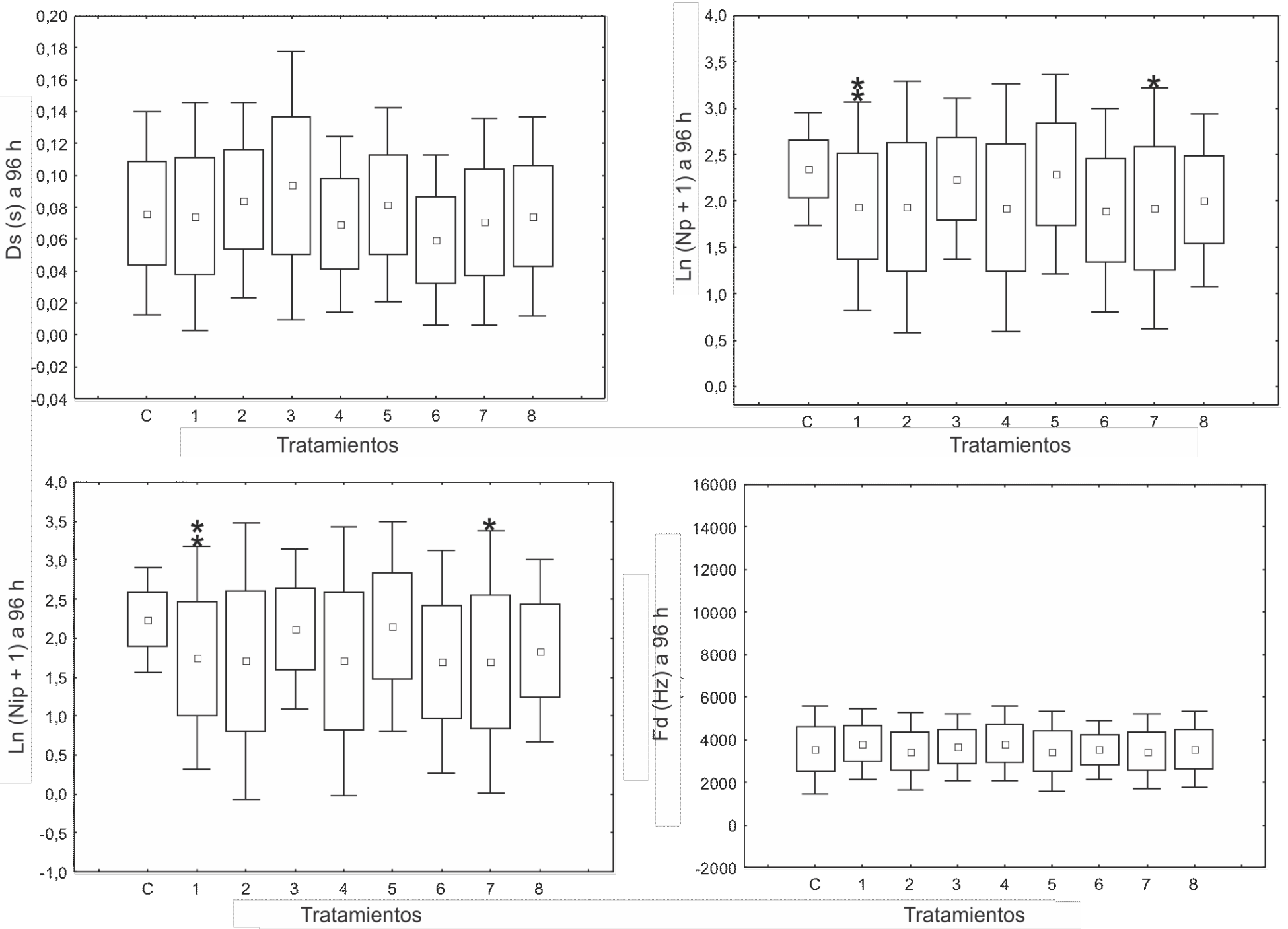

Figura 50. Resultados de la comparación múltiple realizada entre los tratamientos (1-8) y el grupo control con agua de bioensayo (C) a $96 \mathrm{~h}$ del bioensayo 3 para las distintas variables bioacústicas medidas. Con asterisco se indican los tratamientos cuyas diferencias resultaron significativas respecto al grupo control con $p<0,05\left(^{*}\right)$ y $p<0,005\left(^{* *}\right)$. Ds: duración del sonidos en segundos (s); Ln (Np + 1): logaritmo natural del número de pulsos más uno; Ln (Nip + 1): logaritmo natural del número de interpulsos más uno; Fd: frecuencia dominante en $\mathrm{Hertz}(\mathrm{Hz})$ 

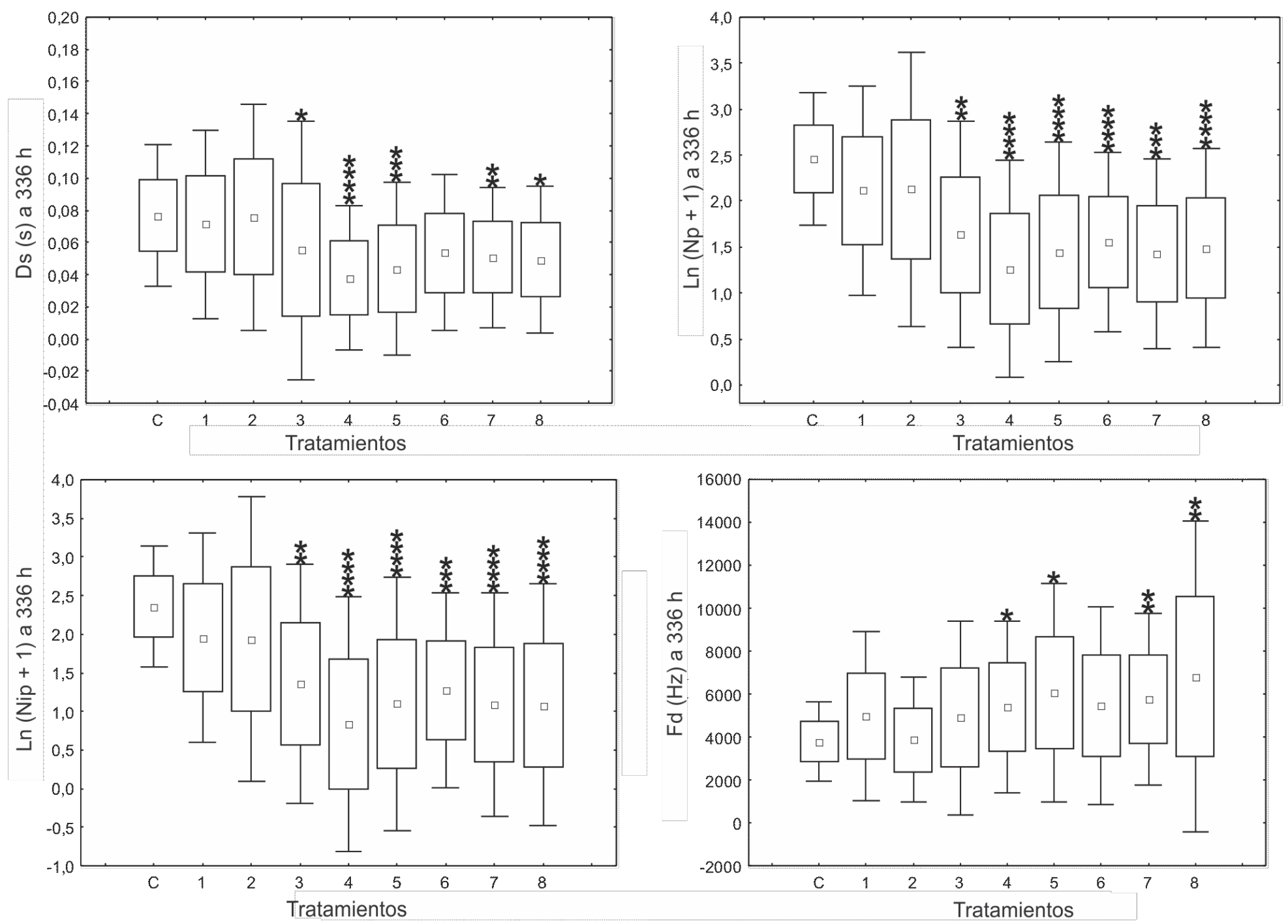

Figura 51. Resultados de la comparación múltiple realizada entre los tratamientos (1-8) y el grupo control con agua de bioensayo (C) a $336 \mathrm{~h}$ del bioensayo 3 para las distintas variables bioacústicas medidas. Con asterisco se indican los tratamientos cuyas diferencias resultaron significativas respecto al grupo control con $p<0,05\left(^{*}\right), p<0,005\left(^{* *}\right), p<0,0005\left(^{* * *}\right)$ y $p<0,00005\left(^{* * * *}\right)$. Ds: duración del sonidos en segundos (s); Ln (Np + 1): logaritmo natural del número de pulsos más uno; Ln (Nip + 1): logaritmo natural del número de interpulsos más uno; Fd: frecuencia dominante en $\mathrm{Hertz}(\mathrm{Hz})$ 

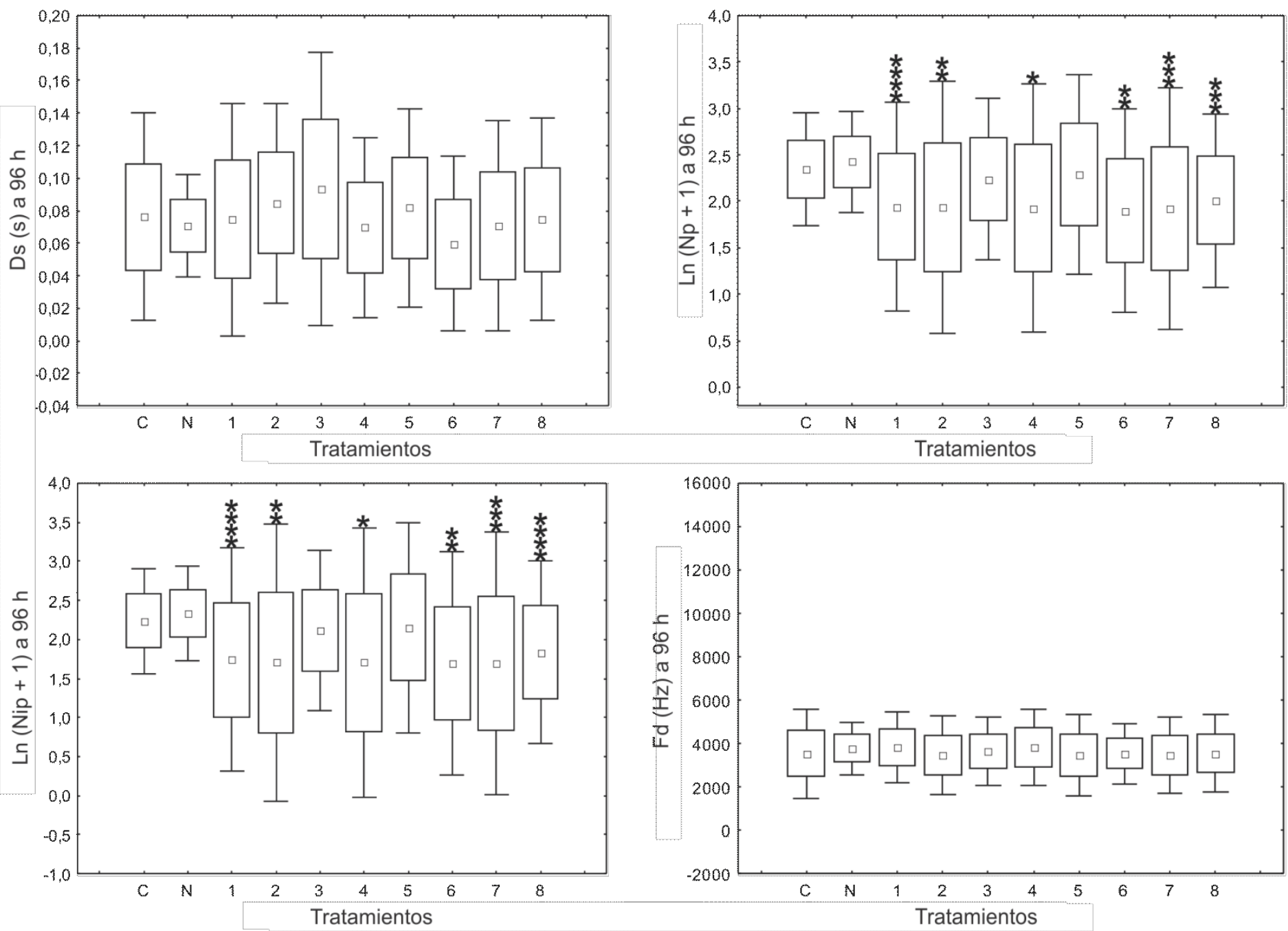

Figura 52. Resultados de la comparación múltiple realizada entre los tratamientos (1-8) y el grupo control (N, sonidos característicos de larvas de STD 31) a $96 \mathrm{~h}$ del bioensayo 3 para las distintas variables bioacústicas medidas. Con asterisco se indican los tratamientos cuyas diferencias resultaron significativas respecto al grupo control con $p<0,05\left(^{*}\right), p<0,005\left(^{* *}\right), p<0,0005\left(^{* * *}\right)$ y $p<0,00005\left(^{* * *}\right)$. C: control con agua de bioensayo; Ds: duración del sonidos en segundos (s); Ln ( Np + 1): logaritmo natural del número de pulsos más uno; Ln (Nip +1): logaritmo natural del número de interpulsos más uno; Fd: frecuencia dominante en Hertz $(\mathrm{Hz})$ 

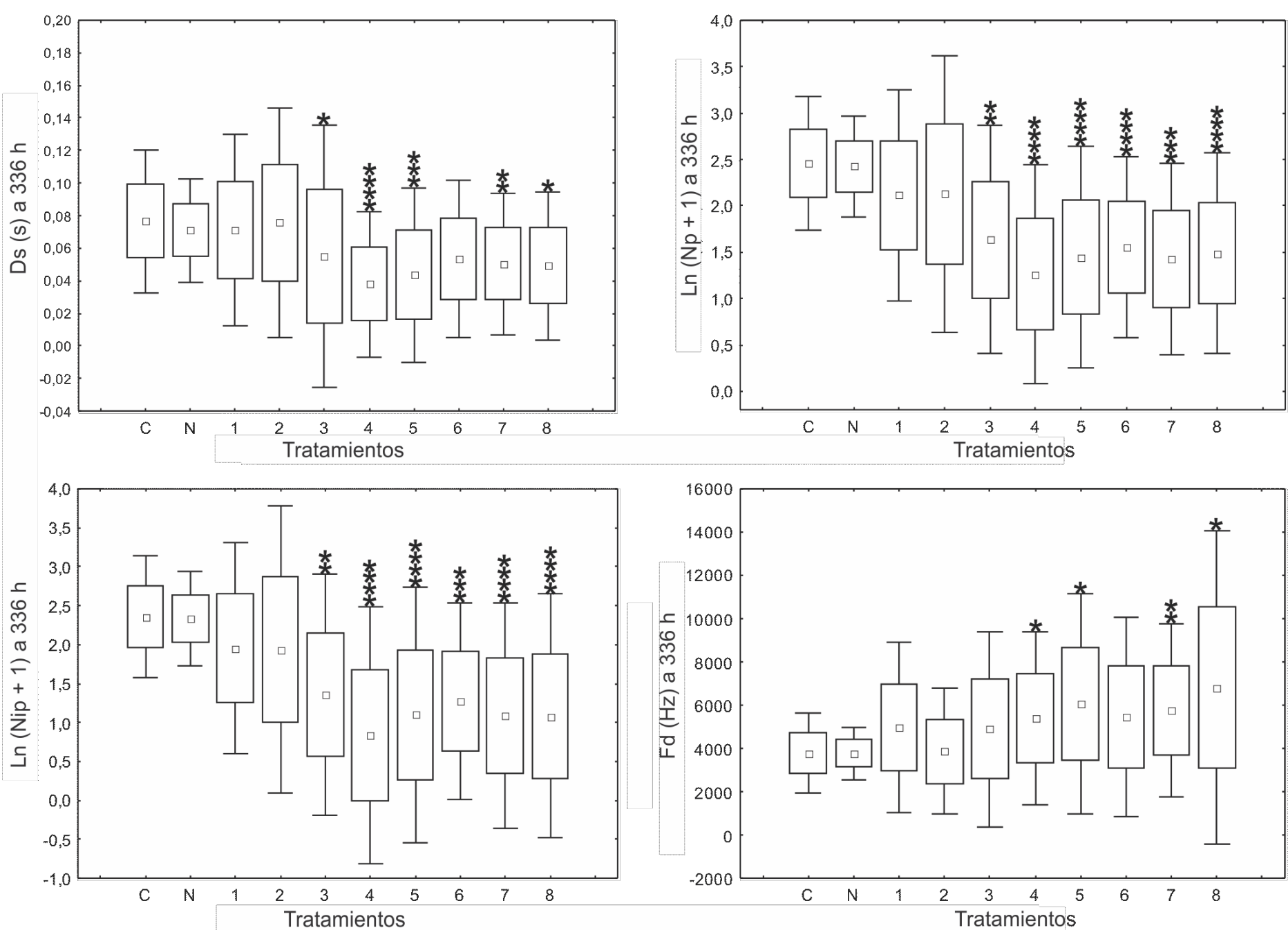

Figura 53. Resultados de la comparación múltiple realizada entre los tratamientos (1-8) y el grupo control (N, sonidos característicos de larvas de STD 31) a $336 \mathrm{~h}$ del bioensayo 3 para las distintas variables bioacústicas medidas. Con asterisco se indican los tratamientos cuyas diferencias resultaron significativas respecto al grupo control con $p<0,05\left(^{*}\right), p<0,005\left(^{* *}\right), p<0,0005\left(^{(* *}\right)$ y $p<0,00005\left(^{* * *}\right)$. C: control con agua de bioensayo; Ds: duración del sonidos en segundos (s); Ln (Np + 1): logaritmo natural del número de pulsos más uno; Ln (Nip + 1): logaritmo natural del número de interpulsos más uno; Fd: frecuencia dominante en Hertz $(\mathrm{Hz})$ 

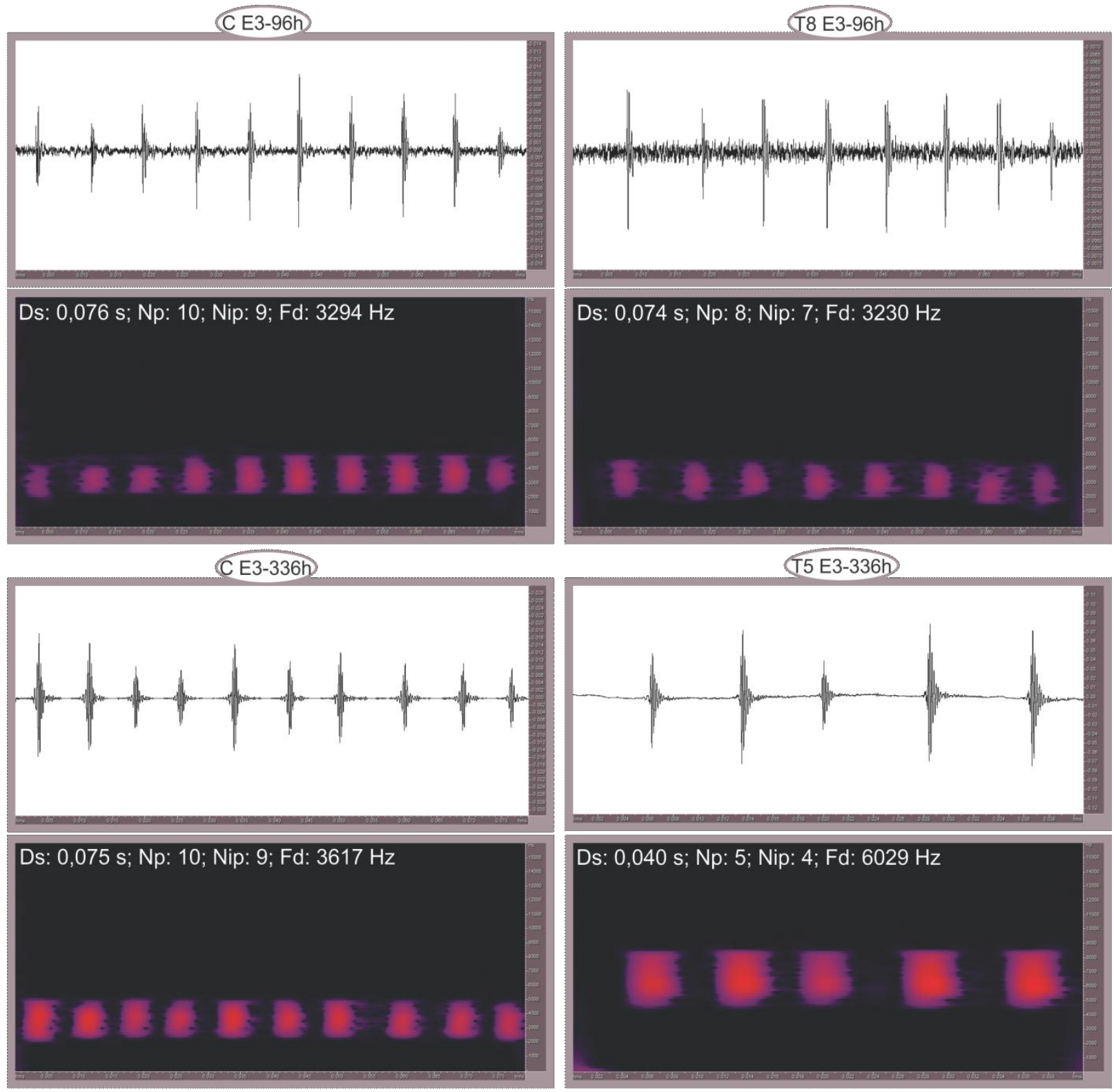

Figura 54. Oscilograma (parte superior; duración del sonido en segundos, $\mathrm{s}$ / amplitud en pascales) y sonograma (parte inferior; duración del sonido, s / frecuencia en Hertz, Hz) característico de los sonidos producidos por larvas de $C$. ornata en un medio aéreo en estadio 31 pertenecientes al grupo control con agua de bioensayo (C) y a distintos tratamientos (T) de exposición a clorpirifós (CPF) a 96 h y $336 \mathrm{~h}$ para el bioensayo 3 (E3). Cada gráfico corresponde al sonido emitido por una larva de un determinado tratamiento. T5: 0,25 mg CPF/L; T8 = 0,7 mg CPF/L 
Tabla 27. Media aritmética \pm nivel de confianza para la media al $95 \%$ de las variables bioacústicas analizadas para el bioensayo 5 (E5) realizado en estadio 37 . Entre paréntesis se indica el número de datos involucrados en las medidas de resumen. Ds: duración del sonido en segundos; Np: número de pulsos; Nip: número de interpulsos; Fd: frecuencia dominante en Hertz; Tratamientos (1-5) en mg CPF/L; C: control con agua de bioensayo ( $0 \mathrm{mg} \mathrm{CPF} / \mathrm{L}$ ); Cd: control de dilución con etanol en mg Etanol/L

\begin{tabular}{|c|c|c|c|c|c|}
\hline STD & Tratamientos & Ds & $\mathrm{Np}$ & Nip & $\mathbf{F d}$ \\
\hline \multirow{7}{*}{ 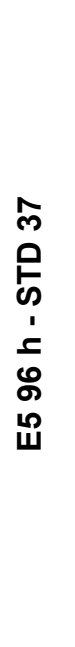 } & $C(0)$ & $\begin{array}{c}0,069 \pm \\
0,009(28)\end{array}$ & $\begin{array}{c}12,929 \pm \\
1,309(28)\end{array}$ & $\begin{array}{c}11,929 \pm \\
1,309(28)\end{array}$ & $\begin{array}{c}3291,750 \pm 560,557 \\
(28)\end{array}$ \\
\hline & $\mathrm{Cd}(0,5)$ & $\begin{array}{c}0,079 \pm \\
0,007(28)\end{array}$ & $\begin{array}{c}13,143 \pm \\
1,815(28)\end{array}$ & $\begin{array}{c}12,143 \pm \\
1,185(28)\end{array}$ & $\begin{array}{c}3409,393 \pm 699,702 \\
(28)\end{array}$ \\
\hline & $1(0,025)$ & $\begin{array}{c}0,072 \pm \\
0,008(30)\end{array}$ & $\begin{array}{c}6,533 \pm 2,091 \\
(30)\end{array}$ & $\begin{array}{c}5,533 \pm 2,091 \\
(30)\end{array}$ & $\begin{array}{c}3981,600 \pm 827,925 \\
(30)\end{array}$ \\
\hline & $2(0,1)$ & $\begin{array}{c}0,070 \pm \\
0,007(30)\end{array}$ & $\begin{array}{c}8,100 \pm 2,048 \\
(30)\end{array}$ & $\begin{array}{c}7,100 \pm 2,048 \\
(30)\end{array}$ & $\begin{array}{c}4181,200 \pm 745,736 \\
(30)\end{array}$ \\
\hline & $3(0,2)$ & $\begin{array}{c}0,075 \pm \\
0,010(30)\end{array}$ & $\begin{array}{c}6,500 \pm 1,634 \\
(30)\end{array}$ & $\begin{array}{c}5,500 \pm 1,634 \\
(30)\end{array}$ & $\begin{array}{c}3959,500 \pm 828,387 \\
(30)\end{array}$ \\
\hline & $4(0,3)$ & $\begin{array}{c}0,057 \pm \\
0,010(30)\end{array}$ & $\begin{array}{c}7,067 \pm 1,944 \\
(30)\end{array}$ & $\begin{array}{c}6,067 \pm 1,944 \\
(30)\end{array}$ & $\begin{array}{c}4349,700 \pm \\
1045,513(30)\end{array}$ \\
\hline & $5(0,5)$ & $\begin{array}{c}0,070 \pm \\
0,012(27)\end{array}$ & $\begin{array}{c}6,852 \pm 1,596 \\
(27)\end{array}$ & $\begin{array}{c}5,852 \pm 1,596 \\
(27)\end{array}$ & $\begin{array}{c}4217,259 \pm \\
1007,763(27)\end{array}$ \\
\hline
\end{tabular}

Tabla 28. Resultados de la comparación mediante una prueba de $t$ de las variables bioacústicas de los sonidos emitidos por larvas pertenecientes a diferentes grupos control del bioensayo 5 (E5) a $96 \mathrm{~h}$. C: grupo control con agua de bioensayo; Cd: grupo control de dilución con etanol; N: grupo control de los sonidos característicos de larvas de C. ornata en STD 37; Ds: duración del sonido en segundos; Np: número de pulsos; Nip: número de interpulsos; Fd: frecuencia dominante en Hertz; g.I: grados de libertad; F: varianza $1^{\circ}$ muestra / varianza $2^{\circ}$ muestra; $p$ : probabilidad asociada a la prueba realizada

\begin{tabular}{|c|c|c|c|c|c|c|}
\hline & Variables & $t$ & g.l. & $p(t)$ & $\mathbf{F}$ & $p(F)$ \\
\hline \multirow{4}{*}{$\begin{array}{l}\frac{1}{8} \\
\stackrel{8}{ } \\
\text { ů }\end{array}$} & Ds & $-1,82655$ & 54 & 0,073297 & 1,298782 & 0,501581 \\
\hline & $\mathrm{Np}$ & 0,12571 & 54 & 0,900427 & 1,808298 & 0,130013 \\
\hline & Nip & 0,15054 & 54 & 0,880897 & 1,796315 & 0,134317 \\
\hline & $\mathrm{Fd}$ & $-0,26923$ & 54 & 0,788775 & 1,558072 & 0,255573 \\
\hline \multirow{4}{*}{$\begin{array}{l}\frac{5}{8} \\
8 \\
\text { i⿱ }\end{array}$} & Ds & 0,58271 & 117 & 0,561210 & 1,441091 & 0,206048 \\
\hline & $\mathrm{Np}$ & $-1,87483$ & 116 & 0,063332 & 1,299582 & 0,360875 \\
\hline & Nip & $-1,85583$ & 116 & 0,066016 & 1,303605 & 0,355464 \\
\hline & $\mathrm{Fd}$ & 1,10825 & 122 & 0,269936 & 7,473177 & 0,000000 \\
\hline
\end{tabular}



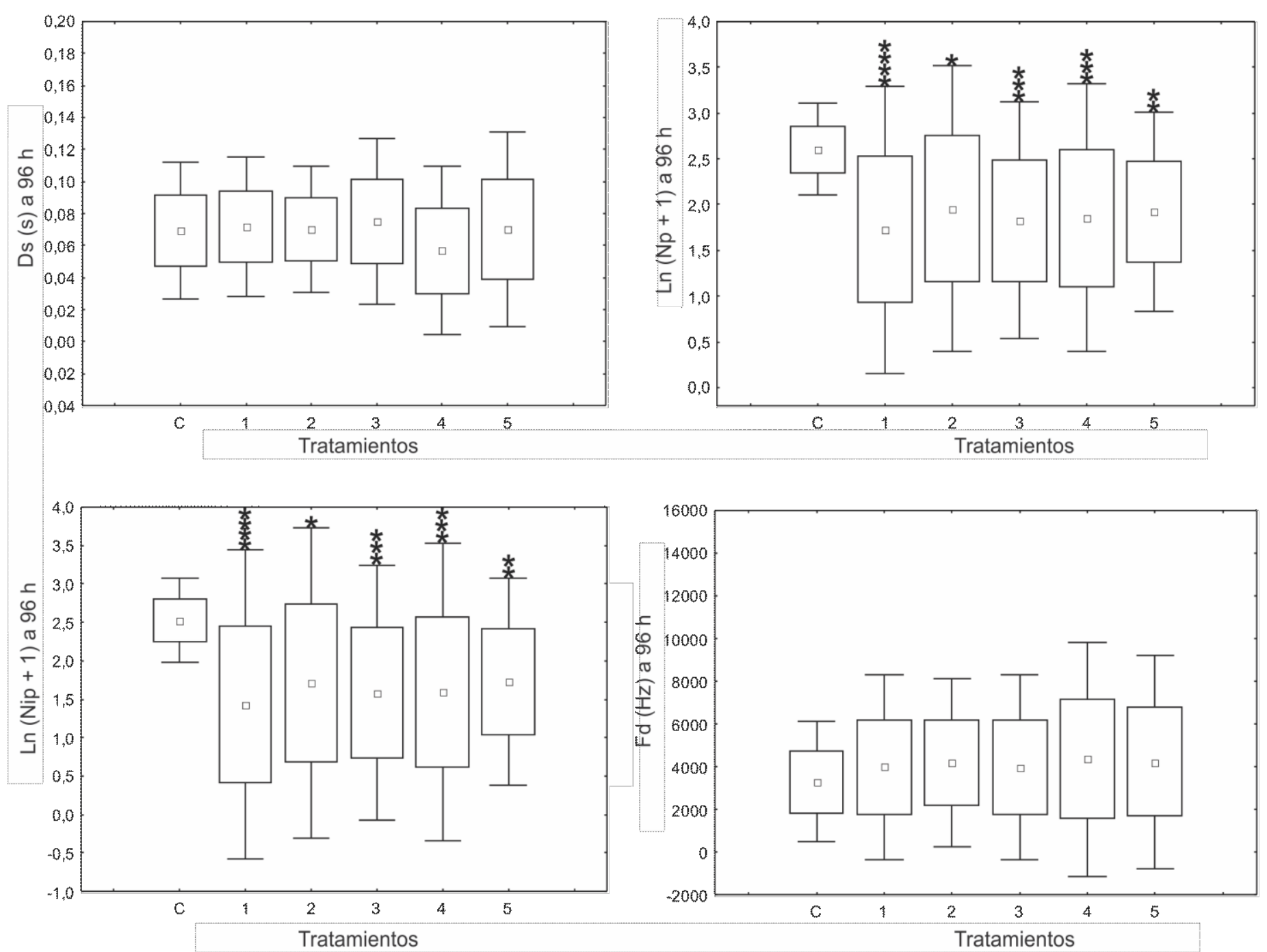

Figura 55. Resultados de la comparación múltiple realizada entre los tratamientos (1-5) y el grupo control con agua de bioensayo (C) a $96 \mathrm{~h}$ del bioensayo 5 para las distintas variables bioacústicas medidas. Con asterisco se indican los tratamientos cuyas diferencias resultaron significativas respecto al grupo control con $p<0,05\left(^{*}\right), p<0,005\left(^{* *}\right), p<0,0005\left(^{(* *}\right)$ y $p<0,00005\left(^{* * *}\right)$. Ds: duración del sonidos en segundos $(s)$; Ln (Np +1$)$ : logaritmo natural del número de pulsos más uno; Ln (Nip + 1): logaritmo natural del número de interpulsos más uno; Fd: frecuencia dominante en Hertz $(\mathrm{Hz})$ 

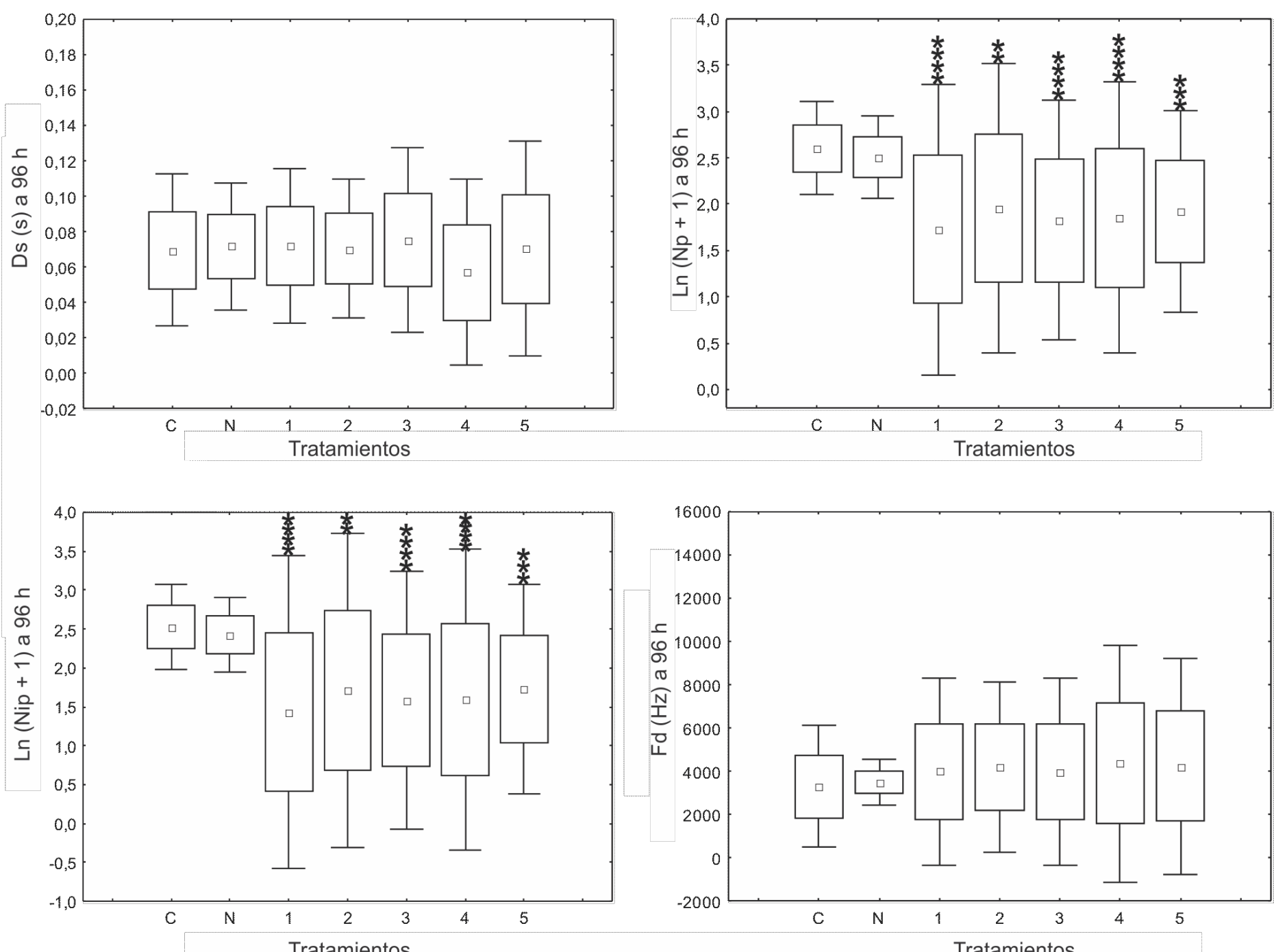

Figura 56. Resultados de la comparación múltiple realizada entre los tratamientos (1-5) y el grupo control (N, sonidos característicos de larvas de STD 37) a $96 \mathrm{~h}$ del bioensayo 5 para las distintas variables bioacústicas medidas. Con asterisco se indican los tratamientos cuyas diferencias resultaron significativas respecto al grupo control con $\mathrm{p}<0,05\left(^{*}\right), \mathrm{p}<0,005\left(^{* \star}\right), \mathrm{p}<0,0005\left(^{* *}\right)$ y $\mathrm{p}<0,00005\left(^{* * *}\right)$. Ds: duración del sonidos en segundos (s); Ln (Np + 1): logaritmo natural del número de pulsos más uno; Ln (Nip + 1): logaritmo natural del número de interpulsos más uno; Fd: frecuencia dominante en Hertz (Hz) 

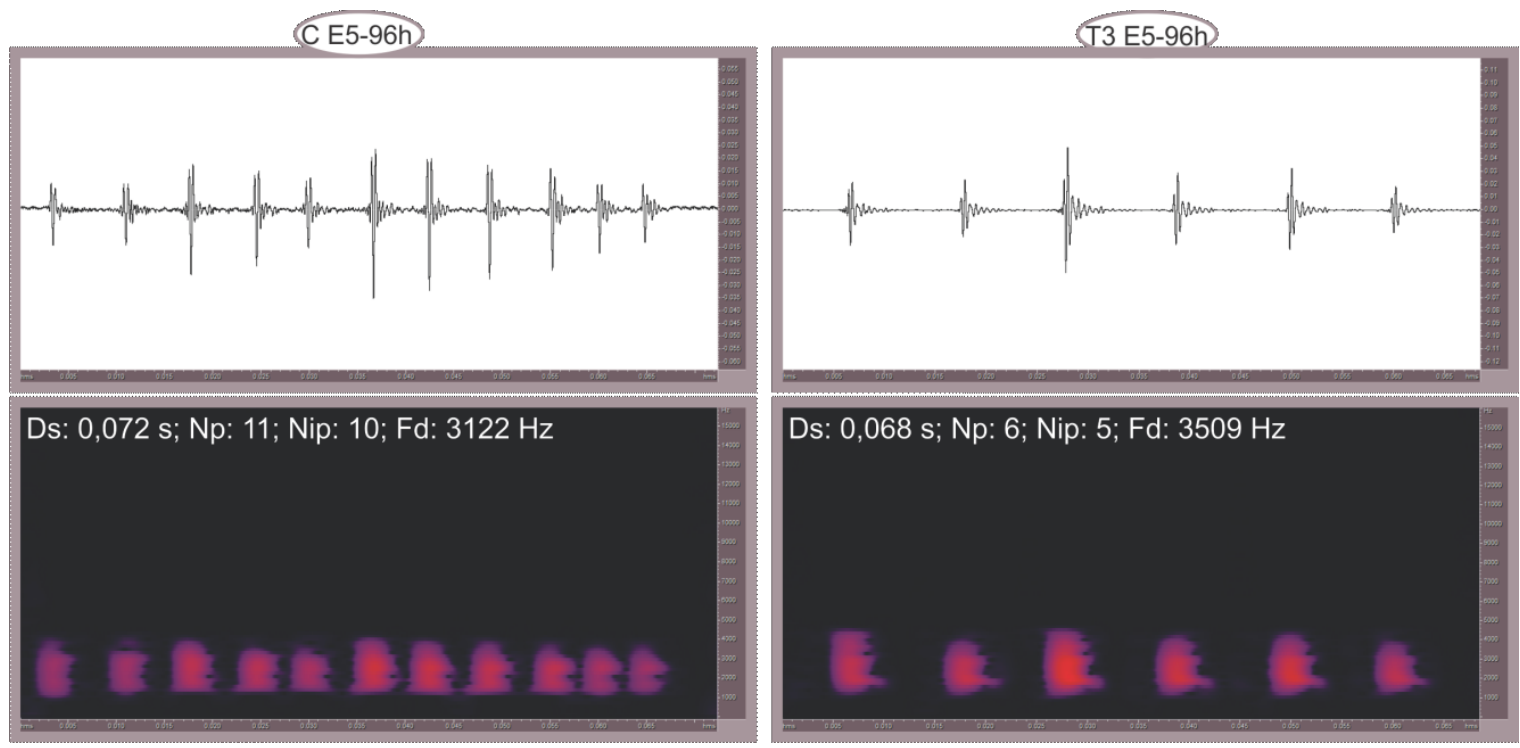

Figura 57. Oscilograma (parte superior; duración del sonido en segundos, $\mathrm{s} /$ amplitud en pascales) y sonograma (parte inferior; duración del sonido, s / frecuencia en Hertz, Hz) característico de los sonidos producidos por larvas de C. ornata en medio aéreo en estadio 37 pertenecientes al grupo control con agua de bioensayo $(\mathrm{C})$ y a un determinado tratamiento $(\mathrm{T})$ de exposición a clorpirifós (CPF) a $96 \mathrm{~h}$ para el bioensayo 5 (E5). Cada gráfico corresponde al sonido emitido por una larva de un determinado tratamiento. T3: 0,2 mg CPF/L

Tabla 29. Resultados de los análisis de correlación lineal $(r)$ realizados entre variables bioacústicas y variables ecotoxicológicas subletales para el bioensayo 3 (E3) y 5 (E5) al final de la exposición aguda (96 h) y crónica (336 h). En color rojo y con asterisco se indican los valores de correlación significativa con $p<0,05\left(^{*}\right)$ y $p<0,005\left(^{* *}\right)$. Ds: duración del sonido en segundos; Np: número de pulsos; Nip: número de interpulsos; Fd: frecuencia dominante en Hertz; ALT.NAT: alteraciones en la natación; LFLC: leve flexión lateral de la cola; LHC: longitud hocico-cloaca en milímetros; ${ }^{(a)}$ no se pudo calcular la correlación por no presentar respuestas

\begin{tabular}{|c|c|c|c|c|c|}
\hline & & Ds & Np & Nip & Fd \\
\hline \multirow{3}{*}{$\begin{array}{l}\text { ச } \\
\text { g } \\
1 \\
\text { జ' }\end{array}$} & ALT. NAT. & $-0,8813^{* *}$ & $-0,6062$ & $-0,6008$ & $0,7354^{*}$ \\
\hline & LFLC & $-0,0606$ & 0,2774 & 0,2803 & 0,4314 \\
\hline & LHC & 0,0907 & $0,1445^{*}$ & $0,1468^{*}$ & 0,0015 \\
\hline \multirow{3}{*}{ 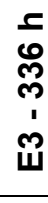 } & ALT. NAT. & $-0,5186$ & $-0,7798^{*}$ & $-0,7770^{*}$ & 0,4238 \\
\hline & LFLC & 0,0684 & 0,0703 & 0,0066 & 0,1039 \\
\hline & LHC & 0,1036 & 0,1244 & 0,1288 & $-0,1531^{*}$ \\
\hline \multirow{3}{*}{$\begin{array}{l}\text { ع } \\
\text { ه } \\
\text { L' }\end{array}$} & ALT. NAT. & 0,4548 & $-0,1086$ & $-0,1155$ & 0,2143 \\
\hline & LFLC & -- (a) & -- (a) & -- (a) & -- (a) \\
\hline & LHC & $-0,2989^{*}$ & $-0,2975^{*}$ & $-0,2780^{*}$ & $0,3020^{*}$ \\
\hline
\end{tabular}




\section{DISCUSIÓN Y CONCLUSIONES}

Tal como se concluyó en el capítulo anterior, el presente constituye el primer bioensayo de exposición de larvas de $C$. ornata, que evalúa efectos a nivel letal y subletal producidos por agroquímicos de uso frecuente en la región Pampeana. Cabe recordar que los efectos ecotoxicológicos convencionales (mortalidad, efectos en la natación, presencia de anormalidades morfológicas e inhibición del crecimiento) han sido abordados en el capítulo anterior. Los bioensayos realizados, además resultan ser los primeros que evalúan efectos sobre la emisión de sonidos. Es decir, constituye el primer trabajo que emplea la emisión de sonidos larvales como un punto final ecotoxicológico de efecto subletal, poniendo a prueba de este modo la utilidad del modelo experimental propuesto.

En lo que respecta a trabajos de bioacústica clásica, la mayoría de los registros son realizados en ambientes exteriores (hábitat natural de la especie). Por lo tanto, se reportan junto con los parámetros del sonido aquellos correspondientes a las condiciones ambientales. Es por ello, que en el capítulo dedicado al análisis y descripción de los sonidos emitidos por larvas de $C$. ornata a lo largo del desarrollo (capítulo 2) se informan las condiciones de grabación (temperatura ambiente y del agua, distancia de grabación a la fuente de emisión). Partiendo de este marco teórico, la desviación de alguna de las condiciones antes mencionadas podría generar un cambio en las características del sonido a grabar. En tal sentido, se mantuvieron constantes las condiciones de temperatura y distancia del micrófono al objeto emisor (larva). Bajo tales condiciones fueron realizadas todas las grabaciones, tanto de los sonidos correspondientes a larvas expuestas a CPF como aquellas no expuestas (ya sea larvas pertenecientes al grupo control con agua de bioensayo o larvas grabadas para caracterizar los sonidos larvales de un determinado STD). Tal como se mencionó previamente, no existía hasta el momento en la literatura científica algún trabajo que utilice a las variables bioacústicas como punto final ecotoxicológico.

Teniendo en cuenta la existencia de una progresión de efectos negativos, la cual fue evaluada en el capítulo precedente, si se incluye en este análisis a los efectos en el sonido, los mismos aparecen en el intervalo de concentraciones en el cual se dan alteraciones en la natación. Luego, aparecen las anormalidades, a continuación se observa inhibición del crecimiento y por último mortalidad. Por lo tanto, el efecto en el sonido resulta ser un punto final de elevada sensibilidad. Retomando las definiciones de biomarcadores antes mencionadas (McCarthy and Shugart, 1990; Markert, 1994), se considera al efecto en el sonido como un buen biomarcador de alerta temprana. 
Si se tienen en cuenta los niveles de CPF medidos en el medio ambiente (Jergentz y col., 2005; Marino y Ronco, 2005; Mugni y col., 2011), los mismos se encuentran dentro del intervalo de concentraciones que inducen efectos en el sonido emitido por larvas de $C$. ornata. Teniendo en cuenta tales trabajos, la mayor concentración medida en agua se encuentra dentro del intervalo que induce efectos en el sonido a $96 \mathrm{~h}$ y la mayor concentración medida en material particulado resulta ser 9 veces superior a la concentración que induce efectos en el sonido. De todas formas, y tal como se mencionó en el capítulo precedente, se debe tener en cuenta que los efectos tanto letales como subletales en campo pueden deberse también a las mezclas de plaguicidas (incluyendo al CPF), tal como informaron Ronco y col. (2008) para especies autóctonas que habitan en ambientes modificados de la región Pampeana, constituyendo tales reportes los primeros acerca del efecto del CPF sobre anuros autóctonos. Es decir, los efectos en campo, teniendo en cuenta las mismas concentraciones evaluadas en laboratorio, podrían ser mayores debido a los efectos sinérgicos de otros plaguicidas y demás contaminantes.

En el presente capítulo se registraron efectos en el sonido emitido por larvas de $C$. ornata. Específicamente, teniendo en cuenta los bioensayos realizados (E3, E5) se concluye que el CPF afecta a los parámetros normales del sonido, entre ellos la Ds, el Np, el Nip y la Fd. Se hallaron diferencias significativas respecto al grupo control para todas las variables de sonidos emitidos por larvas de STD 31, resultando esperable que tales diferencias también aparezcan para todas las variables de los sonidos emitidos por larvas de STD 37 expuestas a mayores concentraciones de CPF que las ensayadas. En tal sentido, se deberán realizar a futuro estudios complementarios en STD 37 (teniendo en cuenta los resultados obtenidos) para poder estimar mejor las curvas concentración-respuesta y consecuentemente los efectos sobre el sonido. Considerando la CL-50 a $96 \mathrm{~h}$ reportada para larvas de $C$. ornata de STD 31 (0,121 mg CPF/L), los efectos en el sonido fueron detectados a partir de concentraciones 4 veces menores $(0,025 \mathrm{mg} \mathrm{CPF} / \mathrm{L})$ que aquella. $\mathrm{Si}$ se consideran las CE-50 de las alteraciones en la natación $(=0,069 \mathrm{mg}$ CPF/L) y la presencia de anormalidades (0,295 mg CPF/L), los efectos en el sonido fueron detectados a partir de concentraciones 3 y 12 veces menores que aquellas, respectivamente. Por lo tanto, se acepta la hipótesis que plantea que la emisión normal de sonidos emitidos por larvas de $C$. ornata se ve tempranamente alterada por el efecto del CPF a bajas concentraciones. A partir de los resultados obtenidos producto de las correlaciones lineales realizadas entre los parámetros del sonido y los diferentes tratamientos, se concluye que el sonido es más corto, consta de menor cantidad de pulsos (y consecuentemente de interpulsos) y es más agudo que un sonido normal a medida que aumenta la concentración de CPF. Es decir, se acepta la hipótesis que plantea que existe un incremento de los efectos perjudiciales producidos por el CPF sobre las variables acústicas, con el 
aumento de la concentración del tóxico en el agua a un tiempo constante de exposición. Complementariamente, si se tiene en cuenta que un organismo invierte energía en recuperar o mantener las funciones vitales fundamentales para su supervivencia (ej. nutrición) dejando de invertir energía en mantener aquellas funciones accesorias (ej. reproducción), y si se considera a la emisión de sonidos como una parte fundamental del mecanismo antipredatorio descripto (ver capítulo 3 ), resulta esperable que las larvas de $C$. ornata continúen invirtiendo energía en emitir sonidos aunque se modifiquen sus parámetros normales.

Respecto a la evaluación de la existencia de correlación entre los distintos puntos subletales convencionales y las variables bioacústicas, se concluye que la presencia de alteraciones en la natación se correlaciona negativamente con la Ds y el Np y positivamente con la Fd. Es decir, a medida que disminuyen o aumentan (respectivamente) estas variables bioacústicas, aumenta la proporción de individuos alterados, siendo a su vez concordante con el aumento de la concentración de exposición a CPF. Para el caso de la presencia de anormalidades morfológicas no se encontró ningún tipo de correlación entre estas variables y las bioacústicas. Respecto a los resultados obtenidos para la LHC, se concluye que los mismos son concordantes con los obtenidos para el capítulo 2, ya que a medida que aumenta la LHC se incrementa la Ds, el Np y Nip y disminuye la Fd. Tal como se concluyó en el capítulo 2, al aumentar el tamaño del organismo también aumenta el tamaño de la caja resonante y con ello las características de los sonidos. Más allá de cuál sea el órgano resonante durante la etapa larval, la producción de sonidos ocurre por el pasaje/salida de aire por una determinada estructura que vibra. Por lo tanto, al aumentar el tamaño de dicha estructura aumentan ciertas características del sonido y disminuyen otras tal como ocurre en la mayoría de los anuros (Gerhardt, 1994).

Cabe recordar, a modo de resumen, que se evaluaron las interacciones predador-presa entre larvas de $C$. ornata y entre éstas y larvas que forman parte de su dieta habitual (sin exposición a plaguicidas), la asociación entre la emisión de sonidos y el mecanismo antipredatorio y los efectos sobre el sonido bajo exposición a CPF. Por lo tanto, resulta esperable que los efectos provocados por el CPF sobre larvas de esta especie, afecten también a las interacciones intraespecíficas, aumentando consecuentemente y de manera indirecta el número de eventos de canibalismo. Es decir, los efectos en las interacciones (Bridges, 1999; Boone y Semlitsch, 2001; Moore y col., 2015) resultan ser un efecto más, que sumado a los efectos que puedan darse a nivel sub-individual, contribuiría negativamente con la supervivencia de la especie. Cabe aquí destacar, que estos efectos no son tan notables como aquellos comúnmente evaluados a nivel individual (ej. anormalidades, mortalidad). Sin embargo, tal como postulan Jefferson y col. (2014), contribuyen a la disminución de las poblaciones de anfibios a nivel global. En tal sentido, se 
deberán realizar a futuro bioensayos que evalúen distintas interacciones predador-presa bajo los efectos del CPF.

Por todo lo antedicho, se propone al sonido como un nuevo punto final ecotoxicológico y al modelo experimental como una herramienta bioanalítica útil para evaluar efectos de plaguicidas y demás problemas ambientales en el ámbito de la Ecotoxicología. Si bien no todas las especies de anfibios emiten sonidos en etapa larval, se considera a los biomarcadores de comportamiento como una potente herramienta para evaluar efectos tempranos. Adicionalmente, si se tiene en cuenta el ya mencionado cambio de paradigma de la relación humano-animal que pondera evitar el sufrimiento innecesario y las exigencias de los comités internacionales para realizar experimentación con animales, el comportamiento resulta ser un excelente método de evaluación de efectos en el ámbito de la Ecotoxicología. Por último, se reitera el hecho de considerar a la especie $C$. ornata como modelo de estudio en Ecotoxicología para la realización de bioensayos de toxicidad en laboratorio, tanto por su facilidad para criarla en condiciones controladas como por su sensibilidad al plaguicida organofosforado evaluado. Esto nos invita a realizar a futuro otros bioensayos de evaluación de efectos subletales, tanto a nivel individual como sub-individual, para su posterior correlación con los efectos aquí abordados. 
A partir de los resultados presentados en el capítulo 1, se puede concluir que se logró criar individuos de $C$. ornata (Co) de todos los estadios del desarrollo e inclusive obtener huevos en cualquier época del año con una alta tasa de supervivencia, resultando esto último la clave para la cría de organismos en cautiverio. Es decir, se cumplió con el principal objetivo de dicho capitulo donde se planteaba desarrollar un protocolo de aclimatación y cría controlada en laboratorio de Co, implementando estándares de bioseguridad, higiene y bienestar animal, para su posterior inducción de la reproducción y el mantenimiento de individuos sanos a lo largo de todo el ciclo de vida. Dada la elevada efectividad del método de inducción artificial de la reproducción utilizado, se propone a AMPHIPLEX como herramienta de manejo reproductivo para la cría en cautiverio de anfibios autóctonos. Cabe destacar, que se logró aplicar el protocolo de cría en otras tres especies filogenéticamente relacionadas a Co, contribuyendo con su validación. En resumen, cuando las investigaciones in-situ resultan complejas de realizar, queda evidenciada la necesidad de criar organismos de manera ex-situ, siendo tal estrategia aún más necesaria cuando el objetivo del estudio es desarrollar un modelo, debiéndose garantizar la reproducción de una determinada especie en laboratorio. El mencionado protocolo de cría posee dos aplicaciones: (1) posibilita el desarrollo de futuras investigaciones ecotoxicológicas utilizando a la especie Co (evitando la extracción de individuos de la naturaleza) y (2) permite la implementación del modelo de estudio propuesto de manera concreta. Además, el protocolo podrá (en caso que se desee) ser aplicado con fines de conservación de ésta y otras especies de anfibios. Resulta interesante destacar que aún no se ha realizado la reintroducción de ejemplares de Co a la naturaleza, ya que se debe contar con más estudios acerca de los posibles sitios de reintroducción.

A partir del desarrollo del protocolo de cría, en el capítulo 2 se logró caracterizar el sonido producido por individuos de Co en distintos estadios del desarrollo, incluyendo larvas, juveniles y adultos. Cabe destacar que dicha caracterización resultó posible aún con escasos instrumentos de grabación. En este sentido, la interacción con especialistas en acústica del LAL-CIC permitió mejorar la grabación de sonidos en distintos medios (agua y aire) y la confiabilidad de tales grabaciones. Además, la calibración del método y su validación permitió proponer una herramienta de medición confiable para grabar no solo a la especie estudiada sino a otras especies de anfibios. La caracterización del sonido presentada en este capítulo resulta ser la primera que analiza la variación de los sonidos producidos desde fases tempranas del desarrollo larval y a lo largo de todo el ciclo vital. Los resultados obtenidos constituyen las bases para 
el desarrollo de una línea de investigación en sí (el estudio de los sonidos en etapa larval) con aplicaciones en el campo de la Acústica y la Biología de larvas de anuros.

A partir de la descripción del contexto de emisión de sonidos de larvas de Co en el capítulo 3, se concluye que las mismas emiten sonidos ante distintas interacciones, ya sea intraespecíficas o con un objeto. Si bien todas las observaciones y pruebas realizadas fueron de carácter descriptivo (no cuantitativo), las mismas permitieron hipotetizar con cierto grado de certeza que el aire empleado en la producción de sonidos durante estadios larvales proviene del estómago, pasa por la glotis (donde existiría una estructura resonante) y luego por la cavidad bucofaríngea (sin salir de la misma).

En este capítulo también se describe el mecanismo antipredatorio para larvas de la familia Ceratophryidae, el cual actúa disminuyendo la frecuencia de predación entre organismos conespecíficos ante la presencia de presas heteroespecíficas. A partir de observaciones producto de la cría de estas especies en cautiverio, se hipotetizó acerca de las posibles señales que podrían componer dicho mecanismo (Fig. 58). En tal sentido, el mecanismo podría estar compuesto por un rápido movimiento de la cola, más la emisión de sonidos, sumado a señales de reconocimiento químicas y visuales seguido de la huida (escape) de la presa del predador. El movimiento corporal, la emisión de sonidos y la huida de la presa del predador, resultan de fácil evaluación por determinación visual (presencial o mediante grabaciones de video y audio) de la interacción intraespecífica. De este modo, se evaluaron las señales intervinientes en el mecanismo antipredatorio de cada una de las especies de la familia Ceratophryidae estudiadas. Cabe aclarar que las señales química y visual no fueron evaluadas, debiéndose realizar a futuro tales estudios de comportamiento. A modo de comparación, para las larvas de Co, C. cranwelli $(C c)$ y $C$. aurita $(C a)$ en rol de presa se describió un rápido movimiento de la cola acompañado por la emisión de sonidos, seguido del escape de la presa del predador (Natale y col., 2011; Salgado Costa y col., 2014b). En cambio, si bien para L. Ilanensis (LI) también se describió un rápido movimiento de la cola seguido del escape de la presa del predador, no se registró la emisión de sonidos asociada (al menos en el rango de frecuencias evaluado; Salgado Costa y col., 2015). Más allá de las diferencias metodológicas, si se comparan los tres mecanismos se concluye que presentan el siguiente grado de eficiencia de mayor a menor: $\mathrm{Co}, \mathrm{Cc}, \mathrm{LI}$.

Los resultados obtenidos en el capítulo 3 sentaron las bases para la ampliación del modelo de estudio propuesto. Es decir, no solo se propone la realización de bioensayos de toxicidad con larvas de Co sino la evaluación de efectos en el sonido y en las interacciones como puntos finales ecotoxicológicos. Dentro de las posibles líneas futuras, se podrá profundizar sobre las implicancias biológicas, ecológicas y evolutivas del contexto y 
mecanismo de emisión y sobre el estudio de las interacciones biológicas de larvas de anfibios.

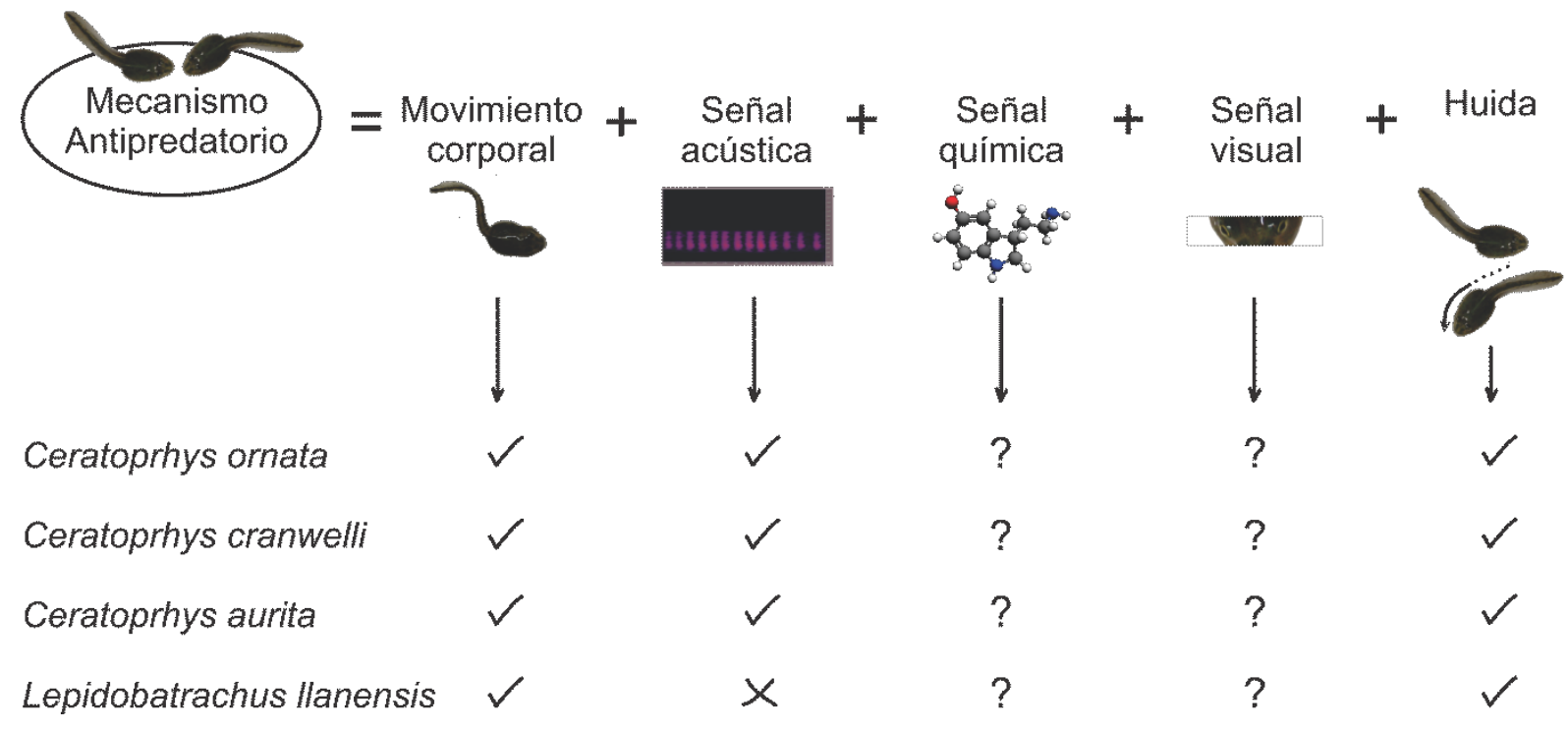

Figura 58. Posible modelo del mecanismo antipredatorio y observaciones realizadas para larvas de diferentes especies

En el capítulo 4, se registraron efectos letales y subletales, entre ellos mortalidad, alteraciones en la natación, presencia de anormalidades (LFLC y SFLC) e inhibición del crecimiento. Es la primera vez que se utiliza a la especie Co en bioensayos de toxicidad dentro del ámbito de la Ecotoxicología, resultando los bioensayos aquí realizados los primeros que evalúan los efectos de un determinado contaminante ambiental en esta especie. Estos bioensayos permitieron conocer la sensibilidad de la especie al CPF y su sensibilidad relativa respecto a otras especies de anuros autóctonos. En este capítulo se realizó el resumen e integración de la información existente sobre efectos y exposición del CPF mediante la herramienta de evaluación del riesgo ecológico y la contextualización de los resultados obtenidos Se concluye que el CPF implica un riesgo muy bajo para las distintas especies de anuros evaluadas, al menos al considerar la exposición ante concentraciones esperadas en el ambiente (ecosistemas acuáticos pampeanos). La especie seleccionada también demostró ser útil para la evaluación de efectos subletales, siendo las alteraciones en la natación (punto final comportamental) un buen biomarcador, ya que se anticipa a los demás puntos finales. Estos resultados constituyeron un paso fundamental para la aplicación del modelo propuesto y la contrastación de hipótesis enunciadas en el siguiente capítulo, mediante su validación con procedimientos ecotoxicológicos normalizados (bioensayos). 
Específicamente, en el capítulo 5 se puso a prueba el modelo experimental propuesto, en el cual se evaluó el sonido como punto final de efectos producidos por el CPF sobre larvas de Co, obteniendo resultados positivos. Es decir, resultó factible la realización de bioensayos y grabación de sonidos. Los datos obtenidos, analizados por los métodos propuestos, permitieron corroborar las hipótesis planteadas y demostrar que existen efectos en los sonidos. Esto último, validó finalmente al modelo propuesto. En particular, resulta posible contextualizar este punto final teniendo en cuenta las curvas realizadas para evaluar la correlación de efectos negativos. Es decir, a partir de la fig. 59, se puede observar que los efectos en el sonido aparecen junto con las alteraciones en la natación seguidos por la presencia de anormalidades, inhibición del crecimiento y por último mortalidad. Por lo tanto, teniendo en cuenta que un buen biomarcador debe ser específico de la respuesta que se está evaluando y que se espera que el mismo sea de alerta temprana, la cual está causalmente relacionada o es predictiva de efectos a largo plazo (Shugart $y$ col., 1992), se propone a los efectos en el sonido como un buen biomarcador de comportamiento. Los resultados obtenidos en éste y el precedente capítulo, permitirán a futuro la realización de más experimentos con el modelo propuesto. Además, permitirán incorporar en la evaluación al punto final interacciones, generando así un modelo completo de evaluación de efectos. Por todo lo antedicho, se propone a la especie como modelo experimental para su utilización en estudios ecotoxicológicos de evaluación de efectos de plaguicidas.

Finalmente, se considera que el trabajo de tesis brinda información de base sobre la ecotoxicología de una especie de anuro autóctona hasta el momento no utilizada. Presenta de manera clara el panorama actual de esta ciencia en Argentina, pudiéndose vislumbrar los posibles caminos a seguir. Muestra una relación entre las hipótesis planteadas y los resultados obtenidos, sustentado por una detallada y rigurosa metodología experimental. Plantea nuevas preguntas y enuncia nuevas hipótesis producto de la investigación. Y finalmente, aporta elementos para abordar la discusión acerca del posible empleo de anuros como indicadores de la contaminación, siendo ésta una de las posibles causas asociada con la disminución numérica de las poblaciones de anfibios a nivel global. 


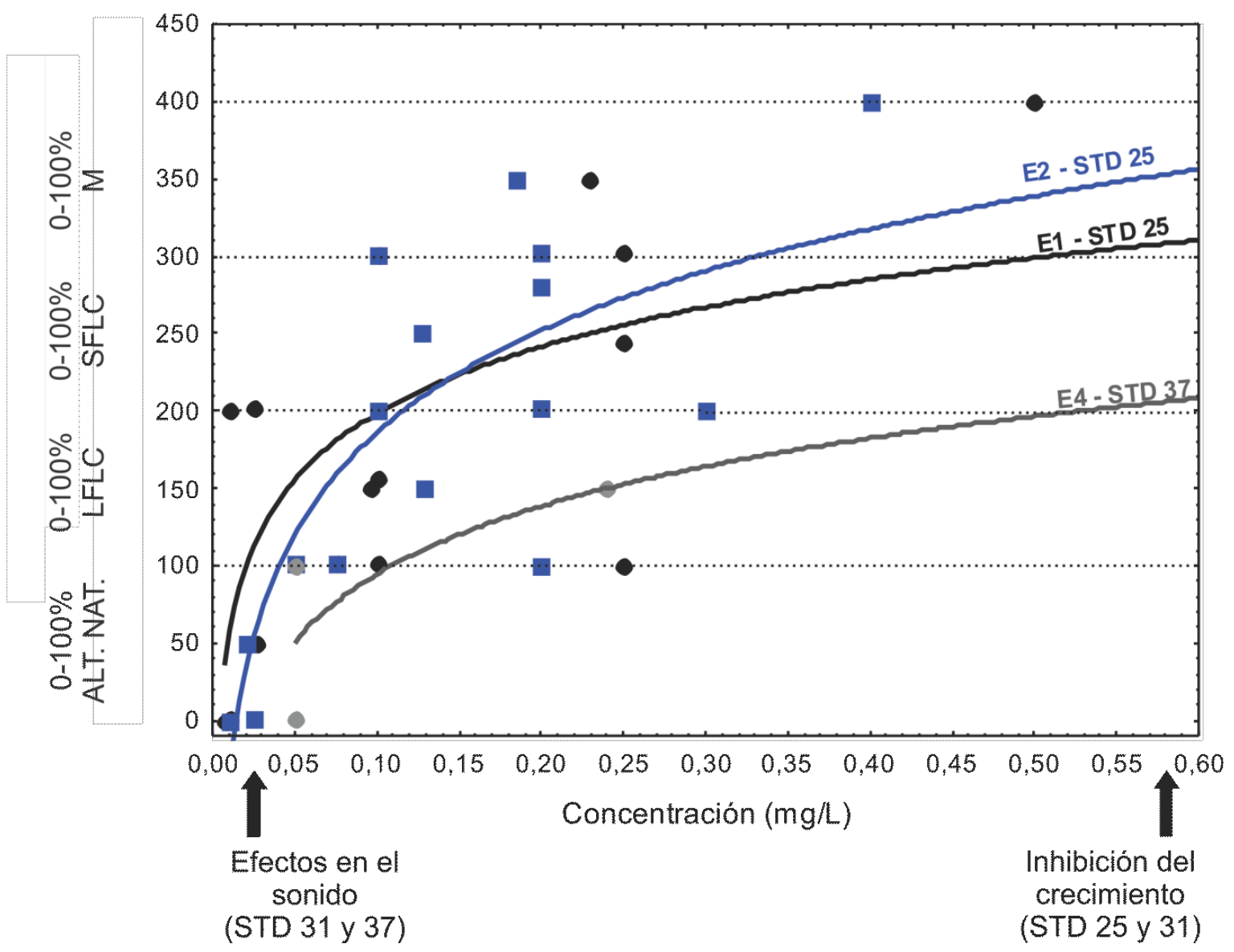

Figura 59. Análisis de correlación realizado para demostrar la progresión de efectos negativos del 0 al 100\%, desde la la aparición de alteraciones en la natación (ALT. NAT.), pasando por la presencia de una leve flexión lateral de la cola (LFLC), seguido por una severa flexión lateral de la cola (SFLC) culminando con la muerte (M) de los individuos, para los bioensayos (E) realizados en estadio (STD) 25,31 y 37 bajo exposiciones agudas. Solo se muestran las correlaciones significativas $(p<0,05)$. Con una flecha se indican las concentraciones a partir de las cuales se observan efectos en el sonidos e inhibición del crecimiento en determinados STD 


\section{REFERENCIAS}

AArk, Amphibian Ark (2010). http://www.amphibianark.org/assessmentresults/Rol de Investigacion Ex Situ Argentina.pdf.

AArk, Amphibian Ark (2014). http://aark.portal.isis.org/Amphibian Partnerships/default.aspx.

Abbasi, S. y R. Soni (1991). "Evaluation of water quality criteria for four common pesticides on the basis of computer-aided studies." Indian Journal of Environmental Health 33(1): 2224.

Agostini, M. G. (2013). Ecotoxicología de anfibios en agroecosistemas del noreste de la región Pampeana. Tesis doctoral de la Facultad de Ciencias Exactas, Universidad Nacional de la Plata.

Agostini, M. G., G. S. Natale y A. E. Ronco (2010). "Lethal and sublethal effects of cypermethrin to Hypsiboas pulchellus tadpoles." Ecotoxicology 19(8): 1545-1550.

Akmentins, M. S. y D. E. Cardozo (2010). "American bullfrog Lithobates catesbeianus (Shaw, 1802) invasion in Argentina." Biological Invasions 12(4): 735-737.

Akmentins, M., L. Pereyra, E. Sanabria y M. Vaira (2015). "Patterns of daily and seasonal calling activity of a direct-developing frog of the subtropical Andean forests of Argentina." Bioacoustics 24(2): 89-99.

Aldenberg, T. y J. S. Jaworska (2000). "Uncertainty of the hazardous concentration and fraction affected for normal species sensitivity distributions." Ecotoxicology and Environmental Safety 46(1): 1-18.

Aldenberg, T., J. S. Jaworska y T. P. Traas (2002). "Normal species sensitivity distributions and probabilistic ecological risk assessment." En: Posthuma L, Suter GW II y Traas TP (Eds.) Species sensitivity distributions in Ecotoxicology. Lewis Publishers, Boca Ratón, pp. 49-102.

Alperin, M. (2013). Introducción al análisis estadístico de datos geológicos, Editorial de la Universidad de La Plata, La Plata.

Alroy, J. (2015). "Current extinction rates of reptiles and amphibians." Proceedings of the National Academy of Sciences 112(42): 13003-13008.

AmphibiaWeb (2015). Information on amphibian biology and conservation. http://amphibiaweb.org/. (Ultimo acceso 22 de Junio de 2015).

Antwis, R. y R. Browne (2009). "Ultraviolet radiation and vitamin D3 in amphibian health, behaviour, diet and conservation." Comparative Biochemistry and Physiology Part A: Molecular and Integrative Physiology 154(2): 184-190.

Aparicio, V. C., E. De Gerónimo, D. Marino, J. Primost, P. Carriquiriborde y J. L. Costa (2013). "Environmental fate of glyphosate and aminomethylphosphonic acid in surface waters and soil of agricultural basins". Chemosphere 93(9): 1866-1873.

APHA, American Public Health Association (1998). Standard methods for the examination of water and wastewater. Baltimore: American Water Works Association. Water Pollution Control Federation.

Arellano, M. L., D. P. Ferraro, M. M. Steciow y E. O. Lavilla (2009). "Infection by the chytrid fungus Batrachochytrium dendrobatidis in the yellow belly frog Elachistocleis bicolor from Argentina." The Herpetological Journal 19(4): 217-220.

Arrieta, M., S. Peri, C. Apartin, C. Rosenberg, N. Fink y A. Salibian (2000). "Blood lead concentration and d-aminolevulinic acid dehydratase activity in adult Bufo arenarum." Archives of Physiology and Biochemistry 108(3): 275-280.

ASTM, American Society for Testing and Materials (1991). Standard Guide for conducting acute toxicity test with fishes, macroinvertebrates, and amphibians: E729-788A. 
Attademo, A. M., M. Cabagna-Zenklusen, R. C. Lajmanovich, P. M. Peltzer, C. Junges y A. Bassó (2011). "B-esterase activities and blood cell morphology in the frog Leptodactylus chaquensis (Amphibia: Leptodactylidae) on rice agroecosystems from Santa Fe province (Argentina)". Ecotoxicology 20(1): 274-282.

Attademo, A. M., P. M. Peltzer, R. C. Lajmanovich, M. C. Cabagna-Zenklusen, C. M. Junges y A. Basso (2014). "Biological endpoints, enzyme activities, and blood cell parameters in two anuran tadpole species in rice agroecosystems of mid-eastern Argentina." Environmental Monitoring and Assessment 186(1): 635-649.

Attademo, A. M., P. M. Peltzer, R. C. Lajmanovich, M. Cabagna y G. Fiorenza (2007). "Plasma B-esterase and glutathione S-transferase activity in the toad Chaunus schneideri (Amphibia, Anura) inhabiting rice agroecosystems of Argentina." Ecotoxicology 16(8): 533539.

Attademo, A. M., P. M. Peltzer, R. C. Lajmanovich, M. Cabagna-Zenklusen, C. M. Junges, E. Lorenzatti, C. Aró y P. Grenón (2015). "Biochemical changes in certain enzymes of Lysapsus limellium (Anura: Hylidae) exposed to chlorpyrifos." Ecotoxicology and Environmental Safety 113: 287-294.

Babini, M. S., C. L. Bionda, N. E. Salas y A. L. Martino (2015). "Health status of tadpoles and metamorphs of Rhinella arenarum (Anura, Bufonidae) that inhabit agroecosystems and its implications for land use." Ecotoxicology and Environmental Safety 118: 118-125.

Bantle, J. A. (1995). "FETAX—A developmental toxicity assay using frog embryos." En: Gary MR (Ed.) Fundamentals of aquatic toxicology: effects, environmental fate and risk assesment. $2^{\circ}$ ed., Taylor and Francis, Londres, pp. 207-230.

Bantle, J. A., J. N. Dumont, R. A. Finch y G. Linder (1996). Atlas of abnormalities: a guide for the performance of FETAX, Oklahoma State University, Stillwater.

Barrasso, D. A., R. Cajade, S. J. Nenda, G. Baloriani y R. Herrera (2009). "Introduction of the american bullfrog Lithobates catesbeianus (Anura: Ranidae) in natural and modified environments: an increasing conservation problem in Argentina." South American Journal of Herpetology 4(1): 69-75.

Barrio, A. (1963). "Consideraciones sobre comportamiento y "grito agresivo" propio de algunas especies de Ceratophryinidae (Anura)." Physis 24(67): 143-148.

Barrio, A. (1964). "Importancia, significación y análisis del canto de batracios anuros." Publicación conmemorativa del cincuentenario del Museo Provincial de Ciencias Naturales Florentino Ameghino, pp. 51-79.

Barrionuevo, J. S. y L. M. Ponssa (2008). "Decline of three species of the genus Telmatobius (Anura: Leptodactylidae) from Tucumán province, Argentina." Herpetologica 64(1): 47-62.

Basso, N. G. (1990). "Estrategias adaptativas de una comunidad subtropical de anuros." Cuadernos de Herpetología, Serie Monografías 1.

BBC, British Broadcasting Corporation (2010). Frog tadpoles "scream" underwater discover scientists. http://news.bbc.co.uk/earth/hi/earth_news/newsid_8609000/8609235.stm.

Begon, M., C. R. Townsend y J. L. Harper (2006). Ecology: from individuals to ecosystems. $4^{\circ}$ ed, Wiley-Blackwell, Nueva York.

Bell, T. (1843). Reptiles. The zoology of the voyage of the H.M.S. Beagle, under the command of captain Fitzroy, R.N., during the years 1832 to 1836. Smith, Elder and Company, Londres, Parte 5, pp. 1-51.

Bernabò, I., E. Sperone, S. Tripepi y E. Brunelli (2011). "Toxicity of chlorpyrifos to larval Rana dalmatina: acute and chronic effects on survival, development, growth and gill apparatus." Archives of Environmental Contamination and Toxicology 61(4): 704-718. 
Bionda, C., N. Salas y I. Di Tada (2008). "Effect of temperature on the advertisement call of the Physalaemus biligonigerus (Anura: Leptodactylidae)." Boletín de la Asociación Herpetológica Española 19: 19-22.

Birge, W., A. Westerman y J. Spromberg (2000). "Comparative toxicology and risk assessment of amphibians." En: Sparling DW, Linder G, Bishop CA y Krest SK (Eds.) Ecotoxicology of amphibians and reptiles. Taylor and Francis, Boca Raton, pp. 727-792.

Blaustein, A. R. (1988). "Ecological correlates and potential functions of kin recognition and kin association in anuran larvae." Behavior Genetics 18(4): 449-464.

Blaustein, A. R. y P. T. Johnson (2003). "The complexity of deformed amphibians." Frontiers in Ecology and the Environment 1(2): 87-94.

Blaustein, A. R., D. B. Wake y W. P. Sousa. (1994). "Amphibian declines: judging stability, persistence, and susceptibility of populations to local and global extinctions." Conservation Biology 8(1): 60-71.

Blaustein, A. R., y D. B. Wake (1995). "The puzzle of declining amphibian populations." Scientific American 272(4): 52-57.

Boistel, R. y J. Sueur (1997). "Comportement sonore de la femelle de Platymantis vitiensis (Amphibia, Anura) en l'absence du mâle." Comptes Rendus de l'Académie des SciencesSeries III-Sciences de la Vie 320(11): 933-941.

Bonfanti, P., A. Colombo, F. Orsi, I. Nizzetto, M. Andrioletti, R. Bacchetta, P. Mantecca, U. Fascio, G. Vailati and C. Vismara (2004). "Comparative teratogenicity of chlorpyrifos and malathion on Xenopus laevis development." Aquatic Toxicology 70(3): 189-200.

Boone, M. D. y R. D. Semlitsch (2001). "Interactions of an insecticide with larval density and predation in experimental amphibian communities." Conservation Biology 15(1): 228-238.

Bragg, A. N. (1964). "Further study of predation and cannibalism in spadefoot tadpoles." Herpetologica 20(1): 17-24.

Brailovsky, A. E. y D. Foguelman (1995). Memoria verde, historia ecológica de la Argentina, Editorial Sudamericana, Buenos Aires.

Bridges, C. M. (1999). "Predator-prey interactions between two amphibian species: effects of insecticide exposure." Aquatic Ecology 33(2): 205-211.

Britson, C. y S. Threlkeld (1998). "Abundance, metamorphosis, developmental, and behavioral abnormalities in Hyla chrysoscelis tadpoles following exposure to three agrichemicals and methyl mercury in outdoor mesocosms." Bulletin of Environmental Contamination and Toxicology 61(2): 154-161.

Brodeur, J. C., A. Sassone, G. N. Hermida y N. Codugnello (2013). "Environmentallyrelevant concentrations of atrazine induce non-monotonic acceleration of developmental rate and increased size at metamorphosis in Rhinella arenarum tadpoles." Ecotoxicology and Environmental Safety 92: 10-17.

Brodeur, J. C., G. Svartz, C. S. Perez-Coll, D. J. Marino y J. Herkovits (2009). "Comparative susceptibility to atrazine of three developmental stages of Rhinella arenarum and influence on metamorphosis: non-monotonous acceleration of the time to climax and delayed tail resorption." Aquatic Toxicology 91(2): 161-170.

Brodeur, J. C., J. Vera Candioti, S. Soloneski, M. L. Larramendy y A. E. Ronco (2012). "Evidence of reduced feeding and oxidative stress in common tree frogs (Hypsiboas pulchellus) from an agroecosystem experiencing severe drought." Journal of Herpetology 46(1): 72-78.

Brodeur, J. C., M. B. Poliserpi y M. Sánchez (2014). "Synergy between glyphosate-and cypermethrin-based pesticides during acute exposures in tadpoles of the common South American toad Rhinella arenarum." Chemosphere 112: 70-76. 
Brodeur, J. C., R. P. Suarez, G. S. Natale, A. E. Ronco y M. Elena Zaccagnini (2011). "Reduced body condition and enzymatic alterations in frogs inhabiting intensive crop production areas." Ecotoxicology and Environmental Safety 74(5): 1370-1380.

Brown, A., U. Martinez Ortiz, M. Acerbi y J. Corcuera (2006). La situación ambiental argentina 2005. Fundación Vida Silvestre Argentina.

Browne, R., J. Seratt, C. Vance y A. Kouba (2006). "Hormonal priming, induction of ovulation and in-vitro fertilization of the endangered Wyoming toad (Bufo baxteri)." Reproductive Biology and Endocrinology 4: 34.

Brunelli, E., I. Bernabò, C. Berg, K. Lundstedt-Enkel, A. Bonacci y S. Tripepi (2009). "Environmentally relevant concentrations of endosulfan impair development, metamorphosis and behaviour in Bufo bufo tadpoles." Aquatic Toxicology 91(2): 135-142.

Buikema Jr. A., B. Niederlehner y J. Cairns Jr. (1982). "Biological monitoring part IV—toxicity testing." Water Research 16(3): 239-262.

Burkhart, J. G., J. R. Bidwell, D. J. Fort y S. R. Sheffield (2003). "Chemical stressors". En: Linder G, Krest SK y Sparling DW (Eds.) Amphibian decline: an integrated analysis of multiple stressors effects. Society of Environmental Toxicology and Chemistry, pp. 111-128.

Bush, S. L. (1997). "Vocal behavior of males and females in the Majorcan midwife toad." Journal of Herpetology 31(2): 251-257.

Cabagna, M. C., R. C. Lajmanovich, P. M. Peltzer, A. M. Attademo y E. Ale (2006). "Induction of micronuclei in tadpoles of Odontophrynus americanus (Amphibia: Leptodactylidae) by the pyrethroid insecticide cypermethrin." Toxicological and Environmental Chemistry 88(4): 729-737.

Cajade, R. (2012). Ecología poblacional y relaciones interespecíficas de dos especies simpátricas del nordeste argentino: Physalaemus albonotatus y Physalaemus santafecinus (Anura: Leiuperidae). Tesis doctoral de la Facultad de Ciencias Naturales y Museo, Universidad Nacional de La Plata.

Cajade, R., E. F. Schaefer, M. I. Duré, A. I. Kehr y F. Marangoni (2010). "Reproductive biology of Argenteohyla siemersi pederseni Williams and Bosso, 1994 (Anura: Hylidae) in northeastern Argentina." Journal of Natural History 44(31-32): 1953-1978.

Calderon, M., P. González, M. Moglia, S. Oliva Gonzáles y M. Jofré (2014). "Use of multiple indicators to assess the environmental quality of urbanized aquatic surroundings in San Luis, Argentina." Environmental Monitoring and Assessment 186(7): 4411-4422.

Cappello, V. y N. Fortunato (2013). Plaguicidas en el territorio bonaerense: información toxicológica, ecotoxicológica y comportamiento ambiental. Informe de la Dirección Provincial de Recursos Naturales, Programa Gestión Ambiental en Agroecosistemas.

Carrasco, A. E., N. E. Sánchez, L. E. Tamagno y J. L. Frangi (2012). Modelo agrícola e impacto socioambiental en la Argentina: monocultivo y agronegocios. Asociación de Universidades Grupo Montevideo - Universidad Nacional de La Plata.

Carriquiriborde, P., J. Díaz, G. C. López, A. E. Ronco y G. M. Somoza (2009). "Effects of cypermethrin chronic exposure and water temperature on survival, growth, sex differentiation, and gonadal developmental stages of Odontesthes bonariensis (Teleostei)." Chemosphere 76(3): 374-380.

CASAFE, Cámara de Sanidad Agropecuaria y Fertilizantes (2012). Guía de productos fitosanitarios para la República Argentina. Buenos Aires.

Caswell, H. (1996). "Demography meets ecotoxicology: untangling the population level effects of toxic substances." En: Newman MC y Jagoe CH (Eds.) Ecotoxicology: a hierarchical treatment. Lewis Publishers, Boca Raton, pp. 255-292.

Cei, J. M. (1955). "Chacoan batrachians in central Argentina." Copeia 1955(4): 291-293. 
Cei, J. M. (1979). "Albinismo e canibalismo en larvas de Pleurodema nebulosa de la region precordillerana de la provincia de San Juan, Argentina (Anura, Leptodactylidae)." Publicaciones ocasionales del Instituto de Biología Animal. Universidad Nacional de Cuyo 11: 1-3.

Cei, J. M. (1980). Amphibians of Argentina. Monitore Zoologico Italiano, Universita degli studi di Firenze, Florencia.

Close, M. B., K. Banister, V. Baumans, E.-M. Bernoth, N. Bromage, J. Bunyan, W. Erhardt, P. Flecknell, N. Gregory y H. Hackbarth (1996). "Recommendations for euthanasia of experimental animals: Part 1." Laboratory Animals 30: 293-316.

Clulow, J., V. L. Trudeau y A. J. Kouba (2014). "Amphibian declines in the twenty-first century: Why we need assisted reproductive technologies." En: Holt WV, Brown JL y Comizzoli P (Eds.) Reproductive sciences in animal conservation. Progress and prospects. Springer, pp. 275-316.

Collins, J. P. y M. L. Crump (2009). Extinction in our times: global amphibian decline. Oxford University Press.

Cowman, D. y L. Mazanti (2000). "Ecotoxicology of "new generation" pesticides to amphibians." En: Sparling DW, Linder G, Bishop CA y Krest SK (Eds.) Ecotoxicology of amphibians and reptiles. Taylor and Francis, Boca Raton, pp. 233-268.

Crump, M. L. (1992). "Cannibalism in amphibians." En: Elgar MA, Crespi BJ (Eds.) Cannibalism: ecology and evolution among diverse taxa. Oxford University Press, pp. 256276.

Crupkin, A. C., P. Carriquiriborde, J. Mendieta, A. M. Panzeri, M. L. Ballesteros, K. S. B. Miglioranza y M. L. Menone (2013). "Oxidative stress and genotoxicity in the South American cichlid, Australoheros facetus, after short-term sublethal exposure to endosulfan." Pesticide Biochemistry and Physiology 105(2): 102-110.

De Gerónimo, E., V. C. Aparicio, S. Bárbaro, R. Portocarrero, S. Jaime y J. L. Costa (2014). "Presence of pesticides in surface water from four sub-basins in Argentina." Chemosphere 107: 423-431.

De la Torre, F. (2001). Estudio integrado de la contaminación acuática mediante bioensayos y parámetros fisiológicos y bioquímicos indicadores de estrés ambiental. Tesis doctoral de la Facultad de Ciencias Exactas y Naturales, Universidad de Buenos Aires.

De Vosjoli, P. (1990). The general care and maintenance of horned frogs. Advanced Vivarium Systems, California.

DeGarady, C. J. y R. S. Halbrook (2006). "Using anurans as bioindicators of PCB contaminated streams." Journal of Herpetology 40(1): 127-130.

Delgado, S. C., G. S. Natale, R. A. Herrera y D. A. Barraso (2012). "First record of Batrachochytrium dendrobatidis in Physalaemus fernandezae (Anura: Leiuperidae) for Buenos Aires province, Argentina." Herpetological Review 43(1): 84-85.

Demetrio, P. M. (2012). Estudio de efectos biológicos de plaguicidas utilizados en cultivos de soja RR y evaluación de impactos adversos en ambientes acuáticos de agroecosistemas de la región Pampeana. Tesis doctoral de la Facultad de Ciencias Exactas, Universidad Nacional de la Plata.

Demichelis, S., F. De La Torre, L. Ferrari, M. Garcia y A. Salibián (2001). "Tadpoles assay: its application to a water toxicity assessment of a polluted urban river." Environmental Monitoring and Assessment 68(1): 63-73.

Denoël, M., B. D'Hooghe, G. F. Ficetola, C. Brasseur, E. De Pauw, J.-P. Thomé y P. Kestemont (2012). "Using sets of behavioral biomarkers to assess short-term effects of pesticide: a study case with endosulfan on frog tadpoles." Ecotoxicology 21(4): 1240-1250. 
Di Marzio, W. D., M. E. Sáenz, J. L. Alberdi, N. Fortunato, V. Cappello, C. Montivero y G. Ambrini (2010). "Environmental impact of insecticides applied on biotech soybean crops in relation to the distance from aquatic ecosystems." Environmental Toxicology and Chemistry 29(9): 1907-1917.

Duellman, W. E. y L. Trueb (1994). Biology of Amphibians. Johns Hopkins University Press, Baltimore.

Duellman, W. E. y M. Lizana (1994). "Biology of a sit-and-wait predator, the leptodactylid frog Ceratophrys cornuta." Herpetologica 50(1): 51-64.

Duré, M. I., E. F. Schaefer y A. I. Kehr (2014). "Acoustic repertoire of Melanophryniscus cupreuscapularis (Céspedez and Álvarez 2000) (Anura: Bufonidae): advertisement, encounter, and release calls." Journal of Herpetology 49(1): 53-59.

EC, Environment Canada (1999). Guidance document on application and interpretation of single-species tests in environmental toxicology. Environmental Technology Centre, Environment Canada.

El-Merhibi, A., A. Kumar y T. Smeaton (2004). "Role of piperonyl butoxide in the toxicity of chlorpyrifos to Ceriodaphnia dubia and Xenopus laevis." Ecotoxicology and Environmental Safety 57(2): 202-212.

Elorriaga, Y., D. J. Marino, P. Carriquiriborde y A. E. Ronco (2013). "Human pharmaceuticals in wastewaters from urbanized areas of Argentina." Bulletin of Environmental Contamination and Toxicology 90(4): 397-400.

Emerson, S. B. y S. K. Boyd (1999). "Mating vocalizations of female frogs: control and evolutionary mechanisms." Brain Behavior and Evolution 53(4): 187-197.

Everest, F. A., y K. C. Pohlmann (2001). The master handbook of acoustics. $4^{\circ}$ ed, McGrawHill, Nueva York.

Fabrezi, M. (2006). "Morphological evolution of Ceratophryinae (Anura, Neobatrachia)." Journal of Zoological Systematics and Evolutionary Research 44(2): 153-166.

Fabrezi, M. (2011). "Heterochrony in growth and development in anurans from the Chaco of South America." Evolutionary Biology 38(4): 390-411.

Fabrezi, M. y S. I. Quinzio (2008). "Morphological evolution in Ceratophryinae frogs (Anura, Neobatrachia): the effects of heterochronic changes during larval development and metamorphosis." Zoological Journal of the Linnean Society 154(4): 752-780.

Faivovich, J. y G. Carrizo (1992). "Descripción de la larva de Chacophrys pierottii (Vellard, 1948) (Leptodactylidae, Ceratophryinae)." Alytes 10(3): 81-89.

Faivovich, J., L. Nicoli, B. L. Blotto, M. O. Pereyra, D. Baldo, J. S. Barrionuevo, M. Fabrezi, E. R. Wild y C. F. B. Haddad (2014). "Big, bad, and beautiful: phylogenetic relationships of the horned frogs (Anura: Ceratophryidae)." South American Journal of Herpetology 9(3): 207-227.

Feng, A. S., P. M. Narins, C.-H. Xu, W.-Y. Lin, Z.-L. Yu, Q. Qiu, Z.-M. Xu y J.-X. Shen (2006). "Ultrasonic communication in frogs." Nature 440: 333-336.

Fernández, K. y M. Fernández (1921). Sobre la biología y reproducción de algunos batracios argentinos I. Cystignathidae. Anales de la Sociedad Científica Argentina 91(1-6): 97-140.

Ferrari, L. y M. Vaira (2001). "Advertisement call and breeding activity of Physalaemus cuqui (Lobo, 1993)." Herpetological Bulletin 77: 20-22.

Ferrari, L. y M. Vaira (2008). "Análisis comparativo de la estructura del canto del anuncio de tres poblaciones de Melanophryniscus rubriventris (Vellar, 1947) (Anura: Bufonidae)." Cuadernos de Herpetología 22(1): 25-34.

Ferrari, L., S. Demichelis, M. García, F. De la Torre y A. Salibián (1997). "Premetamorphic anuran tadpoles as test organism for an acute aquatic toxicity assay." Environmental Toxicology and Water Quality 12(2): 117-121. 
Finney, D. (1971). Probit analysis. Cambridge University Press, Londres.

Fox, L. R. (1975). "Cannibalism in natural populations." Annual Review of Ecology and Systematics 6: 87-106.

Fox, S. F., A. L. Greer, R. Torres-Cervantes y J. P. Collins (2006). "First case of ranavirusassociated morbidity and mortality in natural populations of the South American frog Atelognathus patagonicus." Diseases of Aquatic Organisms 72(1): 87-92.

Fraker, M. E., F. Hu, V. Cuddapah, S. A. McCollum, R. A. Relyea, J. Hempel y R. J. Denver (2009). "Characterization of an alarm pheromone secreted by amphibian tadpoles that induces behavioral inhibition and suppression of the neuroendocrine stress axis." Hormones and Behavior 55(4): 520-529.

Frost, D. R. (2014). Amphibian species of the world: an online reference. Version 6.0. American Museum of Natural History New York. http://research.amnh.org/vz/herpetology/amphibia/.

Gaizick, L., G. Gupta y E. Bass (2001). "Toxicity of chlorypyrifos to Rana pipiens embryos." Bulletin of Environmental Contamination and Toxicology 66(3): 386-391.

Gallardo, J. M. (1974). Anfibios de los alrededores de Buenos Aires. Editorial Universitaria de Buenos Aires.

Gallardo, J. M. (1987). Anfibios Argentinos: guía para su identificación. Librería Agropecuaria, Buenos Aires.

Gallardo, J. M. y E. Varela de Olmedo (1992). "Anfibios de la República Argentina: ecología y comportamiento." En: Ringuelet RA (Ed.) Fauna de Agua Dulce de la Republica Argentina. Fundación para la Educación, la Ciencia y la Cultura, Buenos Aires, Parte 1, pp. 1-116.

Galloway, T., R. Brown, M. Browne, A. Dissanayake, D. Lowe, M. Jones y M. Depledge (2004). "A multibiomarker approach to environmental assessment." Environmental Science and Technology 38(6): 1723-1731.

Gascon, C., J. P. Collins, R. D. Moore, D. R. Church, J. E. McKay y J. R. Mendelson III (2007). Amphibian conservation action plan: proceedings IUCN/SSC Amphibian Conservation Summit 2005, IUCN.

Gerhardt, H. C. (1994). "The evolution of vocalization in frogs and toads." Annual Review of Ecology and Systematics 25: 293-324.

Ghirardi, R. (2012). Estudio de quitridiomicosis por Batrachochytrium dendrobatidis en anfibios anuros del Litoral, Cuyo y Patagonia Argentina. Tesis doctoral de la Facultad de Ciencias Naturales y Museo, Universidad Nacional de La Plata.

Gosner, K. L. (1960). "A simplified table for staging anuran embryos and larvae with notes on identification." Herpetologica 16(3): 183-190.

Grenat, P. R., J. A. Valetti y A. L. Martino (2013). "Intra-specific variation in advertisement call of Odontophrynus cordobae (Anura, Cycloramphidae): a multilevel and multifactor analysis." Amphibia-Reptilia 34(4): 471-482.

Günther, A. (1882). "Observations on some rare reptiles and a batrachian now or lately living in the Society's Menagerie." The Transactions of the Zoological Society of London 11(7): 215-222.

Guzy, J. C., E. D. McCoy, A. C. Deyle, S. M. Gonzalez, N. Halstead y H. R. Mushinsky (2012). "Urbanization interferes with the use of amphibians as indicators of ecological integrity of wetlands." Journal of Applied Ecology 49(4): 941-952.

Haas, A. (2003). "Phylogeny of frogs as inferred from primarily larval characters (Amphibia: Anura)." Cladistics 19(1): 23-89.

Hanken, J. (1993). "Model systems versus outgroups alternative approaches to the study of head development and evolution." American Zoologist 33(4): 448-456. 
Herkovits, J. y C. S. Perez Coll (1991). "Antagonism and synergism between lead and zinc in amphibian larvae." Environmental Pollution 69(2): 217-221.

Herkovits, J. y C. S. Perez Coll (1999a). "Bioensayos para test de toxicidad con embriones de anfibio: Parte 1." Ingeniería Sanitaria y Ambiental (Buenos Aires) 42: 24-30.

Herkovits, J. y C. S. Perez Coll (1999b). "Bioensayos para test de toxicidad con embriones de anfibio: Parte 2." Ingeniería Sanitaria y Ambiental (Buenos Aires) 43: 50-55.

Herrera, R. A., M. M. Steciow y G. S. Natale (2005). "Chytrid fungus parasitizing the wild amphibian Leptodactylus ocellatus (Anura: Leptodactylidae) in Argentina." Diseases of Aquatic Organisms 64(3): 247-252.

Hettyey, A., F. Roelli, N. Thuerlimann, A. C. Zürcher y J. Van Buskirk (2012). "Visual cues contribute to predator detection in anuran larvae." Biological Journal of the Linnean Society 106(4): 820-827.

Heyer, W. R., R. W. McDiarmid y D. L. Weigmann (1975). "Tadpoles, predation and pond habitats in the tropics." Biotropica 7(2): 100-111.

Hill, E. F. (1995). "Wildlife toxicology of organophosphorus and carbamate pesticides." En: Hoffman DJ, Rattner BA, Burton Jr. GA y Cairns J. Jr (Eds.) Handbook of Ecotoxicology. $2^{\circ}$ ed., Lewis Publishers, Boca Raton, pp. 281-312.

Hoff, K. vS., A. R. Blaustein, R. W. McDiarmid y R. Altig (1999). "Behavior: interactions and their consequences." En: McDiarmid RW y Altig R (Eds.) Tadpoles: the biology of anuran larvae. The University of Chicago Press, pp. 215-239.

Honegger, R., C. Schneider y E. Zimmermann (1985). "Notizen zur aufzucht von schmuckhornfröschen Ceratophrys ornata (Bell, 1843) (Salientia: Leptodactylidae)." Salamandra 21(1): 70-80.

Hota, A. K. (1994). "Growth in amphibians." Gerontology 40(2-4): 147-160.

Houlahan, J. E., C. S. Findlay, B. R. Schmidt, A. H. Meyer y S. L. Kuzmin (2000). "Quantitative evidence for global amphibian population declines." Nature 404: 752-755.

Hudson, W. H., R. B. C. Graham, F. Pozzo, C. R. de Pozzo, F. Mosca y G. M. Adams (1958). Allá lejos y hace tiempo, Editorial Kraft.

IUCN, International Union for Conservation of Nature (2008). An analysis of amphibians on the 2008 IUCN Red List. www.iucnredlist.org/amphibians.

James, C. (2010). Global status of commercialized biotech/GM crops: 2007. The International Service for the Acquisition of Agri-biotech Applications. Informe $N^{\circ} 37$.

Jara, F. G. y M. G. Perotti (2010). "Risk of predation and behavioural response in three anuran species: influence of tadpole size and predator type." Hydrobiologia 644(1): 313324.

Jayawardena, U. A., R. S. Rajakaruna, A. N. Navaratne y P. H. Amerasinghe (2010). "Toxicity of agrochemicals to common hourglass tree frog (Polypedates cruciger) in acute and chronic exposure." International Journal of Agriculture and Biology 12: 641-648.

Jefferson, D. M., K. A. Hobson, B. S. Demuth, M. C. Ferrari and D. P. Chivers (2014). "Frugal cannibals: how consuming conspecific tissues can provide conditional benefits to wood frog tadpoles (Lithobates sylvaticus)." Naturwissenschaften 101(4): 291-303.

Jergentz, S., H. Mugni, C. Bonetto y R. Schulz (2005). "Assessment of insecticide contamination in runoff and stream water of small agricultural streams in the main soybean area of Argentina." Chemosphere 61(6): 817-826.

Kelley, D. y M. Tobias (1999). "Vocal communication in Xenopus laevis." En: Hauser MD y Konishi M (Eds.) The design of animal communication. MIT Press, Cambridge.

Kerby, J. L. (2006). Pesticide effects on amphibians: A community ecology perspective. University of California, Davis. 
Kiesecker, J. M., D. P. Chivers y A. R. Blaustein (1996). "The use of chemical cues in predator recognition by western toad tadpoles." Animal Behaviour 52(6): 1237-1245.

Klaassen, C. D. (2008). Casarett and Doull's Toxicology: the basic science of poisons. McGraw-Hill Education, Nueva York.

Koestler, A. (1991). "Holons and hierarchy theory". En: Barlow C (Ed.) From Gaia to selfish genes: selected writings in the life sciences. MIT Press, pp. 88-100.

Kollros, J. J. y A. M. Bovbjerg (1997). "Growth and death of Rohon-Beard cells in Rana pipiens and Ceratophrys ornata." Journal of Morphology 232(1): 67-78.

Kouba, A. J., J. del Barco-Trillo, C. K. Vance, C. Milam y M. Carr (2012). "A comparison of human chorionic gonadotropin and luteinizing hormone releasing hormone on the induction of spermiation and amplexus in the American toad (Anaxyrus americanus)." Reproductive Biology and Endocrinology 10: 59.

Ladich, F. y A. H. Bass (2003). "Underwater sound generation and acoustic reception in fishes with some notes on frogs." En: Collin SP y Marshall NJ (Eds.) Sensory Processing in Aquatic Environments. Springer-Verlag, pp. 173-193.

Lajmanovich, R. C., A. M. Attademo, P. M. Peltzer, C. M. Junges y M. C. Cabagna (2011). "Toxicity of four herbicide formulations with glyphosate on Rhinella arenarum (Anura: Bufonidae) tadpoles: B-esterases and glutathione S-transferase inhibitors." Archives of Environmental Contamination and Toxicology 60(4): 681-689.

Lajmanovich, R. C., M. C. Cabagna-Zenklusen, A. M. Attademo, C. M. Junges, P. M. Peltzer, A. Bassó y E. Lorenzatti (2014). "Induction of micronuclei and nuclear abnormalities in tadpoles of the common toad (Rhinella arenarum) treated with the herbicides Liberty ${ }^{\circledR}$ and glufosinate-ammonium." Mutation Research/Genetic Toxicology and Environmental Mutagenesis 769: 7-12.

Lannoo, M. (1999). "Integration: nervous and sensory systems." En: McDiarmid RW y Altig R (Eds.) Tadpoles: the biology of anuran larvae. The University of Chicago Press, pp. 149169.

Lannoo, M. J., L. Lowcock y J. P. Bogart (1989). "Sibling cannibalism in noncannibal morph Ambystoma tigrinum larvae and its correlation with high growth rates and early metamorphosis." Canadian Journal of Zoology 67(8): 1911-1914.

Lascano, C. I., A. Ferrari y A. Venturino (2011). "Sublethal concentrations of azinphos-methyl induce biochemical and morphological alterations in Rhinella arenarum embryos." Chemistry and Ecology 27(6): 557-568.

Lavilla, E. O. (2001). "Amenazas, declinaciones poblacionales y extinciones en anfibios argentinos." Cuadernos de Herpetología 15(1): 59-82.

Lavilla, E. O. y H. Heatwole (2010). "Status of amphibian conservation and decline in Argentina." Amphibian Biology 9: 30-78.

Lavilla, E. O., M. L. Ponssa, D. Baldo, N. Basso, A. Bosso, J. Céspedez, J. C. Chebez, J. Faivovich, L. Ferrari y R. Lajmanovich (2000). "Categorización de los anfibios de Argentina: 11-34." En: Lavilla EO, Richard E y Scrocchi GJ (Eds.) Categorización de los anfibios y reptiles de la República Argentina. Asociación Herpetológica Argentina.

Lebboroni, M., G. Ricchiardino, M. Bellavita y G. Chelazzi (2006). "Potential use of anurans as indicators of biological quality in upstreams of central Italy." Amphibia-Reptilia 27(1): 7379.

Leguizamon, A. (2014). "Modifying Argentina: GM soy and socio-environmental change." Geoforum 53: 149-160.

Lescano, J. N. (2011). "Description of the advertisement and distress call of Chacophrys pierottii and comments on the advertisement call of Lepidobatrachus Ilanensis (Anura: Ceratophryidae)." Journal of Natural History 45(47-48): 2929-2938. 
Licht, P. (1979). "Reproductive endocrinology of reptiles and amphibians: gonadotropins." Annual Review of Physiology 41(1): 337-351.

Licht, P. y D. A. Porter (1987). "Role of gonadotropin-releasing hormone in regulation of gonadotropin secretion from amphibian and reptilian pituitaries." En: Norris DV y Jones RE (Eds.) Hormones and reproduction in fishes, amphibians, and reptiles. Plenum Press, pp. 61-85.

Licht, P., B. R. McCreery y R. Barnes (1983). "Relation between acute pituitary responsiveness to gonadotropin releasing hormone $(\mathrm{GnRH})$ and the ovarian cycle in the bullfrog, Rana catesbeiana." General and Comparative Endocrinology 51(1): 148-153.

Liendro, N., A. Ferraria, M. Mardirosian, C. I. Lascano y A. Venturino (2015). "Toxicity of the insecticide chlorpyrifos to the South American toad Rhinella arenarum at larval developmental stage." Environmental Toxicology and Pharmacology 39(2): 525-535.

Linder G., S. K. Krest y D. W. Sparling (2003). Amphibian decline: an integrated analysis of multiple stressors effects. Society of Environmental Toxicology and Chemistry.

Maneyro, R. y J. A. Langone (2001). "Categorización de los anfibios de Uruguay." Cuadernos de Herpetología 15(2): 107-118.

Manuel-Navarrete, D., G. Gallopín, M. Blanco, M. Díaz-Zorita, D. Ferraro, H. Herzer, P. Laterra, J. Morello, M. R. Murmis, W. Pengue y col. (2005). Análisis sistémico de la agriculturización en la pampa húmeda argentina y sus consecuencias en regiones extrapampeanas: sostenibilidad, brechas de conocimiento e integración de políticas. Naciones Unidas.

Marino, D. y A. Ronco (2005). "Cypermethrin and chlorpyrifos concentration levels in surface water bodies of the Pampa Ondulada, Argentina." Bulletin of Environmental Contamination and Toxicology 75(4): 820-826.

Markert, B. (1994). Environmental sampling for trace analysis. Wiley-Blackwell, Nueva York.

Mastrángelo, M., M. D. S. Afonso y L. Ferrari (2011). "Cadmium toxicity in tadpoles of Rhinella arenarum in relation to calcium and humic acids." Ecotoxicology 20(6): 1225-1232.

Maxson, L. R. y R. Ruibal (1988). "Relationships of frogs in the leptodactylid subfamily Ceratophryinae." Journal of Herpetology 22: 228-231.

McCarthy, J. F. y L. R. Shugart (1990). Biomarkers of environmental contamination. Lewis Publishers, Boca Raton.

McClanahan, L. L., V. H. Shoemaker y R. Ruibal (1976). "Structure and function of the cocoon of a ceratophryd frog." Copeia 1976(1): 179-185.

Medinsky, M. A. y J. L. Valentine (2001). "Toxicokinetics." En: Klaassen CD (Ed.) Casarett and Doull's Toxicology: the basic science of poisons. McGraw-Hill Education, pp. 225-238.

Mercadal de Barrio, I. T. y A. Barrio (2002). "Tetraploidy in Ceratophrys (Anura, Leptodactylidae), analysis of the fossil record." Iheringia, Série Zoologia 92(3): 17-31.

Michaels, C. J., B. F. Gini y R. F. Preziosi (2014). "The importance of natural history and species-specific approaches in amphibian ex-situ conservation." The Herpetological Journal 24(3): 135-145.

Moore, H., D. P. Chivers y M. C. Ferrari (2015). "Sub-lethal effects of Roundup ${ }^{\mathrm{TM}}$ on tadpole anti-predator responses." Ecotoxicology and Environmental Safety 111: 281-285.

Moriarty, F. (1983). Ecotoxicology: the study of pollutants in ecosystems. Academic Press.

Muenz, T. K., S. W. Golladay, G. Vellidis y L. L. Smith (2006). "Stream buffer effectiveness in an agriculturally influenced area, southwestern Georgia." Journal of Environmental Quality 35(5): 1924-1938.

Mugni, H., A. Ronco y C. Bonetto (2011). "Insecticide toxicity to Hyalella curvispina in runoff and stream water within a soybean farm (Buenos Aires, Argentina)." Ecotoxicology and Environmental Safety 74(3): 350-354. 
Nace, G. W., D. D. Culley, M. B. Emmons, E. L. Gibbs, V. H. Hutchinson y R. G. McKinnell (1974). Amphibians: guidelines for the breeding, care, and management of laboratory animals. National Academy of Sciences.

Natale, G. S. (2006). Análisis ecotoxicológico de una comunidad de anuros de la Región Pampeana. Tesis doctoral de la Facultad de Ciencias Naturales y Museo, Universidad Nacional de La Plata.

Natale, G. S. y C. Salgado Costa (2012). "Ceratophrys ornata (Bell, 1843). Escuerzo común." Ficha de los taxones en Categorización del estado de conservación de los anfibios de la República Argentina. Cuadernos de Herpetología 26(Suplemento 1): 131-159.

Natale, G. S., L. Alcalde, R. Herrera, R. Cajade, E. F. Schaefer, F. Marangoni y V. L. Trudeau (2011). "Underwater acoustic communication in the macrophagic carnivorous larvae of Ceratophrys ornata (Anura: Ceratophryidae)." Acta Zoologica 92(1): 46-53.

Natale, G. S., P. Saibene, C. Salgado Costa, R. Herrera y L. Alcalde (2008). "Descripción y comparación del grito agresivo emitido por $C$. ornata y $C$. cranwelli, desde la eclosión hasta la madurez sexual." Congreso Argentino de Herpetología, San Luis, Argentina.

Natale, G., L. Ammassari, N. Basso y A. Ronco (2006). "Acute and chronic effects of Cr (VI) on Hypsiboas pulchellus embryos and tadpoles." Diseases of Aquatic Organisms 72(3): 261-267.

Nebeker, A., G. Schuytema, W. Griffis y A. Cataldo (1998). "Impact of Guthion on survival and growth of the frog Pseudacris regilla and the salamanders Ambystoma gracile and Ambystoma maculatum." Archives of Environmental Contamination and Toxicology 35(1): 48-51.

Newman, M. C. (2013). Quantitative ecotoxicology. $2^{\circ}$ ed., Taylor and Francis Group.

Newman, M. C. y M. A. Unger (2003). Fundamentals of ecotoxicology. Lewis Press, Boca Raton.

Newman, M. C. y W. H. Clements (2008). Ecotoxicology: a comprehensive treatment. Taylor and Francis Group.

Pan, D. y X. Liang (1993). "Safety study of pesticides on bog frog, a predatory natural enemy of pest in paddy field." Journal of Hunan Agricultural College 19: 47-54.

Peltzer, P. M., C. M. Junges, A. M. Attademo, A. Bassó, P. Grenón y R. C. Lajmanovich (2013). "Cholinesterase activities and behavioral changes in Hypsiboas pulchellus (Anura: Hylidae) tadpoles exposed to glufosinate ammonium herbicide." Ecotoxicology 22(7): 11651173.

Peltzer, P. M., R. C. Lajmanovich, L. C. Sanchez, A. M. Attademo, C. M. Junges, C. L. Bionda, A. L. Martino y A. Basso (2011). "Morphological abnormalities in amphibian populations." Herpetological Conservation and Biology 6(3): 432-442.

Pengue, W. (2009). "Cuestiones económico-ambientales de las transformaciones agrícolas en las Pampas." Problemas del Desarrollo 40(157):137-161

Pengue, W. A. (2005). "Transgenic crops in Argentina: the ecological and social debt." Bulletin of Science, Technology and Society 25(4): 314-322.

Pereyra, M. O., J. D. Baldo y E. R. Krauczuk (2006). "La rana toro en la selva atlántica interior Argentina: un nuevo problema de conservación." Cuadernos de Herpetología 20(1): 37-40.

Pérez Coll, C. S., J. Herkovits y A. Salibián (1988). "Embryotoxicity of lead on Bufo arenarum." Bulletin of Environmental Contamination and Toxicology 41(2): 247-252.

Pérez Coll, C. y J. Herkovits (1990). "Stage dependent susceptibility to lead in Bufo arenarum embryos." Environmental Pollution 63(3): 239-245.

Pérez Coll, C., J. Herkovits y A. Salibián (1986). "Teratogenic effects of cadmium on Bufo arenarum during gastrulation." Experientia 42(10): 1174-1176. 
Pérez Iglesias, J. M., C. Ruiz de Arcaute, N. Nikoloff, L. Dury, S. Soloneski, G. S. Natale y M. L. Larramendy (2014). "The genotoxic effects of the imidacloprid-based insecticide formulation Glacoxan Imida on Montevideo tree frog Hypsiboas pulchellus tadpoles (Anura, Hylidae)." Ecotoxicology and Environmental Safety 104: 120-126.

Pérez Iglesias, J., S. Soloneski, N. Nikoloff, G. Natale y M. Larramendy (2015). "Toxic and genotoxic effects of the imazethapyr-based herbicide formulation Pivot $\mathrm{H}^{\circledR}$ on montevideo tree frog Hypsiboas pulchellus tadpoles (Anura, Hylidae)." Ecotoxicology and Environmental Safety 119: 15-24.

Pfennig, D. W. (1997). "Kinship and cannibalism: Understanding why animals avoid preying on relatives offers insights into the evolution of social behavior." Bioscience 47(10) 667675.

Pfennig, D. W. (1999). "Cannibalistic tadpoles that pose the greatest threat to kin are most likely to discriminate kin." Proceedings of the Royal Society of London. Series B: Biological Sciences 266(1414): 57-61.

Pistoni, J. y L. F. Toledo (2010). "Amphibian illegal trade in Brazil: what do we know?" South American Journal of Herpetology 5(1): 51-56.

PNUMA, Programa de las Naciones Unidas para el Medio Ambiente (1998). Decisión 18/32 sobre contaminantes orgánicos persistentes. http://www.chem.unep.ch/pops/POPs_Inc/INC_1/spanish/inf8.html.

Polis, G. A. (1981). "The evolution and dynamics of intraspecific predation." Annual Review of Ecology and Systematics 12: 225-251.

Polis, G. A. y C. A. Myers (1985). "A survey of intraspecific predation among reptiles and amphibians." Journal of Herpetology 19(1): 99-107.

Pollo, F. E., M. S. Babini, C. L. Bionda, N. E. Salas y A. L. Martino (2013). "Micronuclei and nuclear anormalities in anuran larvae from agroecosystems." Biocell 37(3): 119.

Poole, V. y S. Grow (2008). "Amphibian husbandry resource guide." Association of Zoos and Aquariums. A publication of AZA's Amphibian Taxon Advisory Group.

Posthuma, L., G. W. Suter II y T. P. Traas (2002). Species sensitivity distributions in ecotoxicology. Lewis Publishers, Boca Raton.

Power, T. (1989). Review and evaluation of the amphibian toxicological literature. Canadian Wildlife Service.

Pueta, M., F. B. Cruz y M. G. Perotti (2016). "Feeding regime and food availability determine behavioural decisions under predation risk in Pleurodema thaul (Anura: Leiuperidae) tadpoles." Herpetological Journal 26(1): 61-64.

Quinzio, S. I., M. Fabrezi y J. Faivovich (2006). "Redescription of the tadpole of Chacophrys pierottii (Vellard, 1948) (Anura, Ceratophryidae)." South American Journal of Herpetology 1(3): 202-209.

Radcliffe, C. W., D. Chiszar, K. Estep, J. B. Murphy y H. M. Smith (1986). "Observations on pedal luring and pedal movements in leptodactylid frogs." Journal of Herpetology 20(3): 300-306.

Raddi, G. (1823). "Continuazione della descrizione dei rettili Brasiliani." Memorie matematica et di fisica della Societa Italiana della Scienze. Modena 19: 58-73.

Rand, G. M. (1995). Fundamentals of aquatic toxicology: effects, environmental fate and risk assessment. Taylor and Francis Group.

Reeve, E., S. H. Ndriantsoa, A. Strauß, R.-D. Randrianiaina, T. R. Hiobiarilanto, F. Glaw, J. Glos y M. Vences (2011). "Acoustic underwater signals with a probable function during competitive feeding in a tadpole." Naturwissenschaften 98(2): 135-143.

Richards, S. M. (2000). Chlorpyrifos: exposure and effects in passerines and anurans. Tesis doctoral de Texas Tech University. 
Richards, S. M. y R. J. Kendall (2002). "Biochemical effects of chlorpyrifos on two developmental stages of Xenopus laevis." Environmental Toxicology and Chemistry 21(9): 1826-1835.

Roederer, J. G. (1997). Acústica y psicoacústica de la música. Ricordi Americana.

Ronco, A., G. B. Rossini, C. Sobrero, C. Apartin, G. Castillo, M. C. Díaz-Baez, A. E. Ramírez, I. Ahumada y J. Mendoza (2005). "The application of hazard assessment schemes using the watertox toxicity testing battery." En: Blaise C y Férard J-F (Eds.) Smallscale freshwater toxicity investigations. Springer, Vol. 1, pp. 233-255.

Ronco, A., G. Castillo y M. Díaz-Baez (2000). "Development and application of microbioassays for routine testing and biomonitoring in Argentina, Chile and Colombia." En: Persoone G, Janseen C y De Coen W (Eds.) New microbiotests for routine toxicity screening and biomonitoring. Springer, pp. 49-61.

Ronco, A., M. C. Díaz Báez y Y. Pica Granados (2004). "Conceptos generales." En: Castillo Morales G (Ed.) Ensayos toxicológicos y métodos de evaluación de calidad de aguas: estandarización, intercalibración, resultados y aplicaciones. Instituto Mexicano de Tecnología del Agua, pp. 17-22

Ronco, A., P. Carriquiriborde, G. S. Natale, M. L. Martin, H. Mugni y C. Bonetto (2008). "Integrated approach for the assessment of biotech soybean pesticides impact on low order stream ecosystems of the Pampasic region." En: Chen J y Guo C (Eds.) Ecosystem ecology research. Nova Science Publishers Inc., pp. 209-239.

Rosenberg, C. E., A. Salibián y N. E. Fink (2002). "An enzyme-linked immunosorbent assay for measuring anti-sheep red blood cells antibodies in lead-exposed toads." Journal of Pharmacological and Toxicological Methods 47(2): 121-128.

Rovedatti, M., P. Castañé, M. Topalián y A. Salibián (2001). "Monitoring of organochlorine and organophosphorus pesticides in the water of the Reconquista River (Buenos Aires, Argentina)." Water Research 35(14): 3457-3461.

Roy, D., B. Borah y A. Sarma (1995). "Analysis and significance of female reciprocal call in frogs." Current Science 69(3): 265-270.

Rugh, R. (1962). Experimental embryology: techniques and procedures. Burgess Publishing Company, Minneapolis.

Ruibal, R. y E. Thomas (1988). "The obligate carnivorous larvae of the frog, Lepidobatrachus laevis (Leptodactylidae)." Copeia 1988(3): 591-604.

Ruiz de Arcaute, C., C. Salgado Costa, P. M. Demetrio, G. S. Natale y A. E. Ronco (2012). "Influence of existing site contamination on sensitivity of Rhinella fernandezae (Anura, Bufonidae) tadpoles to Lorsban ${ }^{\circledR} 48 \mathrm{E}$ formulation of chlorpyrifos." Ecotoxicology 21(8): 2338-2348.

Saibene, P., C. Salgado Costa y G. S. Natale (2009). "Descripción y comparación del movimiento pedal en tres especies del género Ceratophrys." X Congreso Argentino de Herpetología, Jujuy, Argentina.

Saidapur, S. K., D. K. Veeranagoudar, N. C. Hiragond y B. A. Shanbhag (2009). "Mechanism of predator-prey detection and behavioral responses in some anuran tadpoles." Chemoecology 19(1): 21-28.

Salgado Costa, C. y G. S. Natale (2011). "Registro y descripción del sonido subacuático emitido por larvas de Ceratophrys aurita (Anura: Ceratophryidae)." XII Congreso Argentino de Herpetología, Bariloche, Argentina.

Salgado Costa, C., A. E. Ronco y G. S. Natale (2014a). "Emisión de sonidos en hembras de Ceratophrys ornata." XV Congreso Argentino de Herpetología, Mendoza, Argentina. 
Salgado Costa, C., M. Chuliver Pereyra, L. Alcalde, R. Herrera, V. L. Trudeau y G. S. Natale (2014b). "Underwater sound emission as part of an antipredator mechanism in Ceratophrys cranwelli tadpoles." Acta Zoologica 95(3): 367-374.

Salgado Costa, C., V. L. Trudeau, A. E. Ronco y G. S. Natale (2015). "Exploring antipredator mechanisms: new findings in ceratophryid tadpoles." Journal of Herpetology (en prensa). DOI: $10.1670 / 14-179$.

Salibián, A. (2006). "Ecotoxicological assessment of the highly polluted Reconquista River of Argentina." En: De Voogt P (Ed.) Reviews of environmental contamination and toxicology. Springer, pp. 35-65.

Salibián, A. (2015). "Reflexiones acerca de la Ecotoxicología que viene." Ciencia e Investigación 65(2): 79-88.

Sanabria, E., Y. Ripoll, M. Jordan, L. Quiroga, M. Ariza, M. Guillemain, M. Pérez y H. Chávez (2011). "A new record for American Bullfrog (Lithobates catesbeianus) in San Juan, Argentina." Revista Mexicana de Biodiversidad 82(1): 311-313.

SAyD, Secretaría de Ambiente y Desarrollo Sustentable (2007). Informe sobre deforestación en Argentina. Unidad de Manejo del Sistema de Evaluación Forestal.

Schalk, C. M., C. G. Montaña, J. L. Klemish y E. R. Wild (2014). "On the diet of the frogs of the Ceratophryidae: synopsis and new contributions." South American Journal of Herpetology 9(2): 90-105.

Segura, L. M. S. y J. A. L. Arriaga (2003). Principios básicos de contaminación ambiental. Universidad Autónoma del Estado de México.

Sewell, D. y Griffiths, R. A. (2009). "Can a single amphibian species be a good biodiversity indicator?" Diversity 1(2): 102-117.

Shugart, L. R., J. F. McCarthy y R. S. Halbrook (1992). "Biological markers of environmental and ecological contamination: an overview." Risk Analysis 12(3): 353-360.

Sodhi, N. S., D. Bickford, A. C. Diesmos, T. M. Lee, L. P. Koh, B. W. Brook, C. H. Sekercioglu y C. J. Bradshaw (2008). "Measuring the meltdown: drivers of global amphibian extinction and decline." Plos One 3(2): e1636.

Sotomayor, V., C. Lascano, A. M. Pechen de D'Angelo y A. Venturino (2012). "Developmental and polyamine metabolism alterations in Rhinella arenarum embryos exposed to the organophosphate chlorpyrifos." Environmental Toxicology and Chemistry 31(9): 2052-2058.

Sotomayor, V., T. S. Chiriotto, A. M. Pechen de D'Angelo y A. Venturino (2015). "Biochemical biomarkers of sublethal effects in Rhinella arenarum late gastrula exposed to the organophosphate chlorpyrifos." Pesticide Biochemistry and Physiology 119: 48-53

Sparling, D. W. y G. M. Fellers (2009). "Toxicity of two insecticides to California, USA, anurans and its relevance to declining amphibian populations." Environmental Toxicology and Chemistry 28(8): 1696-1703.

Sparling, D. W., G. Linder, C. A. Bishop y S. Krest (2010). Ecotoxicology of amphibians and reptiles. CRC Press.

Sparling, D. y G. Fellers (2007). "Comparative toxicity of chlorpyrifos, diazinon, malathion and their oxon derivatives to larval Rana boylii." Environmental Pollution 147(3): 535-539.

Sparling, D., C. A. Bishop y G. Linder (2000). The current status of amphibian and reptile ecotoxicological research,.SETAC Press, Pensacola.

Sprague, J. (1995). "Factors that modify toxicity." En: Rand GM (Ed.) Fundamentals of aquatic toxicology: effects, environmental fate and risk assessment. Taylor and Francis Group, pp. 1012-1051.

Stauffer, H.-P. y R. D. Semlitsch (1993). "Effects of visual, chemical and tactile cues of fish on the behavioural responses of tadpoles." Animal Behaviour 46(2): 355-364. 
Stebbins, R. C. y N. W. Cohen (1995). A natural history of amphibians. Princeton University Press.

SubAgr, Subsecretaria de Agricultura (2014). Estimaciones Agrícolas. Ministerio de Agricultura, $\quad$ Ganadería $\quad y \quad$ Pesca. http://www.agroindustria.gob.ar/site/agricultura/informacion_agropecuaria/index.php

Suter II, G. W. (1999). "Developing conceptual models for complex ecological risk assessments." Human and Ecological Risk Assessment: An International Journal 5(2): 375396.

Svartz, G. V., J. Herkovits y C. S. Pérez Coll (2012). "Sublethal effects of atrazine on embryo-larval development of Rhinella arenarum (Anura: Bufonidae)." Ecotoxicology 21(4): 1251-1259.

Svartz, G., C. Aronzon and C. Pérez Coll (2016). "Comparative sensitivity among early life stages of the South American toad to cypermethrin-based pesticide." Environmental Science and Pollution Research 23(3): 2906-2913.

Tobias, M. L., S. S. Viswanathan y D. B. Kelley (1998). "Rapping, a female receptive call, initiates male-female duets in the South African clawed frog." Proceedings of the National Academy of Sciences 95(4): 1870-1875.

Toledo, L. F., C. F. B. Haddad (2009). "Defensive vocalizations of Neotropical anurans." South American Journal of Herpetology 4(1): 25-42.

Toledo, L. F., I. Sazima y C. F. Haddad (2011). "Behavioural defences of anurans: an overview." Ethology Ecology and Evolution 23(1): 1-25.

Trudeau, V. L., G. M. Somoza, G. S. Natale, B. Pauli, J. Wignall, P. Jackman, K. Doe y F. W. Schueler (2010). "Hormonal induction of spawning in 4 species of frogs by coinjection with a gonadotropin-releasing hormone agonist and a dopamine antagonist." Reproductive Biology and Endocrinology 8(1): 36.

Truhaut, R. (1977). "Ecotoxicology: objectives, principles and perspectives." Ecotoxicology and Environmental Safety 1(2): 151-173.

Úbeda, C. y D. Grigera (2007). "El grado de protección de los anfibios patagónicos de Argentina." Ecología Austral 17: 269-279.

Ulloa Kreisel, Z. E. (2001). "Metamorfosis del aparato digestivo de larvas carnívoras de Ceratophrys cranwelli (Anura: Leptodactylidae)." Cuadernos de Herpetología 14(2): 105116.

USDA, United States Department of Agriculture (2015). Foreign Agricultural Service. http://apps.fas.usda.gov/psdonline. (Último acceso 15 Junio de 2015).

USEPA, United States Environmental Protection Agency (1989). Short-term methods for estimating the chronic toxicity of effluents and receiving waters to freshwater organisms. Washington, DC.

USEPA, United States Environmental Protection Agency (1991). Technical support document for water quality-based toxics control. Washington, DC.

USEPA, United States Environmental Protection Agency (1998). Guidelines for ecological risk assessment. Washington, DC.

Vaira, M., L. Ferrari y M. S. Akmentins (2011). "Vocal repertoire of an endangered marsupial frog of Argentina, Gastrotheca christiani (Anura: Hemiphractidae)." Herpetology Notes 4: 279-284.

Vaira, M., M. Akmentins, M. Attademo, D. Baldo, D. A. Barrasso, S. Barrionuevo, N. G. Basso, B. L. Blotto, S. Cairo y R. Cajade y col. (2012). "Categorización del estado de conservación de los anfibios de la República Argentina." Cuadernos de Herpetología 26(Supl. 1): 131-159. 
Valetti, J. A., N. E. Salas y A. L. Martino (2013). "Bioacústica del canto de advertencia de Ceratophrys cranwelli (Anura: Ceratophrydae)." Revista de Biología Tropical 61(1): 273280.

Van Buskirk, J. (2001). "Specific induced responses to different predator species in anuran larvae." Journal of Evolutionary Biology 14(3): 482-489.

van Straalen, N. M. (2002). "Threshold models for species sensitivity distributions applied to aquatic risk assessment for zinc." Environmental Toxicology and Pharmacology 11(3): 167172.

van Vlaardingen, P. L. A., T. Traas, A. Wintersen y T. Aldenberg (2005). "ETX 2.0. A program to calculate hazardous concentrations and fraction affected, based on normally distributed toxicity data." Rivm Repository.

Venturino, A., E. Rosenbaum, A. Caballero De Castro, O. L. Anguiano, L. Gauna, T. Fonovich De Schroeder y A. M. Pechen de D'Angelo (2003). "Biomarkers of effect in toads and frogs." Biomarkers 8(3-4): 167-186.

Venturino, A., L. Gauna, R. M. Bergoc y A. M. Pechen de D'Angelo (2001). "Toxicokinetics of malathion in larval stages of the toad Bufo arenarum (Hensel): Effect of exogenous spermidine." Pesticide Biochemistry and Physiology 70(3): 142-150.

Vera Candioti, J., G. S. Natale, S. Soloneski, A. E. Ronco y M. L. Larramendy (2010). "Sublethal and lethal effects on Rhinella arenarum (Anura, Bufonidae) tadpoles exerted by the pirimicarb-containing technical formulation insecticide Aficida ${ }^{\circledR} . "$ Chemosphere $78(3)$ : 249-255.

Vignati, D. A., B. J. Ferrari y J. Dominik (2007). "Laboratory-to-field extrapolation in aquatic sciences." Environmental Science and Technology 41(4): 1067-1073.

von Bertalanffy, L. (1934). "Untersuchungen über die Gesetzlichkeit des Wachstums." Development Genes and Evolution 131(4): 613-652.

Wacksman, M., J. Maul y M. Lydy (2006). "Impact of atrazine on chlorpyrifos toxicity in four aquatic vertebrates." Archives of Environmental Contamination and Toxicology 51(4): 681689.

Walker, C., S. Hopkin, R. Sibly y D. Peakall (2006). Principles of ecotoxicology. Taylor and Francis Group.

Walters, B. (1975). "Studies of interspecific predation within an amphibian community." Journal of Herpetology 9(3): 267-279.

Wassersug, R. J. y W. R. Heyer (1988). A survey of internal oral features of leptodactyloid larvae (Amphibia: Anura). Smithsonian Institution Press.

Watson, F. L., H. Schmidt, Z. K. Turman, N. Hole, H. Garcia, J. Gregg, J. Tilghman y E. A. Fradinger (2014). "Organophosphate pesticides induce morphological abnormalities and decrease locomotor activity and heart rate in Danio rerio and Xenopus laevis." Environmental Toxicology and Chemistry 33(6): 1337-1345.

Watts, M. (2012). Chlorpyrifos as a possible global POP. Pesticide Action Network North America. www. pan-europe. info/News/PR/121009_Chlorpyrifos_as_POP_final. pdf.

Westerman, A., A. Wigginton, D. Price, G. Linder y W. Birge (2003). "Integrating amphibians into ecological risk assessment strategies." En: Linder G, Krest SK y Sparling DW (Eds.) Amphibian decline: an integrated analysis of multiple stressors effects. Society of Environmental Toxicology and Chemistry, pp. 283-313.

WHO, World Health Organization (2010). Código internacional de conducta sobre la distribución y utilización de plaguicidas. Directrices para el registro de plaguicidas.

Widder, P. D. y J. R. Bidwell (2008). "Tadpole size, cholinesterase activity, and swim speed in four frog species after exposure to sub-lethal concentrations of chlorpyrifos." Aquatic Toxicology 88(1): 9-18. 
Wijesinghe, M., M. Bandara, W. Ratnasooriya y G. Lakraj (2011). "Chlorpyrifos-induced toxicity in Duttaphrynus melanostictus (Schneider 1799) larvae." Archives of Environmental Contamination and Toxicology 60(4): 690-696.

Wild, E. R. (1997). "Description of the adult skeleton and developmental osteology of the hyperossified horned frog, Ceratophrys cornuta (Anura: Leptodactylidae)." Journal of Morphology 232: 169-206.

WWF, World Wide Fund for Nature (2014). Living Planet Report 2014: species and spaces, people and places. http://wwf.panda.org/about_our_earth/all_publications/living_planet_report/

Yager, D. D. (1992). "Underwater acoustic communication in the African pipid frog Xenopus borealis." Bioacoustics 4(1): 1-24.

Yin, X., G. Zhu, X. B. Li y S. Liu (2009). "Genotoxicity evaluation of chlorpyrifos to amphibian Chinese toad (Amphibian: Anura) by comet assay and micronucleus test." Mutation Research/Genetic Toxicology and Environmental Mutagenesis 680(1): 2-6.

Young, B. E., S. N. Stuart, J. S. Chanson, N. A. Cox y T. M. Boucher (2004). Disappearing jewels: the status of new world amphibians. NatureServe.

Zar, J. H. (2010). Biostatistical analysis. $5^{\circ}$ ed., Pearson Education Inc. Upper Saddle River, Nueva Jersey.

Zippel, K., R. Lacy y O. Byers (2006). CBSGMAZA amphibian ex situ conservation planning workshop final report. IUCN/SSC Conservation Breeding Specialist Group. http://www.amphibianark.org/pdf/Ex_Situ_Planning_Workshop_Report.pdf. 


\section{Presentaciones a congresos}

1. Salgado Costa C. y G. S. Natale (2011). "Registro y descripción del sonido subacuático emitido por larvas de Ceratophrys aurita (Anura: Ceratophryidae)." Presentado en el XII Congreso Argentino de Herpetología realizado del 19 al 22 de Septiembre en San Carlos de Bariloche, Argentina. Tipo de presentación: póster.

2. Trudeau V.L., F. W. Schueler, G. M. Somoza, G. S. Natale, C. Salgado Costa, D. Thoney y D. McGinnity (2012). "Hormonal control of spawning in amphibians." Presentado en el World Congress of Herpetology, University of British Columbia, realizado del 8 al 14 de Agosto en Vancouver, Canadá. Tipo de presentación: oral.

3. Salgado Costa C., G. S. Natale, F. lasi, N. Vechiatti, C. Posse y A. E. Ronco (2012). "Caracterización y descripción del sonido emitido por larvas de Ceratophrys ornata (Anura: Ceratophryidae): experiencia de investigación interdiciplinaria." Presentado en el XIII Congreso Argentino de Herpetología realizado del 6 al 9 de Noviembre en la Ciudad de Mar del Plata, Argentina. Tipo de presentación: oral.

4. Salgado Costa C., G. S. Natale y A. E. Ronco (2012). "Reconocimiento intraespecífico en larvas de Ceratophrys ornata y Lepidobatrachus Ilanensis (Anura: Ceratophryidae)." Presentado en el XIII Congreso Argentino de Herpetología realizado 6 al 9 de Noviembre en la Ciudad de Mar del Plata, Argentina. Tipo de presentación: póster.

5. Salgado Costa, C., G. S. Natale, V. L Trudeau y A. E. Ronco (2012). "Reconocimiento intraespecífico en larvas de Ceratophrys ornata (Anura: Ceratophryidae)." Presentado en el VII Encuentro Anual Biólogos en Red 2012 realizado del 15 al 16 de Noviembre en la Ciudad de Mar del Plata, Argentina. Tipo de presentación: póster. Distinguido para realizar una presentación oral del póster. Premio al mejor póster BER 2012.

6. Salgado Costa C., M. L. Fabrega, S. A. Olguin, G. S. Natale y A. E. Ronco (2013). "Efecto del UVB sobre el crecimiento y desarrollo óseo de Ceratophrys ornata (Anura: Ceratophryidae)." Presentado en XIV Congreso Argentino de Herpetología realizado del 17 al 20 de Septiembre en Puerto Madryn, Argentina. Tipo de presentación: póster.

7. Salgado Costa C., G. S. Natale, V. L. Trudeau y A. E. Ronco (2013). "Estudios bioecológicos con larvas de Ceratophrys ornata: descifrando el contexto de la emisión de sonidos subcuáticos, su relevancia, estado de la investigación y aplicaciones." Presentado en las $\mathrm{V}$ Jornadas de Jóvenes Investigadores y II Jornadas de Jóvenes Extensionistas realizadas en la Facultad de 
Ciencias Naturales y Museo de la UNLP del 21 al 23 de Agosto en La Plata, Argentina. Tipo de presentación: oral.

8. Salgado Costa C., A.E Ronco y G. S. Natale (2014). "Emisión de sonidos en hembras de Ceratophrys ornata." Presentado en el XV Congreso Argentino de Herpetología realizado del 7 al 10 de Octubre en Mendoza, Argentina. Tipo de presentación: póster.

9. Salgado Costa C., G. S. Natale, V. L. Trudeau y A. E. Ronco (2014). "Sensibilidad de larvas de Ceratophrys ornata (Anura: Ceratophryidae) al clorpirifos." Presentado en el V Congreso Argentino de SETAC "Producción Sustentable y Compromiso Social para el Cuidado del Ambiente" realizado del 22 al 25 de Octubre en Neuquén, Argentina. Tipo de presentación: póster.

10. Salgado Costa C., V. L. Trudeau, A. E Ronco y G. S. Natale (2014). "Effects of chlorpyrifos on the sound emitted by tadpoles of Ceratophrys ornata (Anura: Ceratophryidae)." Presentado en las XIV Jornadas Anuales de la Sociedad Argentina de Biología realizadas del 1 al 3 de Diciembre en Chascomús, Argentina. Tipo de presentación: póster. Mención al mejor trabajo de la mesa temática Ecología, Toxicología y Comportamiento II.

11. Vechiatti N., F. lasi, C. Posee, C. Salgado Costa y G. S. Natale (2015). "Bioacústica de anuros: medición en cámara anecoica de sonidos emitidos por larvas." Presentado en el XIII Congreso Argentino de Acústica. VII Jornadas de Acústica, Electroacústica y Áreas Vinculadas realizadas del 29 al 30 de Octubre en Buenos Aires, Argentina. Tipo de presentación: póster.

\section{Publicaciones científicas}

1. Natale, G. S. y C. Salgado Costa (2012). "Ceratophrys ornata (Bell, 1843). Escuerzo común." Ficha de los taxones en Categorización del estado de conservación de los anfibios de la República Argentina. Cuadernos de Herpetología 26(Suplemento 1): 131-159.

2. Salgado Costa, C., M. Chuliver Pereyra, L. Alcalde, R. Herrera, V. L. Trudeau y G. S. Natale (2014). "Underwater sound emission as part of an antipredator mechanism in Ceratophrys cranwelli tadpoles." Acta Zoologica 95(3): 367-374.

3. Salgado Costa, C., V. L. Trudeau, A. E. Ronco y G. S. Natale (2015). "Exploring antipredator mechanisms: New findings in ceratophryid tadpoles." Journal of Herpetology (en prensa). DOI: 10.1670/14-179. 


\section{Observaciones de comportamiento relacionadas con la inducción de la reproducción}

Con la finalidad de cuantificar variables relacionadas a la reproducción de individuos adultos de C. ornata, se realizaron observaciones directas y grabaciones de audio y video simultáneas del acto reproductivo (tiempo total de grabación $=6 \mathrm{~h}$ ). Las grabaciones de audio se realizaron con el mismo sistema y metodología utilizados para grabar larvas de esta especie (ver capítulo 2, página 71). Se realizó un análisis del oscilograma (duración del sonido en segundos / amplitud en pascales) y sonograma (duración del sonido / frecuencia en Hertz) de cada sonido obtenido mediante el programa Adobe Audition ${ }^{\circledR} 1.5$ (Adobe Systems Inc.), midiendo de forma manual diferentes variables bioacústicas, entre ellas duración del sonido en segundos (Ds, s), duración del inter-sonido (Dis, s) y frecuencia dominante en Hertz (Fd, Hz) (Fig.60). Cabe recordar que el análisis del oscilograma se utilizó como complemento del análisis del sonograma para la medición manual de variables, dado que no corresponde la utilización de éste por no haberse medido el NPS (dB) mediante un sonómetro. Este instrumento solo se utilizó para calibrar el sistema de grabación y realizar algunas mediciones de NPS $(\mathrm{dB})$ de sonidos producidos por larvas y juveniles de $C$. ornata en el medio aéreo (ver capítulo 2, página 73). Las grabaciones de video se realizaron con una cámara Sony ${ }^{\circledR}$ DCR-HC28 y a partir de las mismas se cuantificó el promedio de duración del sonido (s), la tasa de emisión de sonidos (número de sonidos por minuto) y el tiempo promedio sin emitir sonidos (s).

En todos los eventos de inducción realizados, los machos comenzaron a emitir llamadas de anuncio a partir de los $30 \mathrm{~min}$ de haber sido inyectados. Éstos realizaron su despliegue reproductivo durante $48 \pm 4 \mathrm{~h}$, emitiendo varios sonidos y permaneciendo en silencio durante 20 minutos en promedio. Se describen sus parámetros bioacústicos característicos complementando las descripciones realizadas por Barrio (1963). También se constató la emisión de un sonido conspicuo por parte de las hembras siempre que los machos se encontraban cantando cercanos a ellas y/o antes/durante el amplexo (Salgado Costa y col., 2014a). Estos sonidos fueron más graves y no se repitieron tan frecuentemente como el de los machos. Las variables bioacústicas medidas para cada individuo adulto se detallan en la tabla 30. Los oscilogramas y sonogramas característicos de cada sexo se detallan en la fig. 61. Asimismo, se observó que la especie posee un amplexo de tipo axilar y que se amplexa y se suelta varias veces $(n>10)$ durante todo el acto reproductivo, el cual finaliza cuando la hembra comienza a rechazar al macho inflando sus pulmones y haciendo más dificultoso para el macho poder abrazarla (= amplexo). 

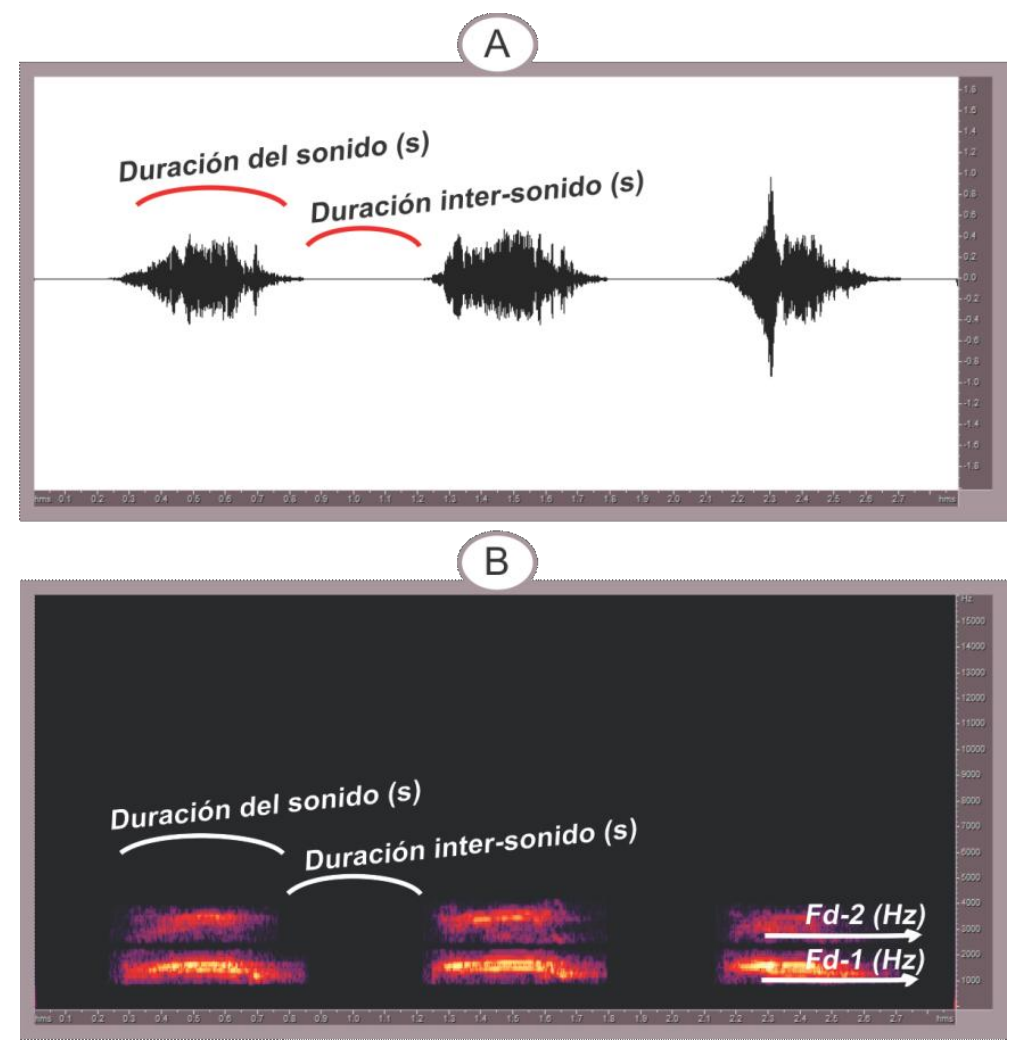

Figura 60. Variables bioacústicas medidas a partir del (A) oscilograma (duración del sonido en segundos I amplitud en pascales) y (B) sonograma (duración del sonido en segundos / frecuencia dominante en Hertz). En el ejemplo se visualizan tres sonidos consecutivos de un individuo adulto macho. Ds: duración del sonido en segundos (s); Dis: duración del inter-sonido (s); Fd-1: primer frecuencia dominante en Hertz (Hz); Fd-2: segunda frecuencia dominante $(\mathrm{Hz})$

Tabla 30. Media aritmética \pm nivel de confianza para la media al $95 \%$ de las variables bioacústicas analizadas para individuos adultos machos $\left({ }^{\Uparrow}\right)$ y hembras $(+)$. Entre paréntesis se indica el número de sonidos analizados. Ds: duración del sonido en segundos (s); Dis: duración del inter-sonido (s); Fd-1: primer frecuencia dominante en Hertz $(\mathrm{Hz})$; Fd-2: segunda frecuencia dominante $(\mathrm{Hz})$; Tasa de emisión: números de sonidos por minuto $(\mathrm{min})$

\begin{tabular}{|c|c|c|c|c|c|}
\hline Sexo & Ds & Dis & Fd-1 & Fd-2 & Tasa emisión \\
\hline$\hat{0}$ & $\begin{array}{c}0,548 \pm 0,076 \\
(10)\end{array}$ & $\begin{array}{c}0,607 \pm 0,183 \\
\text { (8) }\end{array}$ & $\begin{array}{c}1586,400 \pm 106,742 \\
(10)\end{array}$ & $\begin{array}{c}3229,500 \pm 226,334 \\
(10)\end{array}$ & $\begin{array}{l}11 \text { cantos } \\
/ 50 \mathrm{~min}\end{array}$ \\
\hline q & $\begin{array}{c}0,319 \pm 0,050 \\
(8)\end{array}$ & $\begin{array}{c}0,694 \pm 0,107 \\
(7)\end{array}$ & $\begin{array}{c}750,875 \pm 22,506 \\
(8)\end{array}$ & $\begin{array}{c}2669,375 \pm 105,472 \\
(8)\end{array}$ & $\begin{array}{l}5 \text { cantos } \\
/ 50 \mathrm{~min}\end{array}$ \\
\hline
\end{tabular}


A diferencia de otras especies que inician la emisión de sonidos antes que los machos o emiten en completa ausencia de éstos (Bush, 1997; Boistel y Sueur, 1997; Tobias y col., 1998), las hembras de $C$. ornata emiten sonidos siempre en respuesta al canto de anuncio del macho y/o antes/durante el amplexo. Considerando la clasificación de Duelman y Trueb (1994), y el contexto de emisión descripto, se concluye que las hembras de $C$. ornata emiten "llamadas de reciprocidad". Tales llamadas se diferencian significativamente de los cantos de anuncio de los machos (Ds: $t=5,432$, g.I. $=16, p<0,0005$; Fd-1: $t=17,357$, g.I. $=10, \mathrm{p}<0,0005$; Fd-2: $t=5,113$, g.l. $=12, p<0,0005)$. El presente constituye el primer registro y descripción de la emisión de llamadas de reciprocidad para hembras de C. ornata, siendo un aporte a la escasa información al respecto para especies de anuros autóctonas de Argentina. Cabe aclarar que hace referencia a "llamadas" teniendo en cuenta la clasificación de Duellman y Trueb (1994). Sin embargo, algunos autores hace referencia al "canto" como aquél sonido que identifica a la especie en contraposición con las demás llamadas que emite tal especie. Una escueta mención al respecto es realizada por Barrio en la década del 60 (Barrio, 1964). Para el caso estudiado, las llamadas de anuncio de los machos y de reciprocidad de las hembras de $C$. ornata podrían corresponderse con la definición de canto.
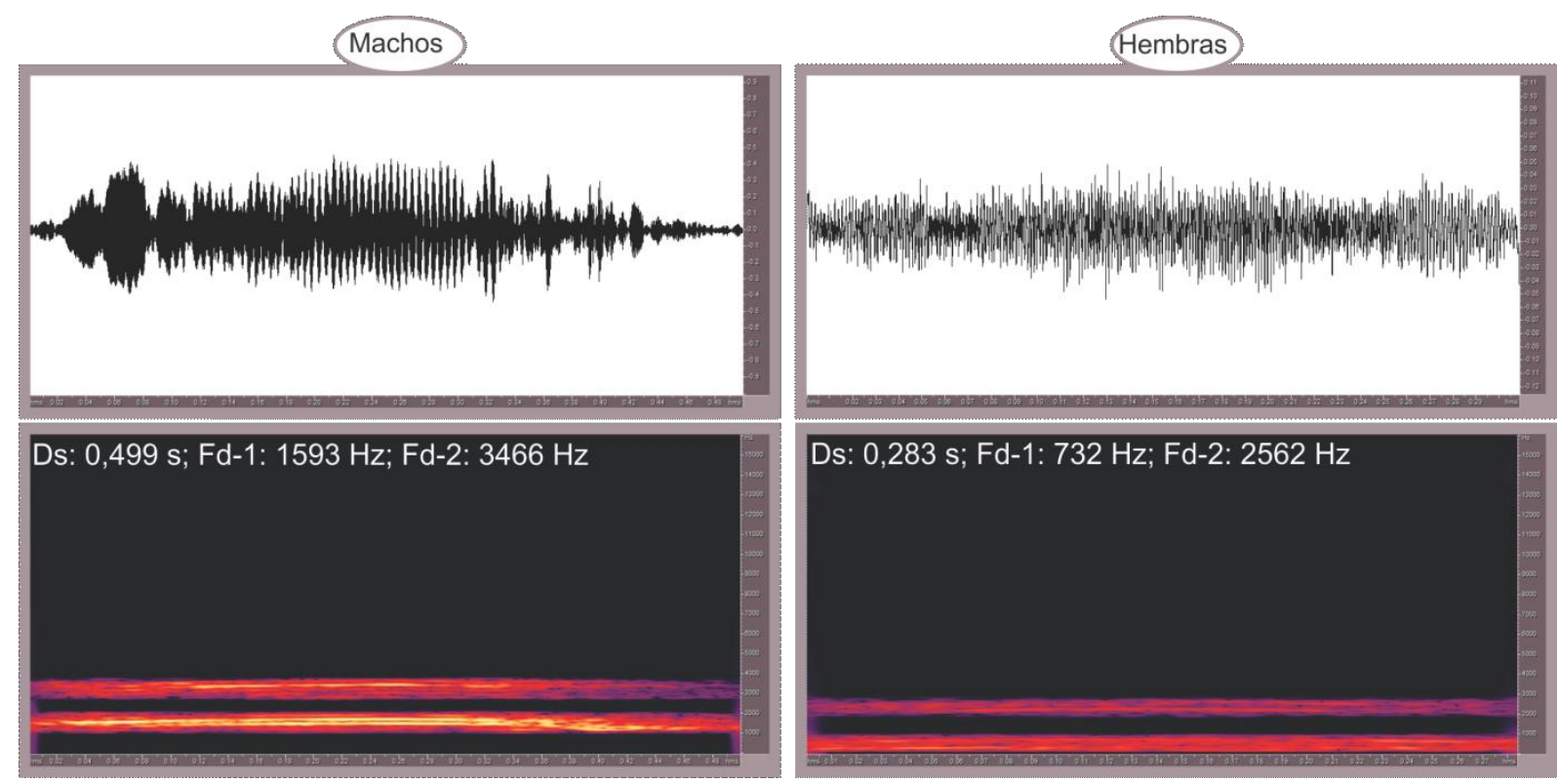

Figura 61. Oscilograma (parte superior; duración del sonido en segundos / amplitud en pascales) y sonograma (parte inferior; duración del sonido en segundos / frecuencia en Hertz) característico de las llamadas de anuncio de machos y llamadas de reciprocidad de hembras de C. ornata. Ds: duración del sonidos en segundos (s); Fd-1: primer frecuencia dominante en Hertz ( $\mathrm{Hz})$; Fd-2: segunda frecuencia dominante $(\mathrm{Hz})$ 


\section{Observaciones biológicas relacionadas con la cría en cautiverio}

Producto de la cría en cautiverio de individuos adultos de la familia Ceratophryidae, se diagnosticaron algunas enfermedades con la asistencia de un veterinario dedicado a la clínica y manejo de especies no convencionales y silvestres. En tal sentido, en relación a la inducción de la reproducción de individuos adultos de $C$. ornata tanto durante este trabajo de tesis (= 5 eventos) como en años anteriores ( $=3$ eventos), del total de hembras inyectadas sólo una presentó retención de huevos (Fig. 62A). El veterinario recomendó suaves masajes en la zona pélvica para facilitar su salida y la aplicación de antibióticos de amplio espectro en caso de constatar putrefacción de los huevos liberados. En tal caso, recomendó colocar a la hembra en una batea limpia y de las mismas características y dimensiones en la cual fue criada, junto a una solución de oxitetraciclina. La dilución recomendada fue de $1 / 2$ cucharada de té en $2 \mathrm{~L}$ de agua debiéndose recambiar la solución diariamente por 10 días. Tal tratamiento fue acompañado con metronidazol jarabe por vía oral $\left(\mathrm{Flagyl}^{\circledR}\right)$, durante cinco días siendo la dosis recomendada de $20 \mathrm{mg} / \mathrm{kg}$ de peso corporal. El tratamiento detallado permitió la cura del individuo, encontrándose en buen estado de salud hasta la fecha.

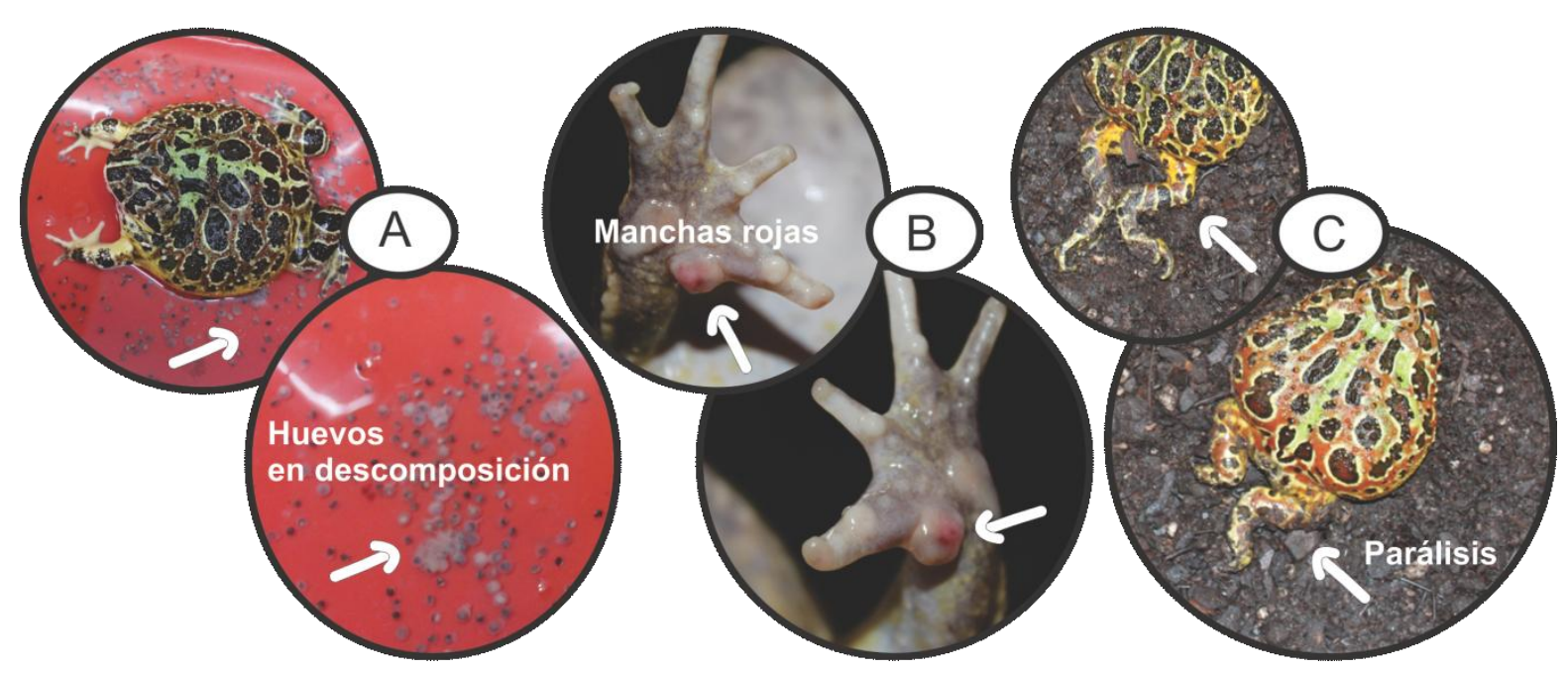

Figura 62. A: Retención de huevos en una hembra inyectada, se observan huevos en estado de putrefacción; B: Manchas rojas a modo de lastimaduras en ejemplares adultos tanto en la parte dorsal como la ventral; C: Parálisis de los miembros traseros por exceso de tiaminasa

En relación a enfermedades producto de la cría de adultos de la familia Ceratophryidae, un problema bastante frecuente fue la presencia de ácaros. En caso de visualizarlos caminando por encima del ejemplar, significa que son ácaros endoparásitos de los anfibios. Caso contrario, es probable que hayan sido transportados en estadio de huevo con el sustrato comprado (=tierra). En este caso, si el animal continúa comiendo normalmente y estando activo, no es necesario tomar 
mayores medidas que el monitoreo de su estado de salud. Frecuentemente, dichos ácaros mueren a las pocas semanas de su eclosión. En caso de ser la especie endoparásita de anfibios, se debe retirar al animal de su recinto y colocarlo en un recipiente adecuado con agua para eliminar los ácaros adheridos a su piel. La tierra debe ser desechada en su totalidad y la batea completamente desinfectada con etanol $70 \%$. Una vez evaporado el alcohol, se debe enjuagar la batea tres veces con agua sin cloro. Los parámetros de calidad del agua utilizada se detallan en el capítulo 1 (ver página 54). El tratamiento aplicado permitió mantener a los individuos en buen estado de salud y reducir la re-aparición de ácaros.

Del total de adultos de C. ornata criados teniendo en cuenta no solo a los adultos inducidos, sino también a los individuos en estadio juvenil que llegaron al estadio, se observaron manchas rojas a modo de lastimaduras a nivel epidérmico (tanto a nivel dorsal como ventral) en solo dos individuos que habían ingresado al cautiverio recientemente (Fig. 62B). El tratamiento recomendado es remover al animal de su terrario y colocarlo en una batea limpia de las mismas dimensiones y características y colocarlo junto a una solución de oxitetraciclina, siendo la dilución recomendada $1 / 2$ cucharada de té en $2 L$ de agua. Se debe recambiar la solución diariamente por 7-10 días consecutivos dependiendo del estado de las heridas. Finalizado el tratamiento, se recomienda renovar por completo el sustrato de la batea antes de re-incorporar al individuo a su compartimento. Tal tratamiento fue efectivo en la totalidad de los casos permitiendo contar nuevamente con ejemplares sanos.

Por último, del total de larvas de C. ornata que alcanzaron la metamorfosis y fueron criadas durante su etapa juvenil $(n=153)$, se observó parálisis de los miembros traseros en solo 10 individuos (todos correspondientes a la inducción del año 2012), seguido de problemas para orinar y defecar (Fig. 62C). El diagnóstico veterinario fue exceso de tiaminasa por frecuente ingesta de pescado crudo (4 veces/semana). El tratamiento recomendado es $1 \mathrm{ml}$ por día de vitamina $\mathrm{B}$ inyectable (marca Kualcovit $\mathrm{B}^{\circledR}$ ). Se deben utilizar jeringas de insulina de $100 \mathrm{U} . \mathrm{I}$. e inyectar intraperitonealmente a cada individuo en la región pélvica. Luego de la inyección se deben aplicar suaves masajes circulares en la zona para evitar el escape de la solución. Las inyecciones deben ser acompañadas por ejercicios para estimular la locomoción, colocando a los juveniles de forma individual en un recipiente con suficiente agua para forzarlo a la actividad de los miembros mediante movimientos natatorios. Luego de dos meses de tratamiento se observó la mejoría de los individuos. A partir del diagnóstico veterinario se disminuyó la frecuencia de alimentación con pescado (1 vez/semana). Esta enfermedad no se volvió a observar en los sucesivos juveniles obtenidos producto de posteriores inducciones de la reproducción. 


\section{ANEXO III - Efectos del UVB sobre el crecimiento y desarrollo óseo de Ceratophrys ornata}

La radiación UVB que alcanza la superficie terrestre posee un rol importante en la síntesis de vitamina D3 y consecuentemente en los procesos de osificación. La falta o bajo nivel de UVB se encuentra asociada con la enfermedad metabólica de los huesos (MBD) (Antwis y Browne, 2009). Durante el mantenimiento y cría de escuerzos en cautiverio en años anteriores al desarrollo del presente trabajo de tesis, hemos observado una alta tasa de mortalidad en individuos juveniles y adultos, la cual se corresponde con flacidez e hinchazón en los miembros traseros, seguido por inmovilidad y muerte. Por lo tanto, se realizó un experimento específico con el objetivo de corroborar el desarrollo de MBD por falta de exposición a UVB y el consecuente efecto sobre el crecimiento y desarrollo óseo de individuos juveniles de Ceratophrys ornata, en condiciones de cría ex-situ.

El diseño experimental (Fig. 63) consistió en cuatro grupos de 10 individuos juveniles cada uno y su exposición a una única dosis de UVB $\left(0,01 \mathrm{~mW} / \mathrm{cm}^{2}\right)$ a tres tiempos de exposición: 1,3 y 7 horas/semana (T1, T2 y T3, respectivamente), más un grupo control sin exposición a UVB. La exposición se realizó durante 28 días consecutivos (respetando los tiempos de cada tratamiento) en dos momentos diferentes con un intervalo entre ambos de igual duración. Luego de cada momento, se realizaron placas radiográficas de tres individuos por grupo, con dos incidencias por individuo: dorso-ventral y lateral. Mediante tales placas radiográficas se midió el espesor corticomedular (ECM) de las órbitas ( $\mathrm{O}$; medido en el ángulo medionucal de la órbita derecha) y mandíbula ( $\mathrm{M}$; desde la región paramedial a la sínfisis mandibular hasta la dentelladura de la mandíbula), el espesor de la corteza (EC) del fémur ( $F$; medido a nivel de la cara lateral de la diáfisis media del fémur izquierdo), espesor de la médula (EM) del fémur (F; medido a nivel de la diáfisis media del fémur izquierdo), espesor de la corteza (EC) de la pelvis ( $P$; medido a nivel del tercio medio del ala del íleon izquierdo), espesor de la corteza (EC) de la tibia-peroné (TP; medido a nivel de la cara lateral de la diáfisis media de la tibia izquierda), espesor de la médula (EM) de la tibia-peroné (TP; medido a nivel de diáfisis media de la tibia izquierda), la longitud hocico-cloaca (LHC; medida desde vértice caudal de la pelvis hasta el límite craneal de las dentelladuras de la mandíbula) y la longitud tibia-peroné (LTP). También se determinó la cantidad total de fracturas (esta variable fue transformada a variable continua mediante el logaritmo natural de cada valor más uno $(\operatorname{Ln} X+1)$. Además, se realizaron mediciones mensuales del peso corporal $(\mathrm{g})$ y la LHC $(\mathrm{mm})$ de cada individuo. Los datos fueron analizados mediante ANOVA de dos factores (grupos y meses de exposición) con test a posteriori de Dunnett. Se realizó una prueba de chi-cuadrado para evaluar la independencia de la presencia/ausencia de enfermedades con la exposición a rayos $\mathrm{X}$ producto de las placas radiográficas realizadas. 
Los análisis realizados arrojaron diferencias significativas para las variables EC-F y LHC. Específicamente, para la variable EC-F se obtuvieron diferencias significativas respecto al grupo control para el factor grupo $(F(3,15)=4,770, p=0,016)$ pero no para los factores grupo-mes $(F(3$, $15)=1,454, p=0,267$ ) (Fig. 64A). Para la variable LHC el análisis arrojó diferencias significativas para el factor mes $(F(1,15)=10,417, p=0,006)$ y para los factores grupo-mes entre los tratamientos y el grupo control $(F(3,15)=3,761, p=0,034)$ pero no para el factor grupo $(F(3,15)$ $=1,482, p=0,260)$ (Fig. 64B-C). Asimismo, no existen diferencias significativas respecto del peso de los individuos para el factor grupo $(F(3,15)=0,760, p=0,534)$ ni para los factores grupo-mes $(F(3,15)=0,179, p=0,909)$. En la fig. 63 se muestra además la curva de crecimiento de cada individuo juvenil. Solo se muestra la variable peso ya que la misma se encuentra perfectamente correlacionada con la LHC ( $r=0,9010, p<0,0005)$. Mediante una tabla de contingencia se corroboró la existencia de independencia entre la exposición a rayos $X$ y la presencia/ausencia de enfermedades $\left(X^{2}=13,918, p=0,455\right)$. Si bien dentro del ámbito de la herpetología es bien conocida la necesidad de utilizar luz UVB para la cría de reptiles, hasta el momento no se habían realizado estudios formales sobre la necesidad de emplearla en la cría de anfibios, y menos aún en la cría de individuos de C. ornata. Los resultados permiten concluir que existe una relación entre la exposición a UVB de individuos juveniles y el grado de osificación, resultando importante la utilización de luz UVB en la cría ex-situ de individuos de esta especie. Sin embargo, la concentración mínima necesaria de luz UVB deberá determinarse en futuros estudios. 


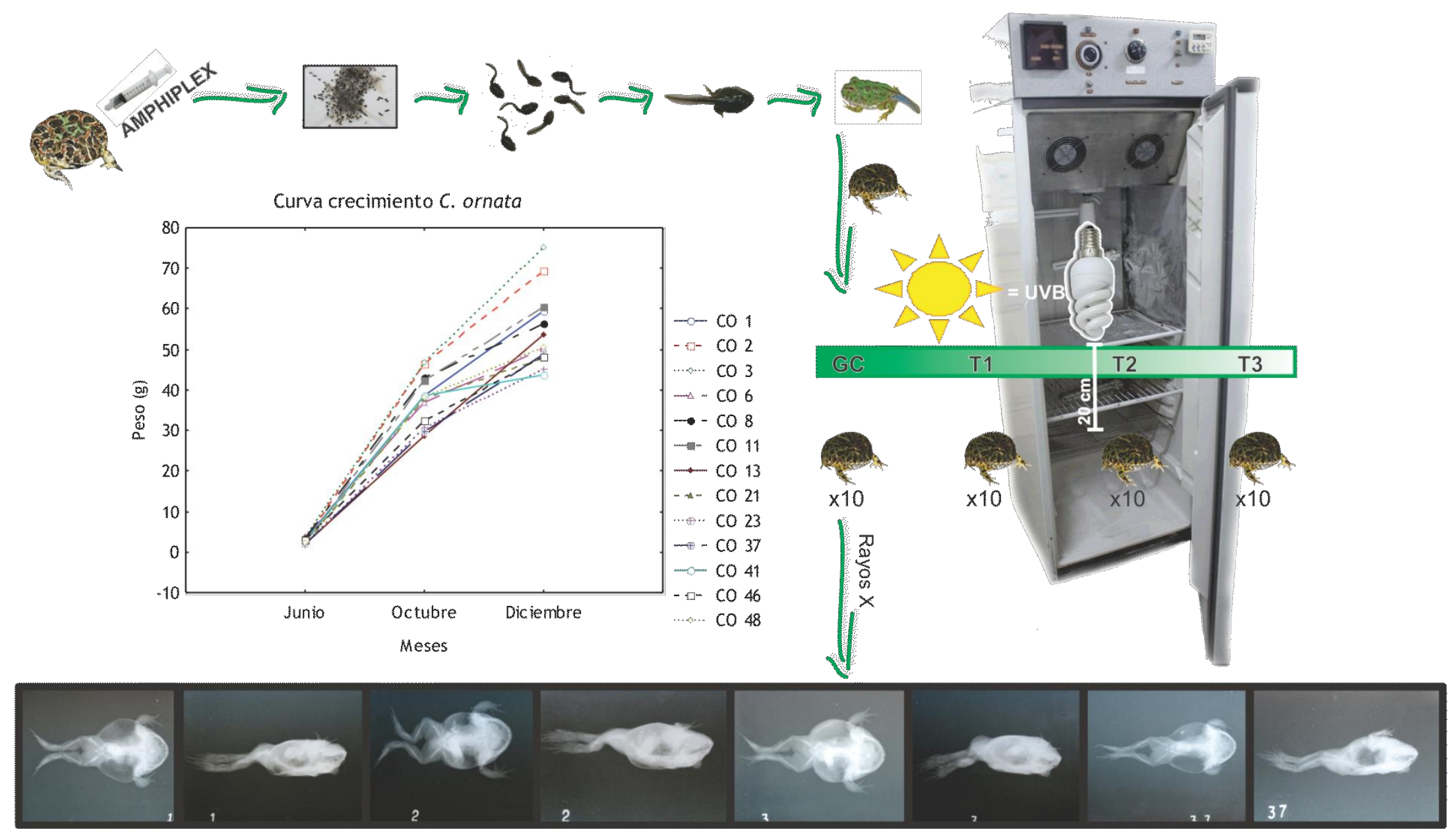

Figura 63: Diseño experimental para evaluar el crecimiento y desarrollo de individuos de $C$. ornata expuestos a una única dosis de luz ultravioleta (UVB) a tres tiempos diferentes (T1-T3). Junio: peso a la metamorfosis en gramos (g); Octubre: peso (g) al primer momento de exposición (siete meses de edad); Diciembre: peso (g) al segundo momento de exposición (nueve meses de edad); C: grupo control sin exposición a UVB; T1: expuestos 1 hora/semana a UVB; T2: expuestos 3 horas/semana a UVB; T3: expuestos 7 horas/semana a UVB 

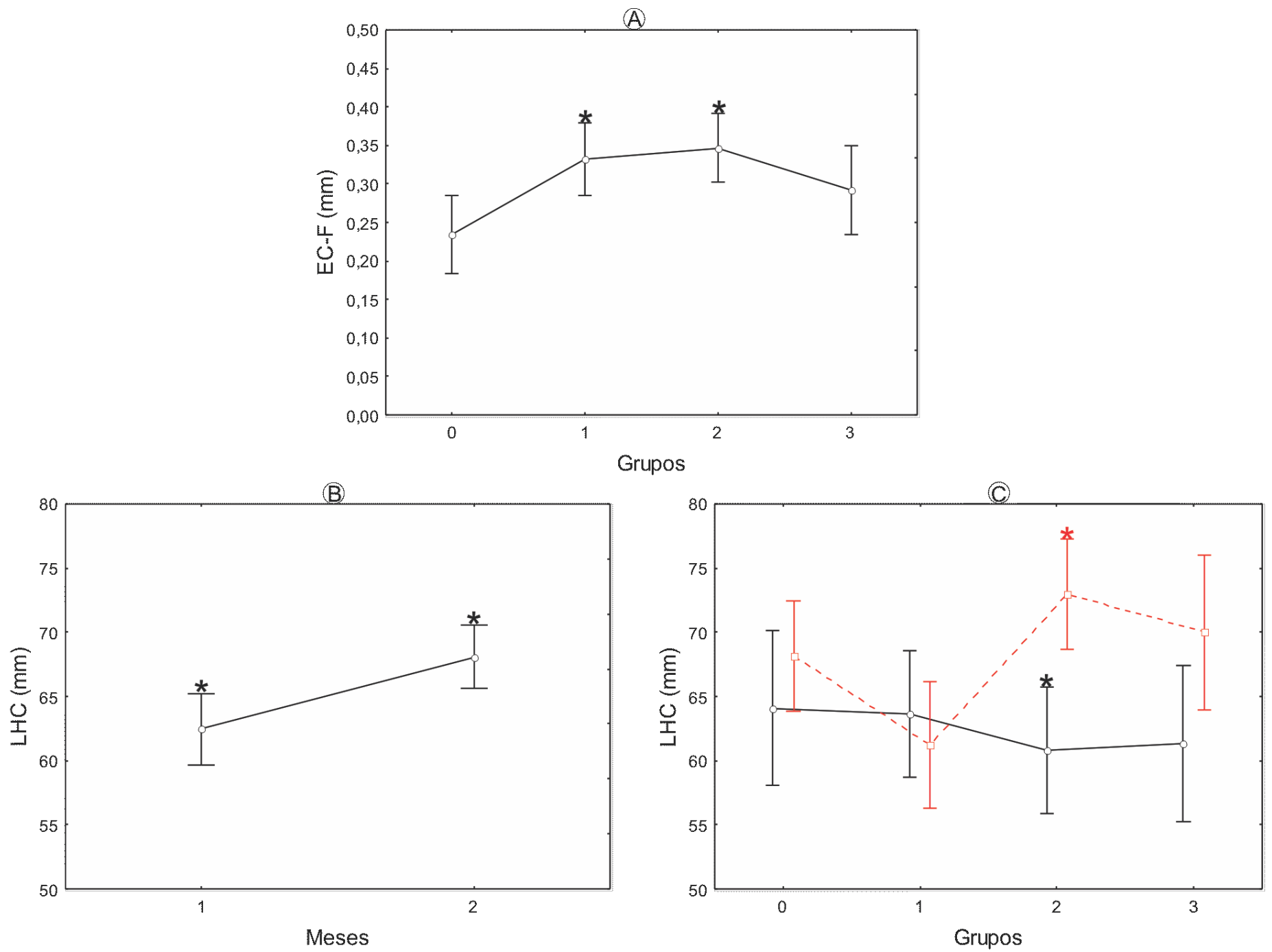

Figura 64. Resultados del análisis de comparación múltiple de dos factores para (A) el espesor de la corteza del fémur (EC-F) en milímetros (mm), indicándose las diferencias significativas para el factor grupo, y para la longitud hocico-cloaca (LHC, en $\mathrm{mm}$ ), indicándose diferencias significativas para el factor mes (B) y para el factor grupo-mes (C). Línea continua color negro: primer mes de exposición; línea discontinua color rojo: segundo mes de exposición; $\left({ }^{\star}\right) p<0,05$ 